


\section{POR CBMSUTARON GWY Glasgow \\ University Library}

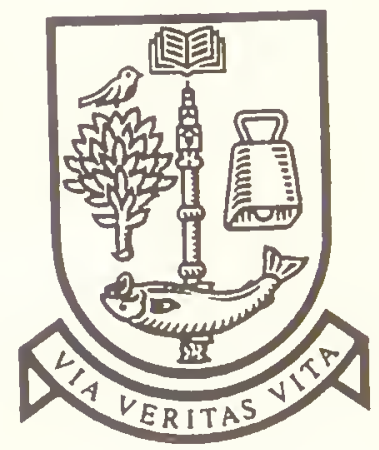





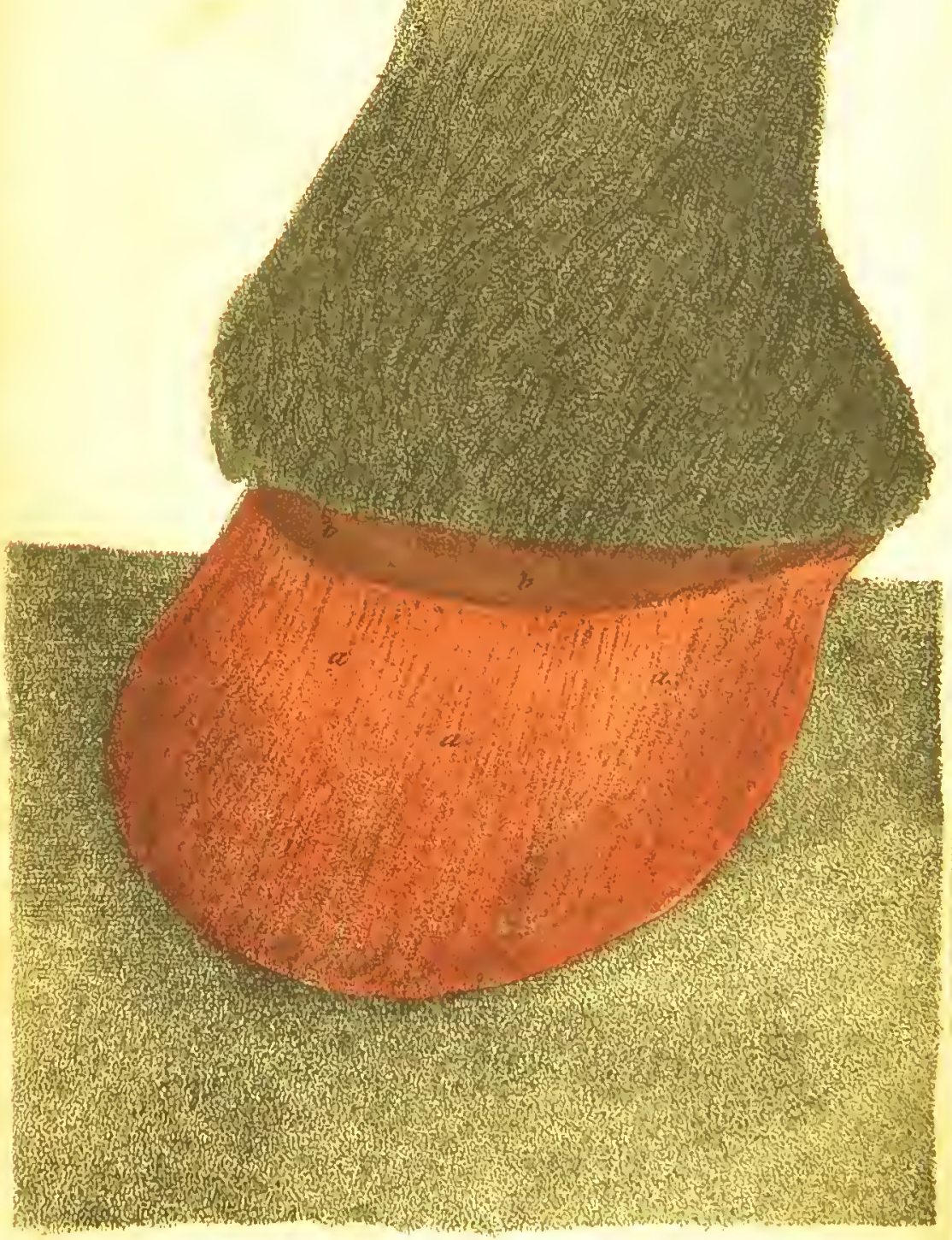




\title{
A TREATISE
}

ov

\section{VETERINARY MEDICINE,}

IN FOUR VOLUMES.

\author{
VOL. I.
}

CONTAINING

\section{A COMPENDIUM OF THE VETERINARY ART;}

$$
\text { ore, }
$$

AN ACCURATE DESCRIPTION OF TIIE DISEASES OF THF, HORSE,

AND THE MODE OF TRTATING THEM;

THE ANATOMY AND THYSIOLOCIY OF THE TOOT: AND

THE PRINCIPLLS AND PRACTICE OF SHOEING.

\section{ILLUSTRATED BI PLATES :}

With Observations on Stable Maungement, Feedug, Exercise, and Condition,

\section{$-1$

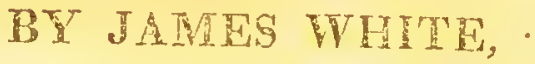

Late Feterinary Surgeon to the First, or Royal Dragoons.

THE TWELTTH EDITION, CONSIDERADLY ENLARGED;

Containing an Account of the new Operation termed NERVING, for the relief of Fotindered Horses, and of a Test for distiuguishing the Glavous.

\section{LONDON:}

PRINTED FOR LONGMAN, HURST, REES, ORMF, AND EROWN ; BALOWIN, CRADOCK, AND JOY; SHERWOOD, NEELY, AXD JONKS; T'. TEGG ; З. WALRER ; AND B. RLFNOLDS. 
C. Baldwin, Printer,

Naw Bridge-8trett, Lomion:

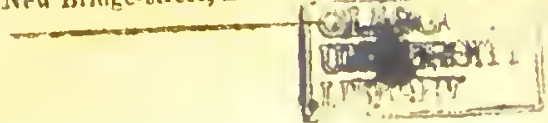


TO HIS ROYAL HIGHAES,

FIELD MARSHAL,

THE

\section{DUKE OF YORK, K. G.}

Commander in Chief of His Majesty's Forces, \&c. \&c.

SIR,

Youn Royal Highness was graciously pleased to patronize the first Publication of this small Treatise, nearly twenty years ago; and so favourably has it been received by the public, as to pass, during that time, through eleven editions. The approbation your Royal Highness condescended then to express of my attempt to improve the general practice of the Veterinary Art, proved an encouragement to further exertion, which has never ceased to operate; and induces me now to offer to your Royal Highness's noticc one result of my experience, the application of which may be found a 2 : 
useful in His Majesty's Cavalry-I allude to a ceriain, easy, and expeditious method of distinguishing the Glander's from those diseases which nearly resemble it. It would be superfiuous to point out to your Royal Highness the utility of this discovery, as it is sufficiently proved by the length of time horses are often kept apart and unemployed, when suspected of being glandered, and the prohability that other diseases are too often mistaken for it. I should not liave presumed to offer this inprovement to your Royal Highness's notice, had not my conviction of its utility arisen from numerous trials, and a diligent attention to the subject for a period of twenty years. - I am, with the most profound respect,

\section{Your Royal Highness's}

Most devoted, obliged,

And humble servant,

\section{JAMES WHITE,}

Late Veterinary Surgeon to the Rirst, or Royal Dragooni. 


\section{PREFACE.}

FEARLY twenty years have elapsed since this work was first published, and cluring that rime eleven very large impressions have been sold. So favourable a reception conld not fail of stimulating the anthor to continued and increased exertions for the improvement of veterinary science, and leading him to consider it as a duty he owed the public to communicate, when opportunities offered, any useful discoveries that may come to his knowledge, whether the result of his own experience or that of others. The present edition is called for at a favourable time, as the ready intercourse we now have with the Continent enables him to give a short accoust of the state of the veterinary art in foreign countries, piaticularly iu France; where it attracted the notice of scientific mon, and where reterinary schools were established at an earlier period than in any other comntry. Bourgelat, the first director and the principal projector of the Frencl veterinary schools, has becn justly regarded as the founder of the veterinary art; being the first who placed in a clear point of view the indispensable necessity of anatomical and physiological knowledge to the veterinary practitioner. Several works were published by Bourgelat on veterinary subjects, winich are sill held in considerable estimation: the principal are " $A$ "Treatise on the Anatomy of Domestic Animals;" "A Rational Matcria Medica;" "A Treatise on the Exterior Conformation of the Horse;" "Essays on the Theory and Practice of shoeing, and 
on Bandages, \&c." Bourgelat's 'Anatomy' appeared first in 1769 , and has passed through several editions. It was translated into German, Italian, and Spanish. Though Bourgelat was the first to place the veterinary art on a proper foundatiou, some attempts were made, at a much earlier period, to diffuse a knowledge of veterinary anatomy, the principal of which was by Ruini, an Italian. This work was published at Venice in 1598, and entitled, "Anatomia del Cavallo, infermita, et suoi rimedii, del Signor Carlo Ruini, Senator Bolognese." It treats of the anatomy of the horse as well as of diseases. This book seems to have been the gronnd work of many other's that were published at different periods afterwards, particularly the anatomical part and the plates, which appear to have been almost literally copied by all of them. Vitel, in his "Analysis of Veterinary Works," in speaking of Solley'sel's, which was priblished in 1098, says, "In the 16th century, many veterinary books appeared, but Solleyscl's worls has caused them to be forgotten; nor have we reason to regret their loss, as they contained only a very imperfect description of the structure of the horse." It appears, however, that Solleysel's celebrated work is in great measure copied from that of Ruini. Snape's Anatomy of the Horse, and the little that Gibson wrote on that subject, seem to have been drawn from the same source. One difference is observable in the plates; those of Ruini being engraved on wood, and his imitators on copper. La Fosse was contemporary with Bourgelat, and communicated several memoirs on veterinary subjects to the Royal Academy. In 1766, Lia Fosse's son published his "Farrier's Guide," which treats also of the anatomy of the horse; and in 1772, his "Cours d'Hippiatrique" appeared, 
a splcndid folio, containing sixty-five highly finished plates, illustrative of the anatomy of the horse. In 1775, a "Dictionary of Farriery" was published by the same author, in 1 vols. Svo. This work contains much usefinl information. In 1771, Vitet's "Vetcrinary Medicine" appeared, in 3 vols. 8 vo. This work treats of the structure of the ox as woil as the horse, and contains many inaccuracies. After the revolution, the art seems to have made but little progress. In 1797, a useful pamphlet on the glanders appeared, the joint production of MMI. Chabert and Huzard. 'This book was printed and distributed by order of the government, in consequence of the grent number of horscs that had been lost, and the contagious nature of the disease. It docs not contain, however, any information that would be new to the English reader. About the same time, M. Chabert published " $\Lambda$ Description of the Digestive Organs of Ruminating Animals;" and soon after, there appeared " $\Lambda$ Manual of the Veterinary Art," by La Fosse, son of the author before noticel, in one 12mo. volume. This practical compendium of the veterinary art seems to have been much esteemed, as a third edition was published in 1803. From this work, as well as from other's of a inore recent date, it appears that the practice of veterinary medicine has not made much progress in France since the time of Bourgelnt. In 18:1, an account was published of some successful experimcnts on the treatment of Glanders and Farcy, by M. Collaine, profiessor of the Royal Veterinary School of Milan. "Ihe successful remedy in these experiments was sulphur, given in very large duses, beginning, however, with four oz. and gradually increasing the dose, until it causcel purging and violent colic. It was then discontimued until these 
symptoms ccased. On repeating it afterwards, it was found that mueh larger doses could be given without ineonvenience. In some cases, it was given to the extent of two pounds, in the course of the day, made into an electuary with honey. It is stated, that a eonsiderable number of horses were thus cured. Besides giving the sulphur, about two quarts of blood were taken off every third or fourtl day during the treatment. The following statement is annexed to the pamphlet:

"The veterinary surgeon attrehed to the imperial brecking stud of Borculo, in Holland, has practised $M$. Collaine's mode of treatment; and, after two months' trial, thirty glandered horses were perfectly cured, ten are in a state of convalescenee, and twenty havedied during the treatment." Notwithstanding the boasted effieacy of this mode of treatment, it appears, from a reeent publication on Glanders, by M. Dupuy, that it has been fairly tried at the Veterinary Sehool at Alfort, and has not, in a single instance, sueeeeded. M. Dupuy's work appeared in 1817 , in one volume, $8 \mathrm{vo}$. and treats of glanders as a tubereular or tuberculous affection, having for its title, "Del'affection tuberculeuse, vulgairement appellée Morve (glanders), Pulmonie (consumption, or phthisis), Gourme (strangles), Tausse Gourme (spurious, or bastard strangles), Farein, (farcy)." Some obscrvations on this work vill be found in the Appendix, under the liond Glanders. The most valuable work that has appeared in France, since the revolution, is " $A$ Treatise on the Anatomy of Domestic Animals," by Professor Girard, 1807, 2 volumes, 8vo. In 1813, there appeared "A 'Treatisc on the Feet," by the same author, in one volume, svo. with six plates, illustrative of the anatomy of the foot, not only of the horse, but of the other domestic aninals, and 
poultry : this, also, is a work of considerable merit. In 1817 , the first part of a theoretical and practical treatise on the horse's foot and shoeing was puiblished, under the title of "Cours 'Theorique et Pratique de Maréchalerie Veterinaire, par F. Jauze." This work was completed in 1818, and forns one large 4.to. volume, with no less than one hundred and ten plates! M. Jauze announces another work as about to be published in five volumes, 8vo. witl numerous plates. This work is said to treat of the internal and cxternal pathology of the larger domestic animals, the veterinary Materia Medica, and the veterinnry jurisprudence. "Every article in this Treatise," the autlor says, "will be described with particular order and precision, and nothing superftuous will be found in it." If we may judge from the work already published, and the number of volumes announced, it seems probable that the readers of the work will be of a different opinion. The introduction to lis Cours de Marécinaleric consists of an cnumeration and short description of the works that have appeared from the earliest times on the art of shoeing; and among these, the ingenious and valuable works of Mr. Bracy Clark make a conspicnons figure, but appear to be brought forward merely as a subject for criticism. "Mr. Clark," says the anthor, "takes great pains to prove that he has discovered that the hoof is elastic, a circumstance that has been known for more than'two lundred years; and that shoeing is productive of injury to the feet, which was known even before it was generally practised. Wild horses, as well as the greater part of those cmployed in agriculture and commerce, in Persia, Etliopia, Tartary, Japan, \&c. are never shoed: how is it, then, that shoeing is so generally practised in Europe? The ansiver is, that shor's are a 5 
sbsolutely necessary, in consequence of the heavy burthens they have to carry, the hard stony roads they are oblinged to travel on, and the necessity they are mokr of exerting, with so litule cessation, the whole of their power, \&c." "These considerations are sufficient to prove that shocing is loth injurious and necessary; and should arrest the pens of those modern writers who are duily claiming, as discoveries, what have been known for four hundred years." Mr. Clark has certainly taken pains to prove that sloes, of whatever form they may be, are always injurious, and that however carefully the hoofs are pared and otherwise treated, as long as inflexible iron shoes are nailed to them, the feet are constantly in a progressive state towards disease. If this be really the case, if shoeing is invariably so injurious, Mr. Clark has an indisputable claim to the discovery.

I cannot find any passage in Mr. Clark's work to justify our author's assertion, that he has taken great pains ( $f$ ait tous ses efforts), to prove that he is the discoverer of the elasticity of the hoof. He says, "I have detected some undiscovered parts in the hoof, and some circumstances in the plan of its structure, before unknown, and especially pointed out for observation its elastic properties." This surely cannot be considered as laying claim to such a discovery. One of the circumstances or parts of the hoof which Mr. Clark claims as a discovery, is that which he calls the coronary frog bund. "This," says M. Jauze, "has been described by Bourgelat, under the name of bourrelet graisseux." Bourgelat, in his "Essay on Shoeing," says, "When the foot is taken out of its horny box (the hoof), the first thing that strikes us is un bonrelet, which forms the superior part of it." 'This name is evidently applied by Bourgelat 
to that part which Mr. Coleman has named coronary ligamenl, or ring. In speaking of the hoof, Bourgelat says, "the thickness of this horny box is not the same through its whole extent: it is most considerable in front, and diminishes gradnally tovards the leels: it is much thinner at the upper part or coronet than below, and the inside quarter is weaker than the outside; the thickness of these, as well as the forc part, increasing towards the bottom. On examining the inner surface of the hoof, we find it extremely thin in its upper part, and presenting a sort of circular groove (un sort de biseau." "This blunder has been noticed by the tranlator of Mr. Clark's work, and M. Jauze attempts to pass it off as an error of the press: for in the third part of this work, which was published some time after the first, therc is a list of errors, in which the word corné is substituted for graissenx. There is also a reply to some observations on M. Jauze's book, by M. Huzard; but it is evident, from the above gutotation from Bourgelat, that the coronary frog band of Mr. Clark was not noticed by that eninent veterinarian: nor is there any cisscription of it in his other works, or in the Tratie du Picl of Professor Girard. "Mr. Clark," he says, "has erred in many other passages (dans unc infinite)." Page 28, line 1 , he says, "in the foot of the ox there is neither pad nor cushion to climinish the renetion of the ground. (Il n'y $a$ mi malelos ni coussins pour pailier les reactiones du. sol)." He is in error, also, when he states that "the camel and the elcphant have a cartilaginous pad on the under part of their fect." Now in Mr. Clark's work, p. 119, the reader will find the matter thus stater:- "Indeed we discover" most clealy, on investigation, that to every animal is given a share of elastic yielding to the foot, in 
order to destroy all jar and resistance, reciprocally to the parts of the foot as to the body, and a change of form takes place in the foot according to the weight or exertion brought upon it. In the elephant, cartilaginous cushions, for this purpose, are secn disfossed under the foot and in the cumel oblong pads; in the ox, this non-resistance 10 the lond is effected by a deep division of the foot to the fetlock joint, thus making of it iwo members, thereby giving a flexibility that answers the same end. In the horse, a single pad is seen, for of such nature is the frog; and this yielding property in the foot of him and his tribe, or tamily, is less, perhaps, than any other family of quadrupeds, on account, it would appenr, of the difficult combination of properties found with him, viz. an extraordinary degrec of specd with a large or heavy body, which, to be impelled witls effect, required parts that should not be too yielding, by which the impulse had been diminished; and hence it is, that this property has been neanly ovcrlooked, and the foot treated by the smiths as though this necessury provision and property had in him no existence more than in a mass of wood of the same figure." It appeared necessary to transcribe the whole of the passange from Mr. Clark's work, that the render may form a just estimate of MI. Jauze's criticism.

Mr. Clark is accused of another crror, in saying that "the thickness of the wall of the hoof diminishes firn the front to the back part." "ihere may be some few exceptions to this rule, but the truih of the statement with respect to the fore feet is well known to those who are acquainted with the structure of the foot, and the lion is so deseribed by Bomrgelat in the above quotation. 'The first part of ML. Janzc's work contains a minute description of the worge or smith's eherp: witls the 
various utensils and tools that are employed in shoeing; this is followed by a description of the origin, properties, \&c. of the coal and wood that is made use of ; and here the reader is favoured with the important information that coals are found in the interior parts of the earth, under stones more or less hard; that the hard and compact substance of trees is named wood, and that the different kinds are distinguished by the generic name of the vegetable which produces it; that it is cmployed in the construction of the forge and utensils, and in forming handles for the varions tools. The next article treats of the use of water in the snith's shop, which he describes as "a cold liquid and transparent body, which lias the property of moistening every thing that it touches;" he refrains, however, from entering into the various distinctions that are commonly made between fountain-water, rain-water, sea-water, \&c. his only aim being to make known, in few words, the uses to which a finit, so universally spread oier the surfice of the carth, is applied in the smith's forge. Having cnumerated its various uses, not in very fow words, he proceeds to article 20 , which treats of iron. 'This elaborate article will not perhaps prove very instructive or entertaining to the veterinary student, though the learning and deep research clisplayed in it nay excite his astonishment; for he wishes to male it appear that he is familiar with the works of the ancients, both Grects and Latin, by citing Pliny, Strabo, Diodorus Siculus, Hesiod, and others, to show that iron was discovered 3200 years ago. After a long dissertation on the different linds of iron and steel, the construction of firnaces, and the means cmployed for separating the metal from the ore; he describes the uses of irou in reterinary melicine. Here the 
reader is informed that "when diluted, vitriolic (sulphuric) acid is poured on iron filings, it dissolves it with heat and effervescence, and, disengagcs from it a great quantity of its inflammable principle, the vapours which arisc being charged with phlagiston." "Stecl differs from iron," he says, "by containing a larger proportion of the inflammable principle." The second part begins with the anatomy of the foot, which is the same as Bourgclat's and Girard's, except in substituting the word bourrelat corné for courome: this change is probably intended to cover the mistake bcfore noticed. 'There are no plates to illustrate the description, exccpt a side-view of a shoed hoof, and a view of the bottom of the hoof of the natural size, and, as M. Jauze says, of the natural form, or bien proportionné; but it is what an English veterinarian would consider as a good representation of a contracted hoof, the frog of which had been trinmed by an ignorant snith. A scale of proportion also is givcn with it, as a basis for the proportion of all the shoes which he describes. This is followed by a description of the various shoes that are to be employed for ill-formed lcogs and fect, and diseascd feet, for horses that cut, forge, \&c. \&c. The anatomy of the foot of the ass and the ox is next described, with the method of shocing them; then comes a description of foreign shoes, beginning with the English, of which there is a tolerable representation. "Horses that are thus shoed," M. Jauze says, "arc not fit to be ridden upon roads that are pared; as the animal must be in constant pain, owing to the sole being so imperfectly defended, and to the shoe being so made as to ben flat on the ground, by which the play of the lower joints is impeded. Many persons in France have, without reflection, and nerely from 
caprice, adopted this method, which is only calculated for ruining horses very quickly. This is what Mr. Clark has endeavoured to show in his work of $1810 . "$

'The reader' should be informed, that the French shoe is made somewhat in this form: so that when the hor'se siands on a plain surface, neither the toe nor the heel have any bearing on the ground. The double curved line is intended to represent a side view of the outer branch of the shoe as it rests on the ground, the latter is shown by the thick horizontal line. This is not given as a correct representation of the degree of curvature which the French give the shoe; but it shows sufficiently that it is the middle of the shoe only that bears on the ground. 'This form, with the concavity of the surface next the foot, is termed the ajusture of the shoe, and is designed to effect a balancing, from the fore to the hind part, which he conceives is necessary to the free and easy motion of the lower articulations or joints (il opere an balancement de devent en arrierè, si necessaive pour entretcnir le jeu des articulutions inférieures des membres).

The third part of the work begins with a minute description of a farrier's apron, with pockets or pouches, in which he keeps his instruments and nails (le tablier à ferrer). 'This highly interesting detail occupies nearly eight pages, and is moreoverillustrated by a plate. Having dismissed the smith's apron, M. Jauze proceeds to a description of the instruments and nails, which are represented by plates, and very minutely described. Then comes the method of pointing the nails, which is followed by considerations necessary for the farrier to keep in mind before and after, as well as cluring, the time he is shoeing. This article contains some useful advice and observations. The next article, 122, is on 
Shoeing; 123 treats de l'aplomb, a term of which the English veterinarian may wish for an explanation. "By the term aplomb, in veterinary language, is meant an equal distribution of the whole weight of the horse upon the four extremities; if one of them sustains more than another, the animal is said to be hors d'aplomb of that extremity. An inequality in this respect may arise from deformity of the body or limbs, or of the feet, in consequence of bad shoeing: there is also a particular or individual aplomb, that is, which relates to the foot considered individually, supposing the horse to be without shoes, if, on planting the foot on the ground, the toc, quarters, and heels, touch it at the same time, which cannot be done unless the foot, as well as the parts adjoining it, are free from disease, and the motion of the joints free and casy, he is said to be aplomb of that foot; but, if one quarter or heel be higher than the other, that foot is not aplomb.

In article 124, on the shoeing of colts, M. Jauze says, "6 the heels should be kept open (bien ouverts), but not by cuttiug away the bars or any other" part." This direction is surely srperfluous, if not mischievous, as it seems to imply that there is some method of opening the heels, which, in shoeing, it is necessary to practice. "The shoes," he observes, "should he lighter than for horses, have less rjusture, and be fastened with six nails only." This article contrins some other usefinl remarks. In speaking of the method of paring the wellformed foot, in article 125 , he observes, that "the toe and heel should be so pared as to correspond with the ajusture of the shoe. He next describes the method of shoeing feet that are defective in form or proportion, but frec from disease; ench defect is consiclered in a separate article. 'Tho method of shosing diseased feet is then described 
(des ferintres pathologiques); each disease occupying a separate artiele, and referring to a description of a suitable shoe, before notieed. These, as well as those of the former class (defective proportion or form), ar'c eonsidered as defunt d'aplomb particulier; but the next class comprehends those failings which depend upon an inequality in the general aplomb (defaut d'aplomb general); among these are forging, eutting, body too long or too short, \&e. \&ce.: these also are eonsidered in separate articles. The work eoncludes with some slort remarks on the shoeing of mules, asses, and oxen. There is an appendix to the book, containing some remarks on a pamplilet lately published by $\mathbf{M}$. Sanfourche, on the means of preserving the aplomb of the horse by shoeing; and an answer to another, containing some observations on the introduction of M. Jauze's work, by M. Huzard.

Having given a short description of this elaborate work, the reader will not, it is hoped, think it wholly uninteresting, if a brief aecount bc added of the present state of the veterinary schools in France and Germany; drawn from a report made by $M$. Sewel, assistant professor of the Veterinary College, London, to the governor's of that establishment. Mr. Sewel first visited the Veterinary School at Lyons, which was established January 1st, 1762. "The museum," he says, "eontains many preparations of great utility and novelty; partieularly museular and blood-vessel subjects, of the full size, and the whole of the nervous system, with the brain, entirely separate from the other parts, and well preserved: shoes of every description, and from various eountries, are also shown. The infirmary stables are not extensive; paved and drained in the ordinary way, and ventilated by the windows only: there are appropriate places 
for the other domestic animals. The forge is com.modious, and well adapted for shoeing horses, and instructing the pupils in the art of making and putting on shoes; all which is superintended by at director of that particular branch of the art. $\Lambda$ botanical garden is attached to the school, and lectures are given on botany and chemistry in rooms adjoining a laboratory. The thearre of anatomy is capable of containing about one hundred pupils; where lecturcs are delivered ou veterinary anatomy, surgery, aind diseases. A convenient dissecting-room is adjoined to the theatre. Behind the building are a yard and paddock, into which sick or lame horses are occasionally tirned. * 'The present dircctor is M. Bredin, who furnished Mr. Sewel with letters of introduction to M. Huzard, inspector of the French veterinary schools, with which he proceeded to Paris. He was accompanied by M. Huzard's son to the Vcterinary School at Alfort, about four miles from Paris, which was opened in 1766, and is now the principal school in France. This is much more complete than the school at Lyons: three large rooms are occupied by the museum and an extensive collection of veterinary works. There is a powertul electrical apparatus for medical purposes. Lcctures on agriculture, rural economy, and mectical

* Accordiog to a report, mate to the Natinnal Convenion by Miess. Gilbert and Huzard, in $\mathbf{1 7 9 5}$, the Veterinary Schuol it Lyons was in a very bad state, and si) situate (in the jaubourg de la Guillotiere), as to be sometimes inundated by the Rhone. In cousequence of their representation, it was remuved in a spot opposite the city, ncar the road leading to Paris. During the siege and bombardment of Lyons, the students were dinpersed by the bombs or shells that were throwo into the house aul stabies; but il Brodiu, the director, contrived to secure the prepara. tiuls. \&e. that were in the musenm, ant sent them alf to at house he possessed at some distance from Lyons, where be collected the students, and continued his iustructions. 
jurisprudence are delivered at this school, in addi. tion to those given at Lyons. Stallions are kept at the expense of government, and scnt anmually into the provinces to improve the breed of horses; asses are also sent for the purpose of producing mules, which are much used in some of the pros vinces. The infirmaries for horses and the other domestic animals are more extensive, and better arranged than those at Lyons; and the forge atfords more convenience for giving instructions in shoeing: there is also a portable forge, which may be removed to any part of the stables, where its use is required. A field of about six acres is sct apart for agricultural experiments. The royal stables at Paris are well constructed buildingswell paved, drained, and ventilated: the horscs do not stand on litter during the day. They appen capable of containing about two hundred horses. An infirmary and forge are attached to the stables. All the royal stud, as well as the cavalry horses, are shoed upon the plan established by the vetcrinary schools, under the supcrintendancc of a resident veterinary surgeon.

The following year', Mr. Sewel visited the veterinary schools in Germany; and on his return, made a report of his obscrvations to the governors of the London Veterinary College, of which the following is an cxtract. The Veterinary School at Vienna is inferior to that at Alfort; but it affords a greater scope for practice, the stables and other accommodations being calculated for recciving a considerable number of patients : all of them were then occupied, which afforded Mrr. Sewcl an opportunity of seeing some diseases peculiar to the season, which was very hot and dry; the principal of these were lameness, called fever in the fect, and lethargic attacks. The lameness was treated as it 
is in this country, with the addlition of turning the patient into a paddock, where the grass was high, kept watered, and well shaded with trees. 'The horses with lethargy were also kept in the paddock, under the trees, and their heads were often placed under a shower bath. From the number of those that were in a convalescent state, Mr. Sewel concludes that the treatment was successful; though he says, it does not accord with the theory or treatment of the disease taught in this couniry. 'They consider the lethargic symptoms as dependant on some disorder of the digestive organs and liver, and treat it accordingly. The pupils are taught shocing practically at the forge. The shoes are different from our own and those of France.* The stables are not of the first order, but roomy and floored with wood, a common practice in Germany. The other accommodations are very good; such as box stalls, and places for other domestic animals. The stables liave no other means of ventilation than by the windows, some of which open above the horses: the plan of draining is very good, and the litter is removed during the day, unless required for particular cases. The phurmacy (place where medicines are prepared and dispensed), and other offices, are well arranged. The buildings are constructed of wood, and are considerably dilapidated; but it is expected that the whole will be soon rebuilt. An old hermaphrodite horse is shown he"e, in which the male form seems 'to predominate; of which, Mr. Scwel considers it a malformation. The imperial stable is a fine spacious building, floored with wood, well

* According to M. Jauze "the German shoes are, of all others, the most injurious fur horses that have setnd feet. There arc three large crampons (caulking); one at the toe and at each beel, which make the shoe vcry heavy, and takes off the ap umb
of the foot." 
drained, and ventilated, and capable of accommodating sevcral hundred horses; an infirmary is attached to it; also a forge, and a good contrivance for suspending and securing restive horses, for shoeing, or other operations. The horses, as well as those of cavalry, are shoed upon the school plan. Prince Charles's stables are exceeding good as a model on a small scalc; the floor is peculiar, being made of wooden piles or picces, cut out of a rounded figure like large paving stoncs : they are well drained and ventilated.

At Praguc and Dresden, Mr. Sewel found nothing vary interesting except the roynl stables at the latter place: in the coach-horse stable, a covered strean of water passes down the centre, which kecps it always clean and swect. They are wcll ventilated, lofty', lighit, and spacious, and floored with wood. The saddle-horses work unshoed from spring until autumn, when the wet season commences; their feet are in a finc state of preservation in conscquence: the kennel of boarhounds is worth attention.

Late in August, Mr. Sewel visited the Veterinary School at Berlin; which was founded by the late king, Frederic the Second. The theatre of anatorny, museum, and dissecting rooms, form one detached building, probably the most handsome and commodions structure of the kind in Europe. The museum is less cxtensive than that at Paris, but larger than the museum at Vienna, and contains some noveltics which the latter does not possess. It has a complete series of skcletons, from the horse and ox down to the smallest quadruped, and the skin of an African horse, which has not the slightest appearance of hair upon it: there is a good collection of shoes of different countries. The forge is well conducted, and the pupils manually instructed by the professor. The 
method of securing horses for shoeing or operations is very ingenious, and worthy of imitation. The king's horses are shoed at the school forge, and the cavally are shoed according to the plan of the school. The stables are well constructed, paved, and ventilated; the box stalls, and places for other domestic animals, are well arranged. Litter is not used during the day, but sand is strewed under the horses. The stables were full of patients of all descriptions: there were several cases of lameness and lethargy similar to those at Vienna, and their treatment was nearly the same. There was a case of locked jaw that had been cured by a method different fiom tliat employed in this country.* A riding-house is attached to the scliool, for the instruction of pupils intended for the ariny; who receive pay from the time of entrance. There is a beautifully constructed warm watel and vapour bath, with a loom adjoining, to receive the patients after bathing, which is heated occasionally by a stove; the bath is supplied with hot or cold water by an ingenious hydraulic contrivance. The royal stables are handsome buildings, and kept in excellent order. Sand is used under the horses instead of litter in the day time. 'They adjoin the river Spree, into which there is a paved slope, which enables them to bathe or wash their horses. Mr. Sewel brought with him some useful instruments for relieving oxen or sheep that are hoven or blown; he has, since his return, sent them into the country for trial: they are said to be employed, witl great success, in Germany.

On arriving at Hanover, $\mathrm{Ml}_{1}$. Sewel was introduced to Professor Havemann by assistant Pro-

* Ind the governors of the Veterinary College known that locked jaw is very rarely cured in this country, ile'y would perhaps liave desired Mr. Sewel to descrilse the successful mode of treating it to which lie alludes. This eommunication, probably, with the other useful observations he may have aade, will be publighed at a more conrentent time, 
fessor Houseman, whom he had secn in England. The infirmary stables had much dilapidated during the war, from being occupied by foreign cavally. There were no patients in them. The royal stables, which will contain between two and thrce hundred horses, are near the school: they are handsome buildings, well constructcd, light, airy, and spacious; the windows have canvass shades.

In Holland there are no veterinary schools. The royal stables at the Hague are wcll constructed, and in fine order. 'The heads of the stalls and bottoms of the mangers are lined with.glazed Dutch tile, and are kept in the clcancst statc, with very little troublc. Sand is used in the stalls in the day time. At Brussels, there was nothing worthy of attention except an effectual method of draining a large barrack stable, which $\mathrm{Mr}_{\mathrm{r}}$ : Sewcl does not describe. He says, that by inquirics and observation, he obtained in Holland some usefil practical information, which, with the new remedy for locked jaw, the German method of treating lcthargic complaints, and the various improvements lıe may have obscrved in the practice of the veterinary art, he will no doubt communicate to the public.

It is difficult, perliaps impossible, to form a correct comparative estimate of the state of vetcrinary science in this country and France, merely by perusing the works of the French professors and veterinary practitioners; but, if one miglit presumc to judge from such evidence, the author would feel no hesitation in saying, that he thinks the veterinary art has made greater progress in England, than in France. In the latter country, it was cultivated by men of sciencc, at an early period; but herc, it call scarccly be said to have existed till the establishment of the Veterinary College. Some 
good practical works appeared before that time, particularly Gibson's and Clarke's; but the anatomy and physiology of the hor'se liad not been attended to. Since that period, however, it has been assiduously studied; and to the acquisition of this essential branch of knowledge we may attribute the great improvement that has been made in the treatment of diseases. French practitioners appear to be still influenced by the humoral pathology, as it is termed, and consequently depend too much on decoctions of plants, and other vegetable preparations, in acute diseases, many of which are nearly, if not quite, inert with respect to the horse; while similar diseases in this country are often subdued by one copious bleeding. Much praise, however, is clue to the veterinary practitioners of France for the great attention they appear to pay to morbid anatomy. The accuracy and minuteness with which morbid subjects are examined after death, and the scrupulous attention with which every symptom of a disease is observed and noted, is worthy the imitation of British practitioners.

The splendid work of Professor Coleman, on the Horse's Foot and Shoeing, and the more recent publications of Mr. Bracy Clark on the same subject, are of superior merit, I believe, to any thing that has appeared either in this country or on the Continent; and Mr. "Sewel's Nerve Operation, for the relief of foundered horses, is likely to prove a valuable discovery.

Wells, October, 1819.

** Mr. Wurte now resides in the city of TVells, Somerset, where lie may be consulted on the diseases of horses, either personally or by letter. 


\section{A COMPENDIUM}

\section{OF TISE \\ VETERINARY ART.}

\section{CHAPTER I.}

TIIE STAELE.

S S the prescrvation of health ought to be considered as an object of equal, if not superior importance, to that of curing or allcviating clisease, and as it can only be accomplished by a proper mamagement of the horse with respect to feeding, exercise, and the gencral cconomy of the stable, I think it proper to begin with this subject.

In the construction of a stable there is, perhaps, no circumstance more deserving attention than that of ventilation, or of having contrivances for the ready admission of fresh air, and for the escape of that which has becn rendered impure by breathing; and it is really extraordinary that so little attention should have been paid to so important a circumstance. Grooms in general make a point of clusing cvery aperture they can find; and if, at any time, they are prevailed upon to open a win. 
dow, it is commonly so small, and so inconveniently situate, as to be but of little service. Let any one for a moment consider how foul an atmosphere must be produced, in a close stable, in which several horses are kept, by the constant exhalation of unwholesome vapours from the litter, by the steams of perspiration from the skin, and by noxious airs from the lungs: and he will not be surprised at the long catalogue of diseases, to which this improper trentment must subject these useful animals.

If a doubt remain in the mind of any one as to the impropriety of such close stables, let him enter one early in the morning, on it's being first opened, and he will experience such a painful sensation in the eyes, and so violent a cough, as will afford him the most convincing proof of the noxious and stimulating nature of such an atmosphere; yet such is the obstinacy and ignorance of grooms in general, that they camnot be prevailed upon to abandon this injurious practice. Even at this time stables are generally built too low, and unprovicled with effectual means of ventilation.

A stable should be as lofty as it can be made conveniently, at least twelve feet; the foul air will then circulate in the higher parts, and the animal will not be constantly breathing an unwholesome atmosphere, which he must do when the ceiling is scarcely higher than his head. Proper apertures must be also made in the ceiling; communicating with the atmosphere by square wooden tubes, so 
contrived as not to admit the rain into the stable; the foul air and other unwholesome vapours will then readily pass off, while a proper quantity of fresh air may be admitted by means of windows. The next circumstance to be attended to is nearly connected with, and not less important than ventilation; namely, the so constructing a stable, as to be able to regulate it's temperature, or keep the air at any degree of heat that may be thought proper. It is generally allowed, that a uniform temperature in a stable is very desirable; and it is certail, that many of the diseases of horses are caused by sudden changes in this respect. Even slight variations of temperature, if frequent, are injurious; yet few stables are to be found, where this inconvenience is effectually guarded against. 'Гo accomplish this desirable purpose, the windows should be in different sides, so that when a cold wind blows from any point, it may be shut out, while fresh air is admitted by the opposite window. There should be several of the apertures we have described in the ceiling, that they may be occasionally shut, either wholly or partially, so that, by means of these and the windows, the temperature can at any season be easily regulated, according to the weather, or state of the hor'se's health, more accurately if a thermometer be kept-an instrument which appears to be a necessary appendage to a well-conducted stable. If, during the cold days of winter, the contrivance we liave proposed should be found insufficient to laise the tempera- 
ture of the stable to the desired point, the air may be easily warmed to any degree, by means of stoves placed on the outside, with iron ehimneys passing through the stable. It may be plaeed in the saddlcroom : this, however, is seareely necessary.

Light is also a thing of mueh importanee in the construetion of a stable; and, for the purpose of admitting it readily to every part, the windows should be large, and properly placed.

There is no doubt that the cyes of horses are often injured by dark stables; and when a horse is just taken from a dark situation, it is easy to perceive that light at first irritates the eye, and gives pain; and this is more remarkable when he is brought suddenly into the sunshine; nor is it to be wondered at, that so deliente an organ as the eye should suffer materially from the frequent repetition of this sudden ehange.

Though a light stable is desirable, the sunshine should not be allowed to fall on the eyes of a horse as he stands in his stall; nor should the walls or ceiling be of a white eolour, as, under sueh eircumstanees, the eyes would be over stimulated and rendered weak; and when it is eonsidered how liable horses are to diseases of these organs, and how frequently they terminate in blindness, no one will think any cireumstanee tending to their preservation too trifling to be notieed. With regard to the best eolour for the walls and eeiling, a stone or dove colour is perhaps to be preferred, and may be made by mixing a little lamp-black, ivory 
black, or blue-black, with the common whitewash.

The door should be larger and higher than we usually see it; for horses are very liable, in passing through a narrow or low one, to strike their hips or heads. I have seen some troublesome accidents happen in this way; besides, even if the hair be struck off about the hips, it is thought a blemish, because it may not grow again; or, if it do grow, the hair may be white.

In fitting up the interior of a stable, particular attention must be paitl to the size of the stalls, which should not be less than six feet wide, and the sides sufficiently high to prevent any sort of contact or communication between the horses. I know it will be urged as an argument against this, that they are sociable animals, and thrive better with a companion than when alone; this is certainly true: but on the other hand, I am convinced, from long observation, that horses do not feel themsclves in solitude, when they are thus prevonted from touching or playing with their neighbours; besides, if we consider the numerous accidents tliat liappen from low stalls, how fiequently they kick or bite, and otlıerwise injure cach other, there can be no doubt, I think, of the superior advantage of high stalls. At this moment, I have under my care a fine mare, who, from kicking very high, got her hind leg over the stall, and lias received a deep and extensive wound, which will probably prove fatal. The stalls should also be of 
considerable depth, that a horse may not, by drawing back, have the power of kicking those in the adjoining stalls. The method of scparating horses by means of bails or poles, suspended by chains, I think very injudicious; the only recommendation it can possibly lave is the little expense that attends it, and it's allowing a great number of horses to stand in a stable. I am convinced, however, from what I observed during the time I had the honour of serving in the royal dragoons, that, notwithstanding these recommendations, they are really in the end more expensive tu government than stalls would be; scarcely a day passing without some accident happening from the bails: many dangerous, and some fatal wounds were occasioncd by them. I once saw a horse breali his spine or back bone, by endeavouring to rise while under the bail; and several horses lost their sight from being bitten in the eye: but the most serious inconvenience perhaps attending bails, is the impossibility almost of feeding crery horse equally; some horses feeding very slowly, and others so expeditiously as to devour, as well as their own, great part of their neighbour's allowance, in a short time. To this may be added, the facility with which contagious diseases are communicated, the disturbance a horse is liable to when fatigued, and the difficulty of lying down quietly.

The floor of the stall should be made of hard brick, as a more equal surface is then formed than can be obtained by paving with pebbles. Very 
little declivity is necessary to drain off the urine; and as great inconvenience sometimes arises from suffering a horse to stand in a stall where the fall is considerable, creating unnecessary excrtion in the muscles of the hind leg, and kecping the ligaments constantly in a tense state, it has been recommended to make the drain in the middle of the stall, whereby the lind and fore feet of the horse might stand on a level. In whatever way, however, the stall is made, it should be carefully cleaned twice a day, that none of that putrescent matter may accumulate which generates ammonia, or that pungent vapour which is so abundantly found in close filthy stables. An iron rack is preferable to one of wood, being more easily kent clean, and furnishing no splinters; which, where wooden racks are used, sometimes injure the mouth. The manger may be so contrived as to slide into the wall like a drawer; and then, while the groom is wisping lim, he would have nothing to lay hold of with his mouth, by which practice horses often become crib-biters. 'The height both of the rack and manger sliould be such as to enable the horse to feed witl the greatest ease: the former is sometimes made so high that the horse is obliged to exert the muscles of his neck considerably in order to reach it; and this has been so placed, under an idea of it's having a tendency to make him carry his head more gracefully: it is more probable, however, that the only effect of it is to make the horse uncomfortable while feeding. It has indeed 
been lately recommended, as the best plan, to place the racks on a level with the manger, so that the horse may feed as he does in a state of nature. This plan is particularly described and represented by a plate (pl. 1, vol. iv.) It has been tried both for waggon and saddle horses; that is, both single and double, and found to answer cxtremely well. It was observed, however, that some horses would throw out part of the hay with their noses when it was of a bad quality; but, by placing one or more bars across on the upper part, from the front to the back, this was effectually prevented. 'The nanger should be rather wide, and not less than eighteen inches deep. When a horse is fed prineipally with eliaff or cut-hay a deep manger is particularly neecssary, as many horses, in endeavouring to piek out the oats from the chaff, will throw out a grent deal of the food with their noses when the manger is shallow. In large, stables, where many horses are kept, such as post or waggon stables, each stall is to contain two horses, which will require a space of twelve fect. A manger is plaeed at each end, and the hay crib in the eentre. A very short halter is sufficient to allow the horses to lie down, and then there is no danger of entangling themselves with it, an aecident that often oceur's when long lialters are used. La Fosse, in his Mrunucl d'Hippiatrique, say's that the fall in the floor of the stall should not be more than one incli to two yards; and this, I think, is quite suffieient. The gutter behind the stall is commonly too deep, and 
often so placed as to be in the way of the liorse's hind feet. When a stable is properly attended to, scarcely any gutter is required; and when there is one, it should be very shallow, and wide. When a stable is ventilated by means of a tube or chimney, it should be placed in the centre of the ceiling, the opening in which should be large, in proportion to the number of horses kept; it cannot well be too large, but may be contracted upwards, so as to liave a conical shape, or it may be made so as to resemble a dome or cupola. It sliould be carried a few feet above the top of the roof, and have lateral openings by means of slanting boards, but closed on the top; by which contrivance, there wotild be a free communication with the atmosphere, and the rain would be effectually excluded.

There have been different opinions held with respect to the removal of the litter during the day; but when we consider how rapidly and abundantly ammonia or the volatile alkali is generated in it, and how injurious that rapour is to the eyes and lungs, there can be no doubt of the propriety of removing it. Dr. Egan of Dublin has discovered, according to Mr. Peall, that the urine of the horse begins to generate volatile alkali very soon after it is roided: and it is well observed, by the same author, that if this rapour be capable of painfully stimulating a sound and healthy eye, its effects upon one that is inflamed, and, consequently, $\mathrm{cx}$. tremely irritable, must be both highly painful and prejudicial to the organ. In confirmation of this 
opinion, the author relates the following experiment: $\Lambda$ horse, labouring under inflammation of the eye, was removed from the stable, whcre lic kept both eyes constantly shut, and plaeed in a cool, airy situation; in the space of half an hour he began gradually to open his cyes, and, in the space of two or three hours, he kept them open boldly. The horse was again placed in the stable, and in a few minutes he began gradually to close the eyes, and, after an hour or two, kept them constantly shut. Not satisfied, however, with this experiment, though it secms pretty eonclusive, the horse was again removed to the cool situation, and the srime effeet followed as at first. If the vapours produced by foul litter prove so injurious to the eyes, it eannot surely be less prejudicial to the lungs; and it is highly probable that if coughs are not produeed in this way they are often aggravated and rendered ineurable by those irritating effluvia. Another evil to be considered is the propensity observable in many horses to eat their litter. This is often the case with such as have a chronic eough, or are disposed to bccome brokenwinded, or have worms: and, in all these diseases, there is nothing, perhaps, more likely to inerease them than the animal's enting foul litter. It must be obvious that horses employed in severe labour should be allowed to lie down whencver they are inelined to do so; but even then all the litter may be turned out carly in the morning, the floor of the stall swept perfectly clean, and a bed of fresh 
straw put in. If the foul littcr be spread abroad in the open air, and sliaken up two or three times during the day, the greater part would be again fit for litter, and, with the addition of a little fiesh straw, would scrve to replace that upon which the horsc has rested during the day. It has becu said, that horses which stand constantly on litter are apt to feel the difference of the road and bccome tender-footed. Mr. Clark obscrves that the heat arising from the litter occasions a more than ordinary derivation of blood to the logs and feet, and that hence arise swelling or gourdiness of those parts, greasy hecls, and stiffiness or numbness. If the horse lies down for relicf, the heat of the litter soon forces him to get up again, and, after repcatedly lying down, and forced to get up immediately from the above causc, he attempts it no further; he stands upright, or perhaps a little straddling; often shifting the weight of his body from onc $\operatorname{leg}$ to the other. This crect position, in which he is obliged to staud, increases the swelling of his legrs, Stc. and recourse is then had to blecding, purging, diuctics, Sc. Sc.

Lord Pcmbroke, in lis Military Equitation, obscrves that "after working, and at night of course, as also in lameness and sickness, it is good for horses to stand on litter; it also promotes staling; Sc. At other timcs, it is a bad custom : the constant usc of it heats and makes the feet tender, and causcs swclled legs; morcover, it renders the animal dclicate. Swelled lcos may be often reduced 
to their proper natural size, merely by taking away the litter, which, in some stables, where ignorant grooms and farriers govern, would be a great saving of physic and blceding, besides straw. I have seen," he says, "by repeated experiments, legs swell and unswell by leaving litter or taking it away, like mercury in a weather glass." Mr. Blaine is of opinion that "the custom of standing on litter ruins more horses than all the mails and stage coaches put together; that it is the fruitful source of contracted feet, and brings on that ruinous affection with more certainty than the hardest work. In my own stạbles," he says, "no litter is ever suffered to remain under the fore feet during the day. The horses stand on bare bricks, which, in summer, are watered, to make them more cool; by which means I have experienced astonishing benefit. Behind, a little litter is strewed, because they are apt to kick and break the bricks with their hind feet; and because the litter thus placed sucks up the moisture of the urine, which would be detrimental to the hinder feet, which are more liable to thrushes than contraction."

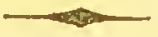

\section{Condition.}

Bx the term condition is to be unclerstood, not only a fat and sleck appearance in a horse; it imulies also a proper degree of health and vigour, by which he is enabled to perform the labour 
required of him without being too much fatigued, or sustaining any injury with regard to his health.

The term condition, lowever, must be considered in a relative sense, as a horse may be in a very fit state, or in condition for moderate work on the road, such as travelling a journey, but' unequal to the exertions reçuired in hunting; and at horse regularly employed in hunting wouk not be thought in the best condition for a race. Every defect with respect to condition must originate either in disease or bad grooming. Under the latter head must be included feeding, exercise, and the general management of the stable; the former will include various disorder's, particularly of those parts which are in any way concerned in the process of digestion and nutrition. In the first place I mean to consider the subject of grooming, and then proceed to a plain description of the digestive and other principal organs of the body, the diseases or accidents to which they are liable, and the most cffectual means of curing them.

\section{Grooming.}

Tuis is a subject of considerable importance, aad requires more attention than is commonly paid to it, as the health and condition of horses depend greally on its being properly managed.

When a horse is in a state of nature, and using only voluntary exercise, there cannot be a doubt 
that the green food, which the bountiful Creator provides for him, is better caleulated than any other to keep him in perfect health, and satisfy his wants; but when lie is domesticated, and cmployed in the various labours for which he is found so essentially useful, it is necessary to adapt the quantity and quality of his food to the llature of the work he has to perform. When, therefore, we unclertake to get a horse into condition, it is necessary first to inquire for what kind of labour le is designed; whether it be for the turf, the ehase, or the road. A horse, without doubt, provicled he is in health, may have lis condition and wind brought to the highest state of perfection it is capable of, merely by juclicious management in respect to feeding, exercise, and grooming; and notwitlistanding the great mystery and secrecy affeeted by those who make a business of training race horses, I will venture to afirm, that it is a very simple proeess, and casily to be accomplished by any one who will attentively consider. the principles we shall lay down, and not suffer himself to be influenced by an ignorant groom. It is a fact, not suficiently known, perhaps, that the strength of an animal, or any part of the body, may be increased to a considerable degree, by means of exercise properly conducted; and as breathing is effected by muscular exertion, it follows that the strength or perfection of this funetion, or, as it is eommonly termed, good u'ind, must depend on the stiength of those muscles by 
which breathing is performed: and by keeping in view this single principle, we shall do more for the improvement of a horse's wind, than we eould by lcarning all the mystcries of training. In order to have a clear idca of the method of getting a loorse into high condition and good wind, let us suppose him just taken from grass: it being understood, that every horse, who works hard during the other parts of the year, will in summer be allowed this necessary relaxation; without whieh the fect, as well as the sincws, joints, ligaments, \&c., of the limbs, will be liable to suffer unaterially; and not unfrequently the general health of the animal is injured by such privation. But should any one be so situate as to be miable to procure this renovating indulgence for his horse, he must endeavour to substitute for it a large airy stable, where the animal may be turned loose. If he camnot get fresh vegetable food, such as luceme, vetches (tares), clover, \&c., he will find earrots a useful succedancum during this time of rest. The horse should be allowed to drink frequently; and, if le be not immoderate, he may be suffered to drink as often and as much as he pleases. He should be fed sparingly with oats; and on no account be allowed beans or any thing of the kind. The best general diet of the dry kind is, perhaps, a mixture of oats, ehopped hay and bran; to be given altcrnately with green fcod; or, if a sufficient quantity of green food can be procured, very little dry meat will be necessary. 
This treatment will serve in some measure as a substitute for a run at grass, provided the stable be large and airy. The light also should be frecly admitted; and, if a convenient court be adjoinings to the stables, the horse may be suffered to run in and out at pleasure: but if therc be nothing but the stable for him to run in, it will be proper to walk ilim out quietly every morning and cvening, allowing him to drink frecly in a running stream or river : the feet, during this time, should be kept cool and moist, for which purpose they may be stopped daily with a mixture of soft clay and cow dung. When a loorse is taken from grass, or from tlic situation and treatment we have just described, in order to be got into a condition for lacing, lunting, or the road, the first object of altention is to bring about the necessary change in his food, and other circumstances, as gradually and with as little inconvenience to the animal as possible. If he be taken from grass; let him be put at first into a large airy stable, and suffered to excreise limself in it. Let him drink frequently; and, instcad of depriving him suddenly of his green food, allow lim at first some carrots, with bran, and a modcrate quantity of oats. Hc slould be walked out once a day at least. His allowance of onts sliould be gradually increased, and that of bran and carrots in like manner dininished, until the latter is wholly discontinued. If lic be a large drinker, he slould be allowed but a moderate quantity at once; but at all times, and in almost 
all circumstances, it is proper to allow a horse water four times a day: whieh, instead of oppressing his stomach, or injuring his wind, will facilitate digestion, and materially eondice to the preservation of health, and the improvement of condition. I am aware of the prejudiee that cxists against this practice-that it is supposed to give a horse a large belly, and render him unfit for galloping any length of timc, without endangering lis wind. I am convineed, however, not only by my own experience, but by that of some cxperieneed sportsmen also, that, so far from injuring a loo'se in any one respect, it is extremely benefieial; and that when a horse is allowed to drink four or five times a day, he is not inelined to clrink much, and often does not drink so mueh in the twenty-four hours, as one that is allowed to drink only twice a day as much as he pleases. As the horse's allowanee of onts is inereased, so should his exercise be; and if this be properly managed, there will be no absolute necessity for bleeding or meclicine. It is neecsary, however, to observe the horse earcfully duribg the tine we are inercasing his allowanec of oats, and diminishing that of carrots and bran; and if he appear dull or have a cough, however trifiing, it inclicates an inflammatory disposition of the body, and points out the propriety of moderate blecding, or a lixative. But under proper management I clo not think such symptons would erer take place, though they almost always do when a horse is changed fiom 
grass to a close stable and dry food too suddenly; and in such cases both bleceling and purging are indispensably requisite to prevent the occurrence of very serious cliseases. It is from this circumstance, perhaps, that the absurd custom of giving exactly three strong doses of physic, as a neccssary preparative, took its origin. When a horse has been taken from grass about a wcek, I think it adviseable to give him a very mild purgative, such as $\mathrm{N}^{\circ} 1$ (see Physic); not that I am convinced of its being absolutely necessary, but because it cannut do any har'm; and if the liorse have been fed too liberally, or not exercised sufficiently-or should the stomach and bowels be out of order, or have any worms in them -2 mild purgative will be of great service. It is on this ground that $I$ always recommend two or three doses of mild physic during the time a horse is getting into condition; but I have secn so many instances of the injurious effects of the strong physic recommended in many books of farriery, and commonly given by grooms, that I think it necessary to advise the reader never to suffer his groom or smith to prepare or prescribe a dose of purging medicine. That such strong doses are oftell given without any immediate bad effect is no proof of their innocence, still less of their utility. I can truly assert, that I have scen many horses quickly destroyed by strong physic, and a great number that have never perfectly recovered from the debility it occasions.

During the first fortuight of the horse's being 
taken into a stable, walking cxercise is most proper; it should be in the morning and evening daily, and eontinued from one hour to two each time. After this it may be gradually inereased to a trot or eanter; and if the exercise oceasion any degree of perspiration, he should be earefully eleaned, and otherwise attended to, as soon as he gets into the stable.

By thus gradually bringing a horse from a state of nature, that is, from the open air and green food, to a comfortable stable and dry grain, he will be in little danger of those troublesome diseases, which are often the consequenee of sudden ehanges, and of a different kind of management; and by duly proportioning his exereise to the nutriment he reeeives, and by gradually bringing the museular system to that degree of exertion for whieh the animal is wanted, there is no doubt that his wind, strength, activity, and general eondition, will be brought to the highest state of perfeetion it is expable of attaining. In cleseribing the general management of horses in the stable, we think it necessary to be very particular, as there are many apparently trifling eireumstanees which have collsiderable influenee on the lorse's health, though grenerally little attended to.

Horses onlployed in hunting, mail, or stageeoach horses, in short, all that are obliged to undergo great and rapid excrtion at eertain periods, require a different treatment from such as work more moderately. The former have oecnsion for 
lying down as much as possible, that the muscles may the more readily recruit their strength. But the latter do not require so much rest in a recumbent state, and suffer no inconvenience from standing the day; therefore their litter should be removed every morning, and shook up in the open air. The advantages of this plan are considerable, though it may be thought, by knowing grooms, an unnecessary trouble. The feet will be thus kept cool; and the hoof will not be so disposed as it commonly is to contract and shrink; for straw, being a bad conductor of heat, causes the ficet to become too hot; in whicl state the lorny matter has ajways a tendency to contract; hence arise sand-cracks, thrushes, \&c. Unless a hor'se has thin, flat soles, it is always proper to stop the feet, as it is termed, with a mixture of cowdung, beaten into a smooth mass with a little fine clay, and a small proportion of potash. This last is intended to keep the stopping moist longer than it would otherwise continue so; but when the stopping is renewed molning and evening it is unnecessary. The feet should be examined daily; and if the soles should appear to be softened too much, that is, if the holn beuds, or gives way in the least under the thumb, by the strongest pressure we can make, the stopping must be discminued. It must be observed also, that stopping is often injurious to the frog, tending to make it too soft, and even rotten; this part, therefore, should be defended, when it appears necessary, by means of tar. 
Horses that lave been aecustomed to stand on litter during the day, sometimes fecl a difficilty in, or reluetanee to staling, when they are deprived of it. In sieh eases, a little straw should be thrown under the belly, so as to prevent the urine from splashing about their legs.

The best food for horses that work hard is onts and hay, with a moderate quantity of beans. The latter, however, should not be allowed, unless the hurse's work be considerable, as under moderate exertion they dispose the system to infiammatory complaints, such as coughs, inflaned eyes, Exc. I am convineed that horses whose labour is serere, are often shjured by being stinted in water, partieularly when they are allowed a large quantity of food. It is a common practice with waggoncrs, when their horses come in from a long and fatignting journey, their strength almost cxhausted by long eontinued excrtion and swcating, to offer them immediately an unlimited quantity of food, and very little (most eommonly not a drop) of water. Under such eireumstances, the stomaeh is not able to digest the food taken in; and it is probable that the staggers are sometimes the consequence of such management. Whicn a horse comes in from a long journey, he should always be allowed a small quantity of water before he is fed; his first feed should be but a moderate quantity; and if he be allowed a little water immediatcly after feeding, it is more likely to promote digestion, and prove beneficial, than to injure tle ani- 
mal. It is certainly a good plan, to give horses a moderate quantity of water just before the end of their journey: and I am satisfied that by allowing them to sip a little water several times, during a long journey, particularly in warm weatler, they are refieshed and invigorated, but never injured. When beans are given to a horse, they should always be broken; and it is probable that onts would be more nutricious in that state. A horse that works moderately does not require more than a peck of good oats, and about twelve or fourteen pounds of hay in the twenty-four hours; but large draught horses require a greater quantity both of oats and hay. The quantity of oats and hay here stated, is the full quantity that should be allowed to a horse who works regularly, but moderately; as in travelling. But as in such cases horses may sometimes be kept in the stable several days without work, the quantity of oats should on such occasions be diminished, and a cold bran mash substituted for it. It should also be observed that some horses will do well with less food than others; and that we sometimes meet with loorses that will eat much more hay than is proper: it is prudent, therefore, to limit the quantity of a horse's food, particularly the hay; this precaution, however, is seldom attended to, either in travelling or other occasions; hence it is perhaps that coughs so often become incurable, and that horses with immoderate appetites become broken winded, or loaded with worms, having largc bellies, harsh staring 
coats, and a general appearance of unhealthiness, notwithstanding they are libcrally fed with oats, or even beans. When a horse eats immoderately of hay it is sure to excite a proportionate degree of thirst; and if this appetite also be indulged, the evil will of course be increased.

Horses employed in hunting, or for expeditious travelling, require great attention as to grooming, feeding, \&c. Their allowance of hay should not exceed twelve pounds in the twenty-four hours; and it should be divided into three feeds-four pounds in the morning, two at noon, and the remainder at night. If a peck of oats be allowed for the same period, it should also be divided into at least three feeds, giving water before each. When a larger allowance of grain is required, which must be the case with humters, post-horses, Scc, cither the quantity of oats may be increased, or a certain proportion of beans may be added; but on no occasion should the quantity of hay be increased for horses of this description. I think there wonld be no danger, and perhaps great advantage, in allowing horses that work hard, either in lunting, posting, or in mail or stage-coaches, an unlimited quantity of good oats, with a moderate proportion of beans, provided it be given at scveral times, so that they may not load their stomachs, and injure the digestive power. If any other food be given with the oats and beans, which, however, appears needless, it should consist of clover-hay, cut like chaff, and a small quantity of 
fresh bran: the former, if not cut too short, will make him masticate his food more perfeetly, and cause it to be digested more ensily: but when a horse has" any lind of cough, or is imperfect in his wind, neither cut hay, chaff, nor bran, should be given, as they are apt to irvitate the throat, and excite conghing; and it is necessary also in this case to sift the oats, and shake the hay, so as to free them from dust, as this will often oecasion a violent cough for a time, and aggravate the original complaint. This will be more effectual, if the onts and hay be slightly moistened with water. Horses of this description being generally greedy of water, and so roraeious as to derour their littcr if kept from hay, it is adviseable to muzzle them immediately after feeding. Some advantage also will be derived from giving them a moderate quantity of earrots now and then, particularly when their work happens to be but modercice, this regetable being nutritious and easy of digestion.--Much has been said by writers on farriery, respecting the kind of water that is most wholesome for horses. The greater part seem to prefer pond water, where the bottom is composed of clay and chalk. It appears to me, that the most desirable kind of watcr is that which horses like best, provided it be not too cold; and I think it probable, that the ill effeets, that have sometimes been produecd by drinking certain kinds of water, have not been occasioned by foreign or impure matters contained in it, but merely by its coldness; and I hare 
found it the best plan to give clear river water in summer, and well water in winter; the latter being warmer in cold weather than watcr exposed to the air, and colder in summer. Some old author (I think Dr. Bracken) has expressed a suspicion, that the hardness, as it is termed, in well water, might occasion the stone or gravel. This is a discase, however, that scarcely ever happens to horses, though we sometimes meet with stones of a large size in the lowels, formed gradually by the earthy matter taken in with the food; and if they were subject to calculous diseases, like men, it is almost impossible that the very small quantity of stony matter contained in hard watcr could have any share in their formation, bcing quite of a different nature from that found in the human bladcer.* It scems to be generally known that brackish water (that is, water impregnated with saline matter, which is commonly met with near the sea) is rather injurious to horses, causing a rough dry cont, and loss of condition. This, perhaps, is not occasioned by any direct operation of the saline matter which such water contains, but by the horse not drinking a sufficient, quantity, on account of its unpleasant taste, for the purpose of digestion.

It is by no means adviscable to accustom horses to warm water in winter, or to let the water stand many hours in a warm stable, so as to become

* La Fosse, in his Dictionnaire Raisonné d' Hippialrique, gives a detailed account of a case of stone in the bladder which waz cured by an speration, 
nearly as war'm as the air of the stable; as it makes the horse liable to the flatulent colic, or gripes, whenever he happens to drink cold water.

In sickness, and during the operation of physic, when it is absolutely necessary to allow warm water, it should never be discontinued suddenly: the change should be brought about as gradually as possible: It is not a good practice to give horses nitre and other medicines in their water or food, because the dose cannot be accurately ascertained in this way; and the water, instead of promoting digestion, often has a contrary effect, exciting nausea, and weakening the stomach. It appears to me a better plan to water horses during their exercise, at a pond or running stream, than in the stable, except it is in winter; and even then it would be adviseable, were it not for the inconvenience they are liable to suffer from standing in the water while drinking: but the common practice of galloping them immediately after is highly improper.

It has been asserted by some, that hor'ses work better, and more effectually preserve their wind and condition, when allowed only a small quantity of water; or, as they express it, "it matters not low little he drinks, provided he feeds heartily." This opinion, like many others, lias arisen from the foolish and mischievous practice of forming general rules upon a few facts, or a very limited experience; and too often, I fear, from examining those facts through the medium of prejudice. It 
must be granted, that we sometimes meet with horses that become loose in their bowels, and fall off in condition, sweating violently, and appearing fatigued from moderate exercise, if allowed to drink even two pails (five or six gallons) in the twentyfour hour's; particularly when they are employed now and then in hunting, or any kind of violent exercise : but this is to be attributed to a weakness of constitution not often met with in horses, and points out to us the necessity of observing a horse attentively when we first undertake the management of him, in order to ascertain what quantity of water is most conducive to the preservation of his health and condition; and if we find a horse shivering, and his coat staring immediately after drinking freely, it is not to be hastily concluded, that he is to be allowed only a small quantity of water daily. In such a case, a very moderate quantity should be given at once, and the horse should be exercised immediately after, in which way he will generally be soon brought to drink a proper quantity in the course of the day without inconvenience. The best time for exercising horses is, early in the morning, as soon as the stable is opened : during which time the stabledoors should be kept open, and the foul littel. thrown out. As liorses that work moderately do not require a bed in the day-time, it will be adviseable in such cases to remove all the litter from the stall, and expose it to the air; spreading only a small quantity at the back part to prevent the horse from splashing his legs in staling. It will perhaps 
be thought unnecessary to excrcise horses that work, particularly such as are employed in hunting or expeditious travelling: I think, however, they are always the better for it, provided it be done witl prudence. It certainly is not proper to take out a horse for exercise that is designed for hunting the same day; but in the intermediate days it should never be omitted; and if a horse's work be moderate, such as ten or twelve miles a day, a little exercise in the morning will enable him to perform it better. Horses of a full habit, or such as are subject to humours, are greatly benefited by exercise, which, on such occasions, may be carried so far as to produce sweating. But great care is then necessary : they should be walked about for some tine, that they may cool gradually; and as soon as they return to the stable, they shonld be well wisped, and their legs hand-rubbed. Swelling of the legs, grease, inflamed eyes, and other troublesome complaints, will be thus more effectually prevented than by blecding every now and then; which, though it affords temporary relief, will gradually increase the disposition to disease. The excreise which a horse enjoys, when liept loose in a large stall, is particularly beneficial, and should always be allowed when the stable is sufficiently large to admit of it, instead of being kept constantly in one position, his head tied to the manger, and his fore legs generally higher than his hind legs: lic can then turn himself about, and cnjoy comparatively a state of liberty, 
In summer, or whenever the weather is temperate, horses should be cleaned in the open air when they return sweating from work or cxercise: for, if put immediately into a warm stable, they often continue to perspire so long as to suffer some injury from it. The common practice, however, of washing the legs with cold water should never be allowed, unless the horse be exercised, or have his legs well rubbed immediately after. It is superfluous, perliaps, to point out the impropriety and danger of plunging a horse into a river while sweating from severe exercise, a practice commonly adopted by proprietors of post and stage-coach horses: that it is often done with impunity must be granted; but it is probable that many of them suffer from the treatment, though the ill effect is not immediately observed.*

When a horse returns from exercise or work, his feet should be carefully picked out and washed:

* It appears, from the cxperiments of Dr. Curric, that, when the heat of the skin is above the natural degree, the applieatinn of cold water is highly refreshing and invigorating; but when the heat of -the system has heen in some measure exhausted by eontinned exereise and perspiration, it will generally produce considerable debility; and in the human body the most dangerous consequences have ensucd from it. The sane obserwation applies to cold water taken into the stomaeh, which on such an ecasion has heen known to eause sudden deatl. It is probable, therefore, that many of the diseases of these poor animals arise from the debility which this treatment oceasions; and perhaps the miselice would be greater, were it not that the river or pond is gencrally at a little distance from the stable, so that they get some excreise immedintely after their immersion, and that the stable is generally very warm. 
and if the hoof be dry and brittle, feeling hot, and appearing contracted, a mixture of cow-dung and soft elay should be applied to the soles. The horse's heels also require attention; and if any small ulcer, or crack, as it is termed, be observed, or if they be tender, swollen, or smell offensively, the proper remedies should be immediately applied. These things, however, very rarcly happen when the groom does his duty. It should be remembered, that when a horse is changing his coat, that is, about the latter end of September and beginning of Octobcr, he is more susceptible of cold than at any other time; and as the coat then falls off so readily, the curry-comb should be laid aside, and the horse exposed as littlc as possible to cold or rain. Moderately warm clothing, and frequent hand rubbing to the legs, will be found highly useful at this time. When these precautions are neglected, horses often become weak and unfit for much work, sweating profusely from moderate exereise, and sometimes purging: troublesome cough and staring coat generally accompany these symptoms. The common remedies on this occasion are bleeding, or strong purgatives, which are sure to incrcase the debility; nor are antimonials, or medicines that act upon the skin, proper to be givel. The most effectual medicines are those of the lonic kind, with moderate stimulants (sce White's Veterinary Materia Medica); and when the bowels are loose, a small proportion of opium. These, however, will avail little, unless assisted by due attention to grooming. Though we lave so strongly 
recommended ventilation in stables, it must not be inferred that a cold stable is desirable; horses seem to thrive most in one that is moderately warm. I have known old horses, that could not be kept in condition in a cold stable, even upon the lighest feed, do well when removed to a warmer one: this, however, is the effect of habit; and it is probable, that if a horse were accustomed, fiom the time lie is first taken up, to a cold stable, he would never require any other: but when from his youth he has been kept in hot stables, his body constantly clothed, and his stomach frequently stimulated by cordials, it cannot be supposed that he is able to endure cold. It is necessary, therefore, on purchasing a liorse, to discover in what manner he has been kept, and whether he have been accustomed to any particular management; for instance, the custom of giving cordials to horses after a liard day's hunt, is often rendered necessary by the practice of keeping them without food or water on the moming they are so employed. In describing the peculiarities in the structure and economy of the horse's stomach, we have observed, that this organ is remarkably small, requiring to be supplied frequently with food. When a hunter, theng goes out with an empty stomach, and is perhaps kept out eight or ten hours without fecding, generally galloping great part of the time, the stomach is so exhausted on his return, that lic lias scarcely any appetite, and refuses his food, until the stomach is roused by a strong cordial: a habit is thus induced, and cordials, after a time, become as necos- 
sary to a horse accustomed to it, as spirit to a dram-drinker.

Yet there surely can be no danger in giving a moderate quantity of oats and water very early in the morning previous to hunting. If he have to walk four or five milcs to covcr, there can be no danger of his stomach being oppressed by the time he arrives, nor a doubt of his performing better than he would otherwise have done. La Fosse, in his Manuel d'Hippialrique, in speaking of the distribution of foragc, says, "experience has often demonstrated that the most serious eonsequences may ensue when a horse is subjected to violent exereise upon a full stomach. The indigestion thus oecasioned of ten eauses violent colics, whieh sometimes prove fatal." I have known many instanees of this; and when we consider how often post and stage-coaeh horses are suldenly attricked during their work with gripes or fret, as it is commonly termed, arising entirely from this cause, it will appear astonishing that it has not cxcitcd the attention of post-masters and other proprietors.

This crror is eertainly more mischievous than the opposite one just before noticed: and if it be true, and I see no reason to doubt it, that oats which eseape being crushed or broken by the teeth, though properly soaked by the saliva and juice of the stomach, are not burst or broken down in this organ, but are uniformly voided whole in evcry case where the husk, over which the gastric juice has no power, remains entire. If this be admitted, how advantageous would it bc in both, and, indeed, 
in all cases, to fecd the animals with bruised oats only, as we should thereby insure their being wholly and speedily digested. With regard to huntcr's, it would perhaps be a good plan to give them only some oatmcal mixed with water early in the morning, when they are to be employed in hunting. Mr. Peall, the author I have here quoted, furthcr observes, that it admits almost of demonstration that a saving of at least one-fourth of the quantity of oats given to horses might be effected by submitting them to the action of a machine called an oatbruiser; as a considerable quantity of oats is swallowed by every horse which cscapcs the action of the teeth, and passes through the intestines without contributing, in the smallest degree, to the animal's nourishment. And if this rule holds good in every instance, even where the teeth are perfect, and with such horses as cannot be considered greedy feeders, how much more must it be the case with very young loorses (when the mouth is tender from cutting teeth and other causes), and very old horses (where the grinding-teeth are often imperfect, and mastication is, of course, imperfectly performed), as well as with such as are voracious feeders. The following striking proof of the utility of bruising grain for horses is given in a communication madc by an intelligent officer who had served long in India, to Mr. Curwen, and brought forward by Mr. Peall.

"I have always been an advocate for cutting hay and straw, and bruising corn, for cattle of every description, and am convinced that any man 
who has paid attention to the subject will soon see the advantage that nust result from the adoption of that practice. My attention was particularly called to this subject by a circumstance which came under my notice when with the cavalry under Lord Lakc on the western banks of the Junna in 1804. Channa, the usual food for the cavalry, bcing scantily supplied, Lord Lake ordered the horses to be fed with equal parts of channa and barley, bruised and steeped in the usual way; but, from the irregrnlarity of the size of the barley and channa, and inattention on the part of those whose duty it was to see it prepared, the greater part of the barley was given entirc, and passed through the stomach and intestincs of the horses apparently little, if "at all, impaired in its nutritive quality. The scarcity of grain which prevailed at that time induced many thousands to flock to the British camp, in search of food, and I daily witnessed, for wceks iogether, many hundreds of these people, of all agges, coming into the lines of our cavalry, and anxiously collecting and carrying away the cxcrement as it fell from the horses. This they cxposed a few hours to the sun, and, by rubbing and sifting it, procured it large supply of good food. 'This detail, which is on some accounts aflicting to humanity, will pro. bably go further in convincing the incredulous upon this subject than the most ingenious theory: It must prove to every unprejuiliced nan that a prodigious waste takes place in the use of corn for" horses, when it is not previously ground or bruised." 
The principal objection that has been proposed to the plan of feeding horses with bruised oats is, that there will be then a deficiency of saliva, which is abundantly produced by mastication, and is presumed, by the objector, io be essentially necessary to digestion. This opinion of the use of saliva Mr. Pcall controverts with much ingenuity; and thinks there is good reason for supposing that the chief purposes which the saliva serves are to lubricate the mouth and palate, and thereby preserve the sensibility of these parts; and to furnish suffcient moisture during the act of masticating food that is dry, so as to fit it for being swallowed, without cxciting any painful or irregular action of the throat and gullet, which would otherwise take place in the act of swallowing hard substances. I bclicve it is generally allowed by those who have given the plan a fair trial, that it has been productive of all the advantage that has been ascribed to it; and it appear's, from the expcricnce of $\mathrm{Mr}$. Chrwerl, that the fecding of working horses on cooked provender is lighly profitable. One great advantage, he observes, is the short time that is required for eating a proper quantity, and its more easy and spcedy diggestion. "A horse," he says, "will take six hours in cating a stonc of hay, whereas le will cat a stonc of stcamed potatocs in twenty minutes." A horse thus fed will, therefore, liave a much longer time for rest than one fed in the common way; and it is probabic, as Mr. Pcall observes, that the stomach bcing thus quickly satisficd, the 
animal will be disposed to sleep or rest, which is favourable to the digestive process. In a letter from Mr. Curwen to Mr. Peall, that gentleman observes, "I can confirm, after great and most extensive practice, every thing I have formerly advanced with respect to feeding horses on (steamed) potatoes. I have found it expedient to add a little more straw, witl a view to rendering the food less costly. A decisive distinction should be made between cut straw and chaff, or the husk of the grain; the latter is perfectly indigestible and dangerous. I strongly suspect I have lost horses formerly by its being used contrary to my order's. The practice of potatoe feeding has been adopted by several gentlemen upon a large scale, all of whom concur in declaring that the opposition to the relinquishing this mode of feeding would now be as great as it was to its adoption. I lave found steamed straw (cut) very good food when I could do no better." Mr. Curwen observes that horses fed upon steamed potatoes should have but little water; and the Bishop of Kildare, another of Mr. Peall's correspondents upon this subject, says he has found that when steamed potatoes are given largely no water should be allowed; and that a horse indulged to the extent of his appetite upon thisfood, will drink little or no water if it bc offered him after feeding.

From these facts, it would appear that mastication is not so essential as some have supposed it to be, and that important advantage, and a considerable saving, would result from the use of bruised 
oats: for, if a horse can eat a stone of steamed potatoes in twenty minutes, thcre can be but little mastication or saliva cmploycd in doing it. When there is no convenicnce for bruising oats, much good may be done by mixing them with what is termed chaff, that is, clover or otlicr hay cut $1 p$, with a small proportion of straw. By this two objects will be accomplished: the oats will be pcrfectly masficated, and, thereforc, wholly converted to nutriment; and a wastc of hay will be prevented. I am satisfied, indeed, that if the wholc of a hor'se's allowance of hay were given him in the form of chaff it would be the means of a considerablc saving. Mr. Blaine thinks that three horses may be supported in this way at as little cxpense as two kept in the usual manncr. The proportions he recommends are one part hay, two of straw, and one of oats; and of this mixture he gives from threc to six pecks daily, according to the size and employment of the horsc: and he observes, that it will add very much to the nutriment which this mixture affords, if the oats are previously bruised. I am inclined to belicve that clover-hay is preferable for this purpose to any other. It is generally thought that this kind of hay is not well adapted for saddle-horses, or such as are employed in quick work; but this opinion, pcrlhaps, has arisen from the too common and mischicvous practice of giving horses as much hay as they will eat, or a great deal more than is proper for them. Horses generally prefer clover-hay ; and it appears 
to contain more uutriment than the other kinds; it should, therefore, always be given sparingly. Chaff soon becomes dry and dusty; therefore enongh only for a few days' consumption should be cut at a time. When good hay cannot be procured, fresh, sweet straw is an excellent substitute, and far better than bad hay, or, perhaps, than such as is indifferent. Hay that has been a little lieated in the mow, or, as it is termed, mou-burnt, is not, I believe, so unwholesome as it is commonly thought to be; but horses are generally fond of it, and, if allowed, would often eat too much. 'It is supposed that saccharine matter is developed by the fermentation which hay undergoes in the mow, and as that which is mow-burnt appears to contain more saccharine matter than any other, it is probable that it may be found preferable when used with discretion, provided it has not been too much heated; for when it has become quite brown there will generally be found a considerable degree of acidity in it, which probably would be injurious if eaten freely. Hay that is dry, and void of smell, is certainly bad; but that which is dusty, mouldy, and of a bad small, is exceedingly prejudicial. Dry hay should be moistened with water, and, if at all dusty, should be previously well shaken: this is particularly necessary when it is used for horses that are greedy of water, or subject to coughs. Hay after it is one year old rather gets worse than improves, particularly in small mows: after the second year, it should never be used when any that 
is newer can be procured-perhaps good straw is preferable to it, especially if the horse is allowed a suffieient quantity of good oats. It may not be unnecessary to repcat, that all horses should be allowed either a run at giass or green food in the stable during the early part of cvery summer: when it is given in the stable, I belicve vetches or luecrne are the best. Mr. Russel of Exeter has for several years found great advantage fron soiling his waggon-horses with vetches while working them; and though his waggoners were at first prejucliecd against the praeticc, and used cvery means to persuade him from eontinuing it, they are now so convinced of its utility, that they would fecl great disappointment were their horses deprived of the salutary indulgence.

It sometimes happens that notwithstanding every attention is paic, to a horse with regard to fecding, exercise, and grooming, he continues thin and out of condition: this, upon a carcful examination, will often be found to depend upon one of the following eircumstances.

Tenderness of the Mouth.-Young hor'ses, about the period of changing the teeth, are sometimes observed to feed badly, while, at the same time, they look dull and languid, eough more or less, and not unfirequently have a slight degree of ferer. This often depends upon the mouth beeming sore and inflamed, whieh, on an exmmination, will be readily perecivel, and is gुenerally attended with some degree of disturbanec in the funetions of the 
stomacl. In this case, a mild laxative should be given, and the mouth washed by means of a syringe with the following lotion. If the eyes appear to be inflamed, blceching also is necessar'y; and as long as the mouth continues tender, his food should consist chiefly of bran inashes, in which may be put a small proportion of bruised oats or malt, or a little sweet oatmcal.

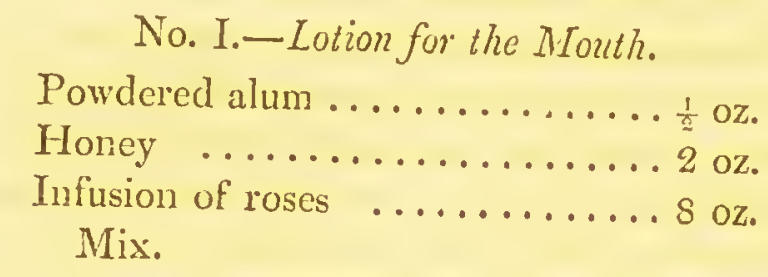

In old horses the insides of the cheeks sometimes become sore, and even ulcerated from some projecting points on the outside of the upper grinding teeth. This is a considerable impediment to mastication, and causes a horse to swallow great part of his oats unbroken. In this case they are not acted upon by the juices of the stomach, but pass off' with the dung unchanged. There are few horses, indeed, that do not swallow some part of their oats unchewed; particularly such as are greedy feéders; hence it arises that birds and poultry so carefully search the dung of horses. The mischief arising from swallowing unmasticated corn is greater than many are awarc of. In the first place, there is a considerable waste of corn; in the next, the digestive powers are fruitlessly cxerted; 
and if the quantity of unbroken corn is considerable, it often swells in the stomach, causing violent colic, and sometimes cven a rupture of its coats; several instances of which have been recordcd by veterinary writers. In stables where several horses are kept without being separated by partitions, which is generally the case in post stables, a horse with a voracious appetite will often rob his neighbours of their allowance, which he cannot well accomplish without swallowing a great deal of it unbroken. In such cases the remedy is sufficiently obvious, and I have before pointed out the great advantage which has been expericnced from bruising whatever grain is given, and when that cannot be done, of mixing it with cut hay and straw, or as it is commonly termed, chaff. When the cheek is injured by the upper grinding tecth, it may be perceived by separating the jaws and pressing out the cheek with the finger; there is also a tenderness observable upon pressing the cheek on the outside against the tecth. The horse's manner of chewing also is remarkable; and he is often seen, after attempting for some time to masticate his hay, to throw it out in the manger, rolled up like a large quid of tobacco. As soon as the tecth arc known to be in this state, the keen or sharp edges should be filed off; for which purpose a hollow file is sold by vetcrinary instrument makers. The sore cheek is to be afterwards washed by means of a syringe, with the lotion, No. I. Horses arc liablealso to caries, or decay of the jaw teeth, and probably 
to toothach. Sometimes we observe a great irregularity in the first grinding tooth, one part rising considerably above the rest: this is easily knocked off with a blunt ehisel and mallet. I have known horses in the constant habit of throwing out their hay in the manger in the form of quids, when no imperfection eonld.be perceived in the teeth: such horses are named by dealers quidders, and are considered of no value. This may depend on some injury in the articulation of the under jaw, or from want of power in tlie muscles coneerned in mastication or swallowing. I have met with two cases where the animals were literally starved from inability to swallow.* It was proved in passing the probang that no obstruetion existed either in the throat or gullet; and when a ball was placed far back in the tlroat, he appeared eapable of swallowing it. The nourishing mashes that were given him were returned by the nostrils, as well as the water he attempted to drink. This horse was able to masticate; therefore the muscles of deghutition or swallowing only appeared to be affected; and this probably was occasioned by a severe attack

* I lave this morning cxamined a horse that died from inability to masticate; that is, he was foreed to work, though gradually losing strength for want of nourishnent; at length he dropped down and died. On the inside of the cheeks I found dcep uicers, one of them communicating with the bony sockct of the tooth, which was carions; the tooth was loose, and casily drawn out with the fungers: from the appearance of the part, this horse must have been suffering a considerable time; but the cause was never sinspected by the owner. 
of sore throat which he had suffered a short time beforc.

In giving balls awkwardly, or rather in drawing the tongue with too much force, the skin underneath it, or the bridle, as it is called, is sometines lacerated in a considerable degrec. It is known by the horsc fecding with difficulty and frothing at the mouth. This may be soon curcd by keeping him on soft food, and syringing the part three or four times a day with the lotion, No. I. The bars of the mouth, or that part where the bit of the bridle bears, are sometimes injured and become an impediment to fecding. When this is not attended to, the bonc often becomes carious, and a troublesome discase will be established. On examining the mouth in such cases, a small ulcer may be scen in the grim, betwcen the tush and the first grinding tooth; and on probing this ulcer, the bare bone, or the carious part of it will be readily felt. When the diseasc has proceeded thus far, I have found it the best plan to scrape the diseased surface of the bone witl a drawing knife, and when the blceding had ceased, to wash it with a solution of sulphate of copper (blue vitriol); atter this a curc may be accomplisherl in a short time by applying the lotion, No. I., wr tincture of myrrh. The skin on the inside of the mouth, ncar the angle or commissure of the lips, sometimes is found swollen and tender, so as to grive pain in feeding. This in stablc language is termed washes, bags, \&c. and are generally got rid of by washing the part with 
some astringent lotion, such as No. I. But when the swclling is considerable and cannot be thus removed, the most prominent part should be cut out with a knile or scissars, and the wound after-. wards washed with a solution of sulphate of copper. A cicatrix will soon form, by which the tumid parts will be contracted and the inconvenience removed. When the mouth is in that tender and inflamed state beforc described, as occurring to young horses, the excretory ducts of the salivary glands under the tongue partake of the affection, becoming red and tumid. The old farriers advise cutting them off; a very absurd and mischievous practice. This appearance they termed paps and barbs, and thought it necessary to remove them even in a healthy state: they resemble very small teats, and may be seen under the tongue.

The lampas, which is a fulness, or swelling of the roof of the mouth near the front tceth, is sometimes an impediment to feeding, but not so often as it is supposed to be. In all young horses this part is rather full, and often on a level almost with the teeth, without being tender or hindering them from fecding. When the mouth becomes inflamed and sore, cither from teething or some disorder of the stomach, the roof or palate of the mouth also is generally in the same statc. For this swelling or lampas, farricrs and grooms think it neccssary to apply the hot iron, and I camnot say that I have ever seen any injury arise from the application, except in a few instances, where it has becn carricd 
too far'; but I have almost always found that after the operation has been performed, and somelotion given to wash the mouth, no further complaint has been made of the horse's feeding. It is better, however, to try the lotion in the first place, which with a close of laxative modicinc and a few mashes, will gcnerally, perhaps, render the operation unnecessary. Whencuer a horse appears to feed with difficulty or pain; if he throws out his hay after clewing it a little, and moves his jaw in an unusual manner, or with difficnlty, or if much unbroken corn is found with his dung, let the mouth be carefully examined, and the cause will probably be found. But if nothing can be seen to account for the horse's fecding bally, if the food and water are good, the manger and rack clean, as well as the pail from which he drinks, and free from any offersive smell; and if it is asccrtained also, that there is no difficulty in swallowing, then it is to be presumed that the stomach and other parts connected with it are in an unhenlthy statc, and that the want of appetitc and loss of condition depend on that circumstancc.

The most common canse of loss of tonc and encrgy in the stomach is feeding upon unwholesome provender, or such as is difficult of digestion; of this kind are musty oats and hay, \&c. By kceping a horse on such unwholesome food for some time, he not only loses strength and condition, but bccomes subject to very scrious diseases, especially when he is made to work hard, or 
to do only what many consider moderate work for lim when in good condition. I have seen very considerable loss sustained by post and coach. horse proprietors by such imprudence. In this case a change of diet is of course the principal remedy ; but when the stomach lias been much weakened, it will be necessary to give some tonic medicine, and to feed the animal more frequently than usual, with small quantities of food, that is light and easy of digestion; such as mashes of ground malt, boiled barley, or oats, \&c. A dose of laxative medicine about once in a wcek or ten days will also be useful during the horse's recovery; and regular walking exercise and good grooming are no less essential. Drinking cold water freely, when heated by exercise, will often produce an injurious effect upon the stomach, and consequently upon the skin and coat; from this cause arise small tumours on various parts of the body, hide bound, rough unhealthy locking coat, loss of condition, and many other evils. The same effects may be produced by making a lorse stand in a cold wind or rain, after having been heated by exercise, especially when the exercise las been such as to cause fatigne or exhaustion; in this case indeed, the most serious disenses are often produced, such as inflammation of the lungs or bowels, general inflammation, or acute rheumatism, or what is commonly termed a violent chill. The digestive organs sometimes become weak gradually without any apparent cause; and such is the comnection of the 
skin with the stomach, that the coat and general appearance of the animal is sure to partake of the affection. This is first indicated by a failure in the appetite, or by its becoming clepraved; the lorse eating his litter 'in preference to good hay, or eating any earthy matter that comes in his way, or licking the walls. This is soon followed by general debility, emaciation, and an unhealthy coat. The most effectual remedies in this case are tonic medicines, nutricious diet, given in a state in which it is easily digested, such as bruised oats, mashes of ground malt, \&c. Previous to the tonic medicine the following laxative should be given.

\section{Stomachic Laxalive.}

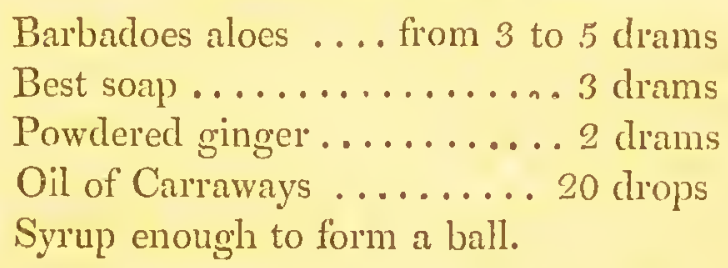

This ball is intended to purge very moderately; but should its operation be move considerable, which may happen when the bowels are weak and irritable; gruel made of wheaten flour or arrow root should be given frecly to restrain it. Mode- . rately warm clothing will be very useful, and brisk friction of the skin, hard rubbing of the legs, with walking exercise, are esscntially requisite. It should be understood, however, that although exercise tends to promote strength, yet if carried beyond 
the animal's power, it is sure to diminish it; therefore, whenever' a horse is very weak, voluntary cxercise only is proper; such as he may get in a large box, or, in favourable weatler, in a small paddock or ficld.

A horse in this state should be fed and watered oftener than usual, and his watcr slould be at the summer temperature.

Worms in the stomach and bowels are a frequent canse of leanness and debility in horses; and while they exist, every exertion to promote condition will be ineffectual. (See Worms.) A defect in the organs of respiration will also produce weakness and emaciation.

If the blood be not duly supplied with that vivifying principle, which is derived from the air by breathing, a grcater or less degree of debility must be the consequence; hence a want of tone is always observable in the stomach and bowels of broken-winded horses, as well as a deficiency in the muscular power in general. The same evils will result from keeping a horse in too close a stable, where the air does not contain the usual proportion of this principle.

Imperfection of the Liver or Pancreas, or Obstruction in the Tules or Ducls, by which their respective Juices are comveyed to the Bowels. (Sce Anatomy of Internal Organs.) - The liver is not often diseased in the loorse, unless it be from internal inflammation. When the exterior surface of the bowels, or stomach, is attacked by inflammation, it will 
spread, if not speedily checked by bleeding, \&c., to the surface of the liver, and other internal parts; and when horses die from thir disease, which they often do, from improper treatment, the liver is generally found inflamed or mortified throughout its whole substance: but this is an acute discasc, and therefore not connected with the present subject. (Sec Inflammation of the Liver.) It sometimes happens, however, that a horse becomes weak and lean, cither from a deficiency or a redundancy of bilc. In the former case, digestion will be imperfect, and the horse frequently costive; the appetite will be bad, the animal languid and sluggish, and gencrally hidebound, the coat looking rough and unhealthy. The best remedy, in this case, is to give small doses of calomel, soap, and aloes, as recommended in jaundice, so as to kecp the bowels in a more open state; or, if the disease have existed some time, give in the first place a mercurial purgative, and afterward the following alterative:

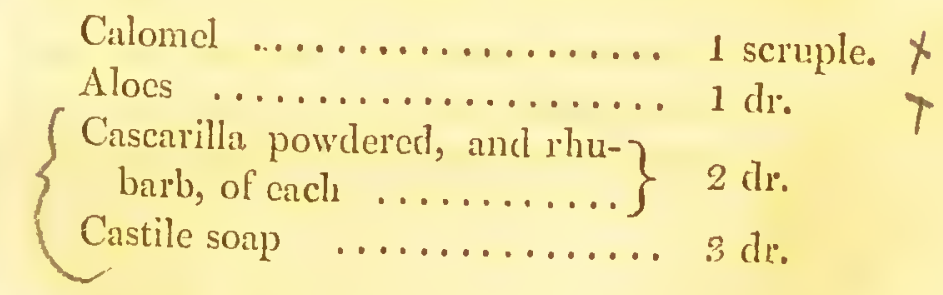

Sirup cnough to form a ball, to be given every morning for five or six days, unless it occasions purging, in which case it is to be discontinued for two or three days. 
The lorse's diet should be light and nutritious, consisting of ground oats, carrots, malt, \&c.: regular exercise is of great use. In the spring or summer, a run at grass is the best remedy. When there is too much bile formed, it occasions a loose state of the bowels, which causes the horse to become weak and thin. This complaint depends upon increased action of the liver, which generally ceases in a short time, without the aid of medicine. Should the purging continue, so as to reduce the animal's strength, the following medicine may be given, and assisted by a light nourishing diet, and very moderate exercise:-

Powdered columbo root ...... 2 dr. Cascarilla powdered $\ldots \ldots \ldots .1 \mathrm{dr}$. Prepared natron .......... 2 dr. Opium ................ $\frac{1}{2} \mathrm{dr}$.

To be given every morning. It is better to try it first without the opium, and it will generally be found to succeed, if the horse be allowed some gruel made with wheat flour or arrow-root: and when the opium is found necessary, one dose will generally be found sufficient to stop the looseness, for some time at least.

There are no external appearances, by which a diseased state of the pancreas can be ascertained, and it is probably very rarely a cause of ill condition. There is reason to believe, that want of con- 
dition depeuds, in some cases, upon an imperfect action of the lacteals, or those delicate vessels which convey the chyle, or nutritious parts of the food, into the blood, or upon some disease of the mesenteric glands through which they pass. * All the internal surface of the bowels is covered with very minute orifices, which are the mouths of the lacteals, and are supposed to be always open, to receive such parts of the digested food as are destined for the nourishment of the system. It is not improbable, that these minute orifices may sometimes be obstructed, or that the lacteals may be deficient in energy. Therefore, when a horse continues thin and ill-conditioned, without any apparent cause, this may be suspected : and the success we have often met with in such cases, by giving a mercurial purgative, joined with a moderate stimulant, or stomachic medicine, seems to justify the opinion. The following formula may be employed on this occasion :- -

\section{Barbadoes aloes ........ $\frac{1}{2}$ oz.}

* Horses that die of atroplis, or mesenteric consumption, have frequently, for some time before death, a discharge from the nostrils, and a swelling of the glands under the jaw, from which circumstance they are generally supposed to be glandered. It is worth remarking, that in every horse I lave examined, that has died from this causc, or been destroyed from being considered incurable, I lave found the anterior mesenteric artery considerably enlarged, and its coat much thickened: upon opcning it, I have invariably seen within it miny small worms, rather smaller than ascarides. 
Rhubarb ............ 2 dr.

Calomel ............ $1 \mathrm{dl}$.

Ginger $\ldots \ldots \ldots \ldots \ldots \ldots+\frac{1}{2} \mathrm{dr}$.

Oil of caraways $\ldots \ldots \ldots .10$ drops.

Castile soap $\ldots \ldots \ldots \ldots .2 \mathrm{dr}$.

\section{Sirup enough to form a ball.}

I should have observed before, that wo some. times meet with horses, particularly those of the blood kind, that have an almost liabitual looseness or diarrhœa; and some that cannot bear even moderate work, or even drinking freely of water, without becoming loose in the bowels, and consequently weak and faint. Such horses are generally observed to sweat much, with the most molerate exercise, and sometimes when standing in the stable. This complaint is sometimes merely temporary, and is most likely to happen in the carly part of spring, or about September and October'; at which period some changes are generally taking place in the coat, by which the bowels, and often the whole system, are rendered irritable and weak. In this case, the symptoms generally disappear with the cause; but, as a horse may remain in this situation a considerable time, and be unfit for work, it is advisable to call in the assistance of medicine. The first medicine to be given is a stomaclic laxative, and after that the tonic ball. The liorse should be clothed moderately, and exposed as little as possible to a current of air: but the 
stable should be well ventilated, and his water at the summer temperature, that is, about fifty degrees by Fahrenheit's thermometer. His exercise ought not to exceed a walk: but he may be taken out twice a day, if the weather be favourable. With respect to those hor'ses that are habitually weak, or washy, as it is termed, becoming loose and weak from moderate work, or other trifling causes, there is 110 great chance of radical cure; but the animal will derive grent benefit from medicine and care, and often be enabled to do his work with spirit, and without much inconvenience. The proprietor of such horses should always be provided with the following cordial, which should be given, not only when the looseness and weakness actually are present, but at any time when consiclerable exertion is required of him. If he be wanted for a journey, or a day's hunt, let him hare a ball a little before he sets off, and another when lie returns. If the horse be very young, it may be worth while to attempt a radical cure, by a long run at grass. Horses of this description require great attention from the groom: they should nevcr be exposed to the air without clothes, unless in the lot days of summer. Their water should be always at summer temperature, and given in small quantities often. Their food should be easy of digestion, their oats and beans given in a broken or bruised state, and their daily allowance should be divided into fonr or five feeds. Their hay should be of the best quality : mow-burnt hay is particu- 
larly injurious. A brisk circulation should be kept up in the skin and extremities, by frequent wisping the body, and hand-rubbing the legs. Moderate exercise is necessary; and the horse should always be attended to the moment he comes into the stable, either from work or exercise.

\section{Stomachic Purgative.}

No. 2.

Barbadoes aloes ........... $3 \mathrm{dr}$.

Rhubarb............... $2 \mathrm{dr}$.

Ginger................ $1 \mathrm{dr}$.

Cascarilla $\ldots \ldots \ldots \ldots \ldots \ldots . .1 \mathrm{dr}$.

Oil of camomile .......... 20 drops.

Carbonate of Soda ......... 2 dr.

Sirup enough to form a ball for one dose.

Tonic Ball.

Salt of stcel ......... from $2 \mathrm{dr}$, to $\frac{1}{2} \mathrm{oz}$.

Columbo root......... $3 \mathrm{dr}$.

Cascarilla bark ....... $2 \mathrm{dr}$.

Opiun ............ 1 scr.

Sirup enough to form a ball for one close.

Remark. - Arsenic is an excellent tonic, but must be given with caution, and in small doses. (See the author's second volume, or Materia Medica, where a great variety of formula for tonics are given.) Sulphate of copper has likewise been given as a tonic; the dose about a dram. 
Cordial Ball.

No. 1.

Caraway seeds, recently powdered .. $3 \mathrm{dr}$. Winter's bark, powdered ........ 2 dr. Prepared chalk ............. $2 \mathrm{dr}$. Opium $\ldots \ldots \ldots \ldots \ldots \ldots \ldots \ldots$. $\frac{1}{2} \mathrm{dr}$. Oil of anise-seeds ............ 20 drops.

Sirup cnough to form a ball for one dose.

No. 2.

Powdered ginger ............. $2 \mathrm{dr}$. Liquorice powder ............ $\frac{1}{2}$ oz. Oil of caraways and anise-seed, of each 12 drops. Treacle enough to form the ball.

This is a more simple ball than the former, and will generally answer the purpose. When it is found necessary to give No. 1, the opium should be omitted if there is occasion to repeat it after a second dose. 


\section{CHAPTER II.}

STRUCTURE AND FUNCTIONS OF THE INTIERNAL ORGANS.

THe hollow part of the body is divided into two cavities by a strong muscular partition, termed the diaphragm or midriff; the anterior part is named the thorax or chest; and the posterior, the abdomen or belly. The thorax contains the lungs and hecert; the abdomen, the stomach, intestines, liver, spleen or milt, pancreas or sweetbread, kidneys, and bladder.

\section{Of the Lungs.}

In describing the lungs, it is necessary to begin with the trachea or wind-pipe, which is a cylindrical cartilaginous tube, extending from the throat to the chest. The trachea is not made up of one entire cartilage, but of several cartilaginous rings, which are united by strong menibranes; and such is the elasticity of these cartilages, that the tube is enabled to preserve its cylindrical form, even when it receives considerable pressure, and thereby affords free ingress and egress to the air in respiration. The membranes also are elastic, so that the windpipe may be either elongatcd, shortened, or 
bent, in some degree. The upper part of the trachea is composed of stronger cartilages than the other parts of the tube, and is termed larynx: to this is connected a curious kind of valve, called epiglottis, which is always open, except in the act of swallowing: it is then forced down upon the larynx, so as to prevent food, or any thing which may be passing over the throat, from falling into the windpipe. The trachea terminates in the lungs, dividing into numerous branches, which, gradually becoming smaller, at length terminate in minute cclls: the lungs, indecd, are made up of the ramifications of the trachea and blood-vessels; the interstices bcing filled with a cellular membranc, which serves to mite them, and gives an miform and homogeneous appearancc to the whole mass. The lungs are covcred with a fine delicate membrane, called the pleura, which also covers the internal surfacc of the ribs and diaplu'agm, and, by stretching across the chest from the spine to the breast-bonc, divides the thorax into two cavities; this part of the pleura is therefore named mediastinum. On cvery part of the pleura, fluid is sccreted for the purposc of preventing a colesion of the parts; and when this is produced too abundantly, it constitutes the discase termed hydrothorax, or dropsy of the chest. 'The plcura, though so fine a, membrane, is impervious to air; which may be proved on the dead animal, by rupturing one or more of the small branches of the windpipe, and then blowing into the lings. The air, which is 
forced in, will then escape through the ruptured parts, and be diffused in the cellular membrane, * so as to make the lungs appear much larger. than they were before. When the air is at length forced to the surface of the lungs, it will be prevented from escaping by the pleura, which will be blown up, and appear like an inflated bladder on the surface of the lungs. If this be punctured, the air will soon escape, and the lungs will return to their original size. This circumstance is noticed, as it is supposed to happen sometimes in the living animal, and to be the cause of broken wind. (See

* The ccllular nembrane is that which connects the various parts of the body with each other; it not only unitcs the skin to the flesh, and the large muscles to each other, but is employed also to connect the minute fibres which compose the skin, muscles, $\& \mathrm{c}_{n}$; and, therefort, it is inferred, that the cellular mem. brane exists in every part of the body, however minute; and is in some parts so fine, as to bc invisible; while in others, as between the shoulder blate and the ribs, it is very conspicuous. The cellular membrane is composed of cells of various sizes, which communicate freely with each other, so that, if a blowpipe be put into onc of thc cells, and air forced through it, all the neighbouringp arts will be blown up to a considerable size. A familiar example of this is the practice among butchers of blowing up the cellular membrane of a shoulder of veal. It soinetimes happens in the case of a fractured rib, that ooc end of the bone is forced into the lungs, so as to wound the branches of the windpipe and the pleura; the air, which is inspired, will then escapc; and, as the wound communicates with the cellular membrane between the muscles of the ribs, the air gradually diffuses itself through all the contiguous parts; and sometimes the whole body, and even the cellular menbrane about the eyc, is infuated from this cause. 
Broken Wind and Chronic Cough). The lungs are divided into two parts, or lobes, one of which is situate in each cavity of the thorax: thcre is also a small lobe or lobulc, as it is termed, within the duplicature of the pleura, which forms the mediastinum. This division scems to have been provided in casc of accidents, it having been proved that when one lobe is incapable of performing its function in consequence of injury or discase, the other has bcen found adequate to the support of life.

The lungs are the organs of respiration or breathing: but thcy do not appear to be actively concerned in the performance of this office: when the diaphragm and the muscles of the belly and ribs contract, the cavity of the thorax is considerably diminished, and the lungs so compressed, that the air eontained in them is forced out througli the windpipe: when this has bcen effected, the muscles relax, and the thorax returns to its original size. There would now be a vacuum between the internal surface of the ribs and the cxtcrnal surface of the lungs, did not the air rush in through the windpipe, and so distend its branches and cclls, as to make the lungs completcly fill the cavity. Thus are the lungs constantly cmployed in inspiration and cxpiration; and this proeess, which we call breathing, is carried on by the combined action of the diaphragm, and the museles of the ribs and abdomen. It is supposed, that the elasticity of the lungs, or rather of the branclics of the windpipe, materially contributes to this important, action, in 
the same manner as a bottle of clastic gum, or Indian-rubber, fills itself either with air or water, from its great elasticity. If a small pipe or quill be tied to the mouth of one of those bottles, and the air pressed out by the hand; as soon as the pressure is removed, the bottle will resume its original form, and conscquently be filled with air again. If the mouth of the bottle or the pipe be put into water after the air has been pressed out, on removing the pressure, the bottle will be filled with water*.

The internal surface of the windpipe and its branches is lined with a membrane, on which is formed a mucous fluid, similar to that which the membrane within the nostrils secretes. When this accumulates, so as to be inconvenient, it is expectorated or thrown up by coughing. In the human subject this mucus is coughed up into the throat and mouth; but in the horse, it is thrown chicfly into the nostrils. The mucous membrane of the windpipe and its branches is the part principally

* It has been supposed, that, if an opening were made in the side, so as to admit the air into the chest, the lungs would collapse: I was induced, therefore, to make the following experiment :-

1 made an opening on both sides of a horse, so that I could introduce my finger into the chest. $\Lambda$ tube was then put into the openings, so as to gire free aduission to the air. The borse was kept in this state nearly half an hour wilhout appearing to Buffer any inconvenience from it. This experiment was repeiled on nnother horse while lying on his side, and in that case wlien an opening was made in the chest, the lung immediately cole laped. 
affected in eatarrh or cold. The disease generally begins at the superior part or larynx, sometimes in the nucous membrane of the throat and nostrils, spreading from thence into the trachea and its ramifications. A catarh, therefore, consists in an inflammation of these membranes, varying in degree and the extent of surface which it attacks: sometimes it is eonfined ehicfly to the pituitary membrane, or that which lines the nostrils; at others, the membrane and glands of the throat are ehiefly affected, when the disease is named quinsy or sore-throat; and often, the whole cxtent of the mncous membrane, even to the air-eells, beeomes inflamed, and seeretes an unusual quantity of mucus, which would soon suffocate the animal were it not every now and then expelled by coughing. That part of the membrane which lines the larynx: is possessed of exquisite sensibility; and when the smallest portion of the food happens to get there, an accident which sometimes occurs, the most violent irritation is produced; and if the animal does not succeed in his efforts to get rid of it by coughing, a fatal inflammation or suffocation is the consequenee. It is worthy of remark, that notwithstanding the great scnsibility of the inside of the larynx, the membrane lining the windpipe seems to be nearly, if not quite, insensible. I have several times made an opening in a horse's windpipe, and scratched the membrane with my forefinger; and even with an instrument, and it has not appeared to give the animal the least pain; but in 
passing up a straw, the moment it touched the larynx, the most violent irritation was produced. It is vely probable, that when the niembrane of the trachea is affected with catarrh, it becomes more irritable. 'Therc is not only an increased secretion of mucus in catarrl, but the quality of the mattel seems to be different: at first, it is much more fluid than in healtln, of a strong saline taste, and very stimulating. As the discase declines, it bccomes thicker, approaching, in appearance, to the matter of an abscess. In some cases, a prodigious quantity is formed and thrown off by the nostrils. When catarrhal discases occur as an epidemic, they are gencrally attended with fever, and soon occasion a considerable degree of debility. Sometimes the disease spreads to the cellular texture of the luugs, constituting the disease tcrmed peripneumony, and then the plcura or investing membrane of the lings before described is likewise affected. The mucous membrane of the windpipe and its branches is liable to other and more durable affections, upon which depend chronic cough, roaring, broken wind, \&c., which will be lloticed leere. after.

\section{Of the Heart.}

'The lieart is placed wearly in the middle of the thorax: it is rather conical in its form, the apex 
inclining towards the left side; its base attached to the bones of the back and ribs: it is loosely invested with a mombrane or sac, termed pericardium, vulgarly heart-bag. This sac always contains a small quantity of fluid, which serves to lubricate its intcrnal surface, as well as the surface of the heart, to prevent their coliesion, and suffer them to move frecly upon each other. Sometimes this fluid accumulates, from a discased action of the vcssels which form it, to a considerable degree. This kind of dropsy generally accompanies that of the chest. The heart is divided into two cavitics, termed ventricles, each of them having a small hollow appendagc, which, from a slight resemblance it bear's to a dog's ear, is named auricle. The blood-vessels proceed from these cavities, the arteries from the ventricles, the rcins from the auricles; the former serving to carry the blood from the heart to evcry part of the body, for the purposes of nourishment, sccretion of the various juices, and stimulating the system to action, as well as for furnishing the various parts with the vital principle; the latter conveying back the blood, thus deprived of its csscutial parts, to the heart, that it may be renovated by circulating through the lungs, as we shall now describe more particularly. When the left ventricle is full of blood, it contracts so powerfully as to forcc its contents into the aorta, or grand artcry, by the almost infnite ramifications of which the blood is distributed all over the body. The arteries at length terminate in the 
veins, which, gradually becoming larger and less numerous, convey the blood into the right auricle, whence it flows into the right ventricle; this also, when it is sufficiently distended, contracts upon its contents, and propels the blood in to the pulmonary artery, by which it is conveyed to every part of the lungs. The pulmonary veins then reccive it, and convey it to the left anricle, whence it is propelied into the left ventricle, that it may again be distributed by the aorta to every part of the body.

In the natural course of circulation, the above order of successive motions is not pursued, for the contraction of both auricles is simultaneous as well as of the ventricles, while the dilatation and contraction of the auricles and ventricles are alternate to each other. Dr. Harvey, the discoverer of the circulation, conceived the whole of the circulatory process to be effected by the contractile power of the heart; but it is now generally considered to be greatly dependant on the arteries also. The arteries are composcd of three coats: the exterior coat is highly elastic; the middle is muscular, and the inner one is a delicate, smootl membrane. "It is a remarkable fact, as stated by Mr. John Hunter, that the large arteries appear to consist almost wholly of elastic matter, while in those of smaller diameter muscularity predominates; and that this last in the capillary or smallest branches exists almost exclusively. Thus, as Richerand observes, the passage of the blood into the large trunks of the arteries, in the vicinity of the heart, is effected 
principally by that organ, but, in proportion as it becomes distant from the heart, several causes retard it; and the blood could not arrive at every part were not the arteries, which are more active in proportion to their smallness and distance from the heart, to act and propel it to all the organs. Dr. Harvey supposed that the arteries communicated with thic veins by an intermediate cellular substance; but this is the case only in the uterus, the splcen, and the eavernous bodies of the penis. Arteries have different terminations: the chicf of which, as it relates to the circulation, are the veins with which they communicate by the intervention of what are termed the capillaries or minute branches of the arteries. The other terminations arc in glands, mucous, and scrous, surfaces. In the glands named kidneys, for example, arteries terminate in urinary vessels as woll as in veins; in the mincous membrane of the windpipe, nose, Sc. ; in mucous ressels; and on the membranes named pleura, peritoneum, \&c.; in scrous vessels or exhalants.

In the capillary arteries, the colour of the blood is lost, by reason of their minute size, which will not admit the red globules or colouring matter of the blood; on this account, the blood-vessels onl the surface of the eyc are not perceptible, unless that part is inflamed; in which case, the red globules are forced into them, and, of course, they become visible. The veins are more numerous and much larger than the arterics: in the latter, the circula- 
tion is effected by the action of the heart, or of their own muscular and eontractile power'; in the veins, lowever, these eireulatory power's have so trivial an energy that nature lias guarded against impediments in the eourse of the blood through these last; in some instances, indeed, has facilitated this eourse, by such a distribution of them as shall ensure the propulsion of the vital fluid by the action of various muscles. In the legs, for example, the blood readily returns in the veins in opposition to gravity; this is effected, in great measure, by the motion of the limbs, and the consequent pressure which the veins receive, and by their having numerous valves within, which open only towards the heart; so tlat, when the vein is compressed, the eontained fluid is necessarily propelled in its proper course.

The blood is thus continually eirculating through the body; and this proeess may be eonsidered as one of the most important aetions that is performed in the animal maeline. If it be stopped for a few seconds, all motion is suspended; and if it be prevented a longer time from going on, vitality is destroyed. The function of the lungs is of equal inportance in the animal econony, and eannot be stopped even for a short time, witlout suspending or totally destroying animation. Aneient physiologists had a very imperfeet idea of the manner in which these organs so essentially contributed to the support of life: the moderns, lowever, have been more successful in their researches; they have 
discovered that the blood derives from the air, which is taken into the lungs, the most important properties, without which it would be a useless vapid mass, totally inadequate to the purposes for which it was designed. If we examine the blood in the left ventricle of the heart, and in the arteries, it will be found of a bright scarlet colour, and replete with those properties which render it capable of nourisling the body, and stimulating the whole system to action : in the veins it becomes of a much darker colour; and when it arrives at the right ventricle is nearly black, and destitute of those enlivening qualities, which it possessed in the left ventricle. Had not the Deity then provided some means for its renovation, it would have been quite unfit for a second circulation, and the duration of life must have been short indeed; but from the right ventricle it is conveyed by the pulmonary artery to the lungs, at the moment they are distended with air; here the blood undergoes a wonderful alteration; it resumes its bright scarlet colour, and is returned by the pulmonary veins to the left side of the heart, with all its original and essential qualities restored to it. It is proper to observe, that there are valves placed in such situations, as effectually prevent the blood from taking a retrograde course. Were it not for this contrivance, the blood would as readily be forced into the left auricle as into the great artery, when the left ventricle, which lies between them, contracts, or shrinks up; and so of the other parts. 
Hence we may learn how important are the functions of respiration and the circulation of blood, how essential to the life of animals, and how dependent they are on each other.

\section{Viscera of the Abdomen.}

$\mathrm{H}_{\triangle \mathrm{VING}}$ finished our description of the thoracic viscera, we proceed to notice those of the abdomen or belly; the first and most important of which is the siomach. Whatever this organ receives is conveyed to it by a long muscular tube, name cesophagrus or gullet. The osophagus originates in the throat, where its size is considerable, but it suddenly diminishes into a small tube, and is continued of the same size to the stomach: the upper part has been thought to resemble a funncl in its form, and is distinguished by the term pharynx.

The pharynx is situate immediately behind the larynx, or beginning of the windpipe; but is not, like it, composed of strong cartilage or gristle; it is formed of membrane with a muscular corering, which, by contracting, forces the masticated food down the gullet, or nesophagus. As it is absolutely necessary to breathing, that the larynx should be always open, it is therefore composed of strong cartilage, which cannot easily, or by moderate pressure, be squeezed together and sliut up: but this structure is not requisite in the pharyux, as it 
only requires to be opened occasionally; and then the muscles of the tongue are able to forcc food or water into it, while its own muscles continue to force the food or water downward, through the gullet, into the stomach. We have before observed, that, while the food or water is passing over the tongue into the pharynx, it cannot fall into the windpipe, on account of its bcing covered by the valve epiglottis, which is forced down upon the windpipe by the food, as it passes into the pliarynx, so as to shut it completely. If at this instant the animal liappen to cough, that is, throw out air with considcrable force from the lungs, the valve is for a moment opened by it, and a little of the food or water is liable to get into the windpipe, whence it is soon cxpelled by violent coughing.

The cesophagus, having passed along the throat and back part of the chest, penctrates through the diaphragm, and terminates in the stomach.

The esophagus of a horse has on its intcrnal surface an insensible membrane, which stretches into the stomach, and lines nearly one lialf of its surface: this peculiarity enables us to account in some measure for the inactivity of many violent poisons when given to the horse. In the human csophagus, this membrane does not exist, the whole of its internal surface, as well as that of the stomacl, being cxquisitely sensible.

If two grains of emetic tartir be swallowed by a man, they soon occasion violent vomiting; whereas two hundred times that quantity would 
produce no sensible effect upon the horse. At the cardiac orifice, or that part where the osophagus enters the stomach, its internal coat is so loose as to be thrown into folds, appearing as if it were designed as a valve to prevent the regurgitation of the contents of the stomach. From this cause, as well as from the insensibility of the membrane, with which great part of the stomach is lined, a horse very rarely vomits; but the opinion, that he is totally incapable of that action, is certainly not true, as I have once seen a horse vomit considerably. This vomiting came on spontaneously, and soon censed. There is no medicine we are acquainted with capable of producing this action in the horse's stomach; and its occurrence is very rare, this being the only case I ever saw: but I have been informed of two similar cases.

When we examine the throat, another valvular structure may be observed (which is peculiarly large in the horse), formed by the epiglottis, or valve of the windpipe, and a membranous substance that hangs from the back part of the roof of the mouth: this is termed velum pendulum palati. These bodies form a very complete valve, which opens downward only, thereby preventing the return of any thing through the mouth, either from the lungs or stomach: thus we find, that a horse breathes only through his nose, except in coughing, by which the valve is so deranged as to allow the air, so thrown out from the lungs, to pass through the mouth. 
In the case of vomiting I have just mentioned, the contents of the stomach were at first observed to pass through the nose; at length, by a violent cough, the valve was deranged, and a considerable quantity of fluid, mixed with masticated hay and oats, was evacuated by the mouth.

That part of the stomach where the csoplagus terminates is called the cardiac orifice; and that where the intestines begin is termed pylorus.

The intestines or bowels consist of one very long tube, which terminates at the anus.

In the horse, the intestines measure nearly thirty yards; but being convoluted, in order to adapt them to the cavity in which they are placed, they have the appearance of several distinct parts.

The internal surface of a horse's intestines is not lined with that insensible membrane, which is found in the osophagus and upper part of the stomacl; ; on the contrary, it is endued with a high degriee of sensibility, and appears to be more susceptible of irritation than that of most other animals. From this irritability of the intestines it is, that many horses have been destroyed by the administration of strong purgatives, and hence arises the necessity of using these medicines with skill and caution.

The intestinal tube is not, throughout its whole extent, of a uniform size: that part next the stomach is rather small, and continues for about twenty yards nearly of the same diameter: it then 
becomes very large, but again diminishes before its termination at the anus. At that part where the small intestines terminate, the canal is cousiderably contracted by the folds of the internal coat, resembling in some degree the termination of the osophagus in the stomach. The first large intestine or crecum is remarkably large in the horse; and it is in this part that large stones are sometimes found. I have seen one that weighed eight pounds.

Anatomists, in describing the intestinal canal, divicle it into two parts, viz. the small and the large intestines: these are subdivided, the former into duodenum, jcjumum, and ilcum; the latter into ccecum, colon, and rectum.

All the internal surface of the intestinal tube is covered with a mucous substance, for the purpose of defending it from the action of acrimonious bodies. The various convolutious of the intestines are held together by a membrane called mesentery, which not only serves this purpose, but affords also a bed for the lacteals, or those small vessels by which the nutricious parts of the food are conveyed to the heart, to be converted into blood. Before we proceed to a particular descrip)tion of these vessels, it will be necessary to explain the process of nutrition.

When food is talsen in to the mouth, it is broken down by the teeth, and so mixed with saliva, as to be in a proper state for entering the stounach : it is then, by the united action of the tougue and mus- 
cles of the throat, forced into the cophagus, whence it passes into the stomach. In this organ it undergoes a considerable alteration; for here Nature lias provided a curious liquid called gastric juice, which has the property of converting it into a soft pulpy mass, of a uniform and homogeneous appearance. When the food ha been thus altered, the mass is forced by a contraction of the stomach into the duodenum or first part of the intestinal canal. This mass, however, does not consist wholly of nutritive parts, or such as are fit for the formation of blood; and another operation is necessary in order to separate them from such as are uscless: this seems to be effected by the bile and pancreatic juice. *

There is a peculiarity, however, in the stomach and intestines of the horse, which it is proper here to describc. The stumach of the horse is small in proportion to his gencral bulk, and has nearly half of its inner surface covered with a strong insensible mombrane of a white colour. This is the part to which botts are generally attached: sometimes, however, they are found surrounding the pylorus in considerable number; and I have seen them so numerous in that part as nearly to fill the cavity. This inscnsible membrane is supposed to enable the stomacls to press upon the solid food it may

- This opinion has becn proved by the experiments of $\mathrm{Mr}$. Astley Conper, lecturer on anatomy and surgery, and assistant surgeon of St, Thiomas's hospital. 
contain, and assist the gastric juice in reducing it to a soft mass: but digestion is far from being perfect in the stomach of the horse, and appears to be completed in the large intestines, cocum and colon. This contrivance seems absolutely necessary in the horse, when we consider the wonderful speed and exertion of which he is capable, and for which Nature appears to have designed him. The ox, the sheep, and other ruminant animals, have four stomachs, the smallest of which, in the ox, is nearly as large as that of the horse. These animals take in a large quantity of food at once, and digest it at their leisure, from which they feel no inconvenience; but the horse, even in a state of nature, is differently employed. Rapidity of motion and strength are necessary to his preservation; and in his domesticated state it is more particularly required. Hence, he is formed with a small stomacl, which requires frequent supplies, and is no impediment to his exertions. From this will appear the absurdity of keeping a horse a considerable time without food or water, and then suffering him to take in a large quantity: incurable and even fatal diseases have arisen from this management.

In the ox and some other ruminant animals, digestion is completed in the fourth stomach. The first two stomachs are connected with each otler, and with a groove-like continuation of the œsophagus. This groove terminates in the third stomach: the thick prominent lips, which form the margin of this groove, admit of being drawn together; so 
as to form a complete canal, which then constitutes a dircct continuation of the œsophagus into the third stomach. The grass or food, after a slight mastication, is taken into the first stomach or paunch, from whence it passes, in small portions, into the sccond stomach, to undergo a further maceration; it is then returned through the osophagus into the mouth to be ruminated. When the ruminated food is swallowed, the groove is shut, so that it passcs directly into the third stomach, where it is farther prepared for the separation and absorption of chyle, and then passes into the fourth stomach, in which the process of digestion is completed.

The horse, in a statc of nature, is almost constantly feeding: and the food, which he takes in, is retained but a shor't time in thestomach; some change secms to be going on ncarly through the whole of the intestincs, and appears to be completed in the cœcum or blind gut, which, in the horse, is remarkably large and capacious. F'rom these curious contrivances, the horse's stomach, in a statc of nature, is never so loaded with food as to hinder the action of the lungs, and impede his velocity. 'This, lowever, does sometimes happen from the folly, negligence, or cruelty of his kccper. I have been the more particular in describing the stomach, as the subject is connected with, and will tend to clucidatc, some important diseases.

The bilc is formed by the liver, a large glandular body, divided into several lobes, and situate imme. 
diately behind the diaphragm, to which it is firmly attached. The form of the liver is too well known to require a particular description; we have only to observe, therefore, that the bile, which it secretes, is conveyed by the hepatic duct into the duodenum, within three or four inches of its origin. In man, and the greater part of quadrupeds, all the bile does not flow immediately into the intestines, there being a small vessel connected with the hepatic duct, which conveys a certain portion into a sac, that is attached to the liver, and called the gall-bladder, whence it is occasionally expelled: but this does not exist in the horse.

From what we have just said of the peculiarity in the digestive organs of the horse, the reason of his having no gall-bladder will readily appear. In $\mathrm{man}$, and many animals, the food is retained a considerable time in the stomach; during which, the bilious fluid or gall is not wanted; therefore Nature has provided a reservoir, the gall-bladder; for as the bile is constantly forming by the liver, so would it be as constantly flowing into the first intestine were it not for the gall-bladder, which would have occasioned a great waste of this useful fluid. During the time of digestion, the food is shut up in the stomach, the pylorus being closed, and the first intestine empty. The orifice of the duct, which conveys the bile into this intestinc, being without its usual stimulus, the digested food becomes torpid; and, as the action of the whlole duct depends upon its orifice being stimulated, the 
bile, instend of passing through it, flows into the gall-bladeder, where it remains until the digestive process is so fill completed, that the food begins to flow from the stonach into the intestinc. The biliary duct is then stimulated to action; the gallblicder partakes of the irritation; and, assisted by the pressure of the elistended intestine, contracts upon its contents, and forces the bile through the duct, into the intestine, where it ningles with the digested food, and causes a scparation of the chyle or nutritious parts.

It must be olvious, that, as the horse is ahnost constantly fecding, and ats digestion is continually groing on in his stomach and intestines, that a constant flow of bile is necessary, and therefore that a gall-bludder would be uscless, perhaps injurious. 'The pancreas is also a glandular body, and sccretes a fluid somewhat resemblingr saliva, which is conveyed by the pancreatic duct into the duodenum, at the same place where the hepatic duct enters. When these fluids (the bile and pancreatic juice) are poured into the intestinc, they mingle with the mass of digested food, which has been expelled fiom the stomach, and separate from it all those essential parts which are fit to be converted into blood: this process is termed chylification. We have before observed, when describing the mesentery, or that nembranc by which the intestincs are lickel togrether, that an inmense number of small delicate vessels are spread over its surface, nitmed lacteals, from their containing a fluid which, 
in its appearance, resembles milk. This fluid consists, in fact, of the essential parts of the food proceeding to the heart, in order to be converted into blood. All the lacteals open into the intestines, and cover the whole of their internal surface, where they are always disposed to absorb the nutritious parts of the food in its passage throngh the intestinal canal. Some physiologists suppose, that the mouths of the lacteals have the power of selecting such parts of the food as are fit to be converted into blood, that no previous separation takes place, and that the bile serves only as a natural purgative, constantly stimulating the intestines, thereby keeping up a small degree of motion in them, and promoting the expulsion of the feculent parts of the food.

It will probably be asked, how it is that the mass of food passes through the intestines, since they are so convoluted that it camnot possibly be effected by the power of gravity? but, if we examine their structure, this phenomenon may be readily explained. The intestines are composed, in great measure, of muscular fibres, some of which run in a circular, and others in a longitudinal direction: when the circular fibres contract, the diumeter of the canal is diminished; and when the longitndinal fibres are in action, it becomes shorter; and, by the combined action of these fibres, the food is graclually propelled through the whole length of the intestinal canal. The motion thus excited may be distinctly seen in an animal recently killed, 
and in some it continues a considerable time after death. The intestine, however, is not entirely composed of muscular fibres: its internal surface is lined with a fine nervous and vascular membrane, which is endued with exquisite sensibility, and has the power of forming on its surface a mucous substance, which serves to protect it from the action of acrimonious bodies. Beside the muscular and nervous coat, there is another, which enters into the composition of the intestine: this is a thin membrane, called peritonceum. The peritonæum not only forms the third and external coat, it likewise envelopes all the organs contained in the abdomen, forming in the external coat, and is closely connected with them, and is then so reflected as to form a kind of sac, in which they are all inclosed. Thus are the intestines composed of three coats, which are closely in contact with each other; the peritoneal, the muscular, and the nervous coat.

We have yet to describe the course of the lacteals, or those vessels which take up the chyle or nutritious parts of the food. We have before observed, that they are spread upon the mesentery, whence they pass on towards the spine, becoming larger and less numerous in their progress; at length they terminatc in a large tube, which runs along the spine, and is named the thoracic duct: this pours its contents into a large vein near the heart, to which part it is immediately after conveyed, and converted into blood.

The kidneys are two glandular bodies, situate 
within the loins; their office is to separate urine from the blood. The mine, thus separated, is conveyed by two tubes of considerable length, termed urelers, into the Lladder, which is composed of three coats like those of the intestine; and when it has received a sufficient quantity of urine to stimulate its muscular fibres into action, it contracts upon the urine, and forces it out throngh the urethra or urinary canal. We have now finished our sketch of the abdominal and thoracic viscera; which has been given with a view to render the description we are about to give of internal diseases more intelligible to those readers who are unacquainted with anatomy, than it would otherwise have been. 


\title{
CHAPTER III.
}

\author{
INFLAMMATION.
}

IT was supposed by the celebrated Börhare, and other physiologists of his time, that inflamnittion depended on a visciclity of the blood, which renelered it unfit for circulating in the finer vessels; and that hence arose obstructions, and those appearances by which the discase is characterized. 'This opinion, however, has obtained very little eredit wich modern physiologrists, and is now universally rejected; it having been proved, that blood drawn from an aninal labouring under inflammattion is more fluid, and remains fluid longer, than that which is taken from the same animal when in health.

The most prevailing opinion at present respecting inflammation is, I belicve, that it consists inan increased action of the heart and arteries, when general; wherelyy the blood circulates with unusual velocity, throwing the whole system into derangement; and when locul, or cxisting in at particular part, the increased action is in like manner confined to the vessels of that part.

* In local inflammation, though the larger arterics of the part have their action increased, it is probable that their small น 5 
When a part is inflamed, there arises in it an unusual degree of heat, generally attended with considerable tension and swelling; the sensibility and irritability are always increased, and produccel by it in parts where it did not before exist. In bones and tendons, for example, scarcely any sensibility can be perceived when they are in a state of health; but, when inflamed, it is roused to in alarming degree, and the most dangerous conscquences may ensue from it.

Inflammation has four modes of tcinnination: the first is termed resolution; that is, when the disease after going a ccrtain length, gradually disappears again: the second suppuration; that is, when matter is formed, or an abscess produced: the third is named effusion, which implics an extravasation either of blood, coagulable lymph, or

branchcs, which, from thcir minute size, are terned capillary arteries, are in a state of debility, and distended with blond, which they are incapable of gctting rid of; the larger illterics, acting with unusual strength aud quickness, will of course force a grcater quantity $\mathrm{nf}$ blnod than usual into these delicate vessels, so as to stretch them beynd their tone, and render them incapable of contracting upon their contents. This accounts for swelling, heat, and reduess nf an inflamed part, and shows the ntility of local bleeding on such occasions; it points ont also the efficacy of general bleeding, and purging, in local inflammation, which tend to moderate the action of the larger arterics, and cause them tn pour no unne biond into their minute branclics than they are eapable of forcing intp thcir tcrminations-the veins. We thought it proper tn sily thus much of the theory of inflammatiou, as it may lead to a better practicc than is conmnuly adopted in treating the inflammatory complaints of horses. 
serum: and the fourth, gangrene or mortification, by which is meant the death of the inflamed part.

Inflammation of the exterial parts is generally occasioned by some mechanical injury, such as wounds, bruises, \&c.: sometimes, however, it arises from inlernal inflammation or symptomatic fever, and is then to be considered as an effort of nature to cure the internal disease. Thus we sometimes find in fevers abscesses taking place on the surface of the body, whereby the fever is considerably diminisled, and, in general, terminates favourably. When intermal inflammation or fever is transferred to an external part, the feet are generally the parts affected; hence we have foundering, pumnice-feet, \&c. and the horse is commonly said to have a chill fallen into his feet. Sometimes soon after a smart attack of fever, beginming with violent shivering, quick pulse, \&c. one or both of the hind legs becomes swollen, hot, and extremely painful: the febrile symptoms then usually disappear, or are mucl lessened.

Inflammation is often produced by plethora or redundancy of blood in the body; in which case it is sometimes general, the whole arterial system having its action increased: this also may be considered as an effort of nature to get rid of the superfluous blood, and in such cases she must be assisted by copious bleeding. It more commonly lrappens, however, that the redundant blood is determined to some particular part, occasioning Ircal 
inflammation; very frequently falling upon some of the internal organs, and the lungs are peculiarly liable to suffer: from this source, indeed, their most dangerous fevers arise. The eyes, also, are very apt to suffer when a horse becomes plethoric, to which cause, I believe, almost all the diseases of that delicate organ may be attributed.

In the treatment of external inflammation, we should endeavour to bring it to the most favourable termination, that is, resolution; unless when it arises from an effort of nature to cure some internal disease; -it is then desirable to bring it speedily to suppuration; that is, if a tumour happens to form in any part: but from whatever cause inflammation may attack the feet, the most active measures should be employed for its resolution. The remedies to be employed for resolving inflammation are, local or general bleeding (see Index, Bleeding), purgatives, fomentations, poiltices, or the saturnine lotion: other cold applications have been used with success, such as sal ammoniac dissolved in vinegar, goulard, \&re.

When inflammation takes place in tendinous parts or joints, the saturnine poultice has been found an uscful remedy, and in the latter case I have often found blister's cxtremely efficacious. $A s$ in these cases the inflammation generally proves more troublesome, and as the pain which it oceasions is often so considerable as to produce symptomntic fever, it becomes necessary to employ, with- 
out loss of time, the most prompt and efficacious means for its reduction *. With this vicw, we cxcite arlificial inflammation in the contiguous skin and cellular membrane, which are parts of far less importance in the animal cconomy than joints or tendons, and capable of bearing a considerabic degrec of inflammation, without much inconvenience to the animal: this is done by means of rowcls and blisters, and the inflammation, thus cxcitcd, will tend, in a considerable degrec, to diminish that which is going on in the morc important part. Should we fail in our cndcavours to resolve inflammation, it will probably terminate in suppuralion; and when it appcars that the diseasc does not abate by the use of the remediics we have recommended, an assiduous application of fomentations and poultices will expedite the suppurative process, and afford great relief to the animal. When the inflammation, or rather the swelling which it occasions, arrives at this statc, it is tcrmed an alscess, in which, when the suppuration is compicte, and it contains matler, a fluctuation may be felt, upon its being presscd by two fingers altcrnately. This point being ascertained, an opening is to be made with a lancet or knife, in such a way that the mattcr may be completely cracuatcd, and a future accumulation prevented: it is then to be dressed with digestive liniment or ointment. Should the wound appear indisposed to heal when this treatment has 
been pursued for a short time, discharging a thin offensive matter, and wanting that red appearance by which the healing process is indicated, the detergent lotion will soon remove these unfavourable appcarances; the discharge will become whiter and thicker, and red granulations of new flesh will sprout up. Should these granulations, however, become luxuriant, constituting what is commonly termed proud flesh, they arc to be kept down by mcans of the caustic powder. It sometimes happons, that when a part is inflamed and swollon, instead of going on to suppuration, it degencrates into a hard and almost insensible tumour: this depends oll the inflammation having terminated in effision of coagulable lymph, and is to be removed by stimulating embrocations or blisters.

When infiammation runs very high, as is somctinnes the case in violent bruises; or deep and extclisive wounds of the lacerated kind, it may terminate in gangrene or mortification, which is generally attended with danger: in this case, the matter discharged, instead of bcing white and thick, consists of a dark-coloured fluid, of a peculiar offensive smell; the constitution is grenerally affected, the pulse bccoming quick, weak, and sonctimes irregular; the appetite goes ofl; and there is a great degrec of debility. *

Wheis any of the internal parts are inflamed, a fever is gencrally produced, the violence of which 
will depend upon the importance of the inflamed organ, as well as upon the extent and degree of the inflammation; some of the internal parts being more essential to life than other's, and, when inflamed, occasioning of cour'sc greatcr derangement in the system. The only favourable termination, to which internal inflammation can be brought, is resolution; and the most vigorous measures should le adopted in order to effect it. The most important remedy in these cases is copions bleeding, and the carlice it is employed the more effectual will it prove: the next remedy is exlcrnal inflammation, antificially excited by means of rowels and blisters. 'The fever powder and occasional clysters atre of considerable service. 


\section{8}

\section{CHAPTER IV.}

FEVER。

'THE ferer's of horses bear very little analogy to those of the human body, and require a different treatment. Writers on farricry have described a great variety of fevers, but their observations appear to have been drawn from the works of medical authors, and their reasoning sccms entircly analogical. I can distinguish only two kinds of fever, the one, an idiopathic or original clisense, and therefore properly termed simple; the other, depenclent on intcrnal inflammation, and very justly denominated sympiomatic fevcr. For example, if the lungs, bowels, or stomach, were inflamed, the whole system would be thrown into disorder, and a symptomatic ferer produced: but if a collapse of the perspiring vessels happen to take place, the blood will accumulate in the interior parts of the body; and though inflammation is not produced by it, the unequal distribution of the blood alone will occasion that derangement in the system which constitutes the simple fever. * The simple

* Fever is often preceded, or rather commences, with shivering; from which circumstance it seems reasonable to infer, that an interruption of the functions of the skin is either a cause of ferer, or materially connected with it. 
fever does not oecur so frequently as the symptomatic, nor is it by any means so formidable in its appearanec; yet it is necessary to give it the earliest attention, for unless nature receives timely assistance, she will be sometimes mable to get rid of the load which oppresses her; and the blood will aceumulate in the interior part of the body, until inflammation in some of the viscera is produced, and a dangerous disease established. The following are the symptoms of simple fever:--shivering, succeeded by loss of appetite, dejected appenranee, quick pulse, hot mouth, and some degrree of debility: the horse is gencrally costive, and voids his urine with difficulty. The disease is often aceompanied with quiekness of breathing, and, in a few cases, with pain in tlie bowels, or symptoms of eolic.

As soon as a horse is attacked by this disease, let him be bled freely; and if costiveness be one of the symptoms, give a pint of enstor oil, or the oil of olives; and Iet a clyster of warm water-gruel be injected.* After the operation of the laxative, the fever powder is to be given once in twelve hours, and eontinued until its diuretic effect be-

* I have lately found the following drink a very useful laxative on these occasions :-

Take of Barbadoes aloes powdered ........ 3 drams.

Prepared kali ..................... $1 \frac{1}{4}$ dram.

Castor oil ........................ 4 oz. to $60 \mathrm{oz}$

Simple minc water and pure water, of each, .. $40 z$.

Mix for one dost. 
comes considerable. Warm water and mashes are to be frequently offered in small quantities; warm clothing, frequent hand-rubbing, and a liberal allowance of litter, are also necessary: and when the fever runs high, it is advisable to insert rowels about the chest and belly, in order to prevent internal inflammation from taking place. When the disease apperrs to be going off, the horse looking more lively, and the appetite returning, let him be led out for a short time in some warm situation, and give now and then malt mash for the purpose of recovering his strength.

FEVER-POWDER.

$$
\text { No. } 1 .
$$

Powdered nitre ......... from $\frac{1}{2}$ to $1 \mathrm{oz}$. Camphor and tartarised antimony, of each ........ $\}$ from 1 to $2 \mathrm{dr}$. Mix for one dose.

$$
\text { No. } 2 .
$$

Powdered nitre ............... 1 oz. Unwashed calx of antimony ...... $2 \mathrm{dr}$. Mix for one dose.

No. 3.

Antimonial powder ........... $3 \mathrm{dr}$. Camphor .................. I dr. Liquorice powder .............. 3 dr. Mix for one dose. Syrup enough to form the ball. 


\section{Symplomatic Fever.}

Tine symptomatic fever is generally occasioned by high feeding, close stables, and a want of propor exercise: sometimes, howcver, a sudden transition from a cold to a hot temperature is evidently the cause of it. In this respect it is different from the simple fever, which, as before observed, sometimes arises from exposing a horse suddenly to cold air, when he has been accustomed to a warm stable. Horses that arc taken from camp or grass, and put suddenly into warm stables, are extremely liable to those internal inflammations on which symptomatic fever depends, and many thousands have fallen victims to this kind of treatment.

When a fever is symptomatic, it is not perceived by shivering, nor is it so sudden in its attack as the simple fever: * but when it is not subdued by an early application of remedies, the symptoms gradually increase in violence, until they present a very formiclable appcarance. When the cliseasc, however, is occasioned by great and long continued exertion, it gencrally comes on suddenly; and the complaint has a very dangerous appearance in its carliest stage.

* Fever that commences with shivering, has often terminated in a fatal intammation of the lungs, when neglectcd or improperly trcated. 
The symptomatic fever has many symptoms in common with the simple fever, which are, loss of appetite, quick pulse, dejected appearance, hot mouth, and debility; and if to these be joined difficulty of breathing, and quick working of the flanks, with coldness of the legs and ears, we may conclude that an inflammation of the lungs is the cause of the fever. If the horse hang down his head in the manger, or lean back upon his collar with a strong appearance of being drorsy, the eyes appearing watery and inflamed, it is probable that the fever depends upon an accumulation of blood in the vessels of the brain, and that the staggers are approaching: in this case, however, the pulse is not always quickened; sometimes, indeed, I have found it unusually slow. *

When the symptoms of ferer are joined with a yellowness of the eyes and mouth, an inflanmation of the liver is indicated. Should an inflammation of the bowels be the cause, the horse is violently griped. An inflammation of the kidneys will also produce fever, and is distinguished by a suppression of urine and an inability to bear pressure upon the loins. When inflammation of the bladder is the cause, the hor'se is frequently staling, voiding only very small quantities of urine, and that with considerable pain. Extensive wounds, and particu-

* Nearly the same symptoms are produced, when the stomach is oppressed or loaded, and incapable of digesting its contents. See Slaggers, and Discuses of the Slomach. 
larly those of joints, will also produce symptomatic fever. Sometimes several of the internal parts are inflamed at the same instant; and indeed when inflammation has existed for a considerable length of time, it is seldom confined to the organ in which it originated: the disease spreads to other viscera; and when more than one organ is inflamed, the symptoms will generally be complieated: still, however, the essential remedies are the same, that is to say, copious and carly bleeding, with rowels, \&c.

Having now given a general description of symptomatic fever, I shall proceed to treat of those cascs separately to which above I have briefly alludecl.

\section{Inflammation of the Lungs.}

Thrs is a very dangerous discase, and one to which horses are exccedingly liable: the frequency of its occurrence is oceasioned by improper management, and not by any natural defect in the constitution of the animal: it may therefore be prevented by proper attention in the grcom. Mcdical writers make a distinction betwcen inflammation of the lungs and that of the pleura, or the membrane which covers those organs, calling the former peripneumony, and the latter pleurisy: this distinction, however, is not necessary in vetcrinary 
nosology, since we never find these parts affected separately in the horse. * The progress of this disease is often very rapid; and unless proper remedies are employed at an carly period, it fiequently terminates fatally.

Its approach is indicated by the following symptoms :- loss of appetite, an appearance of dulness and disinclination to motion, unusual quickness in the motion of the flanks, hot mouth, and sometimes a cough. If the disease, by adopting an inert or improper mode of treatment, be suffered to proceed, all these symptoms will increase; respiration will become extremely quick and laborious, the pulse more frequent, and at the same time weak. A striking appearance of uneasiness and anxiety may be observed in the animal's countenance: the nostrils expanded, the-eyes fixed, and the head inclining downward; the legs and ears become cold, and the debility is so considerable, that he is incapable of moving in the stall without great difficulty; he never lies down, unless 'so much weakened as to be incapable of standing. The disease, however, is not always so rapid in its progress as we have here described it, and not unfrequently a considerable remission may be observed, which is occasioned probably by an effusion of serum or

* On examining the bodies of horses that die of this disense, we always find the lungs diseased as well as the pleura: it is proballe, however, thit the inflannation generally begins in the pleura, and spreads gradmally to the'lungs. 
water having talien place in the chest; and this remission is sometimes so conspicuous, that we are led to give a favourable prognosis, the horse beginning to feed again, and the pulsc becoming less flequent. But this flattering appearance often proves fallacious; the disease soon returns with accumulated force, and puts a period to the animal's life. I have seen cases, where bleeding has not been performed with sufficient freedom, in which the inflammation, bcing checked in some clegree, at length terminated in a plentiful effusion of water in the chest: when this happens, the horse returns to his food, looks morc lively, and in short the symptoms of fever in a great measure disappear. There remains, notwithstanding', an unusual quickness in respiration, generally accompanied with a cough; the hind legs swell, and the horse very rarely lies down; a rough unhealthy appearance may also be observed in the coat, the skin feeling as if it stuck to the ribs; and the animal continues in a state of weakness. After some time, the inflammation generally returns, and then speedily ends in death. It sometimes happens, that the inflammation terminates in suppuration: in this case also the fever is in some degl'ce lessened, and the horse begins to feed a little; but he still remains in a vcry feeble state, has a weak cough, and discharges fetid matter from his nostrils; at length the disease again becomes violent, and soon puts a period to his sufferings. On cxamining the membrane within the eye-lids, which may be done 
by gently opening them with the finger and thumb, or by lifting the upper eye-lid, it will generally be seen unusually red; and when this redness is considerable, and docs not disappear after copious bleeding, I have generally found that the disease terminates fatally. An unfavourable termination is likewise to be apprehended, when there is a great loss of strength at the commencement of the disorder, the horse appearing to ramble when moved out of the stall or stable, and looking stupid and insensible to what is doing to him. In these bad cases, the blood is a long time in coagulating-I have seen it remain in a fluid state nearly half an hour.

The first thing to be done, when this dangerons diserse is observed, is, to bleed cofiously, even till the horse begins to faint from loss of blool. I have seen six quarts drawn at one operation, and with the best effect: sometimes indeed the disease will be completely subdued by thus bleeding freely at its commencement. Should the horse be costive, or even if the bowels be in a natural state, it will be advisable to give a pint of castor oil, and inject a clyster of water-gruel. It will then be necessary, in order to divert the infammation from this important organ, to insert rowels about the chest and belly, and to blister the sides extensively. The tow that is used for the rowel should be dipped in a mixture of sweet oil and oil of turpentine; but I believe that blistering the sides is more beneficial than rowels. Let the legrs be kept 
warm by almost constant hand-rubbing; and warm clothing must never be omitted. * Nothing is more pernicious in this complaint than compelling the animal to breathe the impure air and stimulating vapours of a close stable: this is indeed so obvious a truth, that it would be unnecessary to mention it, were it not a constant practice with grooms, on this occasion, to stop every crevice they can find, by which pure air might be admitted, and the noxious exhalations suffered to escape.

If the disease do not appear to abate in twelve. hour's after the bleeding, particularly if it have become more violent, let the operation be repeated, and with the same freedom as at first. We nced not be apprehensive, at this early period of the disease, of any dangerous dcbility ensuing from the loss of so much blood: on the contrary, it will tend to re-establish strength by subduing the inflammation, on which the fever depends. It has rarely been found necessary to bleed several times, and that

* Mr. Colcman aud some other practitioners have advised turning a horse into the open air, without clothing, in inflammation of the lungs. The excessivcly warm clothing often employed in such cases, is, I believe, vcry injurious; and hot close stables are certainly much more so: but $I$ should think this new practice extremely hazardous (except in very mild weather, and in a sheltered situation) for inflammation of the mucous membrane which lines the nose, throat, windpipe, and its branches, which appcars gencrally to be produced by the too sudden application of cold to the skin: in such cases, it must surely be of importance to restore the skin to a due performance of its functions, by a liberal use of the brush and wisp, and moderately warm clothing. (See Caiarrhal Fcver.) 
very plentifully; but it must be reeolleeted, that when the fever has existed for some time, and has nearly exhausted the horse's strength, bleeding seldom does good, and in some instanees, I believe, has been the means of hastening death. When suppuration takes place in the lungs, though there is little probability of saving the animal, his life may be prolonged by giving frequently good water-gruel and infusion of malt. Opium, salt of hartshorn, and other eordials, will also be of service. I have generally given the following ball on these oecasions; and though I have never secn a horse recover after suppuration had takcn place in the lungs, yet these remedies have eertainly afforded considerable relief.

Salt of hartshorn (earbonate of ammonia) $1 \frac{1}{4} \mathrm{dr}$. Opium .................... $\frac{1}{2} \mathrm{dr}$. Powdered anisceds ............. $\frac{1}{2}$ oz.

Sirup enough to form a ball for one dose.

When the mode of treatment here reeommended is adopted before the disease has gained mueh ground, it will gencrally sueeeed eompletely. Considcrable weakness will of eourse remain after the fever has been removed, but this also will gradually go off, if proper attention be paid to the horse's dict and exereise. When the appetite begins to return, it will be adviscable to give small quantities of oats that have been stecped in boiling water or bruised; good gruel, made of sweet oatmeal or 
wheat flour, and sweetencel with sugar or treacle, will also be found serviceable in recruiting his strength; the sweetest parts should be selected from the liay, and given frequently in small quantities. Malt is an excellent restorative on these occasions, but must not be given too freely. When the weather is favourable, let the horse be led out for a short time every day; or if a small paddock can be procured, and the season of the year will admit of it, he may be turned out for a few hours cvery day, while the sun shines, taking care that he is well clothed during that time: by these means he will gradually recover his original strength.

\section{Calarrhal Inflammation or Fever.}

THIs discase most commonly happeus in the spring, when cold easterly winds prevail, and horses that are shedding their winter coats are particularly liable to it. It does, indeed, occur at all other times, and is always caused by exposing a horse to a cold wind, or rain, or suffering him to stand in a cold situation, after lic has been heated by exercise, or kept in a hot stable. Some horses are so susceptible of cold, particularly such as are kept warmly clothed, as to be affected merely by lenving open a door or window of the stable; and sometimes the disease occurs without any perceptible cause. The symptoms are cough, dulness of 
the eyes, loss of appetitc, somctimes sore-throat, and difficulty of swallowing. After a short time, thcre is generally a discharge of matter from the nosc, after which, the discase usually gets better. 'The attack is sometimes more violent; the breathing quick and laborious: and the throat so sore as to prevent the animal from swallowing even liquids. In whatever degree this disease may appear, bleeding is certainly necessary at the beginning, and must be proportioned to the violence of the symptoms, and the state of the horse's strength. In slight cases, moderate blceding, some fever powdcrs and mashes, keeping the animal moderately warm, steaming the hcad, \&c. will generally effect a cure; but when the throat is sore, so as to render swallowing painful and difficult, the extcrnal parts should be blistered freely, and the first bleeding should be large. In this state of the throat, no medicine, either solid or fluid, should be given, as it would tend to irritatc the throat, and increase the inflammation, and would most probably be returned in great measure by the nostrils. Clysters of warm water or gruel, with a little salt and oil, may be thrown up, unless the bowels are already open; the legs and ears should be well rubbed several times a-day, and gruel or mashes should bc offered frequently. Great care is necessary during the horse's rccovery, and a short time aftcr; as he will be very liable to a relapsc, or a continuance of the cough, which then often degenerates into what is termed chronic congh. IRoaring is somc- 
limes a consequence of catarhal inflammation, when improperly treated. When the discharge from the nose is considerable, the nostrils should be kept clean, as well as the rack and manger. When the soreness of the throat is so lessened as to allow the horse to swallow, some mashes of ground malt, or bran and oatmeal, may be allowed, also small quantities of sweet soft hay. Wheatflour gruel, sweetened with sugar or treacle, is a good restorative when a horse has been much weakened by this disorder. 'The following ball may also be given at this period, provided the breathing is casy and the pulse moderate.

Strained turpentine ......... $\frac{1}{2}$ oz. Powdered camphor .......... $1 \mathrm{dr}$. Liquorice powder enough to form a ball.

To be given morning and evening until a diuretic effect is produced: it is then to be discontinued for a day or two. In bad cases, where the breathing is quick and laborious, the pulse quick, and the membranes of the eye red, a repetition of the bleeding is generally necessary, especially when the blood first drawn has a great deal of buff on its surface. And if these symptoms come on when the liorse appears to be in a state of convalescence, a circumstance that sometimes happens, still bleeding is necessary; proportioning the quantity of blood to the animal's strength, and the immediate effect it produces: for sometimes the loss of a moderate 
quantity will cause faintness, when the horse's strength has been reduced by previous disease. When the other symptoms are gone, the cougl usually continues a short time; for which the above ball may be given, and care taken not to expose him to a current of cold air, or put him to any considerable work, until it has quite ceased. Vetches or other green food are very proper during convalescence, and for some time afterwards. It is useful to clothe the bead and ears with a hood in this disorder; but it must be left off gradually. That abominable practice of trimming out the ears, so generally adopted by dealers, is often the cause of catarrhal inflammation. The cpidemic diseases of horses gencrally assume a catarrhal form, and often attack with much severity; are commonly attended with considerable fever, and quickly reduce the strength. (See Epidemic Fever.)

\section{Inflammation of the Bowets.}

Turs disease is equally dangerous, or more so than inflammation of the lungs, and generally more rapid in its progress. It arises from various causes; but is most commonly a consequence of spasmodic or flatulent colic, which, as before observed, often proceeds from suddenly checked perspiration: hence it is that post and stage coach horses so often fall victims to it. It has been, and 
1 believe is still a eommon praetice to plunge these poor animals into a pond or river, as soon as they arrive from a journey, often covered with sweat, and exhausted by exertion. That this is often dorse without any ill effect being immediately produeed, must be granted; but the gradual mischief resulting from it is certainly considerable; and infammation of the bowels or lungs is not an unfrequent conscquenee. This is not the ouly way in whieh post-liorses suffer: they are frequently made to stand, in all weathers, at the door of a public-louse, while the driver is regaling himself within; and are then, perhaps, driven home at a furious rate, to make up for lost time; and, as soon as they arrire, walked about, up to their bellies, in a pond or river: by which the trouble of cleaning both carringe and horses is in great mensure avoided. Saddle-horses are not so often served in this manner as those employed in postchaises and eonehes: but it is a common and very injurious practice in many ims to tie up a horse in the stable-yard, perluaps in a eurrent of air, when he comes in from a journey, while lis legs and belly are washed; and if the ostler liappen to be ealled, he is often left in this state until considerable mischief is done. Some hardy horses are not injured by it, partieularly in summer; but colds, eoughs, grease, catarrhal inflammation, and disorders, of the bowels and lungs, are too often the consequence. Another eause of inflammation of the bowels, is drinking largely' of cold water 
when sweating, or exlausted by exertion. In this case also, the disease first produced is generally the spasmodic or flatulent colic; but, when the horse is not promptly relieved, the distension of the bowels by the confined air often causes a fatal inflammation. From whatcver cause, indeed, fiatulent colic is produced, its continuance is liable to produce infammation. (See Flatulent Colic, gripes or fret). Strong physic, and want of care during its operation, is another cause of inflammation of the bowels; and has been the means of destroying many horses. (See Physic). Violent or rapid exertion when the bowels are loaded is liable also to produce the disease; and the indigestion occasioned by riding or driving a horse at a quick pace, immediately after feeding heartily, is another cause. In this case, the pain is extremely acute. When a horse that is fat, and unaccustomed to exercise, is suddenly put to hard and fast work, he is very liable to that affection of the bowels which is commonly termed molten-grease. (See Moltengrease). Long continued costiveness, or an accumulation of hardened dung in the large bowels, will also cause inflammation; and too sucden a change from grass and the open air to diry food and a hot close stable, has often brought on inflammation both of the lungs and bowels. When inflammation of the bowels takes place, independent of flatulent colic or stroug physic, it is generally rather gradual in its attack: the loorse, at first, Jooks dull, feeds badly, is restless, paws his litter, 
and appears to be in pain; the pulse is quicker than in health; the membranes of the eye red; the urine high coloured; dung hard and in small knobs, often slimy on the surface. If in this stage of the disease he is bled freely, is properly clystered (see Clysters), and has a dose of the oily laxative given to him, he is generally relieved, and recovers in a short time; but when neglected, and especially if stimulating medicines, are given, such as those termed comfurtable drenches, the symptoms become more violent, and the pain in the bowels so considerable, that the horse is frequently lying down, and suddenly rising again, stamping with his hind feet, groaning, and looking round to his flank; his breathing is generally disturbed, the pulse very quick, the ears and legs cold, and sometimes profuse sweats break out. If relief is not afforded, the pain becomes so great, that he appears delirious, throwing himself down suddenly, and rolling about, regardless of the situation, often injuring himself or his attendants, unless he happen to be in a large well littered place, and properly attended to. At length, the pulse is so quick and small that it is difficult to be folt distinctly, which is soon followed by mortification and death. Sometimes the progress of the clisease is remarkably rapid, destroying the horse in the space of a few hours, * at others, it continues one, two, or

* I have lately met with a case of this kind, which seems worth recording. $\Lambda$ waggon-horse, that bad been regularly 
three days. Early and copious bleeding is the most important remedy: having taken off' a proper quantity of blood, that is, from four to six, or seven quarts, according to the animal's strength and the urgency of the symptoms, let the following clyster be thrown up, having previously removed the hard dung from the straight gut, by introducing the hand, and drawing it out.

Warm water or gruel $\ldots .5$ or 6 quarts.
Common salt .........6 to 8 ounces,

If the hor'se is in any degree costive, it will be proper to repeat the clyster several times, or until a sufficient evacuation is procured. (See Clysters.) When the dung that is first drawn out is in small

worked, and whose grinding-teeth had sharp edges, which wounded the inside of the cheek, and rendered unasticatiou painful and difticult, was allowed to remain one day in the stable for rest, and during that time had as much food as he chose to eat. The stables were shut at half past ten, when he appeared to the stable-man to be in good health. About two o'clock next morning, when the stables were first visited, he was found in a most violent fit of colic; and at three, when I saw hiun, was so bad that it was with great difficulty he was bled, and had medicine given him. At five o'clock he died. On opening him next morning, the stomach was found absolutely crammed; and was supposed, by those who lifted it, to weigh from 40 to 50 pounds. The large intestines were distended to an ennrmous degrce, highlyinfamed, and in some parts mortified. There can he no doubt, I think, that this horse's death was occasioned by execssive cating; though it is probable he might have recovered, lat his food been properly masticaled. 
hard knobs, the oily laxative should be given immediately after the clyster, and then let the belly be fomented witl a large rug wrung out of hot water. To do this properly, there should be a man placed on each side the horse, and the rug should be large enough to cover the whole belly. After continuing this some time, let the belly be rubbed quite dry, and, if the pain is violent, let some stimulating liniment be rubbed on it, sucl as the rolatile liniment, or that made with mustard. The legs also, when cold, should be rubbed well witl the same liniment, and afterwards bandaged.

\section{Volatile Liniment.}

Sweet oil ............... $3 \mathrm{oz}$.

Oil of Turpentine .......... 2 oz.

Liquid ammonia .......... $1 \mathrm{oz}$.

Mix.

\section{Mustard Liniment.}

Flour of mustard .......... $2 \mathrm{oz}$.

Liquid ammonia .......... $1 \mathrm{oz}$.

Water enough to give it the consistence of thin cream.

When the horse is relieved, and appears inclined to feed again, he should not have any hay for a day or two: good bran mashes is the best food; and he may be allowed to drink some gruel, made of fresh oatmeal or wheat flour. If the laxative drench and clysters have caused purging, this 
last is particularly proper. Should the pain continue after the bowels have been opened, and the above treatment fairly tried, a repetition of the bleeding may be necessary, particularly if the blood first drawn was sizy (see Bleeding), if the pulse continues quick, the membranes of the eye red, and the breathing disturbed. But, if the pulse has become moderate, the mombranes of the eye of their natural colour, and the bowels sufficiently open, the continuance of the pain may depend on spasm; in which case, the anodyne drench would afford relief. In determining this point, it is necessary to be satisfied that there is no hardened dung collected in the large bowels; for it sometimes happens, in cases of costiveness, that a small quantity of soft or liquid dung will be voided, while the principal obstruction remains: that is, when there is still a large quantity of indurated excrement in the large intestines. It is therefore necessary to be careful in administering the clysters; for the way in which this is sometimes done renders them useless, especially when a syringe and small pipe are employed. A large bladder of an ox or pig, capable of holding five or six quarts, and a pipe, not less than 14 inches in length, are the best apparatus.

Inflammation may attack either the external pcritonæal coat of the intestine or the internal menbrane; the former is generally attended with costiveness, and the latter with purging: but in whichever of these conts the infammation begins, unless 
proper remedies are employed, it soon spreads to the others. When inflammation of the bowels is prodiced by the improper use of purgatives, or by neglect, during the operation of strong physic, the safest and most effectual method of suppressing the excessive purging, is to drench the horse freely with gruel made of arrow-ruot. I have scarcely evel seen this fail when seasonably employed; but, if it prove ineffectual, mix with it $\frac{1}{2}$ oz. tincture of opium. We sometimes see a horse sick, and attacked with colic pains, previous to the operation of physic, particularly when he has not been properly prepared, or has been suffered to eat much after it has been given. In this case, clysters should be thrown up, and the horse walked about; by which means, the physic will operate, and the pain will be removed. 


\section{A TABLE,}

MHOWING TIE DIFFER ENCE BET TIEEN

\section{FLATULENT COLIC OR GRIPES,}

AND

\section{INFLAMMATION OF THE BOWELS.}

Symptoms of Infammation of Symploms of Flatulenl Colic. the Buroels.

1. Pulse very quick and 1. Pulse natural, though small. sometimes a little quickened.

2. Lies down and sud- 2. Lies down and rolls denly rises again, sel- upon his back. dom rolling upon his back.

3. Legs and ears gene- 3. Legs and ears generally cold.

4. In general, attacks 4. Attacks suddenly, is gradually, is com- never preceded, and monly preceded, and seldom accompanied always accompanied by any symptoms of by symptons of fever.

5. No intermissions can he observed. fever.

5. 'There are frequently short intermissions. 
Flatulent or Spasmodic Colic, Gripes, or Fret.

These names are applied in different places to the same disease; that is, violent pain in the bowels; which is indicated by the liorse lying down, and rolling about, then suddenly getting up, and lnoking round to lis flank, stamping with his hind feet, or endeavouring to strike his belly. He seldom remains long up, but gathers up lis legs, and falls heavily down again, generally groaning and looking round to his flank. Sometimes he rolls himself over, and often endeavours to lie upon his back. Thus far the symptoms of flatulent colic resemble those of the preceding complaint, inflammation of the bowels; but there are other symptons by which they may be easily distinguished. The flatulent colic attacks rather suddenly, the horse appenring, immediately before, in good health; the pulse is in its natural state, that is, it beats about 40 in a minute. The membranes of the eye are not redder than usual. There is generally a difficulty in staling, or the horse makes ineffectual attempts to void his urine; but, when he does stale, the urine is of the natural colour. Sometimes the disease is attended with costiveness; but more commonly the bowels are either in their natural state or rather loose. This disorder occur's frequently, and is produced by various causes. Sometimes it is inconsiderable, and goes off without the aid of medicine; or the horse is relieved 
by common domestic remedies, such as warm peppermint-water, warm beer and ginger, or gin and water; at others, it attacks with great severity, and requires the earliest attention. It is difficult to say what is the inost.common cause of flatulent colic; but I am inclined to believe, that it frequently depends upon torpor, or a want of vital " energy, in the stomach and small intestines. Hence it is that drinking largely of cold water so often produces it; also, feeding greedily and swallowing oats or other grain without proper mastication. We find likewise that horses whose digestive organs are weak, such as crib-biters, are most liable to the disorder. Stallions that are pampered for covering, or have stimulating medicines given to them, and horses that have voracious appetites, and are in the habit of eating their litter, are very liable to flatulent colic; in short, by whatever means the energy of the stomach is weakened, a disposition to this disorder is thereby induced; and the best mode of prevention, when such a tendency exists, is to allow ouly a small quantity of food and water at a time: the former easy of digestion, and the latter not excessively cold.

The first thing to be done when a horse is attacked with colic pains, is to put him into a box or large stall, and give him plenty of litter, that he may not hurt himself during the violent paroxysms of pain. The state of his dung should then be enquired into; the pulse and membranes of the eyc examined; and if there is no reason to apprehend 
that the attack is of an inflammatory nature, one of the following drenches should be given; and if the lung is hard, or there is any difficulty in staling, a clyster is to be thrown up, having previously drawn out the hard dung with the hand. It is generally thought necessary to bleed, though 110 syinptoms of inflammation appear: and in young vigorous horses, of a full habit, it may be a useful precailtionary measure; because, in sucli, a violent attack of colic may produce inflammation in a short time. But when the pulse is not quickel than in health, or rather feeble, the membranes of the eye not redder than usual, the bowels sufficiently open, and more especially if the animal is old, out of condition, or in a state of debility, I think it had better be omitted. Should the pain continue after the drench and clyster have been given, let the belly be well rubbed with straw by a man on each side; and if no relief be obtained in about an hour, the drench and clyster should be repeated. Here it is necessary to observe, that if the dung which lias been roided after the clyster is in snall hard knobs, of a dark colour, with a shining or slimy surface, it indicates a costive state of the bowels; in which case, it is proper to give the oily laxative soon after the colic drench, even if the latter have put a stop to the animal's pain, and another clyster should be injected. In obstinate cases, it is necessary to fonent and rub the belly with the liniment, as directed for infammation of the bowels; and if the pulse, during the continuance of the symptoms, be- 
comes quick, the horse should be immediately bled. He may be walked about a short time after taking the clrench and the clyster, unless the pain is violent; but the common practice of urging him on with a whip is absurd and dangerous. I have noticed this disease immediately after inflammation of the bowels, because they are liable to be mistaken for each other ; therefore, it is of importance to attend to those symptoms by which they may be distinguished: and it may not be improper to repeat, that it is no less important to ascertain the state of the bowels; and whenever costiveness exists; to persist in the careful administration of clyster's until a proper evacuation is obtained. In former editions, I have recommended castor oil as the safest laxative; but I have since found that the small quantity of aloes prescribed in the oily laxative renders its operation more quick and certain. When castor oil cannot be procured, sweet oil or linseed oil may be substituted, and, when nothing else can be had, even melted lard will be found useful.

I have seen cases where it was discovered after deatl, that the distended bowel had broken through the mesentery, by which it was completely strangulated, so that nothing could pass through the canal, and the included portion of gut was quitc mortified. Large collections of earthy matter and stones of considerable magnitude are sometimes the cause of colic. Such cases are irremediable. 
Colic Drench.

No. 1.

Tenice turpentine ..... 1 oz. or 2 to $3 \mathrm{oz}$.

Oil of juniper ........ 2 or 3 drams.

Spirit of nitrous ether .... 1 oz.

Water ........... 1 pint.

Mix for one close.

No. 2.

Tincture of opium ..... from 6 drams to $1 \mathrm{oz}$. Spirit of nitrous ether ... from 1 oz, to $1 \frac{1}{2}$ oz. Water or peppermint-water 1 pint.

Mix for one dose.

Ansdyne Drench.

Tincture of opium .......... 1 oz.

Oil of peppermint .......... 20 drops.

Water (warm) ............. 1 pint.

Mix for one dose.

Oily Laxative.

Barbadoes aloes ....... from 2 to 3 drams.

Carbonate of potash ....2 drams.

Water (warm) $\ldots \ldots \ldots \frac{1}{4}$ pint.

Castor oil ......... $\frac{1}{2}$ pint.

Mix for one dose.

Astringent Drench.

Prepared chalk ............ 10 o. 
Gum Arabic $\quad \ldots \ldots \ldots \ldots \ldots \ldots, 1$ oq. Mint water ............. $12 \mathrm{oz}$. Tincture of opium ......... $\frac{1}{8} \mathrm{oz}$.

Mix for one dose.

I am inclined to think, that the drench, No. 2, is the best general remedy for flatulent colic. But when the disease is occasioned by costiveness, the opium is improper, nuless the laxative is given soon after. I have several times mixed one ounce of tincture of opium with the oily laxative, when called in some time after the attack, or when other drenches had been given without effect, and it has proved very efficacious. Oil of turpentine has been often given with success, and is still preferred by some practitioners, probably from its being so cheap; but it is an inconvenient remedy; for unless it is given with the greatest care, it will flow over the lips, and annoy the horse considerably for some time after. The dose is from 2 to 4 ozs. mixed with gruel. As the complaint may sometimes occur during a journey, in situations where no medicines can be procured, I have added a recipe, in the form of a ball, which may be kept by waggoners, chaise-drivers, or others, and is particularly useful to those who have horses that are subject to the disease.

\section{Colic Ball.}

Powdered opium ........... $\frac{1}{8}$ dram.

Camphor ............... 2 dranis. 
Castile soap ............ 2 drams.

Ginger ............... $1 \frac{1}{2} \mathrm{dram}$.

To be formed into a ball, with liquorice powder and syrup. This should be kept in a bladder.

\section{Inflammation of the Stomach.}

The stomach, like the intestines, may be inflamed either on its extcrnal or internal surface. When the external coat is the seat of the disease, the symptoms are nearly the same as those by which peritonæal infammation of the intestines is indicated, and the same treatment is required; the only difference observable in the symptoms is, that in this case the pain scoms to be more acute and distressing than in the other: the same difference may be observed between the large and small intestines, the latter being possessed of more sensibility than the former.

When inflammation attacks the peritoneal coat of the stomach, it very soon diffuses itself to the small intestines and neighbouring viscera; or, if the small intestines be its original seat, it frequently spreads to the stomach, and sometimes to the large intestines also. In cxamining horses, therefore, that have died of these discases, we seldom find the inflammation confined to one particular organ; it more comnonly happens, indeed, that the whole of the abdominal viscera will exhibit mor- 
bid appearances, but in different degrees; those most contiguous to the part first cliseased having suffered considerably, while such as are more remote from it are perhaps scarcely altered; for we can generally distinguish the original seat of the inflammation.

An inflammation of the internal or villous coat of the stomach is not a very common disease, and is generally occasioned either by poisons or strong medicines that have been swallowed, or by that species of worms termed bols. When poisons, or strong medicines incantiously given, are the cause, it will of conrse come on suddenly; the pulse will be extremely quick, and so weak that it can scarcely be felt; the extremities will become cold, and there will be a peculiar dejected appearance in the animal's countenance; respiration will be disturbed: sometimes there will be a cough, and always a high degree of debility. The treatment of this disease consists in giving oily or mucilaginous liquids freely, such as decoction of linseed, gum arabic dissolved in water, \&c.; and, at the same time, medicines that are capable of decompusing or destroying the poison; for which purpose, I believe, the sulphuret of potash is useful in closes of half an ounce, provicled the poison be either mercurial or arsenical. Clysters are to be injected; and, if the disease be accompanied with purging, they should be composed of strong linseed decoction or watergruel. I saw five cases of infaned stomach at one 
time, all occusioned by poison. The above treatment, was pursucd, and four out of the fivc perfectly recovered.

That inflammation which bots produce in the stomach, is indicated by symptoms somewhat different from those just described; indecd, it may more properly be considered as ulccration of the stomach, than inflammation, since, upon examining horses that have died of this complaint, I have always found ulcers of considerable sizc. This disease generally comes on gradually: the horse becomes hide-bound, has a rough unhealthy coat, gradually loses flcsh and strength, though he continues to fecd well, and has a fiequent and troublesome cough. The diseasc pcrhaps will continue in this state for some time, and no scrious consequences are apprehenderl; its cause and seat are seldom suspected; medicines arc given to remove the cough, with common altcratives for the purpose of improving his condition.

In some instances thesc insects are spontaneously dctached, and expellod through the intestines: in such cases, if the stomach have not been much hurt by them, it will gradually recover, and the horsc be restored to his original strength and condition. When this does not occur, thesc worms produce so much mischicf in the stomach, as to throw the whole system into disordcr. The lungs arc particularly liable to sympathise with the stomach in this case, and fiequently becone inflamed in consequence. The inflammation thus produced 
in the lungs is extremely obstinate; and though it may be checked in some degree by bleeding, anc. the other remedies we have recommended for that disease, yet, as the cause cannot often be removed, it generally, I believe, terminates fatally. (Sce Worms).

\section{Inflammation of the Kidneys.}

THrs disease does not occur very frequently, and is generally occasioned, I believe, by an immoderate use of strong diurctic medicines. At the first attack of this complaint the horse constantly stands as if he wanter to stale, sometimes voiding a small quantity of high-coloured or bloody urine. When the inflammation becomes more considerable, a suppression of urine and fever generally take place: if the loins be pressed upon, the animal shrinks from the touch, and appears to feel great pain. There is also a stiffness or lamenes's of one or both hind-legs. In the first place bleed freely, then gire a pint or twenty ounces of castor oil, throw up clysters of warm water, and cover the loins with sheep-skins, having previously rubbed upon them the mustard embrocation. Should these remedies fail of procuring relief, repeat the bleeding; and should not the oil have operated sufficiently, let another dose be given. All diuretic medicines are to be carefully avoided.

Inflammation of the kidneys is sometimes complicated with peritonaal inflammation of the 
bowels, and then, besides the above symptoms, the horse will be often lying down as in colic. I have seen cases where the kidneys seem to have undergone a gradual decay, and lave found them, after death, -disorganised or rotten, though there liad been no symptoms of acute inflammation in them during the animal's life. I have observed in $\mathrm{ex}$ amining after death several glandered horses that had been taking considerable doses of corrosive sublimate, which had operated as a powerful diuretic, that one or both kidneys were much en- 30 larged; and am inclined to believe that an imprudent use of diuretics is often a cause of disense in those organs.

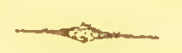

Suppression und Retention of Urine, of Strangurys

"THe distinction that has been made between a suppression and a retention of urine is practical and judicious. The former nost properly points out it defect in the secretion of the kidneys, the latter an inability of expelling the urine whien secreted." - $\rightarrow$ Hey's Surgery. Suppression of urine is a sympton? of inflammation or some other disease of the kidncy, and retention, I believe, most cominonly depends on spasm of the neck of the bladder, an accumulation of hard dung it the straight gut, or $a$ paralytic state of the bladder, brought on by not allowing a horse time to stale when he has ocearetics upon crery tripial occasion tends probably to 
the production of the diseasc; for when a horse is rode or driven a considerable distance without stopping, whilc under the operation of such medicine, an accumulation of urine in the bladder is, of coursc, more likely to happen. Retention of urine does not frequently occur in horses, but a morbid ir ritability of the bladder is often met with, and is generally mistaken for a retention of water, or, as it is commonly called, a stoppage in the water. In this case, the liorse is frequently staling, but voids only a small quantity' at a timc, apparently with some difficulty. When this is observed, the common practice is to whistle, in ordcr to tempt the horse to renew or increase his efforts to"stalc, from an apprehension that the bladdcr is full of urine; whicl is extremely improper, because the bladder, in such cases, is cmpty or nearly so, and the irritability of the bladder is likely to be increased by it. This state of the bladder may be distinguished from that which attends inflammation of the kidney, by the horse being othcrwise in good health, by not expressing much pain in voiding his urine, and by the colour of it, which is the same, or nearly so, as in health, though sometimes turbid from being mixed with the mucus of the bladdcr. But whonever the efforts to stale become more frequent and painful, and especially if it be attended with loss of appetite, quick pulse, and other febrile symptoms, it must be considered as incipient inflammation of the kidneys, and treated accordingly. I have generally found the following ball effectual 
in such cases, making the horse drink fieely of infusion of linseed, decoction of marsh-mallow, or a solution of gum, and emptying the bowels with clysters. Should it be found, however, that the horse is costive, it will be adviseable to give also some laxative medicine.

\section{Ball.}

Camphor ............2 drams.

Liquorice powder and syrup enough to form the ball. One dose.

Retention of urine often attends the spasmodic or flatulent colic, and is then generally considered as the cruse of the disease; but it is only an effect, and, when the colic is removed, the horse stales freely. In obstinate cases of retention, where a horse has not been observed to stale for some time, it is necessary to examine the bladder; which may be done by introducing the hand into the straight gut, through which it may be readily felt when clistended with urine. There are other circumstances which denote a considerable accumulation of urine: some degree of swelling may be observed in the belly, whicl is painful on pressure; the horse is uneasy, and often trying to stale; sometimes he succeeds in his efforts, and voids a small quantity; and, when the bladder is much distended, the urine often dribbles off involuntarily. But the most certain method of ascertaining the state of the bladder is to examine it through the straight 
gut; and if it be found full, an evacuation must be speedily procured or the consequences may be fatal. Having emptied the gut by clyster's, which may be found difficult, and require some care and address to accomplish, and having bled the horse freely, without producing the clesired effect, the following clyster is to be injected; and if that fail, give, about an hour afterwards, the following drench :

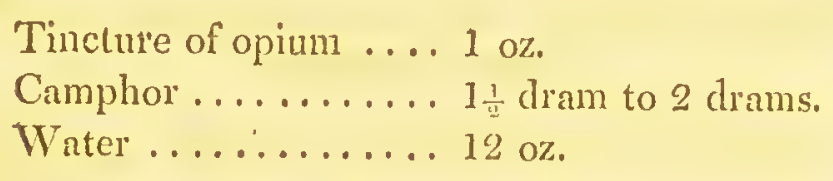

Mix. One dose.

Should this also prove incffectual, recourse must be had to an operation; as it is impossible to introduce a catheter into the horse's bladder, on account of the lengtli of the urethra or passage, and the acute angle or curvature it makes a few inches before it comes to the bladder. It is necessary therefore to pass up the urethra a long smooth round piece of whalebone as far as it will readily go; its end will then be felt a few inches from the fundament, where it is to be steadily kept by an assistant, while the operator carcfully cuts down upon it, and lays open the urethria. A female catheter, properly curved, can be easily passed from this opening into the bladder through which the urine will be discharged; but, to cmpty the bladder completely, shonld it be incapable of contracting, it may be ne- 
SUPPRESSION AND RETENTION OF URINE. 125

cessary to clevate the fore parts of the horse, and make some pressure on the belly as well as through the straight gut. When the retention is caused by inflammation of the neck of the bladder, there may be some difficulty in passing the catheter, and it will nccessarily cause pain: it must thercfore be done with great care and gentlcness. And in such a case we must endeavour to remove the cause by blecding, clyster's, and an oily laxative drench, unless the bowels are already open. When the neck of the bladder is in a healtlyy state, it is casy to pass the finger into the bladder, and, if it be capable of contracting, the mrine will be readily discharged, while its neck is kept open by the finger; but, should the bladder be paralytic, and incapable of contracting, a complete evacuation of its contents cannot be obtained by the means above described. In mares there is no difficulty in passing the cathetcr, or even the finger, into the bladder; therefore, whencver they appear to be suffering from a retention of urine, this sloould be dorie without hesitation. It must be obvious, that whatever may have caused the retention of urine, it will be necessary to preserve the artificial opening that has been made, that the urine may be drawn off occasionally, until that cause is removed. It fortunately seldom happens that retention of urine is so obstinate as to require this opcration. In slight cases, a clyster is often sufficient for the cure: and when it depends on a spasmodic affection of the neck of the bladder, camphor, either alone or with opium, 
126 SUPPRESSION AND RETENTYON OF URINE.

is, I believe, the most effectual remedy. I have also found camphor and nitre succeed, in the following proportions : but, when there is a considerable accumulation of urine, the diuretic quality of the nitre might render it objectionable; and even water should be withheld, as well as every thing that might tend to increase the secretion of urine.

\section{Camphor Clyster.}

Camphor (powdered by means of

a few drops of rectified spirit) $\} 3$ to 4 drams. Olive oil ................ $1 \mathrm{oz}$.

Mix by rubbing them well together; and, when properly incorporated, add

Water, in which one dram of carbonate

of potash has been dissolved ...... $\} 1$ quart. Tincture of opium ............. $1 \mathrm{oz}$.

Mix, and throw it up at about blood heat or a little warmer.

\section{Camphor Ball.}

Camphor (powdered) ....... 9 drams.

Nitre .............. 1 oz.

Liquorice powder and syrup enough to form the ball. For one dose.

Suppression of urine may depend not only on acute inflammation of the kidney's, but from some chronic affection of those organs, or from stony 
matter plugging up the ureters. I have scen a stone, weighing five ounces, that was found in the pelvis of a horse's kidney. The kidneys are sometimes injured by blows on the loins, or by violent exertions, as in leaping, drawing heary loads, or carrying too heavy loads; in such cases, embrocating the loius, and covering them with a fresh sheep-skin, is proper; and when the kidneys become torpid, and perform their functions imperfectly, without any symptoms of inflammation, about an ounce of balsam of capivy may be given, or the following: mixture:

Venice turpentine ........... 1 oz.

To be well rubbed with the yolk of eggs, and when thoroughly incorporated, add, gradually, a pint of mint-water or a strong infusion of ınint or peppermint.

I have known a fatal disease of the kidneys brought on by putting in a rowel that was covered with blistering ointment. It produced an enormous swelling in the chest, where it was inserted, and a total suppression of urine, attendcd with loss of appetite, very quick pulse, and other symptoms of fever. The horse died, and the kidneys were found quite disorganized, apparently from violent inflammation. This horse's kidney, it appears from a recent inquiry, was previously diseased. I mention this case as a caution to practitioners; for although blistering ointment has been often ap- 
plied in this way with a view to excite inflammation more speedily than it can be by other means; yet the probability of the cantharides being absorbed and inflaming the kidneys, will prevent me in future from adopting a practice which, in this case, proves to be hazardous. Whenever the bladder becomes irritable, or retention of urine takes place, in consequence of blistering the lemss severely, the camphor drench and clyster should be given; and in the former case, the mucilaginous drinks, such as infusion of linseed, are necessary: but in all morbid affections of the urinary organs, a costive state of the bowels is injurious, and should therefore be immediately removed or obviated. For this purpose, clysters are peculiarly proper; and if any laxative medicine is required, cither castor oil or the oily laxative is to be preferred to more active preparations.

\section{Dialetes, or Excessive Staling.}

Thrs disease often proves extremely obstinate, and sometimes incurable. I am inclined, however, to believe that if attended to seasonably, it may generally bc cured without much difficulty. The complaint at first consists in an increased secretion of urinc; the horse staling frequently, and in considerable quantity. The urinc is generally transparent and colourless like water, but sometimes 
turbid. It is always attended with unusual thirst, and soon after its commencement, with more or less of fever. When suffered to proceed, the horse becomes hide-bound, weak, and loses flesh, the mouth and tongue dry, and the quantity of urine discharged often exceeds considerably that of the liquid the animal drinks. The disease is generally caused by ill treatment, working a horse beyond his strength, or kecping him on musty oats and hay. It may be bronght on also by an imprudent nse of diuretics, or by allowing a horse that has a voracious appetite to ent and drink immoderately. In the treatment of this disease, con-1 siderable attention should be paid to the horse's diet, which, with the aid of tonic medicines, will generally effect a cure in a short time. He is to be allowed a small quantity of nourishing food sereral times a-day, and his water should be given in small quantities, but oftener than usual, and if his hay and corn were sprinkled or moistened with water, it would tend to moderate his thirst.

I have found the following ball effectual in several cases.

\section{Tonic Bull.}

No. 1.

Opium ........... from $\frac{1}{2}$ dram to 1 dram. Ginger ........... 2 drams.

Gentian root (powdered) $\frac{1}{2} \mathrm{oz}$.

Oil of Caraways or anise-secd ........ 20 or 50 drops. 
Syrup enough to form the ball. 'To be given morning and evening.

Two balls will generally diminish the quantity of urine considerably; and then, if the opium is found to occasion costiveness, or weaken the appetite, it should be discontinued, and a clyster thrown up. In two cases that have lately occurred, sulphate of copper (blue vitriol) has been given with good effect; the preparations of iron or steel, and other tonics, have also been recommended. I have seen lime-water, which has been often prescribed by the old farriers, fairly tried without doing the least good. I have heard of some attempts to cure the disease by giving the horse animal food, which in one instance appeared to have considerable effect; but I believe it was not persisted in, and that horse-flesh was improperly chosen for the experiment. The following tonic balls are less expensive than No. 1, and will generally succeed, if the directions given with respect to the horse's diet are attended to. Good grooming, and regular but moderate or walking exercise, are also necessary.

\section{Tonic Ball.}

No. 2.

Sulphate of copper .......... l dram.

Liquorice powder .......... 3 drans.

Treacle enough to form the ball. To be given once ini 8 or 12 hours. 


\section{No.3.}

Sulphate of iron ....... 2 drams to $\frac{1}{2}$ oz.

Powdered myrrh ....... 2 drams.

Ginger

. 1 dram.

Syrup or treacle enough to form the ball. To be given as above.

When the bowels are loose, about half a dram of opium may be added to each ball, or lalf an ounce of tincture of opium, given with beer or water.

\section{Bloody Urine.}

Horses sometimes discharge blood with their urine in considerable quantity, generally in consequence of violent exertion or blows on the loins, but sometimes it occurs without any apparent cause. If the horse is healthy in other respects, the following ball may be given : but when it is attended with fever, pain in staling, and other symptoms of inflamed kidneys, it must be treated accordingly.

$$
\text { Ball for Bloody Urine. }
$$

Powdered catechu ......... ${ }^{1} \mathrm{o} z$.

Alum ................ $\frac{1}{q}$ to $1 \mathrm{oz}$.

Cascarilla bark ........... 1 to 2 chrams.

Liquorice powder and treacle enough to form 
balls for one dose. To be repeated three or four times, if necessary, allowing an interval of 12 hours between each dose.

When the loins are tender, they should be rubbed with some stimulating embrocation, and covered with a sheep-skin; a clyster also is useful, and cven an oily laxative, if the horse is costive: but if the bowels are rather lax, about a scruple or half a dram of opium may be added to the first and even second and third dose, should the loosemess continue. When the discase is known to be produced by violent blows or strains, and is attended with quick pulse, bleeding is proper. I have more frequently met with this disease in mares than horses, and have seldom found the above ball fail ; but if it continues after three or four doses have been givels, let half a dram of opium be added. As the ball may be found too large for some horses, it may be either divided or mixed with water, and given as a drench. Linseed tea, or some other mucilaginous drink, may be given; aud if the ingredients of the above ball cannot be procured, decoction of ponegranatc-bark, oak-bark, or galls, may be given; to cither of which about one ounce of alum is to be added. Diluted sulphuric acid has been recommended, but it is an incouvenient medicine. 


\section{Incontinence of Urine.}

Thrs term implies an involuntary discharge of urine, which is fiequently, or almost constantly, coming off in drops or very small streams. Tincture of cantliarides has afforded temporary relief; blistering the loins may also be tried: but it is seldom, I believe, radically cured. If the disease depends upon weakness or paralysis of the bladder, it may be known by passing the hand up the straight gut, and pressing gently on the bladder, which will then cause the urine to flow off in a stream. La Fosse, in his Manuel d'Hippiatrique, advises, in this case, when other methods have failed, that an opening be made in the perineum, as I have described in speaking of retention of urine, and injecting in to the bladdler, through a canula, some astringent liquids. Old horses, that have been worked hard, are most subject to this malady; and the best general treatment is that which invigorates the system. A large strengthening plaster on the loins would probably be useful ; and the following ball may be given.

Sulphate of copper ......... 1 dram.

Venice turpentine .......... 3 to 4 drams.

Ginger ............... 2 drams.

Liquorice powder enough to form the ball. For one dose. 'l'o be given morning and evening for a few days. 
If the tincture of cantharides is given, the first dose should not exceed one dran, but it may be gradually and cautiously increased. I have given powdered cantharides to an uscless horsc by way of trying their effect. I began with half a clram; and perceiving no effect, increased the dose daily, till it camc to half an ounce: this proved moderately diuretic, and no more was given. It is worthy of remark, that the horse was supposed to have a disease of the mesentcric glands, cvery method having been ineffectually tried to get him into working condition. After the experiment, he was turned to grass; and, at the end of two months, was taken up quite healthy and fat; in which state, he continued nearly one year, when lie was sold.

Stone in the Kidneys, Ureters, and Bladder.

STONy concretions are oftener found in the kidney's or ureters than in the bladder of horses, and vut seldom in cither. Thcir cxistence is not, I belicve, easily ascertained or discovered. When in the kidneys or urcters, they often occasion excessive pain, which pressure on the loins increases. In the bladder they also causc much pain, and can generally be felt through the straight gut: for this examination the horse should be thrown down and placed on his back. For the former nothing can be clone; and if any thing is attempted, perhaps 
carbonate of potash and clysters are most likely to afford relief. An opiate or anodyne clyster may be useful. La Fosse, in his Dictionnaire d'Hippiatrique, relates a case of stone in the bladder, which was cured by an opcration. The hor'se was about 14. years old; and was often observed to have pain and difficulty in staling, voiding only a small quantity, which was sometimes bloody. Upon introducing the liand into the gut, the stone was distinctly felt; and, after a few days' preparation, by bleeding and opcning medicinc, with a spare dict, the animal was placed on his back, and an opening made in the urethra, ncar the anus, in the manner I have before described. The fore-finger was introduced into the bladder, while an assistant had his hand in the gut, in order to press up the stonc, that it might be felt by the operator, who then introduced an instrument, guided by his finger, with which two lateral incisions were made in the neck of the bladder. The forccps were now introduced, and the stone laid hold of; but it broke into small pieces, which were cxtractch, and found to weigh six ounccs. No dressing was applied to the wound, but some linseed infusion was injccted into the bladder. The horse got up without assistance, was bled three times the same day, and not allowed any solid food. His drink was whitc watcr (bran tea). The bowcls were kept open by clysters. On the fourth day, hc was allowed a small bran mash and somc straw, and this was gradually increased. 'There was scarccly any fcrer'; the wound suppu- 
rated and looked healthy: during some days, part of the urine passed through the wound; and about the twenty-second day it was perfectly healed.

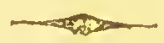

Inflammation of the Bladder.

When the bladder is nuch infaned, its irritability is so increased, that it becomes incapable of containing any urine, contracting upon every drop almost that passes into it from the kidneys. In this complaint, then, the horse is attempting almost constantly to stale, but voids only a few drops of urine, and that with considcrable pain: it is generally attended with quick pulse, and other symptoms of fever. Nothing is more beneficial in this disease than causing the horse to drink largely of linseed decoction, or any other mucilaginous h- quid, and throwing up fiequently clysters of the same: bleeding, and a dose of castor oil, are likewise highly neccssary. After the operation of the oil, let the following ball be given every eighth hour. Should no relief be obtained by these' means, the horse continuing to void his urine ficquently, in small quantities, and with pain, add half a dram of opium to the ball. Costivencss tends very mucli to aggravate this complaint; and, whenever it occurs, let a clyster be injected, and a dose of vil givcr. 


\section{The Ball.}

Powdered nitre $\ldots \ldots \ldots \ldots \ldots \ldots, \frac{1}{2}$ oz.

Camphor ................ I dr.

Liquorice powder .......... $3 \mathrm{dr}$.

Honey sufficient to form a ball for one dose.

Inflammation of the kidneys is always accompanied with great irritability of the bladder; which causes the horse to be frequently, and almost constantly, straining to stale, while only a very small quantity of bloody or dark-coloured urine is voided, and may, therefore, be mistaken for inflammation of the BLADDER. I examined, a short time since, two cases, where this symptom had appeared in a very distressing degree, and found the bladder quite free from disease, but the kidncys much inflamed. I believe, the most certain criterion for distinguishing inflammation of the kidneys, when it is considerable, from a similar affection of the bladder, is the stiffiness or lamencss of one or both hind legs, which is observable when the former are affected.

\section{Inflammation of the Liver.}

THrs disease is indicated by a ycllowness of the eyes and mouth, red or dark-coloured urine, great weakness, and fever, generally accompanied with 
diarrhoen or purging, and sometimes with costivencss; the horse has a very languid appearance, and is almost constantly lying down. Sometimes the progress of this complaint is very rapid, specdily tcrminating in death: at others it proceeds more slowly, the animal lingering for a considerable timic. In this case it not unficquently terminates in dropsy, or inflammation of the bowels. $A$ case I recently met with terminated in this way. It is often complieated with other internal disenses, causing some varicty in the symptoms.

Bleeding can be cmployed with safety only at the commencement of this disease: afterward it generally does harm, by inducing a dangcrous degree of debility. The sides should be blistered; and, if there be no purging, the ball No. 1, given once in 24. hours, until it occasions moderate purging; but, if the bowels be already in a lax state, the ball No. 2, will be better adapted to the complaint, and is to be given in the same way.

The horse is subject also to chronic affections of tle liver, by which the structure of that organ is gradually destroyed, and it becomes so soft and tender as to be torn by the motions of the body'; the conscquence of which is an effusion of a large quantity of blood within the abdomen, and speedy, sometimes sudden, death.

As the horse's liver is less complicated in its structure than that of the ox, shcep, and some other quadrupeds, it is on that account, perhaps, less liable to disease, particularly to those chronic affec- 
tions which so often occur in horned cattle. I should have observed, when speaking of the treatment of acute inflammation of the liver, that, besides copious bleeding at the commencement of the disense, and rubbing some blistering ointment on the sides, a rowel may be placed in the breast.

\section{Bails. \\ No. 1.}

Calomel ................

Barbadoes aloes ............ 2 drams.

Rhubarb ................ 3 drams.

Castile soap ............. 3 drams.

Syrup enough to form the ball.

No. 2.

Castile soap and strained turpentine, of each 3 drams.

Liquorice powder enough to form the ball.

Saundice, or Yellows.

This disease also is indicated by yellowness of the eyes and moutl, lassitude, want of appetite, and some degree of fever. The urine is high-coloured, the dung hard and covered with slime or mucus; sometimes, however, it is attended with scouring. This disease does not often arise from gall stones or biliary concretions, but more com- 
monly, I believe, from diseased action of the liver, in consequence of which, a more acrid bile is secreted, or, perhaps, not a sufficient quantity : it may depend also on some derangement of the digestive organs in general, particularly the stomacl. Bleeding is seldom necessary in this disease, and should be carefully avoided, unless the disease is complicated, and there are other symptoms which appear to render it necessary; such as quick pulse, disturbed breathing, the membranes of the eyes inclining to orange colour, or even redness. This shows that the lungs are in danger, and that blecd. ing is proper. In general, it is attended with languor and debility. If the horse scours, gruel, made with arrow-root or wheat flour, should be given; but, if the dung is hard and slimy, the following laxative is proper:

Barbadoes aloes ........ from 2 to $\&$ drams.

Calomel ............

Castile soap ......... 3 drams. Rhubarb...........2 to 3 drams.

Syrup enough to form the ball. For one dose.

After the operation of the laxative, the horse generally gets better, but there often remains considerable weakness, which requires great care as to feeding and exercise. At this period, some tonic unedicine may be given. (See vol. ii.) 


\section{Strangles.}

Tuis disease generally attacks young horses between the third and fifth year of thcir age, and consists in an inflammation of the membrane of the throat and nose, and swelling of the glands under the throat, accompanied with cough, and a discharge of white thick matter from the nostrils: sometimes there are likewise a soreness of the throat, and difficulty in swallowing. 'The inflamed glands commonly suppurate in a short time, and burst, discharging a large quantity of matter. When this has taken place, the cough and other symptoms generally go off, the sore gradually lieals, and the horse speedily rccovers. In some cases, the strangles assume a more formidable appearance, are attended with a considerable degrce of fever, and the throat is sometimes so much inflamed, that the horse is incapable of swallowing either food or water; but, lowever violent the attack may be, I have always found tlat, by adopting a proper mode of treatment, erery unpleasant symptom may be casily removed, and a speedy recovery cffecterl. It is not a vely uncommon circumstance for the strangles to attack young horses while at grass; and then they arc frequently not perceived until nature has ncarly effected a cure.

The approach of straugles may be known by a dulness of countcnance, watcry eyes, cough, and a slight degree of swelling in the glands under the jaw. As soon as they are discovered, let the hair 
be carefully clipped off from the inflamed glands and contiguous parts of the throat; let a large poultice be then applied to the throat, in doing which it is necessary to take care that it is so secured as to be constantly in contact with the throat; for unless this is attended to, the poultice will be but of little service. I liave generally found, that by rubbing a small quantity of some stimulating ointment on the inflamed glands, previous to the application of eacli poultice, suppuration has been considerably promoted: for this purpose, the following formula will be found useful.

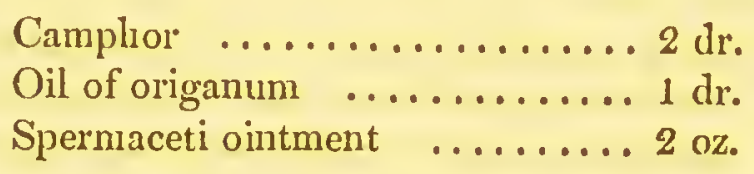

Mix.

When matter is completely formed in tlie glands, which may be known by the tumour becoming larger, and by the skin feeling tense and somewhat elastic, an opening should be made with a lancet and its contents evacuated: this plan is certainly preferable to that of waiting until it bursts spontaneously, as the animal is instantly relieved by it, and the cure more speedily effected. To evacuate the matter perfectly, it is necessary to use moderate pressure with the fingers; and when this lias been done, let a piece of lint, dipped in digestive liniment, be inserted, for the purpose of keeping the lips of the wound open, and allowing the matter 
to escape freely: the poultice is to be continued until the swelling is perfectly reduced. When strangles attack the internal parts of the throat, so as to render the horse incapable of swallowing, and particularly if the external swelling be not considerable, it will be adviseable to apply a blister, and keep the bowels open with clysters. It is very necessary, in every case of strangles, to steam the hend well; that is, to put hot bran mashes into the manger frequently, so that the horse may inhale the vapour.

It is of consequence to distinguish cases of incipient strangles from common colds. In the latter bleeding is a useful remedy; but in the former I believe it does much harm, by interrupting a process of nature. I cannot, by any argument, show why bleeding should be improper in the strangles; indeed, if our practice were guided by theory only, we should be led to consider it as a case of common inflammation, and consequently adopt that mode of treatment which would tend to remove it most expeditiously, and prevent suppuration; and with this view we should have recourse to bleeding and purgatives: experience, however, certainly sanctions a different treatment, and has, I think, fully proved the propriety of using every means for encouraging suppuration. I have seen several hundred cases in which this plan has been pursued, and not one of them terminated unfavourably. Should the inflammation, however, spread to the lungs, occasioning great difficulty of breath. 
ing and fever, and particularly if the horse be past the age of five, bleeding must not be omitted; and if a laxative drink can be givell, it will be found of great scrvice. A rowel in the chest will also do good.

Should a cough or any unplcasant symptom remain after the strangles are healed, let the following altcrative ball be given every morning, until modcrate purging is produced; and if it be found necessary, let it be repcated after an interval of four or five days. It is almost superfluous to add, that great attention must be paid by the groom; the hond, nock, and chost, as well as the body, should be clothed; warm water should be given frequently in small quantities; a large quantity of littcr should be allowed; and hand-rubbing to the legrs should never be omitted.

\section{Alterative Ball.}

Barbadoes aloes ............ 1 $1 \frac{1}{2} \mathrm{dr}$.

Lmetic tartar and Castile soap, of each ........

2 dr.

To be made into a ball for one dose.

As there is often much difficulty in kccping up the poultices, so as to be closely in contact with the discased part, I have often dirceted fomentations to be frequently applied instead of them; and, whenever there is any difficulty in swallowing, I think the swelling should be immediately blistercel. I have observed that, by opening the tumom too 
carly, or while any lardness remains about it, the cure is tlicreby retarded; nor should much pressure be made, in order to squeeze out the matter. If the abscess has been freely opened, a circumstance that should always be attended to, and which can be done without giving much pain, if the operation is not performed prematurely, there will be no clanger of the matter accumulating, or other abseesses forming, provided it be fomented or bathed several times a-day; and if this is properly done, there is no occasion even for putting in a tent. Whenever strangles oceur in so violent a degree as to threaten suffocation, an opening should be made in the wind-pipe. (Sce Vet. Dict. $\Lambda$ r. Broncholomy).

\section{Catarri, or Colit.}

IT would be superfluous to gुive a particular dc. scription of this complaint, since it is so well known, and its appearance so generally mnderstond, that scarcely any one can be at a loss to distinguish it from other discases. It consists in an inflammation in the mucous membrane, which lines the internal part of the nose, throat, \&e., sometimes attended with a slight degree of fever: henee arise the cough and discharge from the nostrils, which are the principal symptoms of catarrh. On the first attack of this complaint, blceding will generally be found an cffectunl remedy; but if it be neglected 
until a considerable diseharge has taken place from the nostrils, it seldom proves benefieial. The following laxative will be found useful if the horse is costive, and may be repeated after an interval of a few days, should it appear necessary.

\section{Laxalive Ball.}

Barbadoes aloes ............. 3 drams. Pure soap

Syrup enough to form a ball for one dose.

Should the laxative be unneeessiry, or after its operation, a dose of fever powder is to be given cvery morning and evening, until the symptoms abate, or a considerable diuretic effeet is produeed, and then every second or third day only.

Sometimes a swelling takes place in the parotid glands, whieh are situate immediately beneath the ear. Should no unusual heat or tenderness be observed in these swellings, apply the stimulating ointment reeommended for strangles; but if they feel hot, be painful, and appear to be in a state of aetive inflammation, a poultiee and fomentation are the best remedies. If the eyes be inflamed and watery, a rowel shonld be inserted under the jaw; and if the inflammation in the throat be so considerable as to render swallowing painful, a blister will afford great relief. Hot bran mashes should be given frequently, whieh will not only serve to lieep the bowels open, but will act as a fo- 
mentation to the inflamed membranes, since the hor'se will be constantly inhaling the vapour which escapes from them. Should he be costive (which is not likely to happen while he is taking bran mashes), let clysters be injected occasionally. The head and chest, as well as the body, should be well clothed, the legs frequently hand-rubbed, and a large quantity of litter allowed; by these means he will soon be restored to health. Should a cold be attended with a-considerable degree of fever, or should the appetite go off, and the flanks work quicker than usual, it is necessary to make some alteration in the treatment. (See Fever and Inflammation of the Lungs). It is necessary to observe, before I conclude this subject, that strangles on their first attack are sometimes mistaken for a cold. This may be productive of mischief, since bleeding is gencrally improper in that complaint: if, therefore, a cold be accompanicd with a swelling of the glands under the jaw,-if they fecl hot and be painful, and particularly if the horse be young,we may conclude that the strangles are approaching, and treat it accordingly.

Should the cough remain after the other symptoms are gone off, give the ball again, or that prescribed for cough; and if necessary, repeat it after a short interval. If the cough continue after this, let the following ball be given every morning for a
week.

The Ball.

Powdered squills ............ $1 \mathrm{dr}$, 
Grm ammoniac $\ldots . \ldots \ldots \ldots . . .3 \pi$. Opium ................ $\frac{1}{2} \mathrm{dr}$.

Syrup enough to form a ball.

The opium is apt to produce eostiveness when continned, and sometimes takes off the appetite; and though it often appears to eure the cough for a time, the permancney of its effect cannot be depended upon. The eongh that remains after a cold is often, I believe, of a local nature, depending probably upon morbid irritability about the la1 ynx, or from the mueus of the part being unusually stimulating. Blistering the throat has often lone good; also, drenching the horse two or thrce times a-day with infusion of linseed, sweetened with honey or trencle; the addition of a little vincgrar has likewise been found useful. I have known instanees of such eonghs being quickly cured, by giving drcnehes, composed of garlie and linsecd infusion, with treacle and buttcr. In short, the remedies that lave oceasionally suceceded in these cases are very numerous. The principal thing to be observed is not to cxpose the horse to a current of eold air, either in the stable or out of it, or suffer him to stand in the cold air or rain; this is sure to licep up, or cven aggravate, the eomplaint, whaterer remedies are employed. 


\section{Chronic Cough.}

Turss complaint is, as has been observed in the preceding artiele, often a consequenee of an illtreated or negleeted eold; but it sometimes comes on so gradually that its origin eamnot be easily determined: and I think it probable that a diseased eondition of the stomaeh and bowels is often materially coneerned in its produetion. Horses that labour under ehronie eough are generally observed to have an inordinate appetite both for food and water; so mueh so, that they will eat even their litter when stinted in hay, and will drink the foulest water; and, unfortunately, it too often happens that this morbid appetite meets with little restraint. A eontinuanee of this injurious habit seldom fails of weakening the stomael and bowels; and, consequently, the whole system. The next degree in the seale of misehief is the produetion of worms: which become a fresh source of poverty and debility. The sympathy between the lungs and the digestive organs is very remarkable; and it is not at all surprising that, under such erroneous management, eoughs, and other diseases of the respiratory organs, should so often oceur. Another cireumstance to be eonsidered is, that when the horse is iput to work, and espeeially if he is rode fast, or required to draw heavy burthens, his stomach and bowels are often so loaded as to impede 
materially the action of the lungs; a frequent repetition of this mischievous practice will probably do an irreparable injury to these important organs, and assist in producing a variety of troublesome diseases. There is still another circumstance to be considered in attempting to explain the manner in which chronic diseases of the lings are produced; and it should be recollected, that a knowledge of this may lead to an effectual mode of prevention. When a horse is allowed to eat more hay than is proper, he is almost always inclined to drink more than he otherwise would; and in this also he is too often unrestrained, except in being allowed to drink only twice a-day; therefore, at such times he, of course, drinks a great quantity. A horse thus mismanaged is seldom treated properly in other respects, unless a hot close stable can be considered in that light-but on that subject, I trust, enough has already been said: therefore, it may be fairly presumed that he is at times suffered to stand in cold wind or rain, perhaps when heated and fatigued by his work, or he may be taken into a pond or river, to save the trouble of cleaning him in the stable. The functions of the skin being thus interrupted, an additional source of injury to the lungs is formed. Thus it is that chronic cough, broken wind, and a variety of disenses, are produced. The shock is sometimes so considerable as to cause an acute disense; as inflammation of the lungs, bowels, or some other in- 
ternal part; but more frequently a foundation is laid for some chronic disorder, which its frequent repetition scldom fails of establishing.

From this view of chronic cough, it will appear that the cure will depend much more upon proper stable management than the exhibition of modicine. His daily allowance of food and water should be moderate, and given at three or four times; the former should be nutritions, but light and casy of digestion: such as mashes of scalded bran and oats, carrots, bruised oats, swect hay free from dust or mould; and whicn there is much thirst, it should be sprinkled witlı water. If the horse is inclined to eat his litter, he should be muzzled as soon as he has eaten his allowance; and, in the day time, he may be kept without litter. His work should be moderate; and great care taken not to expose him to wet or cold, particularly not to let him stand still when so exposed. The ceremony of washing lis legs should be clispensed with. In cold weatliel, his watcl shonld have the chill taken off. He slould be thoroughly brushed and well wisped twice or three times a-day; and, if he is not worked, he is to be exereised moderately twicc a-day. Modcrately warm clothing, and a stable properly ventilated, but not such as may subject him to a partial current of air; or, rather, a loose box, where he may move about, are also necessary. The first medicinc to be given is a mild purgative, or the alterative which will improve the state of the digestive organs, and get rid of any 
worms that may be lodged in the bowels. In accomplishing this his general health will be inlproved; and in consequence of the sympathy that exists between the respiratory organs and those of digestion, the beneficial effect will be particularly felt by the former. After an interval of a week, the dose should be repeated. Should the cough continue after this, the cough-ball or drench may be given. After the chronic cough is cured, the horse will be very liable to a relapse, and will require a continuance of that care and attention with regard to feeding, excrcise, \&c. already pointed out; and, if the complaint is incurable, it is the only means of preventing it from getting worse or degenerating into broken wind.

\section{Mild Purgative.}

Barbadoes aloes ......... $\frac{1}{4}$ oz. to $5 \mathrm{dr}$.

Calomel ............. I dr.

Soap $\ldots \ldots \ldots \ldots \ldots . . . .3 \mathrm{dr}$.

Ginger............. 2 dr.

Oil of caraways $\ldots \ldots \ldots 12$ drops.

Syrup enough to form the ball. One dose.

\section{Allerative Ball.}

Barbadoes aloes ............ $1 \frac{1}{4} \mathrm{oz}$.

Soap .................. $1 \frac{1}{2} \mathrm{oz}$.

Calomel ................. $3 \mathrm{dr}$.

Ginger.................. $6 \mathrm{dr}$.

Dil of caraways $\ldots \ldots \ldots \ldots \ldots .1 \mathrm{dr}$. 
Syrup enough to form a mass, to be divided into six balls. One of them to be given every morning, or until purging takes place, which sometimes is produced by the second dose; but more commonly the third is required, or even a fourtl. In a forner edition, emetic tartar was prescribed instead of the calomel, but I think the latter is best.

\section{Cough ball.}

Gum ammoniacum ........ 3 to $4 \mathrm{dr}$.

Powdered squill ......... $1 \mathrm{dr}$.

Camphor .............. J dr.

Ginger .............. $1 \frac{1}{2} \mathrm{dr}$.

Soap ................. $2 \mathrm{dr}$.

Oil of aniseed $\ldots \ldots \ldots \ldots 20$ drops.

Syrup cnough to form the ball. One dose to be given once or twice a day.

This is sometimes made more efficacious by the addition of opium, about half a dram; but it is medicine that is very apt to produce costiveness and disorder the stomaclı when given daily; and, though it will often stop the cough for a day or two, its beneficial effect is seldom permanent. If the horse becones costive during the treatment of chronic cough, let a clyster be injected, and increase the proportion of bran; giving it in the form of mashes for a day or tivo.

\section{Cough Drench.}

Treacle and vinegar, of eaclı ..... I pound. Tresh squill bruised in a mortar ..... 3 oz. 
Macerate the squill and vinegar for a few lours in an oven not much heated, then press off the liquifl part; add to it as much vinegar as has been lost by evaporation, and afterwards the treacle. This is sufficient for 'four doses; one to be given molning and evening. When squill cannot be had, about four or five ounees of garlic may be substituted.

Tar and tar-water have been recommended for eough; also, eggs mixed with vinegar, and an egg alone unbroken; this last proved an effeclual cure in one case that eame under my notice, for the groom who preseribed the renedy, in attempting to give it, eontrived to get some part of the slrell into the larynx, and killed the animal. I have known the chronie eough much relieved by giving the following powder daily, or so as to inerease the. horse's staling in a moderate degree; and it is worthy of remark, that most of the medieines that are recommended for eough are, more or less, of a diuretic quality. The following eordial diuretie has also been given with good effeet: but the purgative, I think, should always precede those pectoral or cough medicines.

\section{Pow'der.}

Nitre and yellow resin, of each $\ldots \ldots \ldots \ldots \frac{1}{y}$ oz. Caraway sceds reeently powdered $\ldots \ldots \ldots \frac{1}{2} 0 z$. Mix. For one dose. 


\section{Cordial Diuretic.}

Strained turpentine ........ s oz. Yellow resin .............. 4 oz. Linseed or olive oil ......... $2 \mathrm{oz}$. Soap $. . \ldots \ldots \ldots \ldots \ldots \ldots \ldots, 6$ oz. Ginger ............... 4 oz. Oil of caraways $\ldots \ldots \ldots \ldots \ldots \ldots \frac{1}{2}$ oz. Oil of anisc-seed .......... 2 dr.

Linseed powder cnough to form the mass. To be divided into sixteen balls. If the first ball does not produce a diuretic effect, let another -be given the following morning. Melt the resin, turpentine, and soap, together, over a slow fire; and, when perfectly melted and mixcd, stir in the other ingredients, having previously mixed the essential oils with the ginger aud some linseed powder, by rubbing them togetler in a mortar.

These balls will be found very convenient for proprictor's of post, coach, or waggon horses.

\section{- \\ Roaring.}

TuIs disease takes its name from a peculiar sound in respiration, particularly when the horse is put into a brisk trot or gallop. It secms to arise from lymph that has beels effused in the wind-pipe 
or its branches, which, becoming solid, obstructs, in a greater or less degrec, the passage of air. As a remedy for this complaint, blistering the whole length of the windpipe has been recommended; I believe, however, that it is always incurable, unless proper remedies are employed as soon as it is observed to be coming on. It gencrally begins like a scvere cold, with difficulty in breathing, accompanied with a peculiar kind of wheezing: sometimes there is also considerable fever and soreness of the throat. In some cases, it attacks suddenly, and with great violence; in others, it comes on gradually, and is then more dangerons, as it is seldom attended to, and gencrally allowed to estinblish itself before proper remedies are cmployed. It is adviseable, whenever a horse is attacked with the above symptonss, to have recourse immediately to bleeding, purging, and blistering the throat.

There are different kinds of roaring, to which dealcrs have applied appropriate nanics; thus, when a lorse breathes with a shrill or whistling kind of noise in trotting or galloping, he is called at whistler"; and, when the obstruction is principally in lis nostrils, the noise is different, and he is said to be a trumpeter or high blower. Sometimes the wheczing cvidently proceeds from the lungs, and the breathing is somewhat like that of an asthmatic man; but the working of the flanks is not so considerable, or at all like that of a broken-winded horsc. I have met with several cases where the discase was confined to the larynx. In one horse, 
a confirmed roarer, that had been so a considerable time, I found, after death, an ulecr on the inside of the larynx, on one side of the rima or chink. This horse, when standing still, breathed in the natural way, and was in good condition; but when put to work, such as drawing a modcrate wcight, he was execedingly distressed, and breathed so that he could be heard at a distance of twenty yards. Had I suspected at the time the nature of this case, I would, without hesitation, have made an opening in the windpipe, and cndeavoured to cure the ulcer, by passing up a medicated probang. This opcration is by no means formidable. I onee sared a loorse's life by it that was ncarly suffocated, from a small portion of his food having got into the larynx. A probang, such as surgeons use, was smeared with oil, passeci through the opening in the windpipe up through the larynx, and immediately withdrawn. 'This relicved the horse, and the wound in the windpipe gradually healed. (Sec the author's "Vetcrinary Dictionary," Articles Choaking (Appendix) and Broncholomy).

Another case of roaring eame on in consequence of a scverc attack of sore thront, in which there was an apparent enlargement of the larynx, which led to a suspicion of its being partially ossificd; but this, I was informed, did not appear to be the case after death, nor was any discasc found in the windpipe or lungs. Now, as an ulecr in the larynx was very likcly to eseape the notice of the person who examined this horse, and there was 
nothing else found to account for the roaring, I think it probable that ulceration within the larynx was the causc of it. I should have obscrved that, in the first horse, the lungs were perfectly healthy. A third case of roaring, which the proprietor described to me by letter, succeeded to a considerable swelling about the throat; but the cxact nature and situation of which I could not determinc from his description. A fourth case happened in my own stable, without any apparent cause: it was not preceded by violent cold or sore throat. Hc was found in the morning with a troublcsome cough and wheezing, not such as to indicate the prescnce of any foreign inatter, within the larynx: he soon got better, and went home. Soon after, the wheczing returned; and became so loud that it could be heard at a considerable distance. The lorse was clestroyed; and the only morbid appearance to be found was a small ulccr in the larynx, in the sane situation as in the first noticed casc. In this last, as well as in the first casc, it would, I think, have becn worth while to attempt a cure by the means I have described. It appears, from the experiments of $\mathrm{M}$. Gallois, that, by dividing the recurrent nerve (a branch of the cighth pair which passes down the neck), the chink of the larynx is immediately closed citlier partially or wholly, and suffucation or great difficulty of breathing is the immediate conscquence. As this nerve may be wounded in blceding unskilfully, and low down in tlic neck, a knowledge of this fact would lead us, in such a casc, to make an 


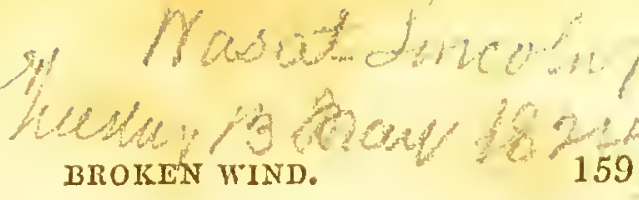

opening in the windpipe, by which the animal would be immediately rclieved, and the divided nerve would gradually be reunited.

\section{Broken Wind.}

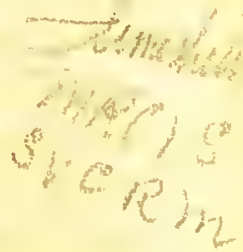

IT seems to be universally allowed that this complaint is incurablc, though it will admit of considerable alleviation: and, if its approach be perceived sufficiently carly, may probably be prevented. Horses that appcar to be most subject to it are those with voracious appetites, that eat evcn their litter, and kcep thcmselves in good condition upon a moderate allowancc of corn: also such as are fed highly, and at the same time not properly exercised. It has been observed by a modern author, * "that the most common appearance of the lungs in broken-winded hor'ses is a general thickening of their substancc, by which their elasticity is in great measure destroyed, and their weight specifically incrcased, at the same timc that thcir capacity for air is diminished. During life, the lungs entirely fill the cavity of the chcst, so as to leave no space between their outward surfacc and the inward :urface of the ribs. (See Structure of the Lungs.)

* "An Iuquiry into the Structure and Animal Leonomy of the Ilorse, by Richard Lawrenec, Veterimary Surgeon, Birmingnam," 4to.; at work of inucl general merit. 
Thus they dilaic and contract, following up by their own clasticity the action of the ribs and diaphragm. If the chest be punctured in the dcad subject, the air rushes in, and the lungs collapse: but if the horse werc broken-winded, the lungs do not collapsc. This state of the lungs sufficiently accounts for the difficulty of respiration; for ats their faculty of dilatalion is destroyed, the rits camol expand withont forming a vacuum in the chesh, which the pressure of the external air prevents, which may be readily perccived in the case of broken wind; for then the intercostal muscles are so strongly retracted, as to furm a decp furrow betwcen evcry rib, as wcll as a depression in the flanks. On this nccount air is received into the lungs with great difficully, but its expulsion is nol so diffcull, as the return of the ribs and diaphragm naturally force it out by their pressurc. 'Thus in broken-winded horses iuspiralion is very slow, but exspicalion is sudden and rapid, as may be scen by the flanks returning with a jerk."

It appear's to me, that the obscrvations of $\mathrm{Mr}$. Lawrence on this subject are not correct. The lungrs of broken-winded horses, that I have examined, have generally been unusually large, with numerous air-bladder's on the surfacc. This must have arisen from a rupture of sonic of the air-cells; for, in this case, some part of the air which is inspired will necessarily get into the cellular membrane of the lungs, and diffuse itsclf until it arriys 
at the surface, when it will raise the pleura so as to form the air-bladders we observe. * This is the reason that the lungs of broken-winded horses do not collapse when the chest is punctured; and this will serve to explain the peculiar motion of the flanks in broken-winded horses, which does not consist, as Mr. Lawrence asserts, in a quick expiration and very slow inspiration, but quite the reverse; air is reccived into the lungs very realily, which is manifested by a sudden falling of the flanks, but is expelled slowly, and with greal difficully, as may be perceived by the longwcontinued cxertion of the abdominal muscles. +

* See Description of the Functions of the Lungs, \&ca, as above, plage 4.

+ A short time siuce, a liorse, completely broken-winded, was given to me for the purpose of making experiments relative to the glanders, a disease which has for many years occupied my attention. On destroying the animal, and cxamining the lungs with grcat care, very littlc discase could be observerl. So far from their being thickencr, and in the state $M r$. Liw rence describes, they werc specifically lightcr thah natural; and, though no air-bladders were perceived on the surface, there was evidently a great deal of air diffused in the ccllular membrane of the lungs, which must have heen occasioncd by a rupture of one or morc of the air-cells, or minute branches of the windpipe; there heing no other source from which it could lave been produced. Now this was a rase of simple broken wind, which may be easily distinguished, not by an unusually quick motion of the flanks, but by an uaequal motion. The flanks of a brokicnwinded horsc are a long time in clrawing 11 or contracting, which shows the difficulty he feels in cxpclling the ail fron his lungs, or in exspiring; but when that is effected, the flanks drop suddenly, which shows that the air coters the longs, or that the animal inspires with much grcater casc than he exspircs. It often 
When the membrane which lines the windpipe and all its branches has been affected with inflammation, it becomes thickened in consequence, and the capacity of the lungs will of course bc diminished; this will cause a quickness in respiration, but not that irregular or unequal kind of breathing by which broken wind is characterised. The complaint which is thus produced is commonly termed thick wind; and the horse so affected, if madc to move rapidly, wheezes like an asthmatic person, and is unfit for any violent exercise. It not unfiequently happens, I believe, that this complaint proves a cause of broken wind: for when the membrane is much thickencd, many of the fine: branches of the windpipe are probably obstructed in a greater or less degree: the violent coughing, which usually accompanies this disease, will, under such circumstances, be very liable to rupture some of the air-cells. The same effect may be produced by violent exercise when the stomach is distended with food or water. I believe, however, that a plcthora, or fulness of habit, is most commonly the remote cause of broken wind. In that case, there is generally an undue detcrmination of blood to the lungs, whereby the sccretion within the airvessels is increased, and perhaps rendered some-

happens, howcver, that broken wind is complicated with thickness of wind, and, as I lave before obscrved, is sometimes ocensioned by it, which probably gave rise to the opinion we have entdeavoured to refute. (See Cough, Asthma, and Thickncss of Winl, Appendix). 
what acrimonous and viscid, exciting a violent and troublesome cough. *

Whencrer a horse appears to be imperfect in his wind, if he cough violently, particularly when exercised, with unusual working of the flanks, and if at the samc timc he appear to be in good health and spirits, feeding heartily, and eager for water, let him be bled modcratcly, and take a laxative ball : by these means, assisted by a bran dict and regular exercisc, the lungs will soon be relieved, and the cough, if not complctely removed, will be considerably diminished. Afterward give the following ball every morning for a weck, and take carc that regular exercisc is never omitted: it will be adviscablc also to prevent the horse from filling himself too much with hay or water. The latter should be given five or six times a-day, in small quantitics; for the common method of stinting a horsc in water, when his wind is supposed to bc bad, is ccrtainly prejudicial. Corn should be given

* It is not very inprobable that air is sometimes sccreted or formed in the eellular membrane of the lungs; in which ease a lorse would be broken-winded without any rupture of the aircells. I have seen a horsc beeome brokcn-winded rather suddenly, and when a violcnt cough had not preceded: I liave also seen the symptoms of broken wind removed by turning a loorse out, but they returned when he was taken into the stable again; and I rceollect a horse, that would sometimes breathe very well, and at other timcs appear completely lokken-winded. From these circumstances, it does not appear iriprobable, that the cause of broken wind is sometimes a morbid formation of air in the cellular meabrane of the lungs. 
sparingly, as high feeding tends very much to arggravate the complaint. Bran is a useful clict, if mixed with corn; and if carrots, or any other succulent vegetable, can be procured, they will be found of considerable scrvice. The vapours which arise from foul litter, and the air of a close stable, are extremely pernicious. I have scen very good cffects from turning the lorse into a paddock during the day, when the weather is favourable. When the cough and other symptoms have been removed, these means must still be persevered in, or the discase will probably return: regular and long-continued excrcise tends more than any thing to keep it off; but violent excrcise is extremely improper. Whonever costiveness occurs, it should be removed by means of a clyster and bran mashes; and should the horse be disposed to eat his litter, it is to be prevented by means of a muzzle.

\section{The Ball.}

Powdered squills $\ldots \ldots \ldots \ldots \ldots . .1 \mathrm{dr}$.

Gum ammoniac $\ldots . \ldots \ldots \ldots \ldots$, $\frac{1}{2} \mathrm{oz}$.

Powdered anisc-sects ........ 3 dr.

To be made into a ball with syrup, for one dose.

The cordial diuretic prescribed for chronic cougin will be found an exccllent palliative for broken wind.

In this complaint, the digestive organs are always more or less affected: hence it is that such lorses are always so flatulent, and are so apt to 
break wind in the act of coughing. There is no disease, perhaps, which will admit of so much alleviation, or that can be relieved witl so much ecrtainty, as this, by duc attention to stable management. The want of tone or energy in the stomach and bowels, which always attends the complaint, should lead us to pay particular attention to the state of those parts, and allow only such food as is easy of digestion, and give it only in such quantitics, and in such a state, as the stomacl can digrest without extraordinary excrtion. Bruised onts are, therefore, to be preferred; becnuse brokenwinded horses are generally greedy fecters, and more apt than other's to swallow their corn without clicwing it sufficiently: and it has been provesl, that when corn grets into the stoniach unbroken, it it is perfectly indigestible, and passes through the stomach and bowels unchanged. Water may increase the symptoms of broken wind, not only by its quantity, but by its quality, and by its coldness; and improper management with regarel to water is apt also to bring on a fit of the spasmodic or flatulent colic in such lorses. The sympathy between the stomach and the lungs lias already been notiecl, as well as the consent or comnection between the latter and the skin or perspiratory vessels: hence it is that exposure to wet and cold, or standing in the cold, after being heated by exereise, is sure to aggravate broken wind; though turning the horse out where there is but little grass, in temperate weather, generally afords great relief, and 
often removes, for a time, every symptom of the disease. Bran mashes are exceedingly useful when there is a disposition to costiveness; and small quantities of green food may be given with advantage. In short, in attempting the cure of chronic diseases of the lungs, of which there is a considerable variety, but differing more in degree than in kind, it is essentially necessary to pay strict attention to the state of the stomach and bowels, to restore their lost tone as far as it can be done by a proper management of diet, air, and exercise, and an occasional use of medicine; considering the latter, however, as subordinate to the former. Nor is it less necessary to avoid all unnecessary exposure to cold wind and rain, especially sudden changes of temperature; which is a most fertile source of disease in all animals, by interrupting the important functions of the skin. The frequency of those disenses, the great loss and inconvenience they occasion to proprietors, and the numerous disputes to which they lead, in the purchase and sale of horses, have induced me to notice them at some length, and in the present edition (the 12th), to treat of them in succession. 'The place of the following article also is changed in this edition; because it is, in some measure, connected with the present subject. 


\section{Worms.}

THEne are three kinds of worms found in horses. The most common and mischievous reside in the stomach, and are named lots. They are of a reddish colour, and seldom exceed three quarters of an inch in length. At one extremity they have two small hooks, by which they attach themselves, and the belly seems to be covered with very small fect: they are most frequently found adhering to the insensible coat of the stomach, and then they do not appear to cause any considerable uneasiness or inconvenience. Sometimes, however, they attach themselves to the sensible part, and do great injury to this important organ, keeping up a constant irritation, therely occasioning cmaciation, a rough, staring coat, hidebound, and a cough. I have met with several instances of their destroying the horse, hy ulcerating the stomach in a considerable degree; and cases are recorded where they have penetrated quite through the stomach. It is astonishing with what force these worms adhere, and how tenacious they are of life: they have been found to resist the strongest poisons, nor lave we yet discovered any medicine capable of destroying them, or of detaching them from their situation. It seems probable that this worm, like the caterpillar, undergoes several changes. It is said to be originally a fly, which, depositing its eggs in the horse's coat, causes an itching, that 
induces him to bite the part. In this way he is supposed to swallow some of the egges, which, by the heat of the stomach, are brought to maturity, and produce bots. When the bots are fit to assume the chrysalis statc, they arc spontancously detached, and graclually pass off with the feces. This is the most rational account we have of their production.

It has been asserted, that the fly from which bots are produced crawls into the anus of horses, and deposits its eggrs there; that the worms when hatched soon find thcir way farther up the intestines, and often penetrate into the stomach. This account is litcrally copicel by a late writcr on Vetcrinnry Pathology; * but it appears to me rather strange, that any one who has considered the structure of the horse's intestines should for a moment give creclit to it. It secms impossible indecd for thesc worms to crawl from the anus to the stomach; and, as far as my ouservation goes, they are never found residing in the intestincs. Sometimes we find two or threc, but they are crislently proceeding toward the anus to be cxpelled. I have before obscrved, that I am not acquainted with any medicine that is capable of detaching or destroying these worms, though I have frequently tried the strongest mercurial preparations, and many powerful medicines.

I have used the yellow emetic merenry or the vitriolnted quicksilver, as recommended by the

* Ryding's Tetcrinniy Patholozy. 
writer just quoted, as wcll as every other mereurial preparation, but never saw a single bott expelled by them.

The next worm we have to describe is very slendel, of a blaekish colour, and seldom exeeeds two inehes in length. It is never found in the stomaeh, and very larely in the small intestines, the largest part of the canal being generally the plaee of its residence. IIerc it proves a eonstant souree of irutition, oceasioning loss of eondition, a rough unhealthy looking coat, and frequently a trouble. some cough. A variety of altcrative medicines liave becil proposed for the destruetion of worms of this kind, and some of them are supposed to be infalliblc: I believe, lowever, that none of them mc possessch of much cficacy, and we ought not, thereforc, to depend upon them.

The following are the alteratives to whieh $I \mathrm{aln}$ lude:-savin, lue, box, xthiops mineral, antimony, sulphur, cmetic tartar, calomel, and vitriolater. quicksilver; the last two, if given with aloes, so as to purge briskly, and partieularly the ealomel, are exeellent remedies; but givell merely as alterative, they do no grood.

I have generally found the following ball vely effectual, giving the preceling night from half is dram to a dram of calomel. I have often mixed. the calomel with the ball, and found it equally of fieacious: the formor method, liowever, is genen
rally preferen. 


\section{The Ball.}

Barbadoes aloes ............ $6 \mathrm{dr}$.

Powdered ginger............ $1 \frac{1}{2} \mathrm{dr}$.

Oil of wormwood $\ldots \ldots \ldots \ldots . .20$ drops.

Prepared natron ............ 2 dr. .

Syrup enough to form a ball for one dose.

It is often necessary to repeat this medicine, but there shoulu always be an interval of ten days be. tween each dose.

The third kind of worm is of a whitish colour, frequently seven or eight inches in length, and generally found in the lower part of the small intestincs. Worms of this kind are not so common as the others, but appenr to consume a considerable quantity of chyle, or the nutritious parts of the food. They may be got rid of by the same means that we have recommended for the small blackish worm.

We may always be satisfied of the existence of worms in the intestines, when a whitish or light straw coloured powder is observed immediately beneath the anus. I have sometimes succeeded in destroying worms, by giving one dram and a half of aloes. every morning, until purging was produced.

There is another kind of worm, but it is not commonly met witl. I have seen them in horses whose small intestines were loaded with long white worms, and the large oncs with ascarides. 
These worms bear some resemblance to the tapeworm, except in being generally very short and small. They are of a whitc colour, and of flat figure, and seldom morc than an inch in length, and one-eighth of an inch in brcadth. They appear to attach themselves to the intestines by means of small hooks, which they have at one of their extrenities or cnds, like botts. When detached from the bowel, thcy move about in the warm fluid with considerable activity. The best account of botts that has ever been published was communicated by Mr. Bracey Clarke to the Linnean Society, and publisied in their Transactions. 'The substance of this communication may be found in my Veterinary Dictionary. As almost all horses that are kept at grass during the latter part of summer have botts, and as they have often been found in the stomach after death, when it has been ascertained that the horse had not suffered any inconvenience from them, Mr. Clarke scems to think that they may answer some useful purpose. I have seen, however, several cases where they have evidently been the cause of the most serious mischief. One horse had symptoms of pherenilis or mad staggers, and was relieved by plentiful bleeding and purging. Soon after, he was again attacked and died. On examining the stomach, it wats found that a small opening had taken place in the sensible part of the stomach, through which some botts had fallen into the abdomen; many other botts werc still adhering' to the stomach. I did not ex- 
amine this horse myself, and saw him only at the first attack, but received the information from the man who opened him. Mr. Clark of Edinburgh mentions a similar case, which I think worth noticing. 'A horse had been ill some days (the symptoms are not described), and when Mr. Clark came to see him, the scrvant was giving him a drench, composed of linsced-tea, nitre, and honey; with the last hornful he mixed rather more than half an ounce of spirits of hartshorn. The horse scemed rery uneasy after the drink: he was soon seizcd with a violent trembling and shaking; a profuse sweat broke ont all orcr his body, and ran down his sides as if water had been poured on him; at the same time, lis legs and ears were quite cold: he lay down in grent agrony, was soon after convilsed all over, and died in about half an hour from the time the drink was swallowed. The stomacl was immediately examined, and found highly inflamed; a mortification had taken place on onc side, in which there was a small hole, through which a leaden probe passed into the cavity of the stomacli from the outcicle. The conts of the stomach were considerably thickencel, and of a darkish red colour, resembling that of liver; at the same time, it was considcrably distended, and full of blood. On tmining it inside ont, an incredible number of botts were found sticking round the sicles and lower part of the stemach, insomnch that it appeared entirely covered with them: and so finnly were the heads of these vermin fixed in the 
coats of the stomach, that in endeavouring to pull some of them off', when alive, they broke in two.'

'The great irritation,' Mr. Clarkobserves, 'caused by such a number of botts sticking to the conts of the stomach, had, no doubt, occasioned the inflammation which, from its continuance, was tending to mortification before the drench was given, which would lave occasioned the horse's death in a short time; but there is every reason to think that the drench hastened it. This horse was very fat, and just out of the dealer's hands.' Mr. Clark does not state what the symptoms were for which the drench was given; but, judging from its composition, I should think they were such as indicated some pulmonary affection : nor did lic examine any other part. I met with several cases that occurred nearly about the same time, at Southampton, in young troop-horses, lately received from the dealers' hands. They were all attacked apparently with inflammation of the lungs; but there was a greater degree of debility than usually occurs in that disease, and nore depression or anxicty in the countenance. Bleeding afforded no relief; and when carried to a considerable extent, hastened the animal's death. The mucous membranes bott of the bowels and lungs were affected; and there was a troublesome cough: extcrual inflammation was excited in a considerable degree to no purpose. Castor oil secmed to afford more relicf than. any thing clse, and one only, out of six, recovered; and he remained in a feeble state for a long time. 
In all that died, the lungs were found to have been almost destroyed by the violence of the inflanmation; and there was a prodigious quantity of congulated lymph, resembling yellow fat, adhering to the lungs, pericardium, and diaphragm, and a considerable quantity of yellowish fluid. A great number of botts were found in the stomach, with sloughing ulcers in the sensible part, surrounded by a high degree of inflammation, approaching to mortification. In some the ulecrs had penetrated through the coats of the stomach; and on some of the ulcers there was a blackish slough, resembling half-burned or scorched leather. A case, exactly similar to thesc, occurred to a young troop-horse at Croydon.

From all these circumstances, it cannot, I think, be doubted that botts are occasionally productive of serious injury, and perhaps do even more mischief than we are aware of. Mr. Clark mentions a case where a horse died from taking a pint of vinegar ; and suspects very reasonably, that the stomach was previously injured by botts. At the same time, it must be allowed, that they are often found in the stomachs of horses that have been killed by accidents, or destroyed on account of glanders, attached sometimes to the sensible part, and particularly about the pyloris, without having caused any kind of disorder or apparent inconvenienec. Under what particular circumstance they become so injurious it is not, perhaps, casy to determine; and if there were any symptoms by which their. 
existence in the stomach could be, with certainty, known, probably little or no advantage would be derived from it, from the great difficulty of killing or detaching them. From the relief which castor oil afforded in one of the six horses, the only one that recovered, and I believe, but do not exactly recollect, the only one that took castor oil, or, at least, so much as he did, it nay be worth while to give it a further trial. Emollient drinks of linseedtea and honey may also be givelr, and every thing of an irritating nature avoided: though these mily neither detach nor destroy botts, yet they may put a stop to the irritation they occasion before the stomach is irrecoverably injured. The most common symptoms of botts, when injuring the stomach, are cough, staring coat, hidebound, quick weak pulse, disturbed breatling, sometimes symptoms of colic, but not violent, slimy dung, staggers, great debility, and anxiety of countenance. Other symptoms may perhaps occur, and these may not always be present, but the treatment is innocent, if not efficacious, and, with the aid of clysters, would gcnerally remove such symptoms, on whatever cause they may depend. The propriety of bleeding, and the extent to which it may be carried, must be determined by cxisting circumstances. (Sec Inflannmation of the Langs, Bourels, Sc. and Bleeding.) Oil of turpentine having been strongly recommended to me by a medical gentleman, for the worms that inhabit the intestines, particularly ascarides, or the very short, slender; or needle-litic 
worm, I have on several occasions preseribed it; and in every instanee there was a grent number of asearides voided, but none of the long white wornis: I have also reeeived favourable reports of it from some of my correspondents. The dose in which that gentlcman advises it to be given is four ounces in a pint of gruel, having kept the horse without food for three or four hours before, and a short time after. During the day, he is to be fed sparingly with bran mashes, and have but a small quantity of hay. He advises, also, that the bowcls be brought into a moderatcly loose state before the turpentine is exhibited, by giving the horse, the day before, thrce or four drams of aloes, with a little soap. As to the radical cure of worms, it is not suffieient to evaeuate those that may be lodged in the bowels, but their future aeeumulation must be prevented. 'To aeeomplish this, it is necessary to inquire on what cause their formation depends. That they are most commonly found in hor'ses that are kept on unwholesome food, that have voracious and depraved appetites, and are consequently unhealthy and weals, is a faet well known; but that they are also produced sometimes in horses that are allowed a sufficient quantity of wholesome food, is equally true: but such horses are generally inclined to ent their litter; and it is but seldom that means are employed to prevent them. It is probable, I think, that a disordered or weakened state of the stomach and bowels, however indueed, is the circunstance upon which their production de- 
pends. The digestive organs may become disordcred not only by unwholesome food, and want of a sufficient quantity, but likewise by irregular fecding-by eating too much even of the best food; by a habit of drinking too much water at a time, by which the stomach is often distended, and its tone gradually impaired; by a frequent use of cordials or strong purgatives; by immoderate work; and, in short, by any thing which is injurious to the gencral hcalth of the animal: for so important are the functions of the stomach and bowels, that when disordered, the wholc system is more or less affected; and they, in like manner, sympathize with every important part of the system. In discases of the mesenteric glands, through which the lactcal; pass, that is, the vesscls which convey the nutritious parts of the food or chyle, the animal becomes wcak and cmacinted; and in such cases, we gencrally find worms in the bowcls: and what is remarkable, the large mesenteric artery is almost invariably diseased; its cavity more or less enlarged; its coats much thickoned; and small worms, somewhat resembling, but less than ascarides, arc almost always found within it. I have latcly met with an extraordinsy case of this kind? $\Lambda$ horse had been cmployed in carrying coal from the coal-pits near Mendip to Shepton Mallet, by' onc of those persons who feed their horses principally, if not wholly, with whatever they can pick up on the road; he gradually became so wcak and emaciated that he was left at the kemel, where 
the knife soon put an end to his sufferings. I found the grinding-teeth so unequally worn, with kcen edges, wounding the inside of the cheek, that he could not have masticated his food, or at least very imperfectly, for a considerable time. One of the teeth was quite loose and rotten, and easily taken out, the socket being decayed; two or three others were nearly as bad, and some were full half an inch higher than the others: there wore deep ulcers, with callous colges, within the cheeks. The small intestines were nearly filled with long white worms, and in the large bowels there was an immense number of ascarides, and some of the short flat worms before described. The mesenteric artery was prodigiously enlarged; and being taken out with that portion of the aorta or large artery from which it branched off, weighed about ten pounds: it consisted of two tumour's; the first and largest was in the truuk of the artery, and was connected with the second by about three inches of healthy artery, except being larger than natural. They were rather globular in their form; and upon being opence, were found to consist of a substance that resembled firmly coagulated pus, throngh the centre of which the blood had preserved its courac:- the sidcs of this canal were smooth, like the inside of an artery, and contained a small quantity of hlood, sufficicnt to show that it had $1 \mathrm{r}^{\circ}-$ cently conveyed blood. The congrulum adhered but loosely to the sides of the ristenticel artery, and on a small part of its surface there wis a 
little fluid pus. There were but few of the small worms found in this case, and they were at the mouth or origin of the artery. That part of the aorta from whieh it arose was healthy. It is impossible, perhaps, to account satisfaetorily for the presence of worms in an artery; and probably we can only conjeeture how they are ggenernted in the bowels, but we know what is practieally useful: whieh is, that whatever materially reduces the general health and strength, is likely to induee that state or eondition in the stomach and bowels which is favourable to the production of worms; and that when they are brought into this state, worms will be gencrated whatever food is taken in. If the subject be viewed in this light, we should not be satisfied with merely expelling worns from the bowels, but endeavour also to correct that morbid condition, upon whiels their produetion depends, by a prudent use of purgative and tonic medicines, striet attention to diet and the functions of the skin, and regular exereise, but not more than is compatible with the object in view; the improvement of health and strength. (12th Edition.)

\section{Hidebound.}

Tus term implies a tightness of the skin, whieh feels as if it were glued to the ribs, the coat having at the same time a rough unhealthy appearance. 
This complaint is generally occasioned by worms or want of attention in the groom: it occurs sometimes, however, without any manifest cause. In such eases, give the alterative ball, No. 1, every morning, until moderate purging is produced; and if this do not suceeed, try the alterative, No. 2, which is to be given every morning for eight or ten days, taking eare to assist its operation by warm clothing, good grooming, and regular exereise. The exercise should not be eonfined to walking, but may be carried so far as to exeite a moderate perspiration. Great care must afterward be taken that the horse does not get cold. Let him be put into the stable while warm, and immediately clothcd: when the legs and head have been well cleaned, remove the eloth, and eontinue to rub the body with large wisps of clean straw, until it is quite dry.

I eannot forbear mentioning here a remedy that is employed in some parts of Staffordshire for this complaint, as it elearly evinces how neessary it is to rescue this valuable animal from the barbarous and absurd treatment of illiterate blacksmiths. An aceomt of this operation was sent me by a gentleman who saw it practised a few months ago. "The head and legs of the horse * being secured, two men (one on each side) pull the hide from the ribs in about fifty places with pincers." The pro-

* I have since been informed that I mistook the gentleman, and that the unfortunate subject of the operation was a bullock; the folly and cruelty of the proceeding are, however, the sime. 
prictor of this unfortunate animal must surely have beell destitute of common sense or liumanity, to allow an ignorant unfeeling farrier to perform so cruel and fruitless an operation.

Allerative Balls.

No. 1.

Barbadoes alocs .......... 1 oz.

Castile soap .............. $9 \mathrm{dr}$.

Powdered ginger ........... $6 \mathrm{dr}$.

Syrup cnonglı to form a mass, to be divided into four doses.

No. 2.

Tartarised antimony $\ldots \ldots \ldots 2 \frac{1}{2} \mathrm{oz}$.

Powdered ginger ......... $1 \frac{1}{\mathrm{a}} \mathrm{oz}$.

Opium .............. $\frac{1}{y} \mathrm{oz}$.

Syrup cnough to form a mass, to be clivided into eight balls.

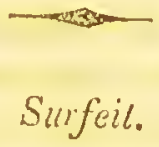

Thrs absurd term is given by farricrs to a disease of the skin, consisting in small tumours or knobs which appear suddenly in varions parts of the body, sometimes in consequence of drinking largely of cold water, when the body is unusually warm; but it appears frequenily without any ma: 
nifest cause. It may be easily cured by bleeding moderatcly, or giving a laxative ball: sometimes, indeed, it goes off without any medieal assistance. There is another disease of the skin, of the same name, which is generally more obstinate, and attacks horses that are hidcbound and out of eondition. In this, a great number of very small scabs may be felt in various parts of the body ; the loorse is frequently rubbing himself; and sometimes the hair falls off from those parts which he rubs. This complaint approaches to the nature of mange, and requires the same treatment, assisted by a generous dict, good grooming, and regular cxereise.

\section{Mange.}

This disease is seldom met, with cxcept in stables where scarcely any attention is paid to the horses, and where their food is of the worst quality: it is certainly very contagious, and may in this way attack horses that are in good condition. It is known to exist by the horse constantly rubbing or biting himself, so as to remove the hair, and sonictimes produee ulceration; the hair of the mane and tail frequently falls off, and small scabs are observed about the roots of that which remains. The mange is, I believe, a local disease, and requires only the following ointment or lotion for its removal: in obstinate cases, howcrer, it may be 
adviseable to try the effect of the following alterative.

\section{Mange Oinlment.}

No. 1.

Sulphur vivum, finely powdered ..... 4 oz.

Oil of turpentine ............ $3 \mathrm{oz}$.

Hog's lard $\ldots \ldots \ldots \ldots \ldots \ldots 6$ oz.

Mix.

No. 2.

Oil of turpentine $\ldots \ldots \ldots \ldots \ldots \ldots .4 \mathrm{oz}$. Strong sulphuric acid .......... 2 oz.

Mix cautionsly, putting in the acid by a little at a time, and add

Hog's-lard (previously melted) ....8 oz. Train oil ................6 6 oz. Sulphur vivum .............4 oz.

Mix.

The acid and the turpentine should be allowed to combine perfectly, and bccome a blackish liquid mass, before the other ingredients are added. The preparations of quicksilver, sucl as mercurial ointment, solution of corrosive sublimate, \&c., are sometimes employed for mange; but are certainly not so safe, and perhaps not more effectual than the sulphur or sulphur vivum, which, if properly applied, scldom fails of curing the disease. It is not sufficient merely to cover the affected parts 
with the ointment; but cvery part should first be well curried, even till they become sore, and then the ointment should be thoroughly rubbed in with a brusl. The following is a clicap composition, and is generally cfficacious.

Oil of tar $\ldots \ldots \ldots \ldots \ldots \ldots \ldots \ldots .68 \mathrm{oz}$ Oil of turpentine $\ldots \ldots \ldots \ldots \ldots \ldots .4$. oz. Sulphur vivum, finely powclered ..... 2 oz. Mix.

In slight cases of mange, where only a small part of the skin is affected, and the smell of sulphur, which is very strong and disagreeable, is objected to, the above lotion may be used, or the following, which are more easily made.

Corrosive sublimate $\ldots \ldots \ldots \ldots \ldots \ldots 1 \mathrm{dr}$. Muriatic acid $\ldots \ldots \ldots \ldots \ldots \ldots \ldots .3 \mathrm{dr}$. Water.$\ldots \ldots \ldots \ldots \ldots \ldots \ldots \ldots 1$ piut.

Mix.

Or, corrosive sublimate $\ldots \ldots \ldots \ldots 1 \mathrm{dr}$. Muriate of ammonia .......... $\frac{1}{2} \mathrm{Oz}$. Water $\ldots \ldots \ldots \ldots \ldots \ldots \ldots \ldots$ l pint. Mix.

\section{Mange Lotion.}

White hellebore, powdered ........ 4. oz. 
Boil in 3 pints of water to 1 quart, then add

Muriate of quicksilver .......... $2 \mathrm{dr}$. that has been previously clissolved in 3 drams of muriatic acid.

\section{Alterative for Mange.}

Muriate of quicksilver .......... $\frac{7}{2}$ oz.

Tartarised antimony .......... 3 oz.

Powdered anise-seeds ..........6 oz.

Powdercd ginger ............. 2 oz.

Sirup enough to form a mass, to be divicled into sixteen balls, one of which is to be given every morning.

Should these appear to diminish or take off the appetite, or create a purging, they must be discontinued two or three days.

\section{- \\ Apoplexy or Staggers.}

TH1s disease generally begins with an appearance of drowsiness, the eyes being inflaned and full of tears, and the appetite diminished; the disposition to sleep gradually increases; and in a short time the horse is constantly resting his head in the mangcr, and sleeping. The pulse is seldom much altered; in a few cases, I have found it unusually slow: costiveness and a defective secretion 
of urine commonly attend this complaint. Sometimes the disease will continne in this state for several days; at others, it assumes a formidable appearance very early, or even at its commencement, the horse falling down and lying in a state of insensibility, or violent convulsions coming on. Sometimes a furions delirium takes place, the horse plunging and throwing himself about the stable, so as to render it dangerous for any one to come near him. From this variety in the symptoms, writers on farriery lave divided the disease into the slecpy and the mad staggers.

There is another kind of staggers, which arises fiom a distension of the stomach, and most coinmonly attacks horses employed in agriculture, or in any kind of hard work, when their condition is not equal to their labour, and particularly when they are badly managed with respect to food and water. Since the author left the army, he has met with a great number of cases of this kind; and being informed that it uniformly proved fatal, destroying a very considerable number of horses annually, he was led to pay particular attention to it; and was the more strongly induced to this, from finding his own treatment unsuccessful.

The bodies of horses that died of the complaint were carefully exanined, and at length a mode of treating it was discovered, which, if seasonably employed, often proves successfil. As the disease is now known to originate in the stomach, it will be describer moder that head in the Appendix. (Sec 
Stomach Staggers.) It is sufficient to observc hicre, that it may be distinguished from apoplexy, or genuine staggers, by a yellowness of the eyes and mouth, and a twitehing or eonvulsive motion of the muscles of the breast ; the horse appears very feeble, the head hanging down, as if oppressed with a eonsiderable weight; the fore legs totter, and frequently give way suddenly, so that the animal appears to be on the point of falling, but he rarely falls down, except in the last stages of the eomplaint; he seems to be insensible, and often forces his head against the wall with sueh violenee, that the projeeting parts are mueh bruised.

From the view wc have given of the staggers, it will appear, that the terms which farriers have adopted to distinguish its different appearances are very inadequate; and that it would be better. to distinguish the disease under the two following hcads: viz. the idiopathic and the symptomatic staggers. In the former, bleeding is the grand remedy, and seldom fails of affording relief, if employed with freedom at the eommeneement of the disease. It will be adviseable also to give the following purgative dranght, and injeet a stimulating elyster, composed of a gallon of water and eight ounees of eommon salt. Should not the symptoms abate in eight or ten lours after the bleeding, thcre will be great probability of obtaining relief by opening the temporal arteries, and suffering them to blecd freely.

I once snw a case in which the effieney of this 
plan was remarkably conspicuous: the horse had been labouring under the disease for several days, and delirium had taken place, though he had been bied freely, and, in every respect, according to the account I received, treated properly. When I saw him, he was lying down in a state of insensibility, having just before been plunging and throwing himself aboit very violently: the attendants supposed him to be dying; and, indeed, I should have been of the same opinion, had not the pulse retained some degree of strength. I immediately opened both temporal arteries, and, after they had bled about ten minutes, the lorse got upon his legs, appeared perfectly easy, and from that moment gradually recovered, without the assistance of any other remedy.

When the disposition to sleep is not removed by the first bleeding, the head should be blistered and a rowel inserted under the jaw.

\section{Purgative Draught.}

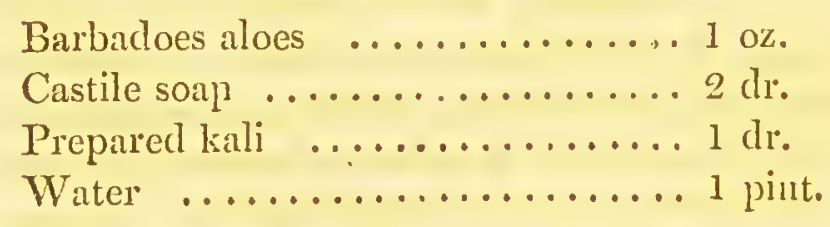

Mix for one dose.

In the third volume of my Treatise on Veterinary Medicine, this disease (stomach or symptomatic staggers) is treated of at considerable length, and 
a particular account given of a similar disorder which occurred ncar Swansea, by which one proprictor lost more than 100 horses. The discase is noticed also in the Appendix to the present volume. I have only to add here, that $\mathrm{Mr}$. Blaine considers the stomach staggers as dependent "on a specific inflammation of the stomach; distinct and differing from those inflammations of that organ brought on by the usual causes of such affection." The stomach is certainly found more or less inflamed, and sometimes the small intestines; even the lung's, when the animal survives four or five days, are also affected with inflammation. The question then is whether this inflammation is the cause of the stomach beconing distended or the effect of it. It is not improbable that the disorder depends upon some morbid condition of the stomach; but in all the cases that have come to my knowledge, where the animal was curcd, strong slimulanls were enployed, gencrally in conjunction with purgatives; now, if it were an inflammalory affection, it is but reasonable to suppose that it would be rather aggravated than curcd by stimulants. I think it likcly, thereforc, that the inflamed appearance of the stomach after death is an effect of the distention it has suffered. Onc case (sec vol. iii.) was cured by beer and ginger; another with suake-reot, musferred giving the medicine in the form of a ball in the third volume, from the probability of wasting great part of the calomel when given in a liquid 
form: it may, however, be suspended in a small quantity of thick gruel; and if given carefully and expeditiously in that form, would certainly be better. It is to be regretted, that the veterinarian is seldom consulted before the stomach is distended beyond recovery; therefore, I think it right to suggest that as soon as the disorder is observed, and the remedies prescribed cannot be procured in time, that some of the common domestic stimulants be immediately given; such as ginger, wallun brandy, rum, or gin and water, mustard, \&c. Clysters are an important part of the treatment; and if there is no clyster-pipe and bladder at hand, the hard dung should be removed by raking, as it is termed, that is, drawing it out carefully with the hand. *

I have for several years found gruel made of arrow-root, and when that cannot be had, of fine wheat flour, the best remedy for diarrhœa or scour-

* Since writing the above, a case has occurred, which proves that the stomach may be loaded, or even crammed, with food without producing the peculiar symptoms of this discase, symptomatic or stomach stiggcrs. This case is described under the head Infammalion of the Bowels. Though the cuatents of this stomach weighed more than 40 pounds, they had a difierent appearance froin that found in the stunachs of staggered horses; being less $d r y$, and partially digested. This circumstance scems to prove that symptomatic staggers depends on some morbid condition of the stomach, and not simply on its heing distended with food ; for in this case, the symptons produced by the distended stomach were those of violent colic, which destroyed the horse in four or five loours. 
ing, whether it be caused by checked perspiration, or over-physicking.

\section{Diarrhae, Purging, or Scouring,}

Is generally caused by new oats or bad hay, sometimes by exposure to wet and cold, particularly in the moulting season: some hor'ses have a constitutional weakness of the bowels, and can scarcely do any work, or drink freely of cold water, without being attacked with some degree of diarrhœa; in this case, he should have a little cordial medicine after a day's work, and a handful or two of wheat-flour should be mixed with his water, which should have the chill taken off. If the disease continues, the astringent ball is to be given. When the disease is brought on by bad hay or new oats, a change of diet is generally sufficient for its removal. Should it be occasioned by worms, or should small slimy knows be mixed with the dung, give, in the first place, a dose of laxative medicine, sucl as three drams of aloes witl an equal quantity of soap, or the oily laxative. When diarrhoa is accompanied with griping pains, the horse lying down and rolling about, let it be treated accordingly. (See Colic, Gripes, and Infammation of the Bowels.) In obstinate cases of diarrhœa, unattended with pain, fever, or loss of appetite, three or four drachms of catechu may be added to the ball. Gruel made of arrow-root, or 
even wheat flour, is often sufficient to put a stop to the disease; particularly if assisted by grood grooming, and proper attention to diet and excrcise.

\section{Astringent Ball.}

Powdered opium $\ldots . . \ldots \ldots \ldots . . \quad \frac{1}{8} d r$. Sub-carbonate of soda ......... 1 dr. Powdered cassia or ginger $\ldots \ldots \ldots 1 \frac{1}{4} d x$. Flour and sirup cnough to form the ball.

Should the form of diench be preferred, the ball may be mixed with a little warm beer, or gruel made of wheat-flour, and given with a horn.

\section{Molten Grease.}

Tirs absurd name was given by the old veterínary writers to a clisease in which the mucous or internal coat of the intestines is particularly affected, but accompanied generally with a consitcrable degrec of fever. From the dung being slimy or covered with the mucus of tie bowels, in a state somewhat rescmbling fat or grcasc, and the blood, when coagulated, having a coat of size or buff" on its surface, those ingenious gentlemen fancied that the fat of the body hat been melted, and mixed with the blood; that it was then gradually deposited upon the bowels, in order to be expelled from the system: the size, also, found on the surfuce of 
the blood that had been drawn from the animal, was supposed to be fat or grease. Another circumstance which tended to confrm them in this error, was, that it is generally brought on by violent excrtion or hard riding, at a time when the lorse is fat, and unaccustomed to such exercise. Lorses taken up fat from grass, and put too hastily. to work, cspecially if the wonther is hot, are very liable to the disorder. Let the horse be bled, and if the dung is solid or in knobs, give a dose of castor wil or the oily laxative; but, if the bowels are loose, let the horse chink frequently or be drenched with infusion of linsecd or arrowroot gruel. Sometimes it is attended with griping pains, but not so acute as those which ocenr in spasmodic colic; or there is a tenesmus or irritation in the rectum, which causes the horse to be frequently voiding a small quantity of dumis. When either of these symptoms occur, cmollient elysters shoukd be thrown up; and, if they fail, the opiate clyster may be tried. Molten grease is sumctimes accomprniad with more serious symptoms, denoting an inflammatory affection of the luings, and must then be treated accordingly. When the pain in the bowels is considerable, the belly should be well rubbed with the liniments prescribed for the infammatory colic. The quantity of blood to be taken off, and the propricty of repeating the opelation, must be deternined by the riolence of the attuck, the stute of the pulse, the appearaince of the blood, and the continuance or abatement of the 
symptoms. Onc copious bleeding is often sufficient in simple or slight cases; but whencver the fever runs high, and the case is complicated, with an inflammatory affection of the lungs, it is generally found necessary to blecd several times. (See Appenaix.)

\section{Dysentery.}

'Tus clder La Fosse and other" French veterinarians of his time considered dysentery and molten grease (cras fondu) as the same disease; but the younger La Fosse, in his Mamue? D' Hippiutrique, says, "This discase, which many mistake for molten grease, is an inflammatory affection of the bowels." Hesays, that purgatives and every thing of an irritating nature should be carefully abstained from, and that the only remedy is emollient ciysters, allowing the horse to eat a little sorrel, and giving him to drink white water (bran tea) with a small quantity of vinegar. In speaking of the gras fondu, or molten gicase, he observes, that clysters are the only remedies, unless there are symptoms of putridity, and then the clysters should be acidulated with vinegal. Ie does not point ont the means of distingnishing those diseases from each other; and, as he prescribes the same remedy for both, perliaps he had never met with a discase which resembled the dysentery of the human subject. I have never scen such a case, and 
am inclined to believe that it very rarely, if ever, occurs.

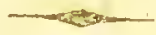

\section{Dropsy.}

A Coldection of watery fluid in the cavities of the brain, the thorax or chest, and the abdomen or belly. Sometimes dropsy is'superficial, the water collecting in the cellular membrane, under the skin, generally under the belly, in the sheath, and hind legs; sometimes extending, also, to the breast and fore legs. Dropsy of the brain or hydrocephalus occurs but schiom : the symptoms are constantly hanging down the head, or leaning it on one side the stall, or resting it on the manger. The pulse is seldom much affected. In one case, the horse appeared free from pain, except when suddenly put into motion, when he would be seized with violent spasms, and fall dlown: in two or three minutes he would get up again, and appear easy. This horse, being of no value, was destroyed, and about six ounces of fluid were found in the ventricles of the brain. The remedies are blistering the head, a rowel under the jaw, a brisk purgative, and afterwards diuretics. It is to be distinguished from inflammation of the brain or mad stagrers, in which the horse is delirious, and often clangerous to approach, a discase that requires more expeditions and plentiful bleeding than any other. (Soe Strrgers.) Dropsy of the chest is grincrally a consequence of inflammation of the 
lungs; and when it happens, those important organs liave almost always sustained too much injury to be restored. (Sce Inflammution of the Lungs.) Sometimes, however, it comes on gradually; and there may be a chance of curc by the use of diuretics mixed with tonics, a mourishing dict, brisk friction of the skin and extremities: blistering the sides may also be uscful. Dropsy of the belly or ascites: this diseasc, like the former, is gencrally an effect of infammation; but here the affected membrane is the peritoncum, and the discase is sometimes curable. This kind of dropsy is generally attended with considerable swelling about the belly, sheath, and hind legs. If these swellings are pressed with the finger, an indentation will renain, They are also free fiom inflammation and tenclesness. When scarified, the punctured parts will discharge a fluid, at first mixed with a little blond, from the wounded skin, but soon becoming limpid and transparent like water: by this operation the external swelling of the belly and sheath will be considerably diminished, but the water within the belly will remain until proper remolics are cmployed. Diuretics are the most useful nuedicines in all dropsical affections; but they must be assisted occasionally by tonics and cordinls, and always by great attention with respect to groomings exercise, and diet. Dropsy of the belly most commonly attacks horses that are liept at grass in colk, marshy situations, in the carly part of spring and winter. In such cases it is generally attended 
with considerable weakness; and I have been informed, by an intelligent practitioncr, who has had considerable experience in this kind of dropsy, that the following drench has so generally proved efficacious as to be considered quite a specific in the complaint: "Take five quarts of strong ale, set it on the fire, and skim off the white froth which rises; put into it a handful of wormwood, with the stalks, and let them boil gently together until reduced to about a quart. To this add one ounce and half of long pepper and grains of paradise, three ounces of treacle, and from two to four ounces of Castile soap. The whole to be given at one dose, and the hor'sc exercised immediately after till he sweats." This appears to be a potent drench, the cssential ingredients of which are the soap, pepper, and grains of paradise; for the spirituous parts of the ale and essential oil of the wormwood must be completely dissipated by such long boiling. I have nercr had a case of dropsy under my care in which this prepuration appeared a suitable remedy, nor should I be inclined to have recourse to it, as the common cliuretic inass, joined with cascarilla bark, ginger, and gentian-root, would be a more convenient medicine, and, I belicve, equally efficacions. $\Lambda$ s this kind of dropsy commonly happens to lorses that are kept in cold, marshy situations, it no doubt depends principally on checked or suppressed perspiration; therefore, good grooming, moderately warm clothing, excrcise, and cvery means calculated to restore this dis- 
charge, must be the grand object in the treatment, while diuretics are given for the purpose of getting rid of the water already collected. Dropsy of the belly sometimes depends on clrronic disease of the liver, and is then generally incurable. Superficial dropsy often happens in horses independently of internal dropsy, and is then easily cured by mild diuretics, good grooming, and regular exercisc.

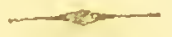

\section{Anticor.}

As inflammatory swelling about the breast, - sometimes extending upwards in the course of the windpipe, and accompanied with difficulty in swallowing, disturbed breathing, quick pulse, and other symptoms of fever. According to Solleysel, it is a dangerous sickness, arising fiom redundancy or inflammation of the blood: it is known, he says, by a swelling of the breast, just opposite to the heart, whence it takes its name (anticaur or avantcour $)$. Before the swelling appears, he informs us, that the horse groans, hangs down his head, and refuses his food; and that if the swelling ascends to the throat, it is present death. M. de Seunicr, another Fench author, says, that "this disorder is mortal to horses if not soon relieved; especinlly in hot countries, where 25 , at least, dic out of 30 that are scized with it: but in Holland it is just the reverse; for out of 30 it is a chance but 2 recover, 
if properly treatcd." It is known, he says, by a swelling under the belly, extending from the sheath or udder quite up between the fore legrs. Gibson describes it as an inflammation of the gullet and throat. From this variety of description, it is probable that the name has been given to different diseascs. Whenever such a swelling appears, let it be treated according to the symptoms with which it is accompanied. If it be hot and tender, it must be fomented; and if there be any symptoms of fever, let the horse be bled; if costive, clysters and the oily laxative are proper; if the bowels are open, give the fever powder or ball; if the swelling be situated upon the windpipe or throat, so as to occasion difficulty in swallowing or breathing, let it be blistered. By proceeding thus cautiously, there will be no difficulty in treating swellings about the chest, of whatever nature they may be found to be, from a careful examination of the symptoms. It should be recollected, that dropsical swellings are free from hoat and tenclerness, and rather colder than the healthy parts of the body; also, that when pressed on with the thumb or finger, an indentation remains for some time after.

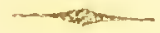

\section{Glanders.}

This disease is contagious, and has, I belicve, hitherto proved incurable. The most essential 
thing to be known with respect to the glanders is the method of preventing its being communicated to sound horses, and the appearances by which it may be with cerlainly distinguished from other diseases. The symptoms are, a discharge from one or both nostrils, and a swelling of the glands under the throat. If one nostril only be affected, it generally happens that the swollen grland is on the same sicle of the throat. Sometimes the disease remains in this state for a considerable time, at others, the discharge increases, becomes of a greenish colour, and very fetid; ulceration takes place within the nose, and the swollon gland becomes harder, and fecis as if closely attached to the jaw-bone.

A cold has sometimes becn mistaken for the glanders, but may very easily be distinguished from it. In colds, there is gencrally a cortain degree of fever, the eyes appear dull or watcry, the appetite is diminished, and there is almost always a congh. If the glands of the throat should swell, they are not so closely attacherl to the jaw-bone as in the glanders, but feel loose and moveable under the skin; they are also generally in a state of active inflammation, fecling hot, and softer than in the glanders. In colds, both nostrils are almost always affected; in the glanders, it frequently happens that the discharge is from one only. In colds, I have never seen the nostrils ulceratcd; in the glanders, it always happens, though at different periods of the disease: sometimes ulceration takes 
place at its commencement, at others, a month or two may elapse before it can be perceived.

The strangles lave been sometimes mistaken for the glanders; but in this disease the inflamed glands very soon suppurate and burst, whereby all the other symptoms are generally removed, whilst in the glanders the glands seldom or never suppurate. In order, however, to avoid all danger, it is adviscable, the moment a horse is perceived to have a discliarge from his nose, to put him into a stable where he can have no communication with otlier horses. If the glands of the throat be enlarged and inflaned, apply a large poultice to them, steam the head three or four tincs a-day, let the horse be well clothed, particularly about the head, and grive the fever powder, No.2, every day, or once in twelve hours. Should the discharge arise from a cold, it will soon be removed by these means. When eonsiderable ulceration is perceived in the nose, with the other concomitant symptoms of the glanders, tlie horse should be destroyed instantly.

'The most effectual mode of purifying stables in which glandered horses have been kept, is to remove, or carefully wash, every thing on which the horse may lave depositcd any matter, and afterward to cover every part of the stable with a coat of lime and size.

'Though all the experiments hitherio made, in order to discover a remedy for this destruetive malady, seen to have proved fruilless, I can by no 
means agree with those who think that the subject is exhausted, and that any farther attempts would be supcrflious: such scntiments may indecd be pardonable in those practitioners of the art who know nothing of the anatomy and physiology of the horse, or the properties of medicinc, and consecucntly can have no principles to conduct them in their crperiments; but sincc the art has bcen placel on a more respectable footing, and the practice so much improved by the attention and albilitics of the present professor, wc may expect that some farther and more successful experinents will be made; and that, ultimately, wc may sec this truly useful animal rescuch from a disease so cuinenty destructivc.

It is prêty well known, thet when the renereal discase first made its appearance in Europe, its ravages werc screrely felt, and thousands fell victims to it; almost every medicine in the Materia Hedicn was tried without effect, and it was genorally cousidered as an incurable disorder. Had the practitioners of mericine been then disconraged by the fuilure of so many cxperiments, and given it up as a hopeless uncertaking, it would lave becu unfortunate iadeed for the votiries of the cyprian goldess; but, by porsevcrance, crery dificulty wis sumomicd, and the antidote at length discovered. Thus, although our attcmpts to cure the glanders have hitherto prored ineffectual, it ought by no means io be relimguished as a fruilles inquiry; ratles, indece, ought it to ope- 
rate as a stimulus on the veterinarian, and prompt him to an exertion of all his talents and ingenuity; since the more difficulty there is in the pursuit. the more honour and profit will there be attached to the discovery. 'There may be miany steps to ascend before we can arrive at this desirable object, nud he who makes any progress towards it, does a service to socicty: wc shall not perhaps sudelenly find out the method of curing the disease, though it, may be accomplished by gradual and successive. discoveries.

From the observations I have bcen able to make on the glanders, it appears generally to originate ill contagion, though sometimes, I belicve, it arises spontaneously, or from the respiration of impure air. A renarkable instance of this happened a few years ago: some hor'ses were embarked for the continent; during the royagc, it bccame necessiry to shut the hatchways, whereby a proper circulation of aic was prevented: in consequence of this, sevcral horses were suffocated, and those that survived were immediately attacked with the glanders. Tlat it arises from contagion is proved by almost daily experience. How important, therefore, mast it be, whencver this dreadful disorder occurs, to bear this circumstance in remembrance, and ro employ means which may effectually prevent its spreading? and how many valuable horses might liave been saved, had the proper precautions becn attended to by grooms, and those who have liad the management of glandered horsess? 
Upon considering the origin, progress, and symptoms of glunders, a striking analogy will appear between it and the venereal disense. When renereal matter is applied to a part where a mucous fluid is sccreted, as in the urethra or urinary passage, or the internal surface of the nose, a peculiar kind of infiammation is produced, and poisonous matter formed, which has the power of producing the disease in others. If glanderous matter be applied to the nose of the horse, an inflanmation and discharge of matter will take place, and this matter will possess the same poisonous quality as that which produced it. When the venereal matter is applied to the skin where the cuticle is very thin, or has been abraded, a chancre ar ulcer will be produced, and the contiguous glands will become inflamed and swollen from an absorption of the poison, which will ultimately get int the circulation, and infect the whole system. When the matter of glanders is applied in a similalr way to a horse, it produces a chancre, or, as it is commonly termed, a farcy ulcer: the neighbouring glands are inflamed and swollen; the poison, after a time, gets into the blood, and the horse becomes completely glandered, having, at the same time, the disease termed farcy. When venereal matter is applied to a sound part of the same subject that produced it, it is said to be perfectly harmless: so it is with the glanderous matter. But here it must be observed, that when glanderons matter is applied to the skin of a horse already la- 
boming under the disense, although it be taken from another horse, a clancre is not produced. Medicines which have a considerable quintity of oxygisen in their composition, and which have so wonk an attraction for that clement, as to part with it readily, are the remedies for the renereal ciscase; and of these the preparations of quicksilver are the most remarkable, though nitrous acid and oxymuriate of potash are said also to be antidotes to the venereal poison. I have seen the discharge, and other symptoms of grlanders, considerably diminished by the use of acids, and lave known it removed for a time by means of mercurial preparations. The farcy has been fiequenly cured by means of mercury; but I believe it has never been known to cure the glanders radically; and I have been informed that it has been very finirly tried.

From the knowledge we possess of the grlanders, we may surely be encotraged to pursue the inquiry, whenever it can be done with salcty; and though our experiments may not lead ns to :my infallible remedy for the diseare, they may teach us a nore certain mode of provention than any wo are now acquainted with, and may possibly enable us cren to cure it in its carliest stages. It lias been said, that inoculation with cow-pock matter will remder a horse insusecptible of glanders: but this, I behere, is at present merely conjecture: the idea is crrtainly plausible, and the experiment ought to bo made. (See Glanders, vol. iii.)

When the above article was written, it was gre- 
nerally understood that glanders was communicated by the application of glanderous matter to the nostrils: that the disease was, in the first instance, local, like the vcnereal gonorrhor, and consistcd in inflammation of the mucous membrane of the nostrils, and a consequent increased sccretion of the mucous fluid, which is constantly flowing from the nostrils, and is the most conspicuous symptom of the discase. Since that time, I have made numcrous experiments on glanders; the result of which may be seen in vol. iii., where the subject is largely treatcd of: it is suficient to remark here, that gianders is not communicated in the above manner; and that whenever therc is a glanderous discharge from the nostril, the disease is always constitutiona!. Sevcral haalthy borses had glanderous matter applied to thcir nostrits, large pieces of lint, soaked in the matter, were put up the nostrils, and liept in contact with the mcmbrane, without producing any cffect: but the smallest quantity of the same matter applied by inoculation, to any part of the body, or to the membrane within the nostrils, produced a chancre or farcy ulcer, which spread rapidly, the lymphatics going from the clanere werc, soon after, swollen, forming what farriers term corded veins; and in several parts of these corded lympliaties, small tumours or farcy burls apycared, which soon suppurated, and burst, aud became ulccrs. "The neighbouring glands, that is to say, those with which the affected lymphatics were connected, became swol- 
Icil; at length, a discharge took place fiom the nostrils, and then the glands under the jaw began to swell-in short, the animal was completely glandered. In all the expcriments that were made, this was the progress of the glanderous matter, whatever part of the skin was inoculated. In one of them, the animal (a yomg donkey) was inoculated on the rump, near the tail, and became glandered just as soon as those that were inoculated in the neck or in the face. The time, however, from the inoculation to the appearmec of a glanderous discharge from the nostrils varied considerably. In young asses there was but little variety; they gencrally were glandercd in about a fortnight: but olc horses, though weak, and fit only for the kennel, resisted it much longer. I do not recollect, however, a single instance of the animal's escaping after being inoculated with glanderous matter, provided it was properly done. It is worth remarking, that in however mild a degree the glanders may exist, the efect of the matter by inoculation is procisely the same as if it were taken from the nose of one labouring vinder the last or most virulcut stage of the disease. Horses were isoculated with matter of strangles, of a common abscess, of a cankered loot, and with that which is discharged from the nostrils in a violent cold, and no cifect was produced. Mitter taken from the heess of a horse that had the grease, produced, by inoculation, a peculiar effect; bat it must be that kind of grease where the matter is of dark colour, and 
very feticl, generally giving much pain to the animal. This effect, however, is very different from that produced by glanclerous mattcr. It first causes a small tumour, which bccomes exceedingly tender and painful; the skin covering the tumour assumes a clark reddish colour which gradually becomes darker, and, in about eight or nine day's, it sloughs off, leaving a red sore, full of healthy granulations, which gets well in a few days, though nothing is applicel to it. As the matter discharged from the nose of a glandered horse is capable of communicating the clisease to other's by inoculation, the contagious nature of the disorder is sufficiently established; but it may be asked, in what manner is it commonly communicated? My experiments have, proved that it is nut by the application of glanderous matter to the nostrils, nor by any invisible vapours which escape from the body of the diseased animal; nor can it be produced by the diseased horse rubbing his nose upon the skin of the sound one; becruse that also has been tried, and it was proved that the disorder could not be communicated in that way. It appears to me that the disense is communicated by the medium of the month or stomach. I have not absolutely proved this to be the case, nol liave I made more than fur experiments with a vicw of determining the point. In the first experiment, it was given to a horse made into a ball with a litile fionr, for three successive days: in a short time, a small tumour appeared in the hock, resembling a furcy, and 
there was a slight appearance of dischargye from the nostrils; but circumstances occurring to prevent me from kceping this horse longer, the experiment was not decisive. In the second experiment, about two or three drams of glanderous matter were given to a young ass claily for a week; soon after, he diecl : but there was no appearance of glanders or farey. In a third experiment, wo doses were given; and in a fourth, one close, without any effect. In some experiments, published by M. St. Bel, the first professor of the Veterinary Collegre, glanderous matter was given, mixed with flour, to three horses for the space of a week: the youngest of them was glandered in a month, and the two others some time after. These facts ad. mit of an useful application. Since innculation with glanderous matter will communicate the discase to a horse or an ass, and no other matter will produce a similar cffect, we are furnished with a criterion for distinguishing the discase from those which resemble it, and by which experienced practitioner's have been deccived. They Jead, also, to an effectual mole of prevention, that is, by remoring or thoroughly cleansing every thing on which glanderous matter may lave been deposited. As to the cure of glanders, we are as inuch in the dark, I bolieve, as cver. There ever liave been, and still are, men who profess to cure this, as woll as every other incurable, disorcicr; but, upon repeating their experiments, or investignting their pretensions, I have always found them fallacious. 
It would be superfinous to dwall longer on this subject, as it has bcen so fully discussed in the last edition (the third) of the third volume.

\section{Farcy.}

THE farcy generally appears in the form of small tumours or buds (as they are commonly termed), fiequently in the course of the vcins, from which they are crroncously supposed to consist in a swelling of those vesscls. These tumours generally burst, discharging a thin watery matter, and degenerating into foul spreading ulcers. The contiguous glands are usually inflamed and swollen from an absorption of the poison. This disease sometimes makes its appearancc in diffused swellings of the hind legs, or other parts of the body. The most common cause of farcy appears to be contagion, cither from a glandered or farcied liorse, for therc can be no doubt that these diseases uill reciprocally produce each allier; whence wc may conclude that they both originate from the operation of the same poison, which produces different effects, according to the parts on which its noxious influence is exerted.

There being certain parts only of the body which are obnoxious to this poison, its cffects arc always partial in some degrec: lhus we find the internal parts of the nose particularly liable to be affected 
by it: the skin likewise is very susceptible of its action; and when the horse is suffered to live a suffieient time for the poison to aequire its lighest degree of virulenee, or to produec its full effect, the lungs do not escape the contagion. The furcy may be either constitutional or local : if glanderous matter, or the matter taken from a farcy ulcer, be applied to the skin where the euticle has becn torn or abraded, a chancre or foul ulcer is produced; which may easily be distinguished from alt others by its peeuliar appearance, the edges becoming thick, and the discharge consisting of a thin and rather glutinous matter. It generally spreads rapidly, and never looks red or healthy. The absorbents or lymphatics about the ulcer become inflamed and swollen from an absorption of its poisonous matter. 'The swcllings produced in this way are commonly mistaken for vcins, and hence has arisen the opinion of the blood-vessels being the seat of the disease: the glands, likewise, to whieh those lymphaties lead, beeome inflamed and enlarged: at length small tumours or buds appear in the coursc of these abscrbents, which are small abscesses arising from the infiammation of these vessels.

Thus far the disease is ecrtainly local, and the eonstitution untainted, the poison being arrested by the glands, and, for a time, prevented from mixing with the blood; at length, howerer, it insinuates itself into the cireulation, and poisons the whole mass. Those parts which are susceptible of" 
its action will then be affected, though at different periods. 'The internal parts of the nose are grenerally the first to be attacked: that delicate membrane by which thcy are lined becomes inflamed and ulcerated, discharging large quantitics of matter. The next part which is affected is gencrally the skin, on various parts of which furcy buds (as they are termed) make their appearance, and degenerate into foul spreading ulcers: at length the bones of the nose become carious or rotten; and finally the poison falls upon the lungs, and very scon puts a period to the sufferings of the unfortunate animal. Sometimes the progress of the disease is extremely rapid, and destroys the horse in a very short time; at others it is remarkably slow, and continues in the same state for a considerable time, without affecting either the appetite or strength.

In the first stage of the farcy, while it is perfectly local, a cure may be easily accomplishcd: and, should the disease be discovered quite at its commencement, topical applications alone will be sufficient to remove it. If, indeed, the actual cautery be freely applied at this time, so as to destroy the whole of the poisoned parts, the discase will be completely eradicaled, and the chancre converted to a common sore. This will soon be evinced by the remarkable change that may be observed in its appearance: as soon as the slough comes off; instead of looking foul, it will have a red heallhy appearance, the matter will become white and thick, the healingr process goes on rapidly, and the 
cure is soon eompleted merely by the application of digestive ointment. Should the disense, however, have been neglected, or not perecived at its commencement; should the lymphaties be enlarged or corded (as it is termed by farriers), and the neighbouring glands swollen, the cure is by no means ecrtain. In this case, some of the poison may have got into the eireulation, though its effcets have not been visible. Even in this stage, however, the chancre may be eompletely eured by the actual eatery, or other strong eaustics; and, if the poison should not have passed the glands, the eure will be radical-but if, on the contrary, the smallest portion of the poison should have insinuated itself into the blood, the whole mass will be poisoned, and the symptoms we have before deseribed will successively take place.

Whenever, therefore, the farey has been negleeted at its first appearance, it will be adviseable to give the fillowing ball onee, twice, or even three times a-clay, if the horse's strength will admit of it, taking eare to restrain its inordinate effect upon the bowels or kidneys by means of opium: at the same time it is necessary to keep up the hor'se's strength by a liberal allowance of corn. Malt has been funnd useful also on these ocensions. During the time the loorse is taking this strong medicine, great attention must be paid to him; he must be warmly elothed, have regular exercise, and never be suffered to drink cold water. Verdigris has been much recommended in this discase, but I lave 
never had an opportminity of seeing its effect. (Sce it hile's Veterinary Maleria Medica, ixc.)

It scems probable that the farcy, as well as the glandeis, arises sometimes spontaneously, though not so frequently as it is supposed. I have seen many cases where the disease could not be traced to any source of infection. Still, however, it might have arisen from contact with poisonous matter; for it is not necessary that the mattor should be conveyed immediately from one horse to another, in order to produce the disease: which is often communicated by means of matter deposited upon the manger, or litter, or about the rack; and not improbably sometimes conveyed by the hands of those who have the management of such horses, through inattention or negiggence.

With respect to that kind of farcy which appears in the form of diffised swellings of the limbs or other parts, I believe it seldom originates from infection, and does not often depend perhaps on the action of the glandcrous poison, being merely common cedematous swellings, such as accompany the grease. From this we may account for the efficacy that has sometimes been attributed to purgatives and diuretics, as remedics for the farcy. It has been said that the grease sometimes degenerites into fircy, and becomes contagions; but this I have never seen.

When large abscesses form in consequence of farcy, thcy do not require any peculiar treatment: but it is particularly necessery to suppoit the 
hoi'sc's strength in these cases by means of corn and malt. It has been sripposed, that the farcy depends altogether upon debility; and medicines of the tonic or strengthening kind lave been recommended for its removal.

Muriate of quicksilver .. from 10 grains to 1 sc. Powdered anise-sceds .... $\frac{1}{x} \mathrm{oz}$.

$$
\text { Syrup enough to form a ball. }
$$

The quantity of muriate of quicksilver may be gradually increased as far as the horse's strengih will allow $\because$ When violent sickness, purging, or excossive staling is produced by it, it will be adviscable cither to discontinue it for two or three days, or to diminish the dose considerably. From half a dram to one diram of opium will sometimes prevent such violeut effects.

I have lately heard of a well-marked case of farcy that was cuiced by sulphate of copper: il may be given citler alone or mixed with muriate of quicksilver, or arsenic, as in the following formulæ.

No. 1.

Sulphate of copper ........... I dr.

Liquorice powder.............. $3 \mathrm{dr}$. Syrup cnough to form the ball. To be given twice a-day.

* Consult the author's Materia Medica, or second volume (ar. ticie Murules), in which the properties of this medicine are more fully explained. 
No. 2.

Sulphate of copper.......... I dr.

Muriate of quicksilver ....... 10 grains.

Liquorice powder ............ $3 \mathrm{dr}$.

Syrup enough to form the ball. To be given twice a-day.

No. 3.

Sulphate of copper .......... 1 dr.

$\left.\begin{array}{c}\text { Arsenic and muriate of quick- } \\ \text { silver, of each ........... }\end{array}\right\} \quad 10$ grains.

Liquorice powder ............ 3 dr.

Syrup enough to form a ball. To be given twice a-day.

The effect of these powerful medicines should be curcfully watched; and, if they are found to cause any pain, or produce purging, or take of the appetite, they shoukd be discontinued a short time. Both arsenic and muriate of quicksilver (corrosive sublimaic) have been given to borses in doses of two drams, and cominued several diays without much effect, cxcept that of increasing the urine considerably; but, in a fiw instunces, they have operated powerful!y, and in one instince fatally, in a much snither dose. In the latter case, the grroom continued to wive the medicines (arsenic and sublimate) after the horse was off his appetite, and had a purging, supposing these wore symp- 
toms of the disease, and not the effect of the medicinc.

\section{Epilepsy, Megrims, Vertigo, Fits, \&c.}

Horses are sometimes attacked with fits some. what similar to the epilepsy or falling sickness of the human subject, in which they reel for a short time, and fall down, or suddenly rear up, and fall down. The muscles of the eye ale often affected, so that the eye is fixed and shockingly distorted during the fit. Sometimes he lies motionless; at other's, he struggles considerably. The duration of the fit is sometimes short, at others, it lasts for an hour or two. 13lced, and give the following drench:-Fœtid spirit of ammon. and compound spirit of lavender, of each $\frac{1}{2}$ oz. Water half a pint, or a little more.-When the hor'se is perfectly recovered, a purgative should be given, as the fit may have been caused by worms or some offensive matter in the stomach or bowels. Horses arc sometimes attacked during their work with giddliness or vertigo, which is, perhaps, a similar disease, but in a less degree. 'This in general soon passes off, if the horse is suffered to stand still.

N.B. Bleeding in the tail has becn practised with good effect, when a horse has fallen down, and is motionless, by $\mathrm{Mr}$. Poolc, a respectable farrier. In this operation a considerable artery is opened. 
Catalepsy.

I po not think this disease has been noticed by any English veterinary author: probably none of them had seen it; and as $I$ have never met with such a discase, I can only give a translation of La Fosse's description. "It is astonishing," he says, " that no veterinary author has made mention of catalepsy (immobilité); a disease known to every horse-dealer and farrier, and placed even among those defects which constitute unsonndness (de's cas redhilitoires). When a horse is attacked, he becomes incapable of going forward, or if he is made to move, it is with difhculty. He remains exactly in the position he happened to be at the time of attack; and if his head is lifted up, it remains in that position. This immobility, therefore, resembles the disease which physicians name catalepsy. It may be brought on by sudden fright, the effect of which may even be fatal, as I once witnessed. It may happen also in consequence of some lingering disorder. Hor'ses that have had locked jaw are more liable to it than others: I lave remarked also that ill-formed horses are subject to it; and I have secn horses that had been cured of a strain in the back (tour de baleau) become cataleptic; but in this state they have been able to eat, though very slowly, and they perish insensibly. All my attempts to cure this malady have been fruitless. I have passed setons, given medicines of 
the stimulating, sudorific, and purgative kind, as well as the hot mineral waters, without cffect."-Dictionnaire rnisonné D'Hippiatrique, par M. La Fosse.

I recollect an instance of a young healthy horse dropping down, and dying immediatcly, while the troop in which he was standing fired a feu de joie.

\section{Locked Saw.}

'THis diseasc, very fortmately, occurs but seldom, as it generally terminates fatally. It begins with a difliculty in mastication; at length, the jaws become so completely and immoveably closed, that neither medicines nor food can be got into the stomach. 'The muscles of the neck are gencrally in a state of rigid contraction, and the animal appears to suffer great pain. The cars are crect, and the nose poked out, and the animal is incapable of altering its position. He gencrally neighs when a person enters the stable, in the carly stage of the disease. At length the muscles of the sides and chest are affected, by which breathing is impeded; perhaps the diaphragm participates in the affection, or even the lieart; when of course the animal dies. It is often brought on by trifling causes, such as wounds of the foot, inflammation of the tail, from docking or nicking, \&c.; and sometimes it attacks without any apparent cause. Various remedies 
have been tried in this complaint, but $I$ do not think any effectual mode of treatment has yet been discovered. Immersion in cold water, or even snow, is said to produce a temporary relaxation of those muscles by which the jaws are closed. Opium and eamphor have been strongly recommended. I have lately been informed of a case in which a combination of these medicines completely succeeded. In Ameriea and the West India islands, where the disease is much more frequent than it is in this climate, it is said that strong stimulants have been found effectual in the human subject; it would be adviseable, therefore, to try the same plan on horses, should opium and camphor fail. The best stimulants for this purpose are spirit of hartshorn, ether, opium, and brandy. I have been informed that a blister, applied to the spine or back, throughout its whole length, from the withers to the basis of the tail, has proved suceessful in several eases. I have had only one opportunity of trying it, in whieh it did no good; but the discase had existed for some time, and had become very violent before any remedy was employed. (See Appendix.)

Since the above was written, I have kept several men employed, for some time, in throwing cold water upon a horse with locked jaw, but it produced no effeet. He was then plaesd in hot dung, and no relaxation of the museles took place. Upon a review of every thing that has eome to my knowledge respecting the treatment of this formidable 
disorder, it appears to me that opium and camphor are the best internal remedies: should these fail, I would again try the effusion of the coldest water. Blistering the back, as directed in the Appendix, should not be omitted.

\section{Inflammation of the Eye.*}

When the eye is inflamed, it loses in part its beautiful transpareney, sometimes appearing as if covered with a film; the lirls are partially closed, the haws become more visible, and there is com monly a discharge of tears, or the eye appears watery. Should the inflammation have been brought on by some external injury, and particularly if it be 'not very eonsiderable, the eye-lotion will be sufficient to remove it; but in more violent cases it will be neeessary also to bleed moderately, and give a laxative ball. By these means, inflarmmation arising from external injury may generally be cured in a sliort time. The eyes often bceome inflamed in consequenee of eold and fevers, in which cases the cause is to be chiefly attended to: when this is removed, the inflammation usually eeases.

The most common eanse of this eomplaint is high feeding, without a due proportion of exercise. These cases require great care and attention; for

- Sce Appendix, Diseases of the Eyes. 
unless proper remedies are employed on the first attaek, the disease, though it appenrs to go off, will be frequently returning, and in all probability eventually preduee blindness. The first remedy to be employed on this oeeasion is bleclingr; and the quantity of blood that is drawn should be proportionate to the violenee of the inflammation, and the condition of the animal. Shonld the vessels on the white part of the cye and inner part of the eyelids appear to be distended with blood, great advantage will be rlerived from searifying the latter with a lancet. A laxative ball is to be given, and the bowels afterward kept in a lax state by means of bran mashes. I liave found a seton, placed immediately under the eye, a very useful remedy; but unless the operation is nicely performed, it frequently leaves an unpleasant mark behind, which would lead a person experienced in horses to suspect that the eye had been discased, and might therefore diminish the value of the horse.

A shade, so adapted as to preserve the eye from the irritation of dust and liglit, will be found useful. This kind of infammation generally eones on rather suddenly, sonetimes attacking only one cye, at others both arc affceted. As there is no apparent cause for this sudden attack of inflammation, the groom very eommonly attributes it to seeds or dust lonving fallen from the rack into the eye, and very little attention is paid to it. Notwithstanding this neglcet, the disease frequently goes off, and in some cases its disappearanee is 
ncarly as sudden as its attack: in a short time, however, it again appears as unexpectedly as at first, and again perhaps goes off: In this fluctuating state, it may continue a cousiclerable time, the cyes sometimes appearing transparent, and free from inflammation; at other's, watery, inflamed, and opaque on the surface: at length the interual parts of the cye are affected, and a cataract produced.

It has been supposed that the discases of a hol'se's cye are firequently hereditary, or dependent on some natural defect in the structure. I do not know llow far this opinion may be true, but, nevel having secn a case which seemed to corroborate it, I am not inclined to give it much eredit. It is not very improbable, however, that the eycs of some horses may be naturally weak, and morc liable to become inflamed when exposed to the exciting causes of inflammation, than such as are originally endued with a proper degree of strength: but it appears to me, that where this weakness or aptitude to discasc, exists, it is more fiequently the effect of some injury, which this tender and delicate organ has sustained, than a defect ol nature. Whon the eyc becomes inflamed, it is necessary to inquiro into the cause of the inflammation: if it arise from

* Since this opinion was written, many cases bave occurred which convince me that the common opinion in this respect is true: colts got by stallions that have becouc hlind from opthatmia, or, as it is often tcrned, moon-blindncss, ale certainly more liable to the discase than otlicrs. 
any mechanieal injury, and be not very considerable, there is a probability of its being speedily removed, by means of the remedies I have pointed out; but if the inflammation have arisen without any apparent cause, lepending perhaps upon plethora, or redundancy of blood in the system, there will be some chanee of a radieal eure, provided the proper remedies are employed sufficiently carly. If these be neglected at the commenecment of the disease, though the inflammation after some timc appears to go off, and the eye, to a superficial observer, seems to have reeovered, yet the clisease fiequently returns, and ultimately occasions blindness. Should the disease have oeeurred before, and partieularly if the former attack were violent, there is still less chanee of its being removed, and all our remedies will probably prove ineffeetual. In this case the alterative No. 3, (see Index) may be tried. It frequently happens that when both eyes are inflamed, and a complete cataraet forms in one them, the other beeomes perfectly sound and strong. It must be observed, that when $\Omega$ horse has suffered more than once from this disease, and is in low condition, evacuations must not be made too freely: there are fow eascs, however, where moderate bleeding and a laxative ball are not required. With respect to topical applications, or those remedies which are applied immediately to the eye, I must confess that I have not seen much benefit derived from them, except when the inflammation has completely sub- 
sided, and there remains an opacity or film on the surface; and then eommon salt, fincly powdered, has often proved useful. But if the cye have been in this state for some time, and the opaeity is very eonsiderable, white glass, finely'powdered and mixed with honey, is a more effectual remedy. Whencver the eyes are weak, or in a state of inflammation, the vapours which arise from foul litter should be carefully guarded against; indeed, it is by $n o$ means an improbable conjecture, that, when the eyes are weak, these irritating vapours may often prove the exciting eause of inflammation.

There is a cartilaginous body connected with the ey'cs of horses eommonly termed the haw. Whenever the eye is drawn into the socket (which the horse lias the power of doing by means of a muscle that does not exist in the human subject), the haw is forecl over the eye, so that when dust happens to albere to the surfaee of the eye, he is enabled, by means of this eartilage, to wipe it off; and, as light is painful to the animal when the eye is in a state of inflammation, we gencrally find this organ, on sueh oceasions, drawn more than usual into the socket, and consequently the haw beeomes conspicuous on its surfice. Farriers in this case consider the haw as an umatural cxerescenec, and the eause of the discase : they frequently, therefore, eut it off: 


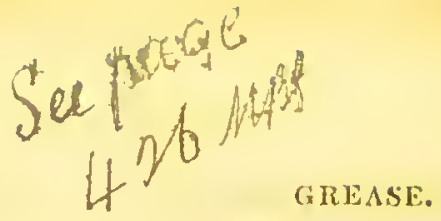

\section{Grease.}

Trrs disease consists in an inflammation, swelling, and consequent discharge from the heck, the matter having a peculiar, offensive smell, and the hecls being sometimes in a state of ulccration; the swelling fiequently extends above the fetlock joint, sometimes as high as the knee or hock. When the inflammation and swelling are considerable, apply a large poultice to the hecls (sec Poul(ice), taking care to keep it constantly moist by adding to it uccasionally a little war'm water; at the same time let a dose of physic be given. After three or four days, the inflammation and swellings will lave abated considerably, the poultice may then be discontinued, and the astringent lotion applied five or six times a-driy. Should the heels be ulecrated, apply the astringent ointment to the ulcers; and if they be decp, and do not heal readily, wash them with the detergent lotion previous to each dressing. Regular exercise is of the highest importance, but it is necessary to choose a clean and dry situation for the purpose.

In slight cases of grease, the astringent lotion and a few diuretic balls will generally be found snfficient to effect a cure; but when the discase is of long standing, and particularly if the horse hare. suffered from it before, there will be more difficulty in its removal. In such cases, the following alterative poswder may be given in the curts every diy, 
until it produces a considerable dimetic effect: in vely obstinate cascs, rowels in the thigh have becn found usefinl.

'Thongh the grease is most commonly occasioned cither by high fecling and want of excreise, or by neglect in the groom, there are eases which secm to depend on grencral debility. I do not belicre that this is crec the exciting cause of the discase, but am convinced that a horsc is rendered morc susccptible of it by bẹing in a state of weakucss, and that the complaint sometimes owes, its continuance to this carsc. When a horse has suffered much from this disease, and particularly if lic appear to be weak and out of condition, a liberal allowance of corn will tend to recover him, if assisted by the astringent lotion and carcful grooming. In cases of this kind cxercisc is csscntially necessary. It must be obvious, that when this disease depends upon debility, a dose of physic would not bc an eligible r'cuncly, yct considerablc bencfit has sometimes becu obtained by giving the following altcrative every morning until the bowels are moderately opened.

\section{Allerative Ball.**}

Barbadoes aloes $\ldots . . \ldots \ldots \ldots \ldots \ldots \ldots$ oz.

Castilc soap ................ I I $I_{\frac{1}{2}}$ oz.

Powclered ginger .............. oz. Syrup cnough to form a mass. To be divided into six balls.

* The allorative ball might perhaps is mure properly naned a lasative, end the powder a dinretic, If the tromble of giving 
This medicine, though of an opening quality, will inprove the horse's strength, and at the same time promote absorption.

\section{Allerative Powder.}

\section{Powdered resin and nitre, of eacl $\ldots .4 \%$ oz.}

Mix, and divide into eight doses.

Nothing tends so much to prevent grease and swelling of the legs, as frequent hand-rubbing, and cleaning the heels carefully, as soon as a horse comes in from exercise. In inveterate cases of grease, where the clisease appears to have become habitual in some degree, a run at grass is the only remedy. If a dry paddock can be procured, where a horse can be sheltered in bad weather, and fed with hay and corn, it will be found extremely convenient, as in such circumstances he may perform his usual labour, and at the same time be kept free from the complaint. In a few obstinate cases I have seen the mercurial alterative of service, giving one ball every morning until the bowels are opened.

a ball every morning be objecled to, and sometimes it may be very ineonrenient, a suflicient dose, such as the following, may be given at onee.

Barbadoes alocs $\ldots \ldots \ldots \ldots \ldots \ldots \ldots \ldots \ldots, \frac{1}{3}$ oz.

Ginger ........................ $2 \mathrm{~d} r$.

Dil of caraways ................... 20 drops.

Soap ......................... $3 \mathrm{dr}$.

Syrup enough to form the ball, For one dose. 
Astringent Lotion.

No. 1.

Alum, powdered .......... 1 oz. Vitriolic acid $\ldots . \ldots \ldots \ldots \ldots . .1 \mathrm{dr}$. Water ................ I pint.

Mix.

No. 2.

Alum, powdered .......... \& oz. Vitriolated copper $\ldots \ldots \ldots \ldots \ldots$. $\frac{1}{2}$ oz. Water .................. $1 \frac{1}{2}$ pint.

Mix.

No. 3.

Sugar of lead $\ldots \ldots \ldots \ldots \ldots \ldots$ \& oz.

Vincgar ..............6 oz.

Water .............. $1 \frac{1}{2}$ pint.

Mix.

The strength of these lotions often requires to be altered. Where the inflammation and irritability of the part are considerable, they must be diluted with an equal quantity of water; but if the inflammation be subdued, and a swelling and ulceration remain, the alum solution camot be made too strollg.

In inveterate cases of grease, where the discliarge is thin, of a clark colour, and very fetid, the hair sticking out or furzy, as it is termed, and the part 
very painful, I have found a strong solntion of sublimate (muriate of quicksilver) effect a curc, after poultices and otlier cmollient applications had proved ineffectual.

\section{Strong Solution of Sullimate.}

Corrosive sublimate ......... $2 \mathrm{dr}$. Muriatic acid $\ldots \ldots \ldots \ldots \ldots 6 \mathrm{~d} r$. - Watce ................ 1 pint. Mix.

Troublesome crucks or ulecrs sometimes talke place in the hecls, which cause much pain, and sometimes lameness; these should at first be poulticed, and afterwards dressed with astringent ointment. I have observed that these crackis are longer in healing: when the loorse is much exereised, and have found it the best plan to turn him loose into a box or shed, and give him no other cxercise.

\section{Astringent Ointment.}

No. 1.

Hog's lard .............. 4. oz.

Oil of turpentine ........... 2 dr.

Watcr of acetated litharge ..... $\frac{1}{2} \mathrm{oz}$.

Mix.

No. 2.

Venice turpentine ......... 1 oz.

Hogg lard ., ............. 4 oz. 
Alum, finely powdered ........ $1 \mathrm{oz}$. Mix.

No. 3.

Fincly powdered alum ........ 1 oz. Treacle ............... 4 oz.

Mix.

No. 4.

Superacetate of lead ......... $1 \frac{1}{8} \mathrm{oz}$. Sulphate of copper ......... $1 \mathrm{oz}$. Honey ................ $88 \mathrm{oz}$

Mix.

Mercurial Alloralive.

Galomel................

Alocs ................... 1 dr.

Castile soap $\ldots \ldots \ldots \ldots \ldots \ldots .2$ dr.

Oil of juniper ............ 30 drops.

To be made into a ball with syrup. For one dose. Aslringent Pouder.

No. 1.

Powdered alum $\ldots \ldots \ldots \ldots .4$. oz. Bole ................. l oz.

Mix.

No. 2.

Vitriolated zinc, powdered bole, of each

$20 \pi$.

Mixs 

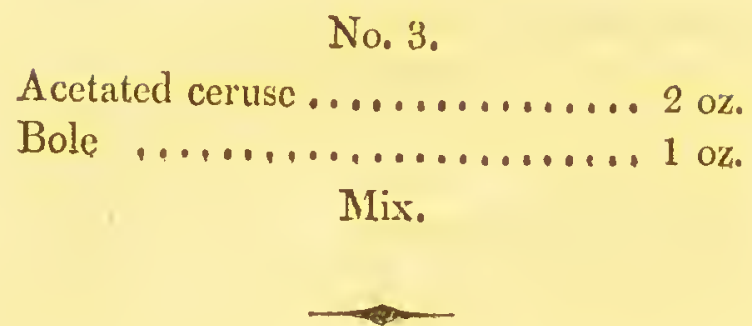

Malanders and Salanders.

Wrres a scurfy eruption appears on the posterior part of the knee-joint, it is termed malanders; and when the same kind of disease happens on the anterior of the hock-joint, it is named salanders. Should these complaints oceasion lameness, it will be proper to give in the first place a dose of physic, or some proper diuretie medicine. Let the hair be carefully clipped off from the diseased part; and let all the scurf be washed off with soap and warn water: a eure may then be soon effected by applying the following ointment twice a-day:- -

\section{The Ointment.}

No. 1.

Ointment of wax or spermaccti .. 2 oz. Olive oil $\ldots \ldots \ldots \ldots \ldots \ldots 1$ oz. Camphor and oil of rosemary, of $\} 1 \mathrm{dr}$. Water of acetated litharge,$\ldots \ldots .2 \underset{5}{2}$ dr. Mix. 
No. 2.

Ointment of nitrated quicksilver, olive oil, of erch $\ldots \ldots \ldots \ldots\} 1 \mathrm{oz}$.

No. 3.

Red precipitate, finely powdered ...2 $2 \mathrm{~d}$. Hog's lard . . . . . . . . . . . . 1 oz.

To be well rubbed together.

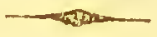

Wounds.

In the former editions of this work this subject was treated of rather concisely: farther experience has, however, convinced me, that the common method of treating wounds is so directly in opposition to reason and nature, as to render a detailed account of the proper mode of treatment indispensable.

Wounds of the human body, when inflicted with a kees instrument, are often cured, merely by bringing the divided parts into contact, and keeping them in that situation by means of suture (stitches), or sticking-plaster and bandage. In a few days nature completely reunites the parts without any inflammation or suppuration having appeared. This surgeons call zmion by the, first intention, and is so desirable a method of healing wounds, that it is generally attempted, even under circumstances which render its accomplishment 
doubtful. In the wounds of horses, this kind of union can scareely ever be effected, from the difficulty of kecping the wounded part in at state of rest, and from the laceration and contusion with which their wounds are generally accompanicd.

To render the subject more clear, we shall divide wounds into the following classes :-

1. Simple incised wounds.

2. Lacerated and contused wounds.

3. Punctured wounds.

4. Wounds of cavities.

\section{Simple incised Wounds}

ARE tlose inflicted with a keen instrument, by which the skin or other parts are neatly divided, without being forn or bruised.

This kind of wound, however, seldom happens to horses: when they do oecur, though there is little probability of effecting a union by the first intention, it shonld always be attempted; and if the divided parts cannot be kept together by stiekingplaster and bandage alone, the lips of the wound should be neatly sewed, so as to be held firmly in contact with each other, with waxed thread several times doubled; and if the situation of the wound will adnit of it, a bandage or roller should be afterward applied to assist in the aceomplishment of this end, and render the stitches less painful. But 
how diffcrent from this is the praetice of farriers: igrnorant of the animal ceonomy, and the wonderful power with whieh the Almighty has endued the animal system, of rceovering itself when injured, and of reprodueing flesh that has been destroyed, they offeiously prevent this desirable union by putting tents (that is, lint or tow moistened with some stimulating liquid) between the lips of the wound, by which they are effeetually lindered from eohering, however naturally disposed to unite. But this is not the only cril of the prietiee; in extensive wounds the injured parts are so irritated by exposure, and their applications, that mortifieation is sometimes the consequenee. Far better than this would it be, to leave the wound to nature, merely kceping it clean, and, when the first inflammation has subsided and white matter appears, bringing the separated parts as near to each other as possible, and retaining them in that situation by means of a bandage. By this method the wound wonkl heal mueh more speedily, and the consequent blemish or sear would be considerably lessened. It is unnceessary to say more of the simple ineised wound, for sliould the attempt to heal it by the first intention fail, it becomes necessary to assist nature, as in lacerated wounds: still, during the wholc eure of a simple wound, it is proper to kecp the divided parts together as well ns we can, which will be found more useful than any balsanie vulnerary or heal- 
iny application, that the most expert farrier's reccipt-book can furnish.

\section{Laceraled and Contused Wounds.}

THE wounds of horses are most commonly inflicted with some blunt instrument, and consequently the parts are rather torn asunder than simply and neatly divided: at the same time, the instrument is generally applicd with such force, that the skin, flesh, \&c., are considerably bruised; for example, when a horse falls upon his knces, is kicked or bit by another horse, in attempting to leap gets his hind or fore leg entangled in a gate, and in other such accidents. In these cases, the laceration and contusion are so considerable, that the kind of union before mentioned is totally impracticable: it is, notwithstanding, adviseable to lieep the divided parts together as well as we can, taking care to allow the mattcr which forms to escape frecly, and avoiding the violent stimulating applications commonly used by farrier's on sucl occasions, which, to say the best of them, always increase the inflammation and danger, and obstruct the cure. I have seen a horse die in the greatest agonies, from a wound received in entangling the hind leg in a gate, by which not only the skin and flesh werc excessively torn and bruised, but the stifle joint was also much injured. In this case, 
the fatal event and the excessive pain were undoubtedly accelerated and heightened, if not altogether occasioned, by the caustic applications of the farrier employed.

In the treatment of extensive lacerated wounds, the first object is to remove any dirt, splinters, or other extraneous matter, that may be in the wound; if a flap of skin hang down, if flesh be nearly torn off, they should be carefully replaced, and never cut off, however unseemly they may appear to the farrier, unless so much bruised as to be irrecoverable. When the parts are so divided as to require considerable pressure to bring them together again, it is improper to sew the wound up, as the tendency of the parts to recede from each other. would constantly keep the stitches upon the stretch, and so irritate the wound as to bring on excessive inflammation, and perhaps ultimately gangrene or mortification. The only thing to be kept in view in these extensive wounds is, to employ the most effectual means for kecping the inflammation within bounds, until suppuration takes place, which is indicated by the appearance of white matter, and the subsirlence of the inflammatory swelling, and abatement of pain and fever. On many occasions, the parts may be brought carefully together, as near ns can be without employing considerable force, and may be supported in that situation by a proper bandage. Whenever stitches are employed in such wounds, and drawn tight, they give excessive pain to the animal, and bring on a dangerous 
degree of inflammation: the violent pain often eanses symptomatie fever, and, after all, the intention of employing them is not answered, as they always separate in two or three days, and leave the wound as open as at first, presenting a mueh more formidable appearance from the mischief caused by the increased inflammation, and the retention of putrid matter. After eleaning a lacerated wound with warm water, which, when its situation and depthr render it neeessary, should be injeeted with a syringe, the divided skin, flesh, \&c., should be earefully brought together, and secured as we have directed above. *

* The common praclice of furriers in these cases is, to apply frecly some stimulating spiritnous preparation, sucla as spirit of wine and eamplor, Friar"s balsam (which is a solution of eertain resins and balsauns in spirit of wiue), brandy, and many other things equally injurious : sume of them nze eve!t a mixture of oil of turpentine and acid of vitriol; and then, as if they were detcrmined to do all the injury in their power, the wound is plugged up $\mathrm{nith}$ a quantity of tow, moistened with the same stimnlating preparation with which the wound wats washed or syringed. A few days ago, I was desired to attend a loorse that had met with a deep and extensive wound by entangling, it was supposed, his fore leg in a gate, while at grass: the farrier laad been there before me; and observing a syringe in his hand, I inquired what liquidl he had employed, and was told, "Brilldy." Upon expressing my fear that so stimulating an application would do mischicf, the farrier immediatrly replied, "There is no danger of that, for $I$ put a little oil with it ; and you know the one is hot, and the other cold." I could not but smile at the ingenuity of the explanation, but requested that nothing of the sort might be again employed.

The popular prejudice in favour of those spirituous or hat. 
If the horse be in good condition, and have not lost much blood from the wound, he should be

samic preparations, as they are termed, in all kinds of wounds, has been the cause of much mischief in veterinary, perhaps not much less in buman, surgery. The credit they have aequired is owing to the wonderful proplerty, with which the animal body is endued, of unitiug parts that lave be'n divided, inerely by keeping them in contact with each other. Many astonishing instances of this have been related by writers on surgery; and it las been proved, that if even a tooth reeently drawn be replaced in its sncket, it will soon beeome as firm as the rest. The spur of a erek, just eut off, being stuck into the counb, will sonu adhere, and grow as it did upon the leg. A respectable anthor relates the ease of a unu who alecidently stepped nu a kecu instrument, and bcarly divided lis font; all the bones, tcudons, \&e., were dividel, (xeept the bntre going to the little toe; he bled profusely, and fainted, by which the hamorrhige was stopped. A surgeon then brought the divided parts together, and seeured then with splints and handige. 'f́lıe mán was thoroughly cured ill a short time, and the font breame als perfect as the other. Surgenns are now so convineed of the power of nature to heal simple and ineised wound, when the divided parts are kept in contace with each other, without the issistance of any spirit, balcam, or salve, which they know rather impedes tlan expedites the cure, that a practitiuner would be langhed at, were he to adopt so absurd a practice: it appears, indcod, thit balsams were first used on aeconut of their glutinons quality, in order to keep the parts more completely in contatet with the same virw, white of egg, gun-water, and other things of the same nature, were emploged. It is to be lanented that the public are still so prejudiced in favour of stimulating preparations, sucl as Friar's balsum, tiucture of inyrrli and aloes, and, above all, the famous liga halsam, which is preferable finu being less stimulating, that a veterinary surgcon eilu hardly vesture to trust uature a little in the tratment of wounds, withnut being accused of negligence. It may be depended upon, hnwever, that in every case of simple incised wounds, where these preparations 
bled rather freely: in other circumstances it will be proper to omit that operation, or take only a small quantity. A purging draught or ball shoukd be given as early as possible, and the horse's diet confined to hay and mashes, or bran: he may be allowed to drink freely and frequently, and must be kept perfectly at rest.

The wound should be cleansed once or twice aday, as may be found necessary, with water at blood heat; which, when the wound is deep, may be done more effectially by means of a syringe. The only external application nccessary at this period is a fomentation. (See Fomentation.) When this plan is adopted, the inflammation, swelling, and fever, which always follow an extensive lacerated wound, will be much more moderate than it would otherwise have been, and in a few clays will have subsicled considerably; a white matter will then flow from the wound, and the horse will not appear to suffer much pain. When this has been accomplished, it is necessary to enclenvour as much as possible to bring the divided parts together, and there will be less danger and pain from drawing the bandage with more force for this purposc.

have been thought to effect a cure, they have not in the least contributed to it: nature has been the restorer, in spite of the obstacles opposed to lier efforts. Wounds that have degenerated juto ulcers, either from had management, or from the parts laving been lacerated or brused, often require the application of stimulants; but cren in such wounls they are not to be employed, until the inllammatim, which necessarily followe the injury, lins subsided. 
Warm water may still be used for eleansing the wound; but when the inflammation is quite gone off, some stimulating liquids may be employed, but these are unneeessary when the divided parts ean be brought into conteet. When this cannot be effeeted, or when there is a loss of substance, the wound eannot heal without the formation of new parts, and stimulants are often required to aceelerate this process. At first, the weaker preparations are to be used, sueh as dilute spirit, or a weak solution of blue vitriol: but when the healing proeess goes on slowly, the matter beeoming thin, and losing its white enlour, the stronger stimulants, as tineture of benzoin, or even oil of turpentine, may be applied, and the eonstitution invigorated by a nutritions diet, sueh as malt and oats, or carrots; and when the diseharge is very eonsiderable, and appears to weaken the animal, this is more partieularly neeessary, and must be assisted by medieines of the tonic kind, such as Peruvian bark, cascarilla, vitriolated iron, and sometimes porter or beer, and even opium; it is only in very deep and extensive wounds, however, where there is a profuse discharge, and conn stitutional weakness, that this treatment is required.

When wounds of this lind terminate fatally, it is gencrally from the violenee of the infammation and symptomatic fever eausing gangrene, delirium, and total cxhaustion. Our first and principal obs, ject, therefore, should be to restrain this inordinate
inflammation by every means in our power; but 
farriers, ever in opposition to nature, gencrally destroy their patients in these cases; torturing the unfortunate animal by the application of violent stimulants, and cven caustics; cramming into the wounds hard tents, and persuading their employcrs that this cruel and absurd treatment will infallibly heal the wound. When we have succeeded in thesc extensive laccrated wounds so far as to bring on a healthy suppuration, a discharge of white matter and an appearance of new flesh , sprouting up in various parts, in small granulations of a red colomr, wc may be satisfied that the danger is over.

At this period we may safely use more force in bringing the divided parts together; and if the wound appear languid, wanting tlat red appealance we liave just described, and discharging thin mattcr, some of the stimulants we have mentioned may be cmployed: still it is improper to cram tents into the wound, or daub them over with stinking ointments. If the red granulations form so luxuriantly as to rise above the level of the skin, they must be kept down by red precipitate, burnt alum, or other applications of this kind; pressurc will also be effectual on this occasion, laying a picce of soft lint on the part, and confining it with a roller. Should the sides or edges of the wound become callous, caustics must be applied to remove the old surface, and then fresh attcmpts should be made to bring then into contact. When the matter lias penetrated from having becn confined, so as to form sinuses, fistula, or pipes, as they are 
commonly termed (that is narrow, deep ulcers r'unning in various directions), their sides, if possible, should be brought into contact by means of pressul'c. If such sinuses have existed for some time, the sides will have become callous, and incapable of uniting; it is then necessary to apply caustic, either by injecting some liquid caustic, such as strong solution of blue vitriol, dilute nitrous acid, Sc., with a syringe, or by dipping lint in the same, and passing with a probe to the bottom of every sinus. (See Fistula, Poll Evil, and Quitlor.) This is the only occasion on which tents are proper. If it be impossible to bring the sides of the sinus into contact, it can only be cured by the formation of new flesh, to promote which, it is necessary to inject daily some stimulating liquid, sucl as spirit of winc, tincture of bcnzoin, \&c.; keeping the orifice open, lest it heal before the deeper part. Even these, lowever, will be found incfectual, if the sides of the sinuses be callous; and then should be preceded by the caustic, as above described (see Ulcers, Fistula, Poll Evil, and Quittor), which sometimes requires to be repented. I thought it necessary to bcthus minute in describing the treatment of lacerated wounds, as it is a subject of great importance, and generally little understood. Under this head it is proper to treat also of gun-shot wornds, in which the ball enter's with such force, and the parts are so much bruised, that their vitality is destroyed; therefore nothing can prevent their separation, on sloughing, as it is termed. This ge- 
nerally takes place a few clays after the accident, and until that period it would be highly improper to use any kind of pressure, or attempt to bring the sides of the wound into contact. The first thing to be done in these wounds is to cxtract the ball, should it have lodged; but we must not employ any violent means to cffect this, as it is more easily cone after the dead parts have scparated and a healthy suppuration has taken place. Sometimes the ball penetrates so far as to be felt near the opposite side of the part, where an incision should then be made in order to extract it. Whencver matter ponds $1 p$, or is confined in any lind of wound, it is proper to make such an opening as will allow it to escape freely: setons are sometimes employed for this purpose. (Sce Wounds of $\mathrm{Ca}$ vilies and Punclured Wounds). In gun-shot wounds it is improper to bleed, as hemorrhage often happens when the dead parts scparate: in other respects they are to be treated as we have above described. Indced, their treatment must depend greatly on the importance and situation of the wounded part, as the ball may penetrate a joint, or the cavity of the chest or belly. (See Hounds of Cavities.) 


\section{Punctured Wounds.}

Tus kind of "ound also often occurs in veterinary practice. 'The fect are particularly liable to it, and not unfrequently they are inflicted through the earelessness or impatience of the groom. During the time of my service in the army, I may truly assert, that more than fifty eases oceurred, in which the wound was inflicted by the fork used about the litter, either by accident or by the savage violence of the groom. It is but just, however, to acknowledge, that a good soldier will sacrifice even his own repose to that of his horse, and thinks nothing a labour that can contribute to the health and comfort of his faithful companion; but among so great a number of men, there are too often some of a different description. Punctured wounds of the feet are most frequent, and are caused either by the horse stepping on a nail, or picking up a nail, as it is termed, or by carelessness of the farrier in shoeing. In the former ease the nail generally enters the frog, and often penetrates the joint of the coffin-bone. (See Anatomy of the Foot.) The sole is generally sufficiently hard to resist the nail; but the frog is commonly of at softer and more spongy nature. When the coffinjoint is wounded, there is langer of an incurable lameness fiom the joint beoming stiff; but by proper management the woind is often elosed in a short time, and the free motion of the bones pre- 
served. (Sce Wounds of Joints, under the head Wounds of Cavilies.). Whenever the foot is wounded by a nail, it is necessary immediately to open the orifice in the horny matter by means of a drawing knife : if the joint be wounded, synovia or joint oil will issue from the wound, but in very small quantity. An experienced person can casily ascertain this point still morc certainly by tracing the wound with a probe. The treatment of this kind of wound will be deseribed in the chapter on Wounds of Cavilies; but when the joint has escaped the injury, after enlarging the opening made by the nail in the horny matter, and cutting away the horn from the contiguous parts, until it becomes very thin, a little tincture of benzoin is to be poured into the wound; the stimulus of which, so far from being injurious, as in lacerated wounds, will soon bring on a secretion of healthy matter; a little tow or lint, dipped in tar or Venice turpentine, is then to be applicd, and the whole foot kept cool by means of a bran poultice. The mest essential part of the treatment is opening wcll the orifice in the horny matter: for in wounds of this kind we always find, that, soon after the nail has been withdrawn, the puncture in the horn nearly closes; but the living parts that have been wounded underneath the horn soon inflame and swcll; consequently, they suffer considerable pressure, as the hom is too thick and inflexible to give room to them as they swell. $\Lambda$ t length matter forms, which, being confined by the horny covering, dif- 
fuses itself between the sensible and insensible parts, sometimes so extensively, as to render it necessary to remove great part, or even the whole, of the latter. This operation, so often cruclly and unnecessarily performed by farriers, is termed drawing the sole. In the ease described, where the parts are separated by the matter, the operation is performed with but little pain to the animal. But those officious practitioners too often tear it off when perfectly healthy, aud with a vicw to remove a lameness, of the cause and seat of which they are totally ignorant. Often have I bcen desired by the owner of a lame horse to draw the sole, under an idea that it was an infallible remedy for an obstinate lameness, or for a desperate wound of the coffin-joint.

When it has been found necessary to remove some part of the horny sole, in consequence of matter having formed under it, a pledget of tow dipped in digestive ointment, or a misture of $\mathrm{Ve}$ nice turpentine and hog's lard, should be applied. Sometimes we find the coflin-bone diseased, in which case the injured part gencrally scparates, and then a new horny sole is gradirally formed. When a horse's hoof is wounded by the farrier in shocing, he is said to be pricked: the nail, instead of being driven into the horny insensible part only, is either forced into the living parts, or so near to them, as, by its pressure, to give such pain to the animal as to cause him to go lame; inflammiation gradually takes place in consequence, and at lẹgth 
matter forms, which, if not allowed to escape by removing the shoe and cutting away the horn with a small drawing knife, spreads uncier the hoof, and after some days breaks out at the coronet. (See Anatomy of the Foot.) In this case, the mischief is not always discovered immediately after sloeing. The pressure upon the sensible parts is sometimes too inconsiderable at first to occasion lameness; so that when the lorse is observed to go lame, the farrier pronounces it to be in the shoulder, and the poor animal is tormented by the strong oils, or even blister's, applied to that part, while he is suffering from another cause. It is in this way that the disease is sometimes allowed to run such lengtlis as we have described. When the nail is so driven as to wound the sensible parts at once, the horse gocs lame immediately after; and the cause being generally suspected, the shoc is taken off; the opening in the horny part enlarged with a drawingknife, and a little tincture of benzoin applied. The lameness is thus soon removed, the shoe reapplied, taking care not to place a nail, or suffer the shoe to press on the injured part, and the horsc be-. comes capable of returning to his work.

When wounds of this kind have been so neglected that matter breaks out from the coronet, it is still necessary to cnlarge the opening in the horn beneath; and if it have closed (whiclı it generally does), the horn must be removed with a drawing-knife, that the matter may escape freely; the upper wound (in tlie coronet) will tlien soon 
heal, by applying the tincture of benzoin. Punctured wounds in other parts are often inflieted with the stable-fork, either aeeidentally or intentionally : I have often known joints wounded in this way. (For the treatment of joint wounds, see Wounds of Cavities.) When the flesh only is punetured, the orifiee must be kept open, by fomenting it frequently, and by means of a small tent, that the wound may heal fron the bottom ; and if the sides beeome callous and indisposed to heal, after the inflammation has been removed, the sinus should be laid open. In punetured wourds of the flesliy part, it is of consequenee to proeure a free exit for the matter: with this view we often make counter openings with a knife, or pass a seton througl the wound, after the infammation has in great measure ceased. In reeent wounds of the punetured kind, irritating applieations are improper': wounds of this kind are frequently followed by eonsiderable pain and inflammation. It is therefore neeessary to keep the orifice open; and if it be small, to enlarge it with a laneet, when the pain and inflammation liave subsided. Should the wound appear indisposed to heal, and be found, upon examining witl the probe, to be as decp as at first, there is reason to suppose that its sides have beeome enllous: a eaustic is then to be applicel throughout its whole course; and, after a day or two, or when white matter is observed to flow from the wound, sueh pressure should be applied, where it is practicable, as will bring the sides 
of the wound into contact, and continued until they arc united. When punctured wounds are so situate, that the matter can frecly escapc, thcre is much less difficulty in curing them, than when they arc in a situation of a differcnt kind; or where the orificc, instend of being the lowest, is the highest part of the wound. 'This inconvenience, howcrer, is somctimcs obviated, by making a new opcring with a knife or lancet, or by passing a scton through the wound: but in some situations this cannot be done; nor can we, in many cascs, apply sufficient pressurc to bring the sides together. The wound can then be licaled only by the formation of new parts, by which the cavity is filled up; to effect which we inject stimulating liquids, such as proof spirit, tincturc of benzoin, or solution of bluc vitriol, taking care to kicep the orifice open, that the bottom of the wound may be first healed. But nothing of this kind slould be donc until the inflammation has subsided: till that period, fomcntations only, or poultices, arc propcr.

The most formidable punctured wounds gुencrally happen whilc a horse is employed in hunting, in leaping over gates or licdges: he is then said to be staked. The decper and more lacerated these wounds are, the more carcfully should we aroid the irritating applications and tents of the farriers, adopting in their stcad the same treatment we have directed for extensire lacerated wounds.

'There is another kind of punctured rounds, 
which is likely to occur in military service; and in a charge of cavalry upon a line of infantry, it is astonishing that so many should escape the bayonet as we generally find do on such occasions.

Those are generally of considerable depth, and often followed by profuse blecting. When the bayonet penetrates the belly or chest, the wound is commonly fatal, particularly if any of the large blood-ressels within these cavities be wounded. When merely the fleslyy parts are wounded, there will be little danger, particularly if there be no considerable blood-vessel opened. The treatment of these wounds is nearly the same as we have already described, exeept that it is more frequently necessary to enlarge the orifice or mouth of the wound; and that there is often occasion to perform a rather difficult operation; namcly, that of tying the artery in order to stop the blecling; for when a large artery is wounded, the lood flows so copionsly as to require the most expeditious means of suppression. It is difficult for a person unacquainted with anatomy to perform this operation of tying the artery. Therefore, if no professional person be present at such an accident, it is adviscable to endeavour to stop the bleeding by pressure, giving up all attenupts to tic the artery, and not placing any dependance upon those preparations called styptics. (Sce Materia Medica.)

Pieces of lint, sceured with bandage, will be found most convenient for this purpose. If the wounded artery be of considerable sizc, which may 
be known by the quantity of blood and the force with which it is thrown out, the bandage should not be removed till the second or third day. *

In these wounds, also, it is necessary to avoid the stimulating applications and tents commonly employed by farriers: but when the inflammation has subsided, and the wound does not appear disposed to heal, they may be used with advantage. It is of importance to procure a free exit for the matter, for which purpose a counter opening may be made, when the situation of the wound will aclmit of it.

All punctured wounds are liable to become fistulous: that is, when the sides cannot be brought into contact by any means, they often become callous. It may be necessary to repeat, that in such cases caustics must be applied to destroy the callosity, and then gentle stimulants are to be injected to promote the formation of new flesh. There is more difficulty in healing wounds of tendons or ligaments, than flesh wounds; and in such cases, after the first inflammation has subsided, the stronger stimulants, and even caustics, are often required. (See the author's Veterinary Materia Medica, or 2d Vol.)

* It is easy to distinguish between a wounded artery aud a veiu. In the latter, the blood is of a darker rerl colour, flows in a uniform stream, and with little force; in the former, the blood is of a bright scarlet colour, and is thown out by jerks, mith considerable force. 


\section{Wounds of circunsscribed Cavities.}

(Under this licad we shall describe wounds of the Chest, Belly, Joints, Sheaths of Tendons, and Blood Vessels.)

When the clicst or belly is punctured, there is generally danger of a fatal termination: the danger, however, is proportionate to the extent of the injury, and is always greater when any of the parts contained in the cliest or belly are injured. This kind of wound is most liable to happen in military serviec, and is most commonly inflicted with the bayonet and ball. Even in small wounds of these important cavities, there is danger of inflammation taking place in the bowcls: it is necessary, therefore, to close the wound as leetly and expeditiously as possible, by sewing it up. Unless it can be accomplislied by sticking plaster and bandage: if stitclies arc employed, the bandage or roller will be necessary. It is proper, alsc, to blced, according to the strength and condition of the animal, and to give a laxative ball, and clystcrs. If swelling and inflammation come on, foment frequently with a decoction of the bitter lierbs. (Sec Fomenialions.) If the wound do not unite by the first intention, white matter will soon make its appcarance. A little tincture of benzoin may then be applicd. In extensive wounds of the abdomen or tolly, the bowels often come out through the open. 
ing, in whieh ease there is considerable danger, thongly the bowels may have escaped the injury. Should they have been wounded, let the wound be very nently stitched up with a small needle and waxed silk, and then gently replaced within the belly, taking care to remove any dirt or other matter that may alhere to them. The wound is then to be carefully closed, as we have before directed, and supported, if possible, with bandage; the end of the silk, however, with which the bowel is sewed, should be kept out of the external wound. Blceding and a clyster are particularly necessary : bran mashes, with strong gruel, or a little swect ontmeal stirred into cach mass, is the most proper diet. If the bowels have been wounded, it is absolntely requisite to kecp the horse from eating hay or straw, or any hard food; for, as the digestive process is far from being perfected in the horse's stomach, the hay or straw might arrive at the wounded part in a state capable of doing great injury. In wounds of the chest, nenrly the same treatment is required : a purgative, howerer, may be given in such cases, beforc inflammation has talien place; but, whenever this happens, whether it be in consequence of these wounds or of wounds of the belly, it must be treated according to the directions given under the heads Inflammation of the Lungs and Bowels.

Wounds of the belly are most eommonly inflicted by the horns of cattle, or by sharp pices of wood, in groing over hedges; and when the bowels 
come out it is generally necessary to cast the horse and put him on his back, in order to replace it. The common practice of farriers in such accidents is to wash the bowels, before it is returned, with some stimulating application; but, if there is any dirt or other matter to be washed off, warm water only should be used. In a case that occurred near Excter, a farrier washed the protruded bowels with camphorated spirit of wine and oil of turpentine, for the purpose, he said, of preventing infammation - the horse of course died. Wounds in the horse's intestines generally prove mortal, either. from unskilful treatment, or from the laccration and contusion with which they are generally accompanied: but it appcars, from the interesting cxperiments and observations published by $\mathrm{Mr}$. 'Travers, that the intestines possess a power of repairing injuries, like other parts of the body. An opening was made in the abdomen of a $\log$, so as to allow the bowels to come out, and an incision of one inch and half in length was then made in the grut. It was then returned into the belly, and the wound in the abdomen was secured by stitches. The animal was scarcely affected by the opcration; took food as usual; and had natural evacuations. At the end of a fortnight, when perfectly recovered, he was killed, for the purpose of examining the bowel, when the wound appeared to be completely healed. In the 18 th volume of the Philosophical Transections, a similar experiment is related by Mr. W. Cooper :- " $\Delta_{\mathrm{n}}$ opening was nuade in the 
abdomen of a large dog, whence the small guts were extruded: after an incision made in one of them, aecording to its length, they were put back, and the wound in the abdomen stitehed up, \&x.; the dog recovered without any ill symptoms, and became perfeetly well in a few days aftcr. The like experiment," he adds, "I have made upon another dog, whieh, in like manner, recnvercd without the applieation of any medicine." It should be remarked, that the bowel does not appear to have been stitched $\mathrm{np}$ when returned into the belly. 'The following experiment, by Mr. Travers, is still more remarkable: "A ligature of fine pack-tliread was firmly tied round the duodenum (small intestine) of a dog, so as completely to obstruct it: the ends of the string werc cut off, and the parts returned; the wound in the abdomen was closed, and the animal expressed no sign of suffering when the operation was eoneluded. On the following day, he was frequently sick, and vonited some milk that had been given him; his breathing was hurried. Third day, his sickness continued, and lie vomited some bilious fluid. Fifth day, he passed a eopious stool, of the same appearanee as the fluid discharged by vomiting: lis siekness from this time eeased, and his breathing was natural; he took bread and milk, and drank abundantly of water. Seventh day, he had three similar evae!nations, and appeared well, eating animal food freely. 'Tenth day, he had a solid natural stool, of a dark colour. On the fiftecnth 
day, his cure being established, he was killed, for the purpose of examining the gut. The ligatmre which was fastened round the intestinc had divided the interior or mucous coat of the grut; the peritoneal or outcr coat alone maintained its integrity. The inflammation which the ligature induces is terminated by the deposition of a coat of lynuph exterior to the ligature, which quickly becomes organized. Whon the liggature thus inclosed is liberated by the ulcerative process, it falls of necessity into the canal, and passes of: by stool. (Sec An Inquiry into the Process of Nature in repairing Injuries of Intestines. By Bonjamin Travers.)

The cavities next in importance to the chest and belly, are those named joints; which in horses are more frequently wounded than the other eavities, These wounds, although from mismanagement. they somctimes prove fatal, yet are of more importance from the circumstance, that without the greatest earc and the most judicious treatment they almost invariably render the horse permanently lame; and sometimes in so considcrable a degrec, that he becomcs nearly, if not entirely, uscless. Previous, howcrer, to entering on the consideration of their treatment, it is desircable to give such an account of the structure of a joint, as may render the directions more intelligible. A joint is formed, gencrally speaking, by the ends or heads of two or more bones: these ends are covered by a laycr of gristle or cartilage, which is of a vielding and clastic nature: this cartilage has on its surface 
a firm but thin membrane, which is constantly forming a slippery fluid, termed synovia or joint oil; it posscsses also absorbent vessels, to prevent an undue necumulation of this fluid. * The ends of the bones, thus covered with a smooth yielding surface, so slippery as to move upon ench other ficely without suffering from friction, are then firmly ticel together by a strong inelastic substance, termed ligament, which completely surrounds the liends of the bones, as far, at least, as they are covered with the smooth cartilage. This ligament, termed by anatomists capsular ligament, is not so tight as to prevent cxtensive motion of the bones, but sufficicntly so to hold them firmly in their proper situation. The joint is thus completely shut up, forming a kind of sac, or what is termed a circumscribed cavity, and the joint oil which is formed is confined to its proper situation. When a joint is wounded, or, in other words, when the capsular ligament is wounded, the joint oil, which is a transparent fluid, of a light yellowish or brownish colour, is scen almost constantly oozing from the wound, particularly when the animal moves the joint. If proper means be not employed to close

* When a joint becomes dropsical, as in bog spavin, it is cither from a loss of pow cr in the absorbent vessels, or in increased action of the vesscls which form the joint oil : perhaps both these caluses inay concur ill producing the discase, the more remote calusc of which is generally hard work, that is, 100 grcat of too long continted motion of the joint. The disease temed uindgalls inay be cxplatued in the same way. (Sec Windgalls, $A_{1-}$ pendix.) 
the wound, inflammation takes place within the joint, occasioning the most excruciating pain, and at first an increased formation of synovia. If the wound continue open, the inflammation and pain become more considerable, and a symptomatic fever takes place, which sometimes proves fatal. It often lappens, however, in this stage of the complaint, that the ressels of the capsular liganent, instead of forming joint oil, pour out a large quantity of glutinous congulating fluid, which, filling the cavity of the joint and becoming solid, totally and permanently obliterates it. The inflammation, pain, and ferer, then gradually subside, and the wound heals; but the joint can no longer be moved, and an incurable lameness is the consequence. From this description will appear the importance of attending to these wounds as carly as possible, and of closing the wound as expeditiously as we can. This, however, cannot be effected by the means we have recommended for other wounds. Ligaments are of a different nature from flesh or skin, and when wounded, cannot be healed without the assistance of strong stimulants, and even caustics: * but these must be used witl great

* It has been supposed, that the violent pain and iufammation, which follow the wnund of a joint, are caused chiclly by the admission of air into the cavity, and a deficiency of synovia, or joint oil, by which the two surfices are exposed to friction. It is certilin, however, that in these romds there is inuch mote synovia formed tham usual; which may be known by the quan. tity that flows from the wound. This increased formation of synovia, hovever, continues only a certain time; after a time, 
cantion, for when they are so clumsily cmployed as to enter the cavity of the joint, the most violent infammation will ensue. Some of the old farriers appear to have known the utility of caustics in these wounds; but, mistaking the principle on which thcy acted, often injected liquid caustics into the joint, and thereby brought on the most excruciating torments. Sometimes their patients were destroyed by the fever which followed; more frequently, however, the joint became stiff or inmoveable, as wo hare before described, and the wound healed. Other farricrs, preferring to cmploy the solid caustics, and failing in their attempts to thrust them into the cavity of the joint, have applied them no farther than the orifice in the capsular ligament, and have, by this fortunatc failure, effected a cure without the loss of the joint. This plan, however, can only be adopted in wounds of a small size, or of the punctured kind, such as those inflicted with the stable fork; and, fortunately, wounds of joints are most commonly of this kind. But we sometimes meet with cases where the wound is of considerable size, and much lacerated: there is scarcely a possibility then of preserving the joint; and if it happen to the larger joints, such as the hock and stifle, there is great danger of its destroying the animal. In such cases,

the congulating lymph is poured out, which, becoming solid, obliterates the cavity; but in large wounds of the principal joints, the animal is often destroyed before this happens, by the symptumatic fever which comes on. 
caustics arc improper; they must be treated as deep lacerated wounds. But in the small punctured wound of a joint, the actuul cautery (hot iron), cautiously applied, lias becn found the most cxpeditious and effectual remedy. I have succeeded also with the lunar caustic (nitrate of silver). Farriers sometimes cmploy the lutler of antimomy (muriate of antimony), and white vilriol (vitriolsted zinc): * they often inject some liquid caustic into the round with a syringe, such as solution of blue vitriol. The earlier the actual cautery is applied, the more speedily will it heal the wound; and it is particularly desireable to have it applied before inflammation takes place in the joint. The iron should have a round point, and be applied when at a clull red heat; the wound should be so seared as to stop the discharge of joint oil. It often happens, that, after a short time, an oozing of synovia is again observed: in such cases the iron must be

* I have heard a farrier boast of possessing a reecipt for a joint humour; or, as he terined it, for "killing a joinl humour." Ill small wounds of the inferior joints, this naan sometimes suc. ceeded. Upon examining the remely, I found it to eonsist ehiefly of white vitriol, whieh indeed was the only active ingredient, This, coarsely powdered, was put into the wound; b)ut as the man supposed its efieacy depended npou its entering the cavity of the joint, and subduing this furmilable hunour, lie of cource tonk great pains to thrust it in with his probe. In larire wounds he gencrilly suceceded in his atlempt, and destroyed either the joint or the animal: but in small wounds of the lower joints, fte merely bronglut it into eontact with tlie wounded ligament, and thereby often effected a cure. 
again applied, and repented, if necessary, several times. I have sometimes succeeded ultimately, though the iron had been applied ineffectually twice or three times. When inflammation takcs place in the joint, the most powerful remedies should be expeditiously employed for its removal, such as bleeding and purging. Fomentations and poultices in such cases are not so useful as blisters, which should be applied rather extensively about the joint; but as long as the wound in the joint remains open, the inflammation will continue; therefore our principal object should be to close the wound. There is no external complaint which occasions such excrnciating pain to the animal as inflammation of a joint, particularly when it has proceeded so far as to ulcerate the bones; several cases of which have come under my obscrvation.

Wounds of the Sheaths, or Memlranes surrounding Tendons.

These require nearly a similar treatment to that we have just described, and, when of the small punctureci kind, are more expeditiously healed by a judicious use of the actual caitery, than by niny other remedy. These wounds also generally discharge something like synovia or joint oil, and, if suffererl to remain open, are prodlictive of very violent pain and inflammation. When they are so 
large as to render the caustic an improper' application, they should be closed as neatly as possible, and kept so by adhesive plaster and bandage. This plan is equally applicable to similar wounds in joints; and, if adopted in time, will often be found very effectual : even when the actual cautery has been applied, and the wound seared so as to be closed, the adhesive plaster will be found a useful assistant, and will often prevent the necessity of repeating the cautery. I have known a wound in the knee joint soon heal, by means of the sticking-plaster alone. The tendons most liable to be wounded are the back sinews: they are enclosed in a strong tendinous sheath, which, like a joint, contains a small quantity of slippery fluid, to render tireir motions easy, and prevent the cohesion of the parts. About the fetlock joint, or rather above that joint, there are small sacs, or little bladders, connected with the tendon and ligaments, which also contain this slippery fluid, and serve to facilitate motion in these parts. * When a liorse is worked too hard, these bladders contain an unusual quantity of the fuid, or synovin, and appear swelled or puffed, constituting the disease termed wind-galls. II' these little bladdérs receive a wound, it is generally followed by violent pain and infammation; and when improperly treated, a very obstinate lameness may be the consequence. In this

* These sacs are nothing more than the shearls of tendons; and when distended with synovia, constitute wind-galls, 
case, nothing is more useful than the sticking plaster, provided the lips of the wound be neatly brought together before it is applied: but if the wound be of the small punctured kind, thc actual cautery, or the lunar caustic, should be first applied. Great care, lowever, is required in this case; for if the iron be not applied very lightly, and its pointed end properly adapted to the size of the wound, it may do much mischief. Blister's arc the best remedies for any swelling that may remain after a wonnd in the sheaths of tendons, or in joints; and if one blister be found insufficient, a repetition of the remedy will generally succeed. The last kind of wound we have to describe is one that happens more ficquently than any other, and is morc easily cured; that is, a wound of a vein. When a vein is properly opened, and afterwards carefully closed in the usual way with a pin and a little tow, it almost always heals by the first intention: but when it is opened by a rusty blunt fleam or lancet, and particularly when the instrument is driven with such violence as to cut not only into, but through the veir, making thus an orifice both before and behind, it seldom heals so readily : on the contrary, inflammation takes place within the cavity of the vein, which gradually cxtends or spreads until either the wonnd is closed, or the vcin obliterated, by the congulating matter whieh forms within it. If the inflammation extend to the heart, the animal is soon destroyed; more commonly, however, the vein is soon plugged up, 
and ceases to convey blood. But even in this case the discase proves very troublesome; in consequence of the jugular or neck veins being the principal channels, by which the blood of the head returns to thc heart. This obstruction to the return of the blood canses a swelling of the large gland under the ear, to which the formation of matter is often a consequence. Sometimes the eye bccomes inflamed; and I have seen symptoms of apoplexy or slaggers produced by this cause. If a horse be turned to grass in this situation, the inconvenience is considerably increased; the position of the head in grazing being unfavourable to the return of blood from the head. The inconvenience arising from a loss of the jugular vcin is not, however, permanent; the smaller vcins gradually cnlarge, and, after a time, return the blood as readily as the jugular or neck vein did originally. When this accident happens, the mischicf may be perceived about the second day aftcr bleeding; somctimes the day following that of the operation. When the orifice in the vein is large, and particularly if the wound in the skin be but slightly closed, or if the horse happen to rub the pin out, the wound bleeds freely; and though it be again pin. ned up, the blood often bursts out after a short time. I have secn a case where the horse har becn blecding, at intcrvals, threc or four days, though the wound had been several times firmly pinncd up: this was very soon stopped by the actual cautery, but the vein was obliterated at that 
part and a little way downward and upward; and the swelling of the gland under the ear took place. When the orifice in the vein is but small, or when the vein is not transpierced, but inflames only from the orifice in the skin having been imperfectly closed, or from hair or blood lodging between the lips of the wound, the first symptoms are swelling and an oozing of moisture from the wound. In this case the vein is often preserved, and the disease soon cured, by applying lightly the actual cautery, and by keeping the horse at rest.*-It must not be supposed, however, that in every case of swelling after bleeding the vein is infiamed: a slight swelling often takes place immediately after the operation, merely from the blood getting into the cellular membrane under the skin: and this swelling is sometimes succeeded by an oozing of moisture from the wound: but all this is soon re. moved by ruibing on it a little soap liniment. When the vein is really inflamed, there is generally a discliarge of blood some time after the operation: and if this clo not liappen, the swelling extends to the gland under the ear, the whole being extremely tender and painful, often rendering the horse almost incapable of masticating or swallowing. When the disease is improperly treated, or suffered to take its own course, sinuses form by the

* Mastication is unfavourable to the cinsing of the orifice in the vein, substantial grivel should, therefore, be given for a day or two. 
side of the vein; so that the probe may be passed in various directions, generally upward towarls the gland, sometimes inward among the muscles of the neck.

The actual cautery is undoubtedly the most effectual application at first: but when the disease has been suffered to proceed so far as we have now described, it is necessary to keep the orifice open, that the matter may escape freely; and, by injecting a solution of blue or white vitriol, cause it gradually to heal from the bottom.

When the gland under the ear is much swollen, and very painful, a poultice should be applied; but when the swelling feels hard, and without tenderness, a blister is more effectual.

A repetition of the blister is sometimes necessary; and care should be taken to prevent the horse from hanging down his head much, or feeding from the ground, which many horses prefer; pulling out their hay from the rack, and throwing it on the litter for that purpose. When the sinuses in the neck do not appear to heal, and the matter has not a free exit, it is necessary to enlarge the opening with a blunt-pointed bistoury; but the operation requires cautinn, as a large artery and nerve are situated near this part. 


\section{Bruises.}

IN recent bruises, fomentations are the most essential remedies, if they are considerable; but in s'ight cases, cold applications, such as the lotion, No. 4 , will generally be found sufficient. When they are violent, a considerable degree of inflammation may be expected to supervene: it will then be proper to give a laxative ball, and bleed moderately.

If abscesses form in consequence of a bruise, discharging large quantities of matter, particularly if the matter be of a bad colour and an offensive smell, the wound also appearing dark coloured and rotten, indicating approaching mortification, the horse's strengtl must be supported by allowing malt mashes or gruel. If the appetite go off, he must be drenched with good water-gruel, and strong infusion of malt: it will be necessary also to give a corlial ball once or twice a-clay.

Should a hard callous swelling remain in consequence of a bruise, the following embrocation is to be well rubbed into the part twice a-day'; and, if it do not succeed in removing it, recourse must be had to a blister.

\section{Embrocation for Bruisess. \\ No. 1 .}

Soap liniment .............. $2 \frac{1}{1}$ or.

Liquid ammonnia $\ldots \ldots \ldots \ldots \ldots \frac{1}{4} 0 z^{\prime}$

Mix. 


\section{No. 2.}

Canphor .................. Oil of turpentine $\ldots \ldots \ldots \ldots \ldots \ldots \ldots 1$ oz. Soap liniment $\ldots \ldots \ldots \ldots \ldots \ldots 1_{\frac{\xi}{\xi}}^{\prime} \mathrm{o} z$. Mix.

No. 3.

Tincture of cantharicles ........ 1 oz. Oil of origanum $\ldots \ldots \ldots \ldots \ldots .2 \mathrm{dr}$. Camphorated spirit ...........6 $6 \mathrm{dr}$.

Mix. Such as warm beer, with a little gentian, and occasionally a little laudanum may be added, particularly if there is any degree of purging.

\section{No. 3.}

Muriate of ammonia .......... I oz. Distilled vinegar ............. 8 oz. Spirit of wine $\ldots \ldots \ldots \ldots \ldots \ldots 6 \mathrm{oz}$. Mix.

No. 4 .

Sugar of lead $\ldots \ldots \ldots \ldots \ldots \ldots \ldots$ oz. Vinegar and water, of each ...... 8 oz. Mix.

This is an cxcellent application for bruises from the saddlc or harness, and may be diluted, if there be much inflammation. 


\section{Broken Knees.}

THe method of treating this accident is describcd generally under the article Wounds, being nothing more than a contused and lacerated wound; lout as it occur's frequently, and, if not skilfully treated, greatly lessens the value of a horse, it may not be amiss to be more particular on the subject. 'The first thing to be done is to cleanse the wound perfectly: and if it be at all deep or extensive, or much bruised, a'goulard poultice is to be applied, by means of the leg of a worsted stocking, taking care to renew it twice a-ciay, that it may be constantly soft and moist. This, in two or three days, will give the wound a healing appearance, and cause a white healthy matter to flow: it may then be discontinucd, and the digestive ointment applied. Should the matter assume a bad appearance, losing its white colour, becoming thin, and smclling rather offensively, it shows that the tendons, ligaments, or even the bonc, has been injured; the poultice, therefore, should be continued longer, or until the foul parts have separated, and the matter has becomc thicker, of a better colom, and free from any fetid smell: the poultice will then be no longcr necessary. Should the new ficsh grow too luxuriantly, or rise above the surfacc, the escharotic powder may be sprinkled on it. The common practice at this period is to apply digestive ointment, and keep it on by means of a bandage; but 
I have found that the most expeditious method of curing broken knees is, after the poultice is left off, to apply the following paste: the granulations, however, when rising above the level of the skin, should be first reduced by the escharotic powder. Mix 1 oz. of finely powdered alum with 2 oz. of pipe-clay, and sprinkle it on the wound, or make it. into a thin paste, about the consistence of cream, with water, and lay it on the sore every morning. Previous to cach application, or once in two days, the wound should be bathed, and made clean, with warm water : no otlicr covering besicles the powder or paste is necessary. By this treatment the wound will soon heal. But we must not stop here; for unless the swelling is completely removed, and the hair regenerated of its original colour and smoothness, the horse would be considered of very little value. As soon, therefore, as the wound is completely lienled, if any swelling be discernible, applly the following liniment, so as to excite a moderate degrree of vesication, or blistering, and repeat it after this effect has perfectly subsided. Should the swelling feel hard and callous, and be of considerable size, the strong blister, No. 1, or No. 2, wil! be preferablc. (See Index, Blisters.)

\section{The Liniment.}

Powdered cantharides ....... $2 \mathrm{dr}$.

Oịl of turpentine $\ldots \ldots \ldots \ldots \ldots \frac{1}{3} \mathrm{oz}$.

Olive oil $\ldots \ldots \ldots \ldots \ldots \ldots 1 \frac{1}{2}$ oz.

Mix, and let it be well shaken before it is applied 
It often happens, after the wound is perfectly healed, that a small scar or mark will be observable; and, though the part may be free from any hardness or swelling, the value of the horse will be greatly lessened by this appearance. A variety of ointments have been recommended for promoting the growth of hair on the part, and thereby removing the blemish: the following I have found more effectual than any of them.

\section{Ointment for Broken Knees.}

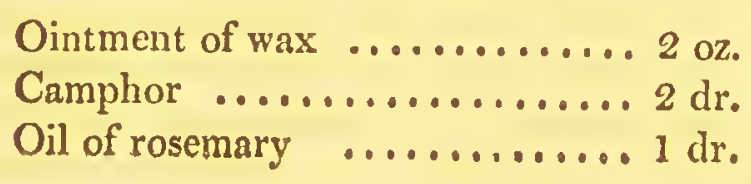

\section{Mix.}

The colour of this ointment should be suited to that of the contiguous hair, which will so conceal the blemish, that it will not be observed, unless the part is strictly examined; and, at the same time, the ointment will cause the hair to grow up gradually, until the mark is completely removed. If the horse be of a bay colour, the legs and knees are generally blackish. In this case, mix a little ivory black with the ointment: if a chesnut colour, Armenian bole may be mixed with it.

In very badly broken knees, we sometimes find the integuments divided obliquely downward, so as to form a flap, which projects outwards; the same 
thing sometimes happens in the front of the fetlock joint: in sueh eases, I have often tried to re-unite the flap by means of sticking-plaster and bandage; and finding that fail, I have shaved off the inner surface of the flap, and the surface of the wound, and made a fresh attempt to re-unite them; but it has never sueeeded: and the flap las become thicker, as well as the surfaee, with whieh it has been in eontaet. For some time I have given up the attempt, and, immediately after the aeeident, have eut off the flap; whieh has proved a much better method: as the wound heals more readily, and the blemish (for some blemish there must be in sueh eases), is considerably less. Previous to the applieation of the ointment, the knee, when perfectly healed, should be rubbed for a short time with some soap liniment, but downwards only, in the direction in which the hair grows.

\section{Fistule in the Withers.}

Thys disense gencrally originates in a bruise from the saddle, and is at first simply an abscess, which, by early attention and proper treatment, may be easily eured; but when negleeted, it degenerates into a fistulous sore, proves extremely diffienlt of cure, and cannot be removed without very scvere treatment.

As soon as the injury is discovered, fomentations IT 5 
should be applied in order to promote suppuration; and when the matter is formed, let the tumour be opened, so that its contents may be completely evacuated, and a future accumulation prevented. The sore may then be healed by dressing it daily with digestive liniment or ointment; but should these prove ineffectual, apply the detergent lotion until the sore assumes a red healthy appearance, and the matter becomes whiter, and of a thicker consistence. When the disease has been neglected in its first stage, and the matter suffered to penetrate among the muscles, affecting the ligaments or bones of the withers, it becomes necessary to adopt a more severe treatment.

The sinuses or pipes are to be laid open with a knife ; and, if it be practicable, a depending opening is to be made, that the matter may run off freely: the sore is then to be clressed with either of the following ointments, which is to be melted, and poured into the cavity while very hot.

The sore is not to be dressed until the sloughis, which this ointment occasions, have separated from the living parts; which grenerally happens two or three days after the operation. If the surface of the sore look red and healthy, and the matter appear to be whiter, and of a better consistence, a repetition of this painful operation will not be required, tincture of myrrh or spirit of wine with a small proportion of sublimate (10 garains to 2 or 3 oz.) being sufficient to complete the cure; but should the sore still retain an unhealthy appear- 
ance, and the matter continue thin and of a bad colour, the loot dressing must again bo applicd.

\section{The Ointment.}

\section{No. 1.}

Ointment of nitrated quicksilver ...... Oil of turpentine ............ 1 oz.

$$
\begin{aligned}
& \text { Mix. } \\
& \text { No. } 2 .
\end{aligned}
$$

Verdigris $\ldots \ldots \ldots \ldots \ldots \ldots \ldots \ldots$. Oil of turpentine $\ldots \ldots \ldots \ldots \ldots \ldots 1 \mathrm{oz}$. Ointment of yellow resin ......... 4 oz. Mix. No. 3.

Oil of turpentine $\ldots \ldots \ldots \ldots \ldots \ldots 2$ or. Vitriolic acid................ 1 oz.

Mix cautiously in an eartlen vessel, placed in a current of air, that the suffocating vapour which arises may be carricd off. When they are perfectly incorporated, add

Common turpentine and hog's lard, of each $\ldots \ldots \ldots \ldots \ldots \ldots \ldots \ldots\}$ o $z$.

To be melted over a gentlc fire.

'This ointment may be made either stronger or weaker, by increasing or diminishing the proportion of vitriol and turpentine. If bones of the 
withers are found to be carious, they should be scraped with a drawing knife.

\section{Poll Evil.}

THis disease also generally originates in a bruise, and requires the same treatment as the fistula. It consists at first in an abscess in the poll, which, by early attention, might be ensily cured; lut if the matter be suffered to penetrate to the ligaments and bones, it frequently proves more difficult of cure than the fistuln in the withers, and camnot be subdued without those strong remedies we have recommended in that disease.

Since writing the above, I have discovered, that the inflammation which produces poll evil does not begin, as is usually the case in other parts, on the surface, or in the cellular membrane under the skin, but between the ligament of the neck and the bones. When we consider the weight and position of the horse's liead, with the great length of the neck, it will readily appear, that the muscles alone are not capable of supporting and moving so great a weight, under such mechanical disadvantages. Nature lias therefore provided a strong ligament, which is firmly fixed to the back part of the head, whence it passes down over the bones of the neck. It is not attached to the first bone, but is firmly fastened to the three next: it then passes 
over the three other bones of the neek in nearly a straight line to the withers, where it is seeurely fixed, giving off a thin slip of ligament in its passage, which is united to the last three bones. It is eontinued from the withers to the baek. This ligament being elastic, allows of suflieient motion in the neck, and so effeetually assists the museles in supporting the head, that they never become fatigued.

When a horse receives a violent blow on that part of the poll which covers the first bone of the neck, which, as we have just observed, is not attaehed to the ligament, the injury will be sustained ehiefly by the sensible parts plaeed between the bone and the under surface of the ligament. The skin may also be hurt, and a slight degree of superficial inflammation may take place. But when inflammation has been thus produeed between the bone and the ligament, it is more likely to proeeed to suppuration; or to the formation of matter; whieh, being so decply seated, cannot find vent at the surface, by bursting the skin like a eommon abseess; therefore it spreads under the ligament, and is so long in arriving at the surface, that both the bones and ligament are highly diseased before any external swelling is observed. This is the cause of the partieular obstinacy of the poll evil, and the great length of time generally required to cure it. From this we may learu, also, how little is to be expeeted from such applieations as are intended to disperse the swelling, and how necessary 
it is to adopt a bold and powerful mode of treatment. I am convinced, from what I have seen, that it is almost impossible to disperse the genuine poll evil; that by attempting it we lose time, and suffer the matter to eontinue its ravages upon the ligament and bones; and that the only effectual practice consists in opening the abscess freely, so that the matter may readily eseape, and the diseased bones be examined. When this has been done, and bleeding has perieetly eeased, apply the ointment, No. 3 , described in the preeeding ehapter, and let the first dressing remain until the dead parts are ready to separate merely by washing. It is sometimes necessary to repeat this applieation several times; and should it appear not suffieiently aetive, the proportion of vitriol and turpentine may be inereased; but in irritable blood-horses it will sometimes prove too strong. A sceond operation often beeomes necessury, particularly if the first have not becn boldly performed; and whenever the matter appears to be pent up, or eonfined in sinuses, the knife and strong dressings are the only remedies. When the wound lias been brought to a healthy state, the tineture of mysrh and sublimate, in the proportions preseribed in the foregoing article, is the luest dressing. 
Saddle Galls, or Warbles.

These consist of inflamed tumours, and are produeed by the unequal pressure of the saddle. If neglected, they become troublesome sores, and are often a considerable time in healing. As soon as a swelling of this kind is observed, let several folds of linen be moistened with one of the following lotions, and kept constantly applied to the tumour until it is reduced; but if matter have becn allowed to form, let it be opened witli a lancet, and afterward dressed with digestive liniment or ointment. Should it appear not to heal readily under this treatment, apply the detergent lotion made lot. When swellings of this kind are large and much inflamed, it will be adviseable to bring them to suppuration as expeditiously as possible, by means of fomentations or poultiees. Should a hard swelling remain after the infiammation is in great measure removed, try the embrocation for strains; and, if this do not succed, recourse must he had to a blister.

\section{The Lution.}

\section{No. 1.}

Superacctate of lead ............ $3 \mathrm{dr}$.

Distilled vinegar ........... 3 oz.

Spirit of wine ............. 4. oz.

Water ............... 8 oz.

Mix. 


\section{No. 2.}

Muriate of ammonia $\ldots \ldots \ldots \ldots \ldots \frac{1}{\frac{1}{3}}$ oz. Muriatic acid $\ldots \ldots \ldots \ldots \ldots \ldots .2 \mathrm{dr}$. Water............. from 8 to $12 \mathrm{oz}$.

Mix.

No. 3.

Soap liniment, and water of acetated ? ammonia, of each ........... 2 oz.

Mix.

\section{Silfasts}

Are occasioned by repeated bruises fiom the saddle, which, instead of inflaming the skin, as most commonly happens, cause it to become callous, and give it somewhat the appearance of leather. One of the following ointments is to be applied until the callous part appear's disposed to separate: it is then to be remored, which requires some force, and even the assistance of the knife. The sore which remains may be healed with hog's lard. The sore may be vashed now and then with the tinclure of myrrh and sublimate, as before prescribed, touching the part once on twice (after the sitfast has been removed! with uitrate of silver (lunar caustic). 


\section{Ointment for Sitfasts.}

No. 1 .

Camplior ................ 2 d $1^{\circ}$. Oil of origanum $\ldots \ldots \ldots \ldots . . .1 \mathrm{~d} d$.

Mix.

No. 2.

Mercurial ointment ......... 9 oz. Calomel .................. $\frac{1}{2} d r$. Oil of turpentine .......... $9 \mathrm{dr}$.

Mix.

\section{Strains.}

THrs is a subject with which every sportsman ought to be well acquainted, since his horses are particularly liable to such accidents. Strains may affect either the muscles, ligaments, or tendons. Muscular strains consist in an inflammation of the muscles ol flesh, occasioned by violent and sudden excrtion. When liganents are the seat of this discase, there is generally some part of them ruptured, whereby very obstinate and sometimes permanent lameness is produced: in this case, also, inflammation is the symptom which first requires our attention. But tendons are the parts most frequently affected, particularly the flexors of the 
fore leg, or back sinews, as they are commonly termed. Tendinous strains are commonly supposed to consist in a relaxation or preternatural extension of the tendon; and the remedies that have been recommended are supposed to brace them up again. However plausible this opinion may be, it certainly is very crroneous: indeed it has been proved by cxperiment, that tendons arc neither elastic nor capalile of extension; and, from investigating their structure and economy, we lea'n, that, were they possessed of these qualities, they would not answer the purpose for which they werc designed. From an idea that a strain in the back sinews depends on a relaxation of the tendons, many practitioners have been apprehensive of clanger from the use of cmollient or relaxing applications, than which nothing can be more useful at the beginning of the disease.

Tendinous strains consist in an inflammation of the membranes in which tendons are enveloned; and the swelling which takes place in these cases depends on an effusion of congulable lymph by the vessels of the infiamed part. Inflammation boing the essence of a strain, we are to employ such remedics as are best calculated to subduc it: and should any swelling remain, it is to be removed by stimulating the absorbent vessels to increased action. 


\section{Strain of the Shoulder.}

Thıs disease is by no mcans so frequent as it is supposed to be, lameness in the feet being often mistaken for it: the difference, however, is so well marked, that a judicious observer will ncver be at a loss to distinguish one from the other.

A shoulder strain is an inflammation of some of the muscles of thic shoulder, most commonly, I bclieve, thosc by which the limb is connected with the body. The lameness which this accickent occasions comes on rather suddenly, and is gencrally considerable. When the horse attempts to walk, the toe of the affected side is generally drawn along the ground, from the pain which an extension of the limb occasions: in violent cnses, he appears to be incapable of extcnding it.

When lameness arises from a disease of the foot, it is gencrally gradual in its attacis, unless occasioned by an accidental wourd, and does not at all hinder the cxtension of the limb: an unusual heat and tenderness may also be percived in the foot; and, as the horse stands in the stable, the affected foot will be put forward, that it may bcar as little as possible of the wcight of the body.

The first remedy usually employed on these occasions is blceding in the shoulder or plate vein; but blecding from the neck is, I believe, equally effectual, and ccrtainly much more easily. and conveniently donc. A laxative ball should then be 
given : and, if the injury be considerable, let a rowel be put in the chest. By means of these remedies and rest, the disease will generally be removed in a short time; a cooling, opening diet, with perfect rest, will also be necessary. When the inflammation and lameness begin to abate, the horse should be turned into a loose stall, and, after a week or two, he may be suffered to walk out for a short time every day: but should this appear to increase the lameness, it must be discontinued. The intention of moderate exercise, after the inflammation is in great measmle subdued, is to effect an alsorption of any lymph that may have been effused, and to bring the injured muscles gram dually into action.

After an accident of this kind, particularly when it has been violent, the horse should not be worked in any way for a considerable time, as the lameness is very apt to recur, unless the injured parts have had sufficient rest to recover their strength. If he can be allowed two or three months' run at grass, it will be found extremely conducive to his recovery, provided he is prevented from galloping or exerting himself too much when first turned out. With respect to embrocations, and other external applications, they are generally useless, unless the external parts are affected; and then fomentations may be employed with advantage.

If the joint formed by the slioulder blade and shoulder bone appenr to be injured, a blister should be applied to the point of the shoulder. In some 
cases, I believe, the muscles named rhomboid, at the upper part of the shoulder blade, are affected: which may be known by the shoulder blade appearing lower than natural. The embrocation (see article Embrocations in the Sccond Volume) may then be rubbed on the shoulder: I have met with one well-marked case of this kind, where the animal perfectly recovered by rest cn'y.

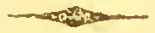

\section{Struin of the Stifle.}

IN this case the stifle joint will be found unusually hot, tender, and sometimes swollen. The rcmedics are fomentations, a rowel in the thigh, and a dose of physic. When by these means the inflammation of the joint has abated considerably, and at the same time the swelling and lameness continue, the cmbrocation for strains, or a blister, should be applied.

Strains in the hock joint require the same treatment.

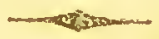

Strain of the Hip Joint, (commonly termed Whirl Bone, or Round Bone).

WHeir lameness occurs in the hind leg, the cause of which is too obscure for the farrier's comprehension, he generally pronounces it to be a strain in the round or whirl bonc, and with all 
that affectation of infallibility so commonly observed in those gentlemen. I have seen several cases of lameness which were supposed to be occasioned by an injury of this part, but, after attentive examination, an incipient spavin was found to be the cause. I would advise, therefore, in such cases, that the hock joint be carefully examined; and, if unusual heat or tenderness be observed on the seat of spavin, it is probable that the lameness arises from this cause, and that it may be removed by the application of a blister. I have met with several horses that had been severely burnt and blistered in the hip, when the hock was eviclently the seat of the disease.

\section{Strain of the Flexor Tendon, or Back Sinew.}

A strain of the back sinew depends, as we have before observed, on an infammation of the membranes in which it is enveloped, * and is sometimes

* The back sinews consist principally of two tendons; one terminating in the botlom of the collin-bone, the other in the posicrns. The latter serves as a steath to the former: between these tendons, a slippery futh is seerctod, which cnables them in move freely on each other. Inseveral parts, howeves, there are membranous bauds passing from oue to tl:e other. These probably. in violent exertions, are sometimes ruptured, whence arise innummation and swelling, rendering motiuns of the parts very painful. This appears to me to constitute what is commonly called a strain of the back sinews. There is a strong tenton, or rather ligament, which arises immediately uncler the linee-juint, at the back part, 
complicated with a rupture of the liganents which are situate immediately under the sinews. When the lameness and swelling are considerable, bleed in the shoulder vein, and give a dose of physic; then let the saturnine poultice be applied, so as to

and soon after joins, and is intimately blended with the outcr flexor tendon. This, I believe, is sometimes ruptured, more frequently, perhaps, infamed, from a sudden and unexpected effort. The suspensory ligament which lies under the tendons, and extends from the back part of the knce to the fetluek-joint, is sonetimes ruptured; but, I belicve, rcry rarely. A little above the fetlock-joint, it divides into two strong branclies, which diverge from cach other, and firmly enbraee the fetloekjoint laterally, of which it appears to be the prineipal support: it then passes obliquely forward on both sides, and unites with the extensor tendon, in front of the postern-bone. The rupture, I beliere, most eommonly happens in one of these branclics. Accidents of this kind cause the most serious kinds of lameness, and are not often perfectly cured. But the former kind, or eommon strain of the back sinews, is not so diun rerous, and is generally eured by kecping the lcg constantly wet with the saturnine lotion, by means eillicr of the poultice or flamsel bandage. Iist, however, is the most essential rcmedy for every kind of strain; and without it, nothing can do any good. It is thoughit by many, a good plan to turn hol'ses to grass whell strimed in the back sinews: but this is not the cisc; as the excrcise a horse gets when thrned ont is sure $t 0$ incrase the lameness. When a strain in the baek sinews is properly and seasonably attended to, it may generally be cured without blistering: and much mischief is often done by the 100 early application of blistors; which shonld never be applied nutil the infammation has conpletely subsided. In very sevcre strains, attended with a high degree of infammation, both blceding and purging must be considcred as essential remelies, and thercfore never onnitted; and it is ndviscable, ill such cases, to sling the loorse so as to relieve as much as posible the injured leg; as the exertion re. quired to lie down and rise up again is often injurious. 
extend from the hoof to the knee, and let it be trequently moistened with the saturnine lotion. When the inflammation and lameness have abated considerably, and a swelling still remains, apply the embrocation for strains, rubbing it well on the part twice or three times a-day. If this do not succeed, recourse must be liad to a blister. It will be adviseable also to turn the horse loose into a large stable or barn, and to give him this kind of rest for a considerable time: should he be worked too soon after the accident, the part is very liable to be injured again, particularly when it has been violent. Should the swelling continue, notwithstanding these remedies have been carefully employed, particularly if it feel callous and hard, and be perfectly free from inflammation, it will be necessary to apply the actual cautery (see Firing): this operation, however, must never be performed while any inflammation remains. These swellings sometimes prove so obstinate, that even repeated blistering and the actual cautery are ineffectual; as soon, however, as the inflammation which cansed them is completely removed, they seldom occasion lameness, yet they will not admit of any violent exertion in the part, and are therefore always an impediment to speed.

Salurnine Lotion.

Acetated lead $\ldots \ldots \ldots \ldots \ldots \ldots .2$ oz.

Vinegar and water, of each ........ 1 pint. Mix. 


\section{Satumine Poulsice.}

Fine bran ............... t peck.

To be made into a thin paste with hot saturnine lotion: to this add as much linsced-meal as will give it a proper consistence.

Embrocation for Slrains.

No. 1.

Oil of rosemary and camphor, of each $2 \mathrm{dr}$. Soft sonp $\ldots \ldots \ldots \ldots \ldots \ldots \ldots 1$ oz. Spirit of wine $\ldots \ldots \ldots \ldots \ldots \ldots \ldots$. ${ }^{\text {oz. }}$

Mix.

No. 2.

Soft soap, spirit of winc, oil of turpentine, and ointment of elder, of $>4 \mathrm{oz}$. ench

Mix.

Strain or Injury of the Back.

TuE lameness produced by injuries of this kind are often incurable, particularly when the ligament by which the hack bones are united is ruptured. These accidents are not unfrequent, and happen sometimes from apparently trivial causes. In staling, for exnmple, when the horse has been stanct- 
ing on slippery pavement, I have known the hind feet slide backward, by which the liganents of the spine were ruptured, and the spinal marrow so affected, that it was found necessary to shoot the animal. When the injury is not so considerable or so forward in the spine as to produce a paralysis of a part essential to life, the gener al health of the horse is seldom much affected by it; and, though the lanieness is generally incurab'c, he may continue healthy anil in good condition. The lameness is very remarkable, and easily distinguished. There is a staggering kind of motion in the hind parts, which appear as if loosely connected with the body, particnlarly when he attempts to trot. The lind legs appear to be drawn forward with difficulty. An injury of the muscles situated within the loins, between the kidneys anil spine, sometimes occurs, and causes the same kind of laneness; hut in this case the horse often voids bloody urine, from the kidneys having bein hurt at the same time, and the lameness is more considerable; the horse being sometimes incapable of moving the hind legs. The treatment of both cases is the sume ; but in the latter it is more prrticularly necessary to bleed largely, to prevent an abscess from forming within the body, which, in all probability, would prove fatal. The bowels should be emptied by clysters and laxative medicine. Let the loins be fomented with woollen cloths wring out of hot vinegar, and afterwards covered with a fresh sheepskin. When the ligaments of the spine are rup- 
tured, the disease is generally incurable. Repeated blistering, setons, large issues made, and kept open by caustics, and several months run at grass, have been found ineffectual. Should it happen, however, to be only a muscular injury, which may be known by the progressive amendment of the lameness, a strengthening or adhesive plaster should be placed on the loins, and the horse turned into a paddock.

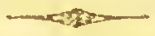

Strair of the Coffin Joint.

When a horse becomes suddenly lame, and no appearance can be discovered to account for it, the lameness is commonly attributed either to a strain in the shoulder or in the coffin joint. 'That this joint is sometimes injured in this way is probable; and it is equally so that many of the lamenesses ascribed to this cause arise from some other injury: it is a convenient name, however, for the farrier; and whatever the nature of the injury may be, if the interior parts of the foot are inflamed, which may be known by its increased lieat, and tenderness when struck, and by no other circumstance being discovered, after a careful examination, to account for the lameness, let the foot be kept cool by a poultice, the sole pared, if it will admit of it, and a blister applied from the coronet to above the fetlock joint. 


\section{Ring-bones.}

The bony excrescences of the postern, which constitute ring-bone, are not always productive of Iameness; this happens only when they are so situated as to impede the motion of the small pastern or coffin joint: in the latter situation, they appear to cause more lameness than in the former. The only chance we have of curing ring-bones is by applying the actual cautery at their first appcarance, and blistering immediately after. Ringbones most commonly happen in short straight pastcrns, where the heels of the hoof are decp. It will be readily scen that in pasterns of this description the parts must suffer more from concussion than in the longer and more oblique pastern. We may not be able wholly to correct this position, but, by lowering the heels, the evil may probably be diminished.

Another kind of ring-bone consists in an ossification of the lateral cartilages of the foot: this most commonly happens to draught horses, and seldom causes much lameness, except when they are very large. They are often a consequence of juitior; and may be considered incurable.

\section{Thorough-Pin.}

By this tem is mant a swelling both on the 
inside and outside of the hock joint. Whell one of the tumours is pressed with the fingers, the fluid which it contains is forced into that on the opposite sidc. From this communication between the two swellings, the discase has probably obtained its name.

It is gencrally a consequence of lard work, and therefore difficult to cure: the only remedies ares blisters and rest.

\section{Windgalls}

Consist in an enlargement of the mucous sacs, which are placed behind the flexor tendons for the purpose of facilitating their motion. The swellings appears on each side the back sinew, immediately above the fetlock joint. If punctured, they discharge a fluid resembling joint oil; indeed they frequently communicate with the cavity of the joint, and therefore camnot be opened without danger of producing an incurable lameness. blisters are the only applications likely to be of sel's vice, and these seldom effect a cure unless assisted by rest. 'This complaint does not often occasion lameness, and is therefore seldom mich attended to; but as it is almost always a conscquence of hard work, and often renders a horse unfit for much labour, it diminislies his value considerably.

I have sometimes applied rollers or bandages to 
the legs with good effect, kecping them constantly moist with the following embrocation :-

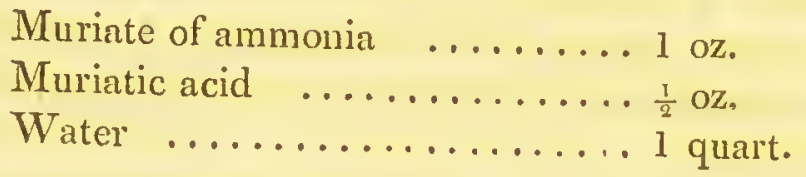

Mix.

\section{Splents}

ArE bony excrescences about the shank bone, $i . e$. between the knee and fetlock joint, and in general are not productive of lameness; and though, during the time of their formation, or soon after, the inflammation then existing causes the horse to go lame, yet this gradually wears off, and no inconvenience is afterwards felt : the splent, however, generally remains. But it sometimes happens that the splent is so situated as to interfere with the suspensory ligament or back sinews, and then it is necessary to attempt their removal; as, in such cases, they grenerally cause lameness. The violent remedies often employed are apt to cause a permanent enlargement of the leg, though they appenr to diminish or remove the splent. The liquid blister is the remedy I usually employ; but, when the swelling is hot and tender, it is proper to adopt the cooling treatment in the first instance, or until 
the inflammation has sribsided. One ounce of sugar of lead, half a pint if vinegar, and a pint of water, form a couling lotion, which is to be frequently applied ; or the part may be kept constantly wet with it by means of a pledget of linen and a bandage. When the liquid blister is applied, it is to be well rubbed on the splent, and repeated, after an interval of about 12 hours: scon afler, the part will be found swollen, and discharging a glutinous fluid, which, drying, forms an encrustation on the surface; but, should it not have produced this effect, a third application is necessary. After a day or two, the cooling lotion should be used and con. tinued until the inflammation has subsided. The same process may then be repeated should it appear necessary. I have often seen lameness attributed to splents, when it has proved to be in the foot; this part, therefore, should always, in such cases, be carefully examined, especially if there be neither heat nor tenderness in the splent, or if its situation be not er idently such as to affect the ligament or tendon. It is a prevailing, but an crroneous, opinion, that splents often cause lamencss; and it too often happens, that the attention is accupied by the splent, while the real disease escipes notice, and the horse is unnecessarily punished. There seems to be a tendency in young horses to throw out superfunus bony matter, which prohnbly depends upon the ligamentous parts being 111duly and prematurely exerted. It has been supposed by Mr. Coleman that, by the inner heel of 
the shoe being usually made thinner, and the immer heel of the hoof being generally lower than the other, the inncr splent bone receives more of the superincumbent weight than the outer; and we find that splents most commonly appear on the inm sicle of the leg.

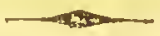

\section{Spavin.}

A SPAvin is a swelling on the inside of the hock, and is of two kinds: the first is termed a bone sparin, consisting of a bony excrescence; the other a loger or blood spavin.

The bog spavin does not so often occasion lameness as the other, except when a horse is worked hard, which generally causes a temporary lameness, removable by rest ; but it does not often admit of a radical cure; for though it is sometimes removed by two or three blisters, it generally returns when the horse is made to perform any considerable exertion.

Tying up the vein which passes over the inside of the hock has been considered the most effectual remedy, from a supposition that the lameness was caused by an enlargement of that vessel : this operation, however, cannot be necessary, since it has been proved that the enlargement of the vein is always an effect, and not a canse of the disease.

Bone spavin consists in a bony enlargement or cxcrescence on the inside of the hock; at first it 
is generally very small, and not easily perceived, unless it is by a careful comparison of the two hocks. The swelling does not always feel hot, nor is it uniformly tender: most commonly indeed the horse will allow it to be handled freely. The swelling sometimes continues in this state a considerable time: the lameness being inconsiderable, and groing off after a little exercise, it is seldom thought worth while to apply any remedy; and the horse is made to continue lis work. Sooner or later, however, the swelling enlarges or spreads, the lameness increases, and the horse works with difficulty, proving very stiff and lame, when first led from the stable, the morning after a journey. When the disease has been suffered to proceed thus far, it often proves incurable: and the only chance of removing the lameness is to fire the part rather severely, and blister immediately after. With respect to the incipient spavin, it may generally be cured by firing moderately and blistering immediately afterwards. Spavin is generally produced by working horses too early, and most commouly happens to those which are cathammed, or have their hocks inclining inward, or towards each other, and the hind legs too much linder the belly; and if in such horses the outside heel of the shoe is turned up, and the inside heel made of the ordinary thickness, the inward inclination of the hocks will be increased, and of course the liability to the disease will be increased.

From these circumstances, it must be sufficicntly 
obvious that the only plan for preventing spavin is to work young horses moderately, and not employ them in liunting or any severe excrcise, until their joints have acquired sufficient firmness; and that probably does not take place till they are six years old. In the next place, the weight of the rider should be duly proportioned to the animal's strength, and the heels of the shoe should be of equal height. (See Shoeing.)

\section{Curb.}

A curs is a swelling on the back part of the hind leg, about five or six inches below the point of the hock. It is seen most distinctly by taking a side view of the leg. Curbs more frequently happen to young horses than such as are arrived at maturity, and especially when the hocks are badly formed, and the hind legs stand too much under the body. Horses of this description are generally active, and may carry a light weight without being injured; but when over-weighted, and particularly if employed much in leaping, a curb or spavin is often the consequence. $\Lambda$ s the disease is not superficial, there is seldom any considerable lieat or tenderness felt in the part, and mild applications do no good: it is always adviseable to have recourse at once either to blistering or firing. I am inclined to give a preference to the latter; having 
several times known the lameness return, after liaving been removed for a time by blistering; but its recurrence after firing very seldom happens. When blistering is atopted, it will be adviseable to repeat the application, taking care to remove the effect of the first blistcr perfectly, by means of the cold lotion before the second is applied. 


\section{CHAPTER V.}

ANATOMY AND PHYSIOLOGY OF THE FOOT.

OF all the diseases to which horses are liable, there are none more difficult of cure, or that occul wo fiequently, as those which attack the foot; and, lowever improbable it may appear to those who have not paid much attention to this subject, it is an incontrovertible fact, that almost all of them are the consequence of bad shoeing, and improper management of the foot.

No one can be aware of the importance of this branch of the veterinary art, but he who has had freruent opportunities of secing these diseases, and lias taken the trouble to inquire into their causes. Such a man will be convinced, that nearly half of the horses that become unserviceable are rendered so by some defect in the fect; and he will find that such defects are most commonly occasioned by a bad method of shocing; thereforc, it must surely be of importance to every man who values his horse, to acquire such a knowledge of this subject, as may enable him to prescrve so useful an animal frem a multitude of discases.

The bad effects which arise from the common practice of shocing are so gradual, that we can 


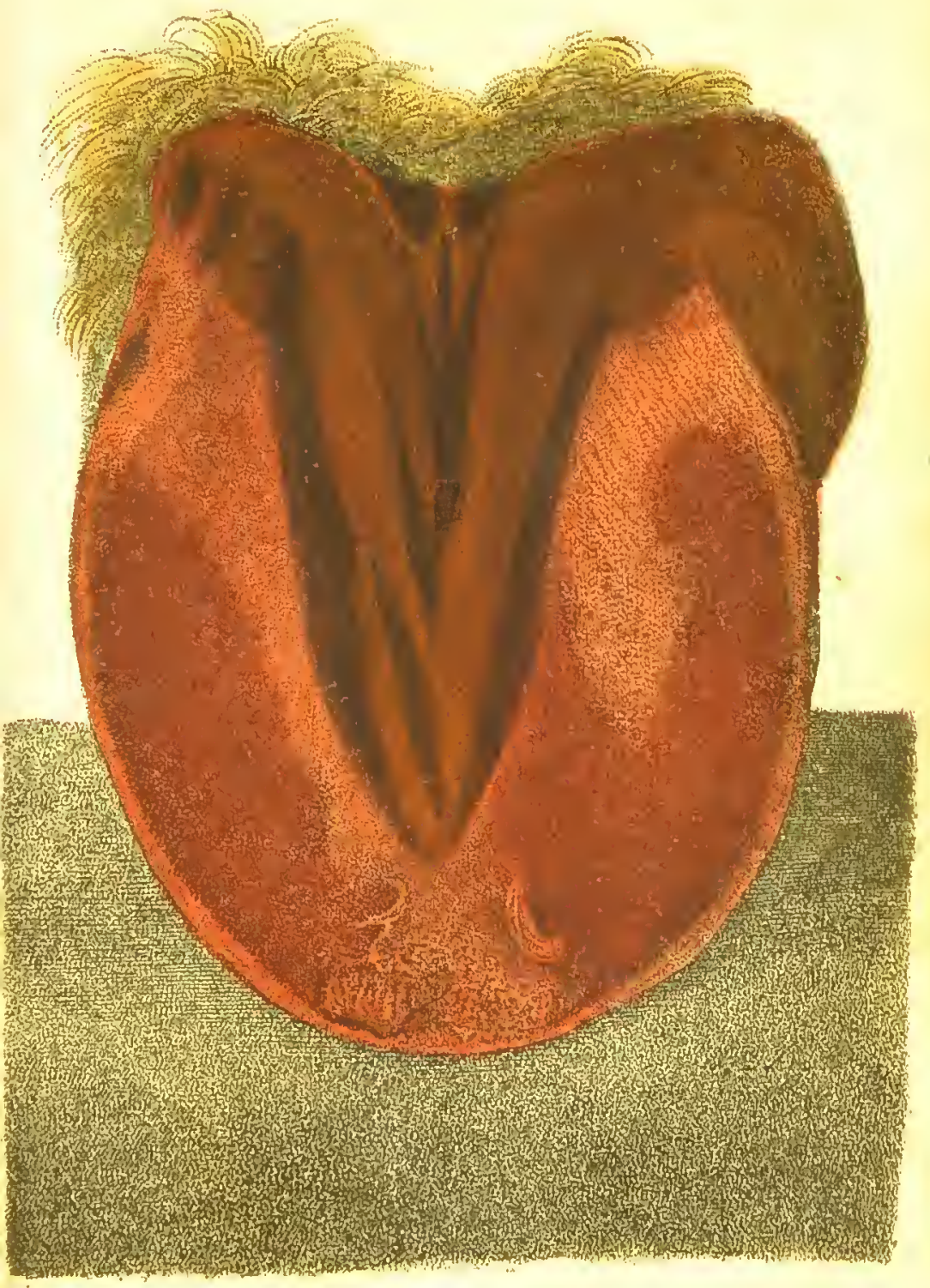

TIV: BOTУOM OF TII: SENSTHLE FOOT.

Engraved ter Mhitei Ferreer. 
easily account for their having bcen generally overlooked: the gradations bctwecn soundness and absolute lamcness arc so numerous, that it has beus found rather difficult to trace the discasc back to its sourcc; and this cannot be done readily without having some knowledge of the structure of the foot, and the particular uscs of the various parts which compose it. It is neecssary also to be well acquainted with the natural form of the foot, in order to detcrmine how fur it has been altered or dcstroyed by any plan of shocing. For cxample, take a horsc that has a sound well-formed foot, lct it bc impropcrly pared, and lct bad shocs be applied; in all probability, lamencss will not be the immediate consequence. By a repetition, howerer, of this practice, it will bc found that the original shape of the foot is gradually altercel, and eventually it will be so far deformed, as to produce perhaps incurable lamencss; therefore, we ought not to be satisfied with a plan of shoeing, increly bccausc a horsc is not immcliately made lame by it, but should examinc also the effect produced by it upon the shape and structurc of the foot; and this rule may invariably be dcpended on, that any modc of shocing and treating the foot, which has a tendcncy to alter the form given to it by Nature, is lighly absurd and destructive; wlyile that practice which tends to prescrve its original form is founded upon sound and rational principles.

It has bcen very justly obscrved, that if wc wish to cxaminc a pcrfect foot, suelı as Nature made it, 
it is generally neecssary to find one that has never. been shod: for the common mode of shoeing is so frequently destructive, that we seldom mect with a horse whose feet have not lost, in some degree, their original form; and this deviation from their natural shape is generally proportioned to the length of time he has worn shoes. From this circumstance, writers on farricry have becn led to form various opinions respecting the most desirable form for a horse's foot; but had they consulted NATURE, this variety of opinion would not have existed; they would have been convinced that the feet of all horses in a state of nature, or not improperly shoed, are nearly of the same shape; and surely no one will dispute that this form, which the Creator has given it, is the most perfect, and far better arlapted to all the purposes for which the animal was designed, than any that can be given by the most ingenious farrier.

A person unacquainted vith the anatomy of the horse's foot would naturally suppose, that the intcrnal parts are simply enclosed by the hoof, and that, by its hardness, it served to protect them from the blows and pressure to which they would otherwise be constantly exposed; but very little reflection would convince him how incomplete and inadequate such a protection would be. Let him be convinced that those internal parts are replete with blood vessels and nerves, and possessed of a high degree of sensibility; let him consider, also, what air immense weight is thrown upon them at every 
step, and what painful concussion must be occasioned to the animal, were this the only safeguard against external injury. Nature, ever provident, has so constructed this part, as to obviate these inconreniences. If we examine any part of the animal economy, we are astonished at the infinite wisdom that is displayed in it. It is not, however, too much to assert, that the structure of the horse's foot is strikingly beautiful and curious: here wc find a variety of wonderful contrivances to prevent any painful concussion, from carrying heavy burdens, or from the most violent exertions; but such is the folly and obstinacy of farriers, that they frequently destroy or pervert the whole of this benutiful mechanism, and the poor animal is doomed to painful labour, or perpetual lameness.

It wonld not be consistent with the objects of this chapter, to give an elabornte description of the anatomical structure of the horse's foot; but it will he essentially useful to give such an explanation of it, as will enable the reader fully to con-prehend the principles of shoeing, and the method of preserving the fect from many troublesome and incurahle diseases.

The horse's foot is made up of a great variety of paris, some of them possessing blood veseels and nerves, like other parts of the body, and highly sensible: others are composed of a dead horny substance, perfectly destitute of feeling. All the external parts of the foot, which when taken together, are termed the coffin, or honf, are com- 
posed of this lrorny substanee; which is not only very hard, but is possessed also of a considerable degree of toughness and elasticity, that render it extremely durable, and well caleulated to protect the sensible parts whieh it eneloses.

The hoof or horny bar of the foot eonsists of the wall or crusts, and its eontinuation the bars, the frog, and the sole. The upper part of the wall, where it is connected with the skin, is termed the coronet, the lower part, in front, the toe; the sides are named quarters, and the posterior parts the heels: liere the wall takes a sudden turn inward, and, passing obliquely forwards, terminates near the centre of the bottom of the foot, on each side of the frog-these inflected tcrminations of the wall are ealled the bars. The following outline figure of the bottom of the foot will serve to illustrate this:

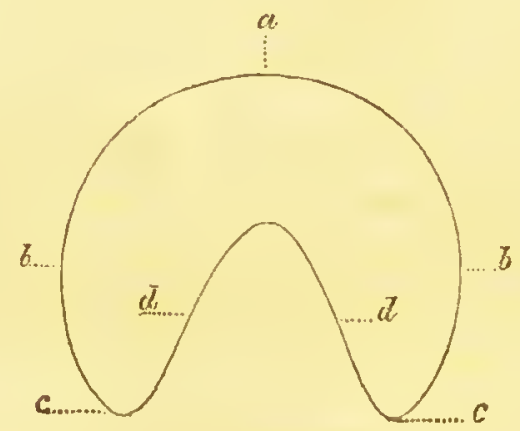

The circular line is the termination of the wall, as seen in viewing the bottom of the foot; a, the 
toe; $b, b$, the quarters; $c, c$, the heels; $d, d$, the bars. The space between the bars and the circular line is occupied by the sole, and the remainder, between the two bars, by the frog. The outside form of the hoof must be sufficiently familiar to every one; and it is only necessary to observe, that the inclination of the hoof, from the perpendicular, in its natural state, is about 33 degrees, according to Mr. Bracy Clark. Feet of this description, however, are rarely met with; and we most commonly see them inclining more to the horizontal line, and sometines more to the perpendicular, which may be illustrated by the following figlule :

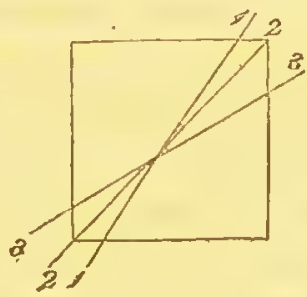

The wall is highest and most oblique in front of the hoof, and becomes gradually lower and more upright to the extremities or heels, where it takes a sudden turn inwards, to form the bars, as before described. (See Plate IV. *)

* Mr. Bracy Clark, in describing the wall of the hoof, obseryes, tlat its figure is trnly a cylinder very obliquely truncated -its truncited cxtremity brought to the ground. This may be exhibited by culling a cylinder of brown paper obliquely, which will give the figure of a hoof of nny slope in front; so 
When we cxamine a hoof that has been recently separated from the foot, an immense number of small orifices, or pores, may be observed in that groove which is found on the inside of the coronet. Into these orifices the extremities of those vessels are inserted which secrete the horny matter, the whole of which appears to be pervaded by a fine fluid, serving to prevent brittleness, and to preserve in the hoof a proper degree of elasticity.

All the internal surface of the crust, except the groove we have just mentioned, is covered by a beautiful membranous or laminated substance, which very much resembles the under surface of a mushroom. This is united, or rather interwovell, with similar laminæ, or membranes, which cover all the anterior and lateral surfaces of the sensible foot, forming a very secure union between the crust and the internal parts. Nor are these membranes possessed merely of great strength: they possess likewise a considerable degree of elasticity, constituting one of those curious springs which Nature has provided to prevent concussion when the animal is in motion. That these lamina form a union between the crust and sensible foot, of sufficient strength to support the animal's weight, has been proved beyond a doubt, by removing from a living horse the bottom of the hoof, that is, the sole and frog. In this case, lad the lamina becil unable to support the horse's weight, the internal that, at a distance, it could not be known from the actual lıoof. 
foot must have slipped through the hoof, so as to come down upon the ground: but this did not happen; and the sole, as it was reproduced, assumed its proper concave form.

As these lamina form so secure a union between the crust and the internal foot, it is evident that the weight of the horse is in great measure supported by the crust, which therefore ought to possess considerable strength; for if it were too weak and flexible, it would not be adequate to the burden which it has to sustain, and must consequently bend to it. In this case, the hoof would lose that oblique form which it had originally, and would approach the horizontal line. (See Fig. 1 and 2, Plate III.) At the same time, the sole would lose its concave form, from receiving an unusual degree of pressure, becoming flat, and at length convex or projecting. (See Fig. 2, Plate II.) But when the crust is sufficiently strong, the internal foot, and consequently the whole aninal, is suspended by those elastic membranes, as a carriage is by its springs; and though the bottom of the internal foot is in contact with the sole, it nevertheless docs not press upon it considerably, except when the horse is in motion, and then the back part of the sole descends a little, being somewhat clastic, and suffers the laminæ to elongate in a small clegrce, so as to prevent any painful concussion.

The bottom of the hoof is formed by the sour, the rrog, and the Bans.

The sole is rather concave, or hollow on its ex- 
ternal surface, and consists of a different kind of horn from that which forms the crust, being of a scaly texture, and sometimes soft and pulverable on its exterior surface: its use is to defend the sensible sole, that lies immediately under it. From its concave form, the horse is enabled to tread more firmly on the ground, and the sensiblc parts are less exposed to blows or pressure than they would be, had it been made either flat or convex; and, being somewhat flexiblc and elastic toward the lieels, it assists in the action of those clirious springs wc have just described.

The frog is a very important part, and requires to be particularly considered. It is intimately united with the sole, but is composed of a tougher and more elastic kind of horn. It resembles a wedge in its form; but towards the heel, where it becomes wide and expanded; there is a separation in the middle, which is continued to the lieel. When the frog receivcs the pressure of the horse's weiglit, this separation is increased, and consequently the frog beconies wider; and, as it is connected with the heels of the crust, the same effect must be produced upon them.

As great part of the frog is placcl behind the coffin bone, all the intervening space between it and the back sinew being filled with a fatty elastic substance, it forms another of those curious springs which Nature has provided to prevent concussion.

When the frog is in contact with the ground, it is evident, from its connexion with the heels of the 
crust, as we have before observed, and with two cartilages, or elastic bodies, which are covered, in great measure, by the heels and quarters of the crust, and belong to the internal foot, that it must tend to widen or expand the heels; and, however they may be disposed to contract, by the foot being kept hot and dry, such contraction cannot possibly take place while the frog bear's on the ground, because it is then opposed by a very considerable part of the animal's weight.

It has been supposed by some, that the principal use of tine frog is to serve as a cushion and point of support to the back sinew. When we consider, however, the structure and relative situation of these parts, this opinion does not appear to be very probable. From what has been saicl of the frog, the reader may judge of its importance, and how necessary it is to attend to its preservation; but such is the mutilating practice of farriers, so determined do they seem, on all occasions, to act in opposition to Nature, that this essential part is generally the first that is destroyed, or rendered useless, *

* The following description is from Br. B. Clark's work:-m "seen from wilhout, the frog makes a bold and projecting appearance, as though it were a solid body of horn; and the smiths, certainly deceived by this alpearance, entertain but indificrent notions of its real structure: for it is, in reality, an inverted arch only of horn, that is, turned downward and reversed in re. spect to the general arch formed by the sole and bar, that its real thickness in horn is not so considerable as, on a first view, it would appear to be. The frog, scen from within, that is to 
The lars form two oblique or slanting ridges, one on each side the frog, in the perfect foot, in-

say, when the font is drawn forth from the hoof, preserits an inverted triangular arch, so intimately connected with the bar and sole, that no one would suspect it to be a distinct and divisible part, one uniform uninterrupted porous surface being every where on this inside: it may, however, he exhibited as a distinct insertcd part, by making a horizontal section of the foot through the nnion of the bar, with the side of the frog, whcn the difference of their structure and appearance, and the line of their applied surfaces, become sufficiently visible and distinct. A hoof exposed to the weather will also be seen, in its decay, to scparate at this part first; so that it is assuredly a very distinct part from the rcst of the hoof. By actual admeasurement, in several instances, we find that the base of the frog occupies a certain division of the general circle of the hoof, and that this division is about a sixtl part of the whole circumference. By knowing this fact, we are not only led to entertain more jlist notions of the form of the foot, and the proportion of its.parts, but it affords us also an easy means of forming a pretty accurate guess of what injury or diminntion the foot las sustiined, at any period of the horse's life, withou" previonsly seeing the original state of the frog."

Mr. Clark then proceeds to describe a circumstance respecting the frog, which has not becn noticed by any other writer on the subject. "The frog is connected, in a very unexpected manner, with the front of the foot; the wings or lateral processes of the base of the frog not only enclose the ends or doublings of the hoof, but the same horm is continucd round the whole line of the commencement of this part of the hoof, immediately beneath the coronary ring, forning a convex band, whose upper edge, or margin, projecting higher than the hoof itsclf, receives, and covcrs over, the tcrminating edge of the skin, where this part mects the hoof, and thus protects it from injury or dislocation by external violence of any kind; it also seems to serve the useful purplose of kecping those parts moist and pliant, preventing irritation: for, when wetted, it appears * 


\section{clining outward, and extending from the heel of the crust toward the toe of the frog: they appear}

readily to absorb moisture, and continues of a darker colour in consequence, whilst all the other parts of the hoof are suldenly dried: it has the power, it would seem, when no extermal wet is artificially applied, of collecting the perspiration of the skin; thus maintaining the proper tenacity and plianey of these parts. Every one used to examining the hoof of the horse must have observed, when the hoof is drawn out of it, a projeeting eminence of soft horn, with a ehannel inside it, heing the upper edge of this hand; this appearance we had long ago noticed without, till lately, observing from whence it had its origin: besides the usc already described of comnecting together the upper circle of the hoof, stuporting and adapting it to the sensitive eircle, it strongly binds the frog in its situation by connecting it with the front of the hoof, and to the upper part of the slope of the ho:ny heels. This band makes a small appcarance at two and three years old; but, as the frog acquires its size, this also completes its bulk and form. This cssential part of the horse's foot appeas hitherto to have remained almost undistinguished; we venture, therefore, for the conveniency of speaking of it wilhout a cireumlucution, to name it the coronary frog band." (See "A Dissertation on the Font of the Horse." By Bracy Clark. M. Jauze, formerly professor of the reterinary sehools at Milan and Alfort. las asserted, in his Cours de Maréchallerie Viterenaire, that this c ronary frog band was described by Bourgelat, and named bnurre'el graissew.x, and that Mr. Clark has improperly claimed it as a diseovery of lis own. On examining Bourgelat's Essai sur la Ferrure, I can sec nothing in his deseription which eorresponds with the coronary frog band. He says, "the foot, separated from t'se hoof, presents scveral objeets worthy of consideration. 'T'he first that strikes us is the bourvelet (coronary ligament of Mr. Coleman), forming the superior portion of this part, and which fills exactly the cavity in the inside an.l supcrior part of the hoof, hesiore described. The inferior porion of this coronary ring or lisament (bourrelet) exhibits inumerable small vesscls, cvidently drawn from the small ori- 
to be a continuation of the crust, being, like it, composed of strong longitudinal fibres. At the part where it joins the crust, a very firm bearing is afforded for the heel of the shoe. (See Fig. 2, Plate I.) The use of the bars is to oppose any disposition there may be in the hoof to contract, by acting as props to the heels; and, by their.slanting position outward, may tend, in some degree, when pressed upon, to expand the heels: but in the common practice of shoeing, they are generally destroyed; for farriers liave supposed that they bind the heels together, and prevent their expansion: they thereforc name them binders, and cut them away in order to open the heels, as they term it. 'This practice, however, is not now so frequent as it used to be. A practice, however, equally mischievous is still too often adopted, which is termed opening or laying open the heels, which consists in cutting away the angle formed by the junction of the bar and crust.

Having finished our description of the honf, we shall proceed to describe the internal or sensible

fices or pores which may be seen on the surface of the above de. scribed cavity, in the upper part of the hoof." The coronary frog band of Mr. Clark is composed of horny matter, covers the superion part of the hoop, extending all around, and is gradually lost in the horvy matter of the frog. M. Jauze has, with more justice, perhaps, disputed some other claims of Mi. Clark to discoveries; particularly that of the elastic properties of the hoof, and the mischievous eflects of shoeing. 
foot, which is represented in Plate V.* as it appears when recently taken from the hoof, the arteries having been injected with wax, coloured red.

All the parts of which the internal foot is composed are, as we have before observed, endued with great sensibility; and so nicely is it adapted to the cavity of the hoof, that it completely fills it, without suffering the least inconvenience from pressure: but when the foot las been improperly treated; when the frog has been deprived of its hard surface, for-the purpose of giving it what farrier's conceive a neat and fashionable appearance as if Nature had been imperfect in this part of her work, requiring a polish from the hands of these ingenious gentlemen; when the frog has been thus mutilated, the bars destroyed, and shoes applied that are cither turned up, or made very thick at the heels; and when this shoe, for the purpose of saving trouble, has been applied to the foot nearly red hot-in such circumstances the lool' must necessarily, contract, whereby its cavity will be diminished, so that the nerves and blood vesisels will be compressed, the circulation of the blood impeded, and infammation and lameness will most probably be the consequence.

All the anterior and lateral surfaces of the sensible foot are covered with that nembranous, or laminated substance, which we have before described; but it differs from those Inmina, which

Frontispiece. 
are found on the intermal surface of the crust, in possessing numerous blood vessels, which can be easily demonstrated by injecting coloured wax into the trunk of the arteries; but the laminæ of the crust cannot be made to appenr vascular, even by the finest injection, and are therefore supposed to be insensible. At the upper part of the sensible foot, where the laminæ terminate, a roundish projecting body may be observed, extending all round the coronet to the back part of the frog: this is termed the coronary ring, Its surface is covered witl the extremities of vessels, which are very conspicuous when the arteries have been injected with coloured wax, or size: it is from this part that the hoof is formed.

The bottom of the internal foot is formed by the sensible frog and sole; the former perfectly resembles in shape the horny frog, to the concavities of which its convexities are nicely adapted. In describing the horny frog, we had occasion to mention its connexion with two elastic bodies or cartilages that are in great measure covered by the heels and quarters of the hoof; but this connexion is through the medium of the sensille frog, which is more immediately united to those cartilages. When the former comes in contact with the ground, and receives the pressure of the horse's weight, the latter is forced upward and rendered wider, and at the same time the cartilages are forced upward and ontward, tending thereby to expand the heels and quarters, and assisting in 
taking off concussion. From the sensible frog and solc, the horn which composes the external frog and sole is secreted. For this purpose they are supplied with numerous blood vessels, the extremities of which may be seen upon their surface, and become very conspicuous when the arteries have been injected with coloured size. Hence we are enabled to account for thrushes and that rottenness of the frog which generally accompanies this disense; for when the sensible frog is compressed and inflamed by a contraction of the lieels, it becomes incapable of performing its principal function, that is, the secretion of horn; and the blood, which should lave been applicd to this purpose, is chiefly cxpended in forming that offensive matter discharged in thrushes. From this we may learn also the cause of that unnatural thinness in the soles of horses that have pumice or flat feet. When the crist gives way to the pressure of the horse's weight, allowing the internal foot to bear so upon the sole as to reuder it either flat or convex, the extraordinary pressure which the sensible sole receives inflames it, and impedes, in a greater or less degrec, the secretion of horn.

The sensible sole lies immediately under the horny sole, by which it is defended from blows or pressure. When the horny sole loses its concave form, and becomes thin and incapable of performing its function, if flat shoes were applied, or if the sole were suffered to bear upon the ground, lameness would be the consequence; and it is for 
the purpose of preserving the sole from pressure, that the concave or hollow shoe is employed in those cases. When these parts, which we have described, are removed from the sensible foot, the tendons, ligaments, and bones, come into view.

In Plate IX. is a back view of the bones, ligaments, and tendons. In this the course and insertion of the back sinew, or flexor tendon, may be seen, as well as the lateral cartilages. The flexor tendon is enclosed in a sheath, which is laid open in one part in order to show the tendon: it has been removed also fiom the bottom of the tendon that its insertion may be clearly secn.

In Plate X. are represented the ligaments, for which purpose the tendons were removed. The lateral cartilages nay be seen in this view also.

In Plates XI. and XII. are a front and back view of the bones. It will be unnecessary to give a particular description of these, as their form and relative situations may be seen by referring to the plate. It may be nseful, however, to point out the sesamoid bones, and the navicula, or nut bone: the former are connected posteriorly with the lower extremity of the cannon, or shank bone: they consist of two small bones, firmly united by means of very strong ligaments; they compose part of the fetlock joint, having a moveable articulation with the cannon bone. Their external part affords a smooth polished surface for the back sinews to slicle upon, and the same ligament which composes this surface comes round the back sinews, so as to 
form a sheath for them, and keep them in their situation. In this sheath a fluid similar to synovia, or joint oil, is formed, for the purpose of rendering it smooth and slippery, and cnabling the tendon to move casily upon it. As these bones project a little, they serve as a pullcy for the tendons to slide upon, and afford a considerable mechanical advantage to the flexor muscles of the limb. The nut bone scrres as another pulley for the tendon or back sincw to move upon: it is connected posteriorly with the cofhin bone and the small pastern, and affords the same kind of polished surface and sheath for the tendon as we have before described. For a more particular description of the foot, the reader may consult Professor Coleman's work on that subject; alșo Mr. Clark's.*

* In saying that the form of the colt's font is always perfect, and of a certain form, $I$ do not menn that this part is more cxempt from disease than others, cven before the application of shoes. Some colts applear to have a constitutional tendency to diseased feet; much lepends also on the soil and climate in which they are bred: thus, colts bied in low swampy grounds are liable to large flat fect, litrge soft frogs, \&c.; while those in hot dry situations are more liable to contraction and lard britte hoofs. 


\section{CHAPTER VI.}

ON THE PRACTICE OF SHOEING.

HaViNG given, in the preceding chapter, a concise description of the horse's foot, and pointed out the uses of the various parts which compose it, I shall now describe the method of shoeing. It will be necessary to premise, that the mode of shoeing most commonly practised lias a destructive tendency, and produces such a variety of diseases, that we seldom meet with a foot that has not lost, in a greater or less degree, its original shape: it must be obvious, therefore, that one kind of shoe cannot with propriety be recommended for general application, and that it is necessary, on all occasions, to adapt it carefully to the state of the foot. This constitutes the most difficult part of the art of shocing; and, from neglecing this precaution, shoes of the best form krave often occasioned lameness.

In Fig. 1, Plale I. is represented a colt's hoof in a state of nature, of which no part has ever been cut away, or ever been shod: this we have given as a standard of perfection, fiom which the goodness of fect in general may be judged of; for surely no one will lycsitate for a moment in admit- 
Mr Colemanis Patent Shoe

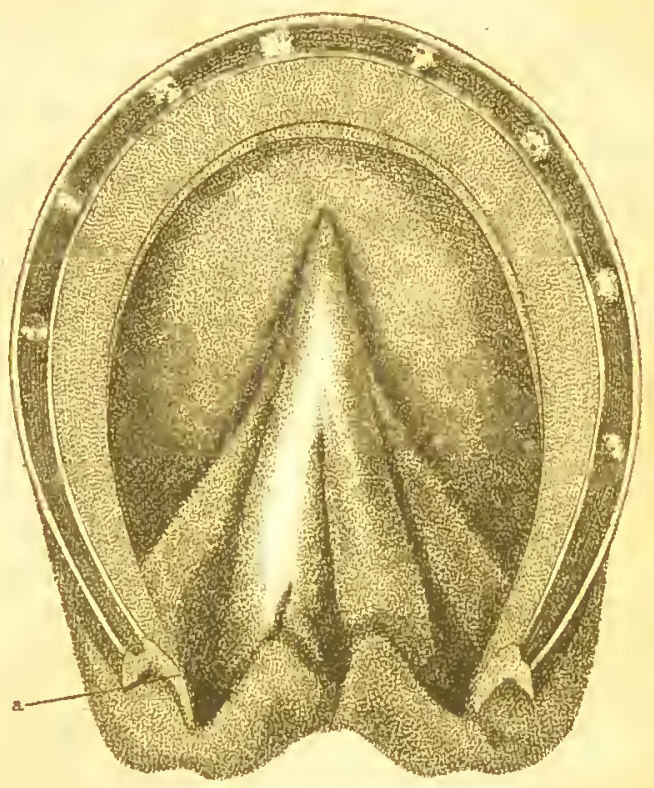


$y$ 
ting that the natural form is the best it can possibly possess.

In Fig. 2 of the same plate is shown ali imperfect or contracted foot, properly prepared for the shoe. In this foot the superfluous horn has been cut away, and an even surfice made for the shoe to bear upon.

If we examine the feet of a huridred colts, it will be found that more than ninety of them are of the same form. It is tiue that sorie may livive. grown more luxuriantly than otliers, whereby the crust will ibe deeper, and the bottom part may have been partially broken, so as to give the foot a ragged and uneven appcarance: still the essential shape is the same; and when this superfluous horn has been removed, it will be found that the bottom of the foot will be nearly circular, the sole concave, the bars distinct, and the frog and heels open and expanded.

In preparing the horse's foot for a shoe, tlie lower part is to be reduced, when luxuriant, which is generally the case, more particularly at the toe; and this is to be done by means of a butteris or rasp : the loose scaly parts of the sole are likewwise to be removed, so as to preserve its concavity.

The junction of the bar and crust affords a firm benring for the lieel of the shoe, and is to be rasped perfectly flat, and so low as to be cxactly on a level with the frog, that they may bear equally on a plane surirace before the shoe is applied; indeed, the whole of the bottom of the crust is to be made 
perfectly flat and even at the same time with the rasp, that the shoe may bear equally on crery part of it. Farriers should never be allowed to do this by means of a hot shoc, which is too frequently the case. If any ragged parts are observed in the frog, they are to be carefully removed with a knifc; for, if suffercd to remain, they might afford a lodgement for dirt and gravel. Thus do we prepare a foot for the shoc; and to a foot of this description, I mean one that is sound and perfect, or that has not suffered any material alteration in its form from improper shocing, the shoe (Fig. 3, Plate (V.) is to be applied.

The toe of the shoe, for a middle-sized horse, is about an inch in wicth, and haif an inch in depth or thickness; the heels about half an inch in width, and threc eighths in depth. The wearing part of the toe is to be made of steel; and it may be observed, that the nails are brought very near to the toe, but not quite rolind it; for when that is done, there must also be a groove made, which considerably weakens that part, and almost all horses wear principally at the toc, rather to the outside. Both surfaces of the shoe are serfectly flat; and the heel of the shoe rests upon the junction of the bar and crust, beyond which it should never extend.

It will be supposed, perhaps, that a shoe which is flat on that surface next the foot will be apt to produce lameness by pressing on the sole; but let it be recollected, that this shoe is recommended only for a sound foot, in which the sole is always 
a little concave; so that it cannot possibly receive any pressure from a flat shoe. It may be said, also, that when the nails are placed so far from the heels, the shoe will not be sufficiently sccure, and will be frequently looscned; but as the shoe bears equally on cvery part of the crust, this objection cannot have any weight. It must be granted, however, when a foot is pared in the common way, that is, when the hecls have been opened, and the shoe so applicd, that nearly an inch of the heel has no bearing upon the crust; that, if the nails wcre placed so far from the hecls as I have recommended, the shoe would be very insecure; for, as much of it as had no bcaring upon the crust would operate occasionally as a lever in raising the mails; and consequently the shoe would frequently be loosened. Farricrs, therefore, find it ncecssary, when the foot has been thus pared, and the shoe applied in this way, to place the nails in the quarter's, by which the shoe is certainly rendered more secure than it would be had they been placed nearcl the toe.

Many disadvantages, however, attend this method. In the first place, by placing the nails in the quarters, they prove a considerable obsiacle to the expansion of the heels; and as tlic crust is generally much thinner at the quarters than at the toe, the scnsible parts are more liable to be wounded : but this does not apply to the hind feet, in which the crust of the quarter's is generally thicker than that of the toe. When a horse ovcrieaches, 
if any part of the shoe has no bearing upon the crust, it is very liable to be struck by the toe of the hind foot; and shoes are often forced off in this way. To this may be added the insecurity of such a shoe when a horse is rode on a deep or heavy ground.

It will probably be observed of the shoe which I have recommended, that it is inconsistent with the princinle which has been laid down respecting the necessity of the frog's receiving pressure. I believe it is an incontrovertible fact, that, unless the frog receives a certain degree of pressure, it will become soft, and incapable of affording suffieient protection to the sensible frog, which it covers; and that the heels will gradually contract, and the natural form of the foot will be destroyed; for I have proved, by experiment, that the bars alone are not sufficient to prevent contraction, though they certainly oppose it with considerable force; but it does not follow from this that it is necessary for the pressure to be conslant, nor do I believe that a shoe which allows the frog to bear upon the ground, when the horse stands upon a plane hard surface, can be always applied, even to sound feet, without inconvenience. There can be no doubt that a horse in a state of nature has his frog almost always in contact with the ground, and then of course he feels no inconvenience from it; but when burdens are placed upon his back, and he is driven about upon hard roads, he is certainly in very different circumstances; and if the frog in 
such cases were constantly exposed to this severe pressure, it would sometimes, I believe, occasion lameness.

In the foot, preparcd for the shoe (Fig. 2, Plate I.), the frog and heels are on a level, and if placed on a plane hard surface, would bear equally; by applying the shoe (Fig.3, Plate IV.), the frog would be raised three eighths of an inch from the ground; so that when the horse is going upon a hard surface, where he would be most liable to feel inconvenience from the pressure on the frog, it receives none; but upon soft yielding ground the frog certainly receives pressure, and without giving the animal any pain. To a liorse that travels or works regularly', and is occasionally taken upoi soft ground, I believe the pressire the frog receives in this way is quite sufficient to preserve the foot in a state of health; but when a horse is kept almost constantly in the stable, standing upon hot litter, particularly in hot and dry wcather, his feet will certainly be undergoing an alterention in their form, and will be in a progressive state towards disease.

In these cases, conträction may generally bé prevented by keeping the foot cool and moist; and it should be remembered, that; wilienever the frog is much exposed to pressure, whether it be by the thin-heeled shoe, or reducing the crust at the hee it is necessary the quarters and heels sliould possess a proper degrec of pliancy. If they be rigid and 
inflexible, it is evident that the sensible frog and cartilages would be placed between two fixed points, and they would consequently be bruised and inflamed. I have indecd seen scveral cases of lameness produced in this way. Whenever the hoof, therefore, appears to be too dry and strong, or to have lost its natural elasticity, it is necessary to kecp the whole hoof moist, either by applying several folds of fannel round the coronet, constantly wetted, or by making the horse stand in the sponge boots during the day: by these means the natural flexibility of the horn would be restored, and the heels and quarters yicld, in a small degree, whenever the horse's wcight was thrown upon the frog.

Having said as much as appears to be requisite of the method of shoeing a sound foot, I shall proceed to describe those diseases of the foot which render a different kind of shoe necessary. In the first place it will be proper to observe, that when a horse, even with a sound foot, has worn shoes that are very thick, or turned up at the heels, particularly if, at the same time, the crust at the hecls have been suffered to grow so high that the frog is kept at a considerable distance from the ground, it would be very improper to reduce thic hecls suddenly, so as to allow the frog to receive pressure, since the back sinews would in this case be injured, and lameness might ensue. In feet of this description, it is necessary to remove from the toe all that 
can be done without exposing the part too much, and to lower the heels gradually: the toe of the shoe should be rather thin, and of the best steel.

The shoe for draught horses should be made flat on both surfaces, provided the sole is of a proper form and thickness; but if flat or convex, and consequently too thin, which is often the case in lorses of this description, the internal surface of the shoe must be concave: still the external surface should be flat; for the convex shoe, which is commonly used for draught horses, prevents them from treading securely, and renders them incapable of exerting the whole of their strength. 


\section{6}

\section{CHAPTER VII.}

\section{DISEASES OF THE FOO'.}

Though the hoof, to a common observer, may appear as a mass of unorganized matter, defending, merely by its hardness, the sensible parts which it encloses; it will be found, apon a careful examination, to consist of a series of small tubes, through which a fluid is transmitted, for the purpose of prescrving its most essential property, elasticity. When a horse is in a state of nature, the hoof is, by these means, as well as by the due exercise of the various parts which compose it, preserved in a proper degree of elasticity and temperature; but when kept in a stable, standing great part of the day upon straw, and his feet placed under the management of the smith-or, if by any means a preternatural degree of heat is excited in the foot, the horny matter, of which the crust or wall of the hoof consists, will be disposed to contract or shrink; and the contraction will proceed more or less rapidly, according to the degree in which the disposition to contraction exists, and the resistance that is oppesed to it. When the crust or wall of the lioof is separated from the other parts, as represented in Plate III. Fig. 2, and exposed to the 
air, its moisture quickly evaporates: and as every part is removed which is capable of opposing contraction, it takes place very rapidly, as may be seen in Fig. 1, which represents the same subject as it appeared a few days after it was stripped from the foot. In the perfect foot, the tondency to contraction is powerfully resisted by the bottom of the hoof, consisting of the frog, bars, and sole, as well as by the coffin bone, and other parts by which it is completely filled, Unless the contractile disposition is considerable, the resistance thus afforded is sufficient to prevent contraction; but when the bars are destroyed, the frog mutilated, the shoes made, and applied improperly, and the horse made to stand great part of his time on litter, contraction will necessarily take place: for, although the internal foot forms a strong resisting power, the pressure it suffers causes a gradual absorption or wasting to take place, and the contraction will procecd as the resisting medium is removed. In speaking of the method of preventing this disease, it is necessary first to inquirc on what the contractile disposition depends; and then state the means that Nature has provided to oppose it, as well as the artificial means that have been, at diferent times, suggested for the same purpose. The foot, like other parts of the body, is liable to become inflaned, or to have its natural temperature increased by various causes; and when this happens, the horny covering or hoof will not be duly supplied with that moisture on which itg flexibility and 
elasticity depend. Horses that are rode or driven hard upon the road, and afterwards kept for several days together upon littcr, and at the same time fed highly, are liable to contraction of the heels: the disease is often produced also by a sudden transition from cold to heat; that is, by putting a horse into a hot stable, upon litter, and feeding him highly, after travclling or standing some time in snow. There appears to be a constitutional tendency in some horses to hot feet; and in some diseases, the fcet become very hot or feverish, as it is termed. If wc compare the fect of post-horses, and others kept and employed in a similar manner, with those used in agriculture, and kept principally at grass, a remarkable difference will be observed: in the latter, we rarely meet with contracted hoofs, while the former are seldom free from it. I know not how this fact can be accounted for, unless it be admitted, that, by avoiding those causes by which a preternatural degrce of heat is excited in the foot, we prevent contraction; as there will not then be any disposition in the horny mattcr to contract. It is not to be inferred, from what has been said, that standing upon littcr, and high feeding, will invariably producc contraction; nor is it to be supposed, that horses employed in agriculture will always be cxempt from it. A horsc "inay be naturally so hardy as not to be susceptible of that morbid heat in the fect, though kept in a situation, and under circumstances by which it would generally be excited in one of a 
more delicate constitution; the natural conformation of his fect, also, may be such as to oppose an effectual resistance to any moderate tendency to contraction. On the other hand, a horse kcpt wholly at grass may have considerable inflammation of the foot from wounds, bruises, and even from some constitutional affection. Mr. Bracy Clark, in his "Dissertation on the Foot of the Horse," has endeavoured to prove that contraction of the hoof is an unavoidable conscquence of shoeing, and that, from the time a loorse is first shocd, his fect will be gradually contracting and losing their original form. He has, thcrefore, takcn great pains to discover some method of applying an iron defence to the foot without nails, which he considcrs the cause of the evil. "The nails," he says, "driven by violent hammering into the square perforations of the shoe, are lodged thercin so firmly as to form with it a solid mass, wholly preventing any movement of the hoof at the parts where they enter, and at some distance from them; the quarters being held in this fixcd state, the rest of the hoof is also robbed of that motion which is necessary to the healthy existcnce of the foot: being thus held for months, and evcn year's, in a constrained statc, it becomes stiff and inelastic, then diminishes in size, and a train of cvils ensue." Mr. Clark suggested, therefore, some contrivances for defending the foot; without the use of nails, which he named paralrites. "Its principle," he says, "is founded upon the circumstance of the 
wall of the hoof being of a cylindrical form; so this defence, embracing a part or portion of the exterior of the cylinder is made to pass underneath, and, by upright teeth passing within it, to embrace the interior also, and by this means is held on. It is a material consideration in the nse of this defence that the line of wear is worn awny three times faster than any other part of the hoof; so this defence, defending this portion, enables it to perform three times the work it is capable of in the natural state of the hoof (without sloees), which is sufficient for many useful purposes; and we may add, that two or more of these shields may be applied, and the defence, on the same principle, carried round the whole, or any part of the hoof." $\mathrm{Mr}$. Clark then describes another kind of shoe, which he says "is strong enough for every kird of road, and will afford the full advantage of all the labour the horse can render, while it admits the movements natural to the foot, at the same time is as simple and easy of application as another shoe." "When the injurious effects of the common shoe first became understood by me, the immediate suggestion that occurred for relicf was a jointed shoe; but as the joint would naturally fall in front of the shoe, and come within the wenting line, so it would be soon worn through, or, if only half through, and the head of the rivet was gone, the two pieres would come asunder, or no longer support eacli other : for it is clear a shoe of two picces, meeting in the middle of the toe, with- 
out any joint or connection, woukl be liable to be torn off in rough roads, and the sides of the hoof torn away with them." This difficulty, however, Mr. Clark got rid of "by the simple application of a steel pin, to rivet them together with, instead of the iron one, and, by making the head of the rivet large, and hardened, it would serve, at the same timc, to defend the joint and steel the toe. In respect to flatness and smoothness, they can be made, if required, as smooth as the common shoe; and as to the mode of fastening, it is, in all respects, the same, viz. with nails, that it is as firmly attached as they can be." Mr. Clark then advances proofs that this shoe does not contract the hoof, which, he belicves, can be established satisfactorily. "A horse of his own, six years old, wore these shoes more than twelve months without the least contraction of the hoof whatever. The same trial was made upon another horse, that had previously worn common shoes, and contraction of the hoof had commenced, which it completely remedied, and restorcd his action. In some other cases, they were found equally beneficial. The movement of the shoc may be seen by taking up the foot, and squeezing it between the hands; on relaxing the pressure, the shoc and foot nay be secn to fly open again. To witness the effects of the common shoe, one was put on for six weeks, and an impressed ring took place round the coronet, or rather upper part of the loof." However ingenious Mr. Clark's reasoning niay appear, 
a few simple facts will be sufficient to show that it is erroneous. If the common mode of shoeing was invariably a cause of contraction, and if its progress was sometimes so considerable as to cause an impressed ring to appear at the upper part of the hoof in six weeks, I would ask, what state must a horse's hoof be in after having been shoed ten or twelve years? I would ask also, does the expansion of a horse's hoof bear any resemblance to that of a hinged shoe? Mr. Blaine very properly observes, that, " if contraction took place at all in the ratio of Mr. Clark's experiments, no horse but at twelve must be completely foundered. If, also, shoeing, good or bad, contracted the feet, and the other alleged causes were really incrt, then we should meet with no difference between the feet of horses used by farmers and others in the country, and those belonging to the inhabitants of large cities, the reverse of which is too well known to be further insisted on." If we examine the hoof when stripped from the foot, the horny frog and sole having likewise been removed, we shall find, that the contraction which takes place is principally at the heels, where the horn is thin and flexible, as in Plate I. Fig. 2, which represents a hoof that had been stripped off two or three days. If, then, when a sloe is applied, the nails are placed round the toe, and as far from the heels as the security of the shoe will admit, the motion of the heels will not be impeded, and some part of the quarters also will 
be unrestrained. As the hoof; when shoed, is constantly growing, and prevented from weariig, the horny matter will accumulate, and require to be removed from time to time. In some horses, the growth or secretion of horn is vely slow, and no inconvenience is experienced from leaving the feet umpared five or six weeks; while in others, it grows more rapidly, particularly the sole, and it becomes necessary to remove the shoes, for the purpose of paring away the superfutous horn once in about three weeks. On examining the bottom of the sensible foot, we observe the whole surface both of the sole and frog corered with minute filaments, which appear to be the extremities of arteries, and probably those which form the horny matter; and on the interior surface of the frog and sole, corresponding pores are seen, from which these flaments appear to have been drawn: the same appearances may be seen in the coronary ligament or ring, and the circular carity, in the upper part of the crust from which it has been taken. When a hor'se, therefore, is standing for scveral days together upon hot litter, and at the same time fed highly, a morbid degree of heat will arise in the feet, the horn will become harder, and less elastic, the secretory vessels will be compressed, and a still higher degree of heat will be excited. It is in this way, I conceive, that contraction and lameness are often produced. Fast trotting horses are particularly liable to hot feet, from the piolent exercise in which they are generally 
too much employed, the high feed they are commonly allowed, and the hot stables in which they are usually kept. The most effectual method then of preventing contraction appears to me to consist in avoiding those causes by which a morbid lieat is excited; and when any tendency to it is observed, to take care that the soles are properly pared, and kept cool, by stopping the feet witl soft clay: if this does not prove sufficient, the whole hoof may be kept moist by wrapping it in a large bran poultice or the spunge-boot; a cooling and opening diet, or even a moderate dose of physic will also be useful: but turning the horse to grass.is, perhaps, the most effectual remedy. Various mechanical means have been recommended for the cure of contracted feet: among these, one, for a short time, acquired considerable reputation. Though a professed secret, it was pretty well known to be nothing more than the old screw shoe with some trivial alteration. Many cures were said, at the time, to have been effected by it; but it was soon discovered that its boasted efficacy was only imaginary, for, though it often afforded temporary relief, it was never found to be productive of permanent advantage. It is probable that the principal cause of the temporary reputation it acquired was the constant state of moisture in which the feet were kept during its application. (See Plale III. Fig. 2.) Mr. Coleman has obtained a patent for a shoe which is represented in Plate XIV. This shoe is intended to prevent contraction of the heels: and is said to be 
more secure than the eommon shoe, as the inner corner of the heels are bent down upon the inside of the bars, so as to prevent any lateral motion in the shoe. This is certainly a desirable property, as the shoe is more seeure, with a smaller number of nails; but when there is a strong disposition to contraction, it would probably do misehief, by bruising the sensible parts, between the heel and the clip of the shoc. The method originally proposed by Mr. Colcman for expanding eontracted heels, that is, for rasping the hecls and quarters, kceping the hoof moist; and allowing the frog to receive pressure, had ecrtainly the good effect of improving the shape of the hoof, and often removed the lameriess for a time; but when the horse was put to work, or kept in the stable, the disease generally returned. When contraction has proceeded so far as to canse lameness, a radieal cure is rarcly practicable; prerention, therefore, is an object of great importanee, and the means most likely to aecomplish this should be carefully attended to. No one ean say what degree of contraction will produce lamencss : we sometimes meet with a hoof so contraeted, and the heels so nearly approximating, that seareely any frog can be scen, while the horse appears free from lameness : at others, we sce a horse lame in the foot, with rery little alteration in the form of the hoof. Though the hecls are the parts where contraction most readily takes placc, yet we often find the whole foot diminished in size: this depends, perhaps, 
upon the connexion of the coronary ring or ligament with the sensible frog; which is such, that whenever the frog is compressed or squeezed together by the horny heels, a similar effect must be produced upon the coronary ligament, of which it seems to be il continuation, as the hoof is formed by the vessels of this ligament. *

\section{FOUNDER, OR FOUNDERING. $†$}

Tus disease seems to depend upon inflammation of the elastic membranes, or processes of the sen-

* Mr. Coleman, I believe, first gave the rame of ligament to this part; the propriety of which is questioned by Mr. Clark, who considers it as a skin in a thickened or condeused state. Though it has not altogether the appearance of ligament, it certainly does not exactly resemble skin: I think, therefore, Mr. Clark's objection is unnecessary. The cireunference of the newly farmed horn, at the eoronet, nust be contrated, which, being gradually pushed forward by the new horn which suceeds it, forms, at lengthy a hoof of diminished size. A representation of Mr. Clark's paratrite and hinged shoe will be fourd in Plale III. Fig. 9. The great benefit which that gentleman scens to alltieipate from this discovery I sinecrely wish may be realized. A further trial sceins necessary to deternine in what degree they are use ful.

+ The ferm founder is often use $l$ in a very vague and indefinite sense.

The eommon appliention of the term is to those incurable lamencsses of the foot by which sumany horses are rendered unserviceable, and which, by farriers and grooms, are generally supposed to depend on some disease of the chest or shoulder; 
sible foot, by which it is united to the hoof, and is cither general or local. It is produced by various

therefore, they uame it chest funder. Gibson, howerer, describes a disease of this hind, which he calls an external pleurisy; "it tany be known," lie says, "by a stifiness of the budy, shoulders, aud fore legs, sometimes with a short dry cough in the beginniug, and a shrinking when a horse happens to be handled in those parts; and perhaps, when not well curcl, proves the original of that distemper which horsencn and furriers call a chest founder." Mr. Bracy Clark, in his "Disscrtation on the Ifuot," observes, in speaking of the founder-" The foot of the horic not unfrequently has its conucxion with the hoof wcakened or wholly detached. The colfin-bonc dislodged, or its adherence impaired, it is pressed down by the natural operation of the weight of the body, and sinking till it meets the sole, it there rests, with its front part beariug on the horn of the sole, forcing it downwards and outwards in sucls a way that this part, fiom being naturally concave, becomes of a flat or a convex form : the horse is then, truly enough, said to be foundercd, or poinmefooted. Many appear to be tive variety or gradations of this sort of affection in fect; and the disease may be formed by a gradual chronic process, or suddcnly, and at once. Cases within our practice lave occurred, where it las happened, after violeut exercise or exertion, and tic body has becn considerably heated, that the foot las bcen suddenly chilled by the imprudent appli. cation of cold water; a most destructive lind of intammation lias cnsued in the vascular tissuc and apparatus, muiting the bone to the hoof (elistic membraucs or processes). These parts being surrounded and confincd by the solid hoof, through which, as it could not penetrate, it nccessarily takics a course to the top of the hoof, and, with drcadful pain and suffering, bursts its way out at the coronct, lacerating and destroying the scxture of these piarts. Nor is it in these eascs the usual process of purulcnt suppuration: but a red watery iclıor cscapes from the vcsscls, and rends the texture of these parts in such a may as to give them very inuch the appearance of a lorn sjonge; and with the sole, also, it sometimes happens, after such sudden chills, that a.de- 
causes; and when considerable, or in a severe clegree, that is, when it attacks rather suddenly, in

structive intammation follows, and the vessels rupturing, pour their lymph ar blood hetween the vaseular and horny soles, which soften the horn, it is presently, with dreadful suftering, forced from its place, and descending, is reduced to a convex form; and, if the altack has been vigorous, it may bring the foot into this state in a few hours, or a mitigated altack may happen, not dislodging the bone from its place, or forcing the horuy sole, but producing various partial derangements of structure in these connecting parts of the hoof; and we have seen callous eulargements of the bones and thickenings of the cellular texture ahout the colonet to arisc from this cause, and, in a less degree, from fiver and hcat induced in the fuot, and the waved, the crooked, ribbed, wrinkled, incurvated (we may add, I think, the contracted), and otherwise deformed hoofs, appear many times to have their origin in affections of this sort. All we wish to observe with respect to the-shoe is, that, if it weakens in any inanner the attachment of the hoof to the bone, it prepares the way for sueh complaints as these: and they will then arise on the application of slighter causes than would produce them in the healthy sound foot." Aecording to Mr. Feron, s Every one almost who has written on the veterinary art describes pretty well the causes and symptoms of this disease, but they are quite silent on the real seat of founder. They say that eold, suddenly applied to the body, whether it be from a current of cold wind, or from plunging the body inco cold water when over-heated, the eflects are the same, \&c. This is all rery true; but these are not all the eavses that may produce those disorders. It will happen, also, by breaking and riding young colte, abont the age of two or threc years: when we may conceive how casy it is to destroy for ever the delicacy of their fibres. Foundering is often produced, also, by shoeing; particularly in the summer season, when the weather is hot, and the roads hard: at this time, if the frog, bars, and sole, have been over-pared or cut away with the buttress, and the horsc exposed to severe and continual exercise, particularly on hard roads, iu- 
cousequence of what is commonly termed a chill, is easily discovered by the increased heat or tender-

Aammation of those parts is sure to ensue, which, in its progress, will extenct to the laninæ (elastic inembrancs), and sensiblc sole. The symptoms, at first, are these; when thc horse begins to cool, he feels very stiff and feeble in his fore quarters, and, when forced to move forward, lie collects his body as it were into a heap, ant brings his fore-feet as far forward under his belly as he possibly can, in order to rcmove the pressurc of the wcight of his body from the fore-legs and fuet. His feet arc extremely hot, and his legs morc or less swelled, and evillently painful to the animal when louched; a violcut fcrer sueceeds, and the horse continally lies down, fouding it inpossible to stand; if he lee up, it is only for a few minutcs. In this deplorable slate, if he is not properly treated, he will soon cast his hoofs, or the case mill speedily tcrmillate in dcalh. By these symptoms, we may perccive liat all this mischief is produced by an infammation of the sensible froge, sensiblc solc, aud lamino (elastic processes or mcmbrancs) of the foot: and that when the aninal recovers without easting his hoofs, there will remain generally a chronic lameness confincd to the foot, and ligaments of the coffin-joint in particulal ; which will continuc with more or lcss violence, according to the damages done to the parts eonfined within the hoof, at the time the horse received the accidcint. It is this chronic lameness; which subsides after the infammation has subsided, that ancient writcrs have becn pleised to call chest. founder, and, vilgarly, grargy (gragsy, from their inability to walk steadily). The cure of this diseasc, impropelly called founder, consists in filst taking the shoes off, in order to rasp the sides of the heels and quarters; and the lorny sole may be cut with the buttress if found too thick: the rasping and rcducing the thickucss of the hoofs will be found cxtremely salutary in easing the parts confined in the horny box called the hoof. The next thing to be done is to scarify the lateral cartilages (the anthor means, of conrse, the skin covering the cartilages, in order to open some of the numerous blood vessels sprcad over thcir surface), and, 24 hours after the opcration, to apply a strone 
ness of the foot, by the pain the animal suffers, often shifting his feet, or constantly lying down,

blister, from the fetlock joints to the hoofs. The followiur day, let the feet be kept constantly in a bath of warm water if he can stand up; if not, he must be well fomented with the same, and poultices of bran and water applied at night. When the blistered parts are nearly well, they should be blistered again, and continucd to be so as long as circumstances require, which may be once a week during five or six weeks [!], not forgetting to scarify the two lateral cartilages perpendicularly with a scarificator or a fleam; whieh, in ease of necessity, may be used with aldvantigre, by making half a dozen cuts to each eartilage. If the animal bleed more thin three quarts, tho bleeding should be stopped with a strong solution of blue vitriol; but if, on the contrary, he should not bleed that quantity, he must then be bled in the neck. During this course, it is necessary to give 6 or 7 drams of aioes as a purgative once a-week, and a diuretic now and thell." M. Girurd, in lis Traitédu Pied, in treating of founder (la fourbure), ohserves, that it is a severe iuflanmatury affection of the elastic processes of the foot (tissu reticulaire) more or less intense and durable, which proceeds sometimes with rapidity, at others slowly, often proving fatal to the animal, and rarely getting well without melical assistance. It is always an effect of some previous irritation, froin whenee proceeds an accumulation of thids in the part, and afterwards a new mode of action (inflammation) in the ressels cont:ining them, and a new secretion: there is, from the beginning, a most acute pain, arising from the pecnliar structure of the foot having become extremely irritable. The wain is propagated to the superior parts, and gradually spreads over the whole linb, commonly exeiting gencral fever. The discise continuing to increase, cruses obstruction in the vessels of the elastie memliranes, and of the serous vesscls which penetrate the horn, and a partial or total separation of the hoof : and if at this period nature is incapable of maling a salutary offorl, by deternining the matter to break out at the coronet, the disease terminates in mortitication and death. Some eascs of fonnder are slow in their prorress, give but little pain, and pro- 
from inability to stand. This high degree of founder is often preceded or accompanicd by considerable ferer, and rhemmatic affection of the muscles of the hind legs, loins, or shoulders. 'There is sometimes, also, quickiness of breathing, as if the

duce serious couscquences only when suffered to go on withoutthe application of proper remedies; whilst others, as rapid in their progicss as they auc dingerous in their effects, arrive, in a short time, to the highest point of iutensity, and not unfrequently prove filal. From this circumstance, the disease is divided into the chronic and the acute founder. The latter is complicated "itis fever, loss of appetite, and weakuces, and sonctimes oceasions the hoof to fall off, and even a mortification of the foot; or it causes an cfiusion of glutinons mattcr from the elastic processes, or of a red or ycllowish serous fluid, which accumulates between the lioof and the scusible foot. The clironic founder gradually undermines and changes the natural organization of the hoof and sensibic foot, and gives rise to various discases. In contracted and brittle hoofs, founder is often acute and dangerous; in large open fect it seldom oceurs, is attended wilh litthe danger, and is generally of the chronie kind." M. Girard. then describes the causes and treatment whieh do not differ materially from that of the above authors and that given in the text. I have thought it necesary to make these quotatious, bceause Mr. Blain asserts, that " of all the definite and well-markcd diseases of the horse this (founder) lias been most mistaken anong the older farriers, and the least noticed among the no. dern. I do not know a single work on the subject of farricry thite docs more than allude to it." Now the works from which tlie foregoing extracts are taken, were all poblished before Mis. Blain's, as was my third volume, where the discase is described. under the head-"Inflammation of the Elastic Membrants by which the Coffin-bone is united to the Hoof." The old French atuthors, Vitet, La Fosse, and Bourgelat, have also described it; particularly La Fosse, in his Dictionnaire d'Mippialrique, and the youngest La Fosse, in his Manuel d' Hippiatrique, las slightly
noticed it. 
lungs were inflamed; but this, perhaps, arises fiom the muscles of respiration partaking of the rbeumatie affection. Plentiful bleeding, opening medicine, and clyster's, are the neessary remedies for this fever; but, from the term chill being commonly applied to it, farriers are often led to adopt a dif-, ferent or rather an opposite kind of treatment. Sometimes the infianmation of the feet comes on at the same time; at others, after the fever has subsided in some measure: the chill is then said to have fallen into his feet. Foundering more commonly attaeks very slowly, and almost impereeptibly. Sometimes it is indieated by a depression or flattening of the front of the hoof, and a flatness or small degree of eonvexity or bulging on the fore, or rather the middle, part of the sole. There is generally a brittleness of hoof, and sometimes a morbid degree of heat is observable, particularly after travelling. Circular marks, or depressions, or wrinkles, are often remarked in the hoof, and the heels are more or less contracted: cases sometimes oceur, in whieh, though the lameness is eonsiderable, nothing remarkable can be seen or felt in the hoof which would lead to a suspicion of the disease being seated in that part; and such horses are eommonly said to be chest foundered or shoultier shook. *

The lanrencss arising from founder is sometimes so slight, and both feet are so ecqually afiected, that

* Sec the two cases annexed to this chipter, where a portion of the netacmpal nerve was remured for this bind of lameness. 
it escapes the notice of the rider; and the imperfect manner of the horse's going is attributed to awkardness, for which the poor animal is improperly punished with the bit, spur, or whip. If the smith is consulted in recent cases of founder, where the lancness is inconsidcrable, he generally takes off the shoe to examine the foot, and finding nothing to account for the lameness, he confidently pronounces it to be in the shoulder or fetlock joint. It is so difficult in thesc cases to distinguish the seat of lameness, there being no cxternal appearance by which it is indicated, that the most expericuced persons have been at a loss what opinion to give of them, or what treatment to pursue. The difficulty, lowever, will be considerably diminished by attending to the following circumstances:If the lameness is only in one fool, obscrve if there is any difference in the heat of the fcet, or if the suspected foot is smaller, or of a different shape from the other. Then let every part of the limb. be carefully examined, and the shoulder extended and bent, observing if these motions occasion pain. Enquire if he stands in the stable with one foot advanced beyond the other; and should nothing be found, after a carcful investigation, to account for the lameness, there will be no danger in con-. cluding that the foot is the part affected, and treating it accordingly: for when lanceness arises from any injury of the shoulder or other part of the limb, cxcept the foot, the cause may almost always be discovcred by a carcful cxanination; and if we 
compare the number of lamenesses which arise from diseases or injuries of the foot with those of the shoulder and leg, the proportion of the former will perhaps greatly exceed what an inexperienced person can imagine: as to the lamenesses commonly attributed to splents, I believe nine-tenths of them are seated in the foot. In these obscure cases of lameness, therefore, the inost prudent plan to pursue is that of taking off the shoe, paring the sole should there be any supcrfiuous horn, and wrapping up the foot in a large bran poultice, in which a little hog's lard may be mixed. 'The loorse should be kept in this state three or four days, and the poultice should be occasionally renewed. About this time the hoof will have been sufficiently softened, therefore, the shoe may be reapplied, but gentiy, and only with four nails, that the horse may be led out on soft or smooth ground, in order to determine whether the lameness is removed or alleviated. If the horse appears sound, the shoe may be secured, and he may be gradually put to work again; taking care, however, that the feet are kept cool by stopping, or other means. If the lameness does not submit to this treatment, blistering the leg may be tried, and if that fail, a run at grass in soft ground. Many incurable cases of lameness occur, depending, I believe, on some disease of the elastic membranes or processes of the foot, which are not so considerable as to prevent the liorse from working moderately, and may be much relieved by keeping the hoof moist and cool: but it too often 
happens in such cases, that the poor animal is whipned into the most painful exertions; almost innumerable examples of which may be seen in our chaises and strge-coaches. It is really afflicting to humanity to be obliged to witness, as veterinary practitioners too often are, the cruelties to which this most valuable, but unfortunate, animal is exposed. In no situation, perhaps, is this so frequent or so flagrant as in those just mentioned; for it is a fact, too generally known to be longer dwelt upon, that when a horse is disqualified by painful, and, as it is considered, incurable lameness, for the turf, the field, or the road, and especially if he has been a good horse, possessing action and spirit, he is consigned to a mail or stage-coach, or what is nearly, if not quite, as bad, a post-chaise. It is much to be regretted, as there seems to be no other remedy for the evil, that the operation first suggested by Mr. Sewel, of the veterinary college, is not more generally known and practised. This operation consists in cutting out a portion of the nerve which supplies the foot; by which the sensibility of that part appears to be destroyed, whilst its vitality renlains unimpaired. Mucl prejudice, I believe, has been excited against the operation by those who have never witnessed its effect, and not a little, I fear, in consequence of incompetent persons having attempted it: I have heard, indeed; of one case where the operator cut out part of the suspensory ligament instead of the nerve; and it.is not improbable, that others, ignorant of anatomy 
and fecling embarrassed from not funding the ncrve so readily as they expected, liave remored a little cellular membrane instead of it, in order to satisfy their employer. It is not unreasonable to suppose, also, that some operators may have heen deceived as to the seat of the lameness, when of course no benefit could result from the operation. In concluding this article, I mean to detail three cases of lameness in which this operation was performed, which will give the reader a better idea of it than ary general description can do. In speaking of the acute founder, I should have observed that, besides plentiful bleeding and moderate purging, it is highly necessary to attend to the state of the fect as soon as they appear to be infiamed, or, in stable phraseology, as soon as the chill, has fallen into them. In some instances, the inflammation has been so violent and so extensive, that the whole foot has mortified and sloughed off, sometimes the inflammation terminates in suppuration, and matter is formed between the hoof and the sensible foot, by which the former is separated either wholly or partially, and cast off. The matter is generally ichorous or bloody, and very foetid. When the inflammation is not so violent or extensive, it causes an effusion of coagulable lymph from the vessels of the elastic menibranes of the foot, by which the coffin-bone is displaced, and forced down upon the sole. The disense often happens even in a less degree than this: authors have, therefore, distinguished two kinds of founder-the 
acute and the chronic. When the inflammation is severe, the feet are extremely hot and painful, so that the horse is scarcely able to stand, and is therefore frequently lying down; when standing, he endenvours as much as possible to relieve the affected foot or feet from the weight of the body. The shoes should be taken off, and the soles pared until they yield, in a slight degree, to the pressure of the thumb. The feet should then be wrapped in a large bran poultice, which is preferable, I think, to minking him stand in water, as with the poultice he can lie down, which affords him great relief. Professor Girard, in his Traité du Pied, relates a case where all four feet were affected in a severe degree, which he cured by making the horse stand during the day without shoes in clay softened with vinegar and a solution of sulphate of iron, rubbing the knees and hocks with oil of turpentine daily, until it caused considerable swelling, giving clysters with nitre in them, and an electuary, composed of powdered gentim, liquorice, and honey. "The horse," he says, "was cured in 2 I days. The salutary effects of this treatment," he adds, "have been frequently experienced in the hospital of the veterinary school at Alfort." Notwithstanding the high authority and skill of M. Girard, I cannot but think that poulticing the foot is preferable to his standing in clay, \&c. during the day, and being placed in a well-littered stall during the night. As to the electuary (un opiat), it certainly could have but little if any, share in the cure. Bleed. 
ing in the toe or coronet has been recommended, and in severe cases may be extremely useful, particularly the latter, and blistering the leg, from the fetlock joint to a little above the knee, or, as $\mathbf{M}$. Girard advises, rubbing in oil of turpentine is likely to do much good. Though the disease is merely local, yet bleeding and moderate purging are generally necessary. The bleeding, both local and general, often requires to be repeated two or three times. I have before observed, that founder is often preceded or accompanied by general fever, and rheumatic affection of the chest, shoulder, or loins. But here it is proper to observe, that in some scvere attacks of local founder, such as may take place in consequence of applying cold water to the fect at a time when they lave been much heated by long-continued and violent exercise, the pain is so intense that il excites symptomatic fever, which requires bleeding, purging, and a strictly cooling treatment.

'The most common cause of founder is violent and frequent trotting upon hard roads, standing still after such exercise in a current of cold air, or in a cold wind and rain, or being plunged into a pond, and rode about in it for several minutes, to save the trouble of cleaning, and afterwards kept in hot close stables; and the most severe effects are thus produced, when the animal's strength has been previously exhausted by orcr-exertion. Though the local founder, in which the foot only' is affected, is most commonly produced by impro- 
per treatment of the foot, bad shoeing, standing too much on litter, and other circumstances, which tend to excitc and keep up a morbid degree of heat in the part, yet the disease may be aggravated, and its progress accelerated, by circumstances affecting the constitution, such as high feeding, hot and close stables, sudden exposure to cold when heated, standing for several days or weeks on litter, with little or no cxercise, and, in short, the same causes that worc enumerated when treating of contraction of the hoof.

Cases of Chronic Founder cured by cutting out a portion of the nerve which supplies the fool.

CASE 1. A carriage-horsc became gradually very lame in the near fore leg. It was considered and treated as a case of shoulder lameness: he was, therefore, blistered in the shoulder, and soon after turned to grass, wherc he remained, about two months without getting better. I saw it in the beginning of September, and as it struck me to be one of those foot lamenesses which are seldom radically cured; but as at that time I laad not scen the effect of the nerve operation, I directed them to pare the feet, blister the legs, and turn him out to grass again. About six wecks after, he was taken up apparently sound, and was brought into the stable, in order to be physiced and got into 
condition for work. Soon after, the lameness returned, and gradually increased. I then suggested the nerve operation as the only probable means of relieving him. He was exceedingly lame previous to the operation; but as soon as it was performed, and he was suffered to get up, he was perfectly free from lameness, and has continued so ever since.

Case 2. A well..bred saddle-horse had been lame about three years, and a variety of opinions had been given by practitioners respecting the nature of the lameness. At different times he had been blistered and fired both in the shoulders and legs, and was kept a considerable time at grass, but the lameness gradually increased, and the horse became entirely useless. The nerve operation was performed on both legs, and the horse was instantly relieved; but when the wounds were healed, and the horse was rode out on trial, the right leg was found to be still very lame. Upon examining the leg, I found that the incision on the right leg had been made above the part where the outside nerve receives a branch from the nerve on the inside of the leg, another incision was therefore made below the former, and anotlier portion of nerve removed; the horse became sound inmediately.

CASE 3. A waggon-liorse had a considerable bony enlargement on the outside of the fetlock joint, which, though it occasioned lameness, did not prevent him from working, and in this state he had been worked for some time. 'The swelling, 
however, gradually increased, and at length became so painful as to render him quite useless. The nerve operation was performed on the leg, and at the same time the actual cautery was applied to the swelling. The horse was considerably relieved immodiately after the operation. As soon as the wounds were healed, that is, thrce weeks after the operation, the horse was put to work, and has continued to do his work ever since (about two months). There is still a little lameness, scarcely perceptible in walking, but he does not appear to be in pain when working.

\section{Sand Crack.}

SAND Cracks are longitudinal fissures, clefts, or cracks in the hoof, generally on the inside quarter of the fore feet; but sometimes in the front of the hind feet. They gencrally occur in the hot and dry months of summer, and scem to arise from a morbid heat and brittleness of the hoof. * Sand cracks may also happen from wounds or bruises on the coronet. Sometimes they are superficial, and do not occasion lameness; at others they are deep

* M. Girard, in his Traité du Pied, says, that many veterinarians who attended the French army in Egypt assured him that nearly all (presque tous les chevaux) the horses brought from France into that country lad sand cracks (avoient la paroi tolljours fendillée, et etvient continucllersent atteints de seimes). 
and extensive, and by compressing the sensible parts, whicl are liable to get between the edges of the crack, much pain and inflammation are excited; and whenever blood is seen to issue from the crack, it is a proof that it has extencled to the sensitive parts, or elastic processes of the foot. Since the disease depends upon heat and brittleness of the hoof, our first object is to correct this morbid state, by keeping the hoof moist and cool. This may be effected by making him stand in spunge-boots, or in bran poultices. In the superficial sand crack, it is sufficient to make a transverse incision immediately above or at the upper extremity of the crack to prevent its spreading; it often happens, however, that the crack has already extended to the coronet, so that there is no room for this transverse incision; in such cases, the horse must be kept at rest, with his foot in a poultice, mntil the new horn is grown sufficiently from the coronet to admit of the transverse incision. When this has been done, it is desirable to turn the horse to grass in soft meadow land; but if he is to be kept in the stable, the foot must be kept cool by stopping. In the deeper and more extensive sand crack, it is necessary to pare away the edges of the crack to examine its extent and direction, particularly if blood has issued from it; for then the sensitive parts may be suffering compression between the edges of the fissure. Sometimes dirt or gravel gets into the crack, and by irritating the sensible parts, causes great pain and inflamma- 
tion. If this be not attended to, the sensible parts become uleerated, and throw up fungous flesh, whieh, being pinched by the sides of the eraek, are a souree of great pain and irritation. In this ease, the eraek must be fieely opencd with a drawing knife, and suitable dressings applied; such as soll1tion of blue or white vitriol, Friar's balsam, witl a small proportion of sublimate dissolved in it $(5$ grains to $1 \mathrm{oz}$.$) tow or lint moistelled with these$ may be bound on the part. In applying a shoe, it should be so contrived as to have no bearing on that part which is immediately under the sand erack. In all sand cracks, the eause of their oeeurrence should be attended to, and as far as possible eorrected or removed. The transverse ineision at the head of the eraek, when practicable, should never be omitted, whieh effeetually prevents it from spreading upward, and then, as the hoof grows down, the crack gradually disappears. To promote the growth of horn, some stimulating ointment may be applied to the coronet; and when the upper part of the hoof appears dry, with numerous eraeks, or rather a roughness on its surfaee, it may be smeared daily with the following ointment. Some praetitioner's firc the sand erack; that is, the common firing iron, made nearly red hot, is lightly applied, so as to stimulate the sensible parts, and eause an effusion of horny matter: they make, also, the transverse line with the same instrunicnt. This plan oftell sneeeeds, but generally is not so effectual as that above described. 


\section{Hoof Ointment.}

Take of tar, pitch, and tallow, equal parts. Melt and stir till cold. This may be made softer: by the addition of lard, if required.

\section{Corn.}

THIS is a troublesome disease of the fore feet; which often occurs, and occasions various degrees: of lamcness. It consists in a bruise of the sensible sole at the heel, between the crust or wall and the bar, and is caused either by the pressure of the heel of the shoe, or the heel of the crust; it some- times occurs, also, from the horn at the heels having become too thick and inclastic. The part called the corn is nothing more than horny matter made red, or of a reddish brown colour, by extravasatcd blood. Smiths generally imagine, that by removing it, or paring it out; they remove the disease; and it is from this misapprehension of the nature of corns that they so often prove obstinate and incurable. Having pared out the corn, as they term it, the same kind of shoe is applicd, or the shoe is so made as to lay off or have no bearing on the affected heel. Thus temporary relief is generally obtained; but the horny matter growing, and the shoe yielding to the horse's weight, soon benrs 
again on the tender part, and the lameness of course returns, often in an aggravated degree. A corn is a disease, or bruise of the sensible or fleshy solc: the red horny matter so named is nothing more than an effcct of the disease; and as by removing it, a spnce is made between the hecl of the shoe and the tender part, the horse is relieved until the space is again filled by the reproduction of horny matter, and the bearing down of the hecl of the shoe.

The most effectunl method of treating corns when produced by the pressure of the heel of the sloe, is to cut off that part of the shoe; that is, about an inch or an inch and half of the heel, and it will be found that such a shoe can be worn without inconvenience. It will be necessary to shoe in this way for a considerable time. But when there are corns in both heels, instcad of cutting off both heels of the shoe, it is better to apply a bar shoe if the frog is solid and sufficicntly prominent for it to bear on; the tender heels may then be so rasped or pared away as to receive no pressure from the shoe. Various applications have bcen recommended for corns. Some practitioncrs apply the actual cautery; others advise caustics, such as butter of antimony, sulphuric acid, \&c.: perhaps tar, with a very small quantity of sulphuric acid ( 1 oz. to $1 \mathrm{lb}$.) is as grood as anything. When corns arc causcd by too great depth, thickness, and inelasticity of the liorny heels; they slould be properly pared, and the foot wrapped 
in a poultice. When colns have been so neglected as to allow suppuration to take place, the matter gencrally breaks out at the coronct, sometimes spreading first under the lrorny solc. In this casc, the horn must be pared away so as to give vent to the matter below, and if the matter has penctrated under the liorny sole, so much of it as is found detached from the sensible or fleshy sole should be cut away. 'The part may then be dressed with Friar's balsam, digestive ointment, or tar; after which, if any inflammation remain, the foot may be wrapped in a poulticc.

\section{Quillor.}

'Thus disease is caused by a neglected wound or' bruise in the coronet, or by a neglected wound or bruise in the bottom of the foot or lower part of the elastic membranes, as in pricks in shoeing. When thesc accidents are not properly attcnded to, the matter penetrates in various directions; sometines affecting the cartilages of the foot, and causing them to become bony. Quittor may be considered as fistulous sore of the coronet, extending in different directions: the extermal sore is gcnerally very small, and cu the inside, towards the heel; the wound or bruise, in which it often originates, being commonly inflicted by the animal himself, either by accidentally treadiug upon it, or by 
endeavouring to rub the part with his other foot. On examining with a probe, we find the sinuses or pipes, as farriers term them, running in different directions. Sometimes the probe can be passed downward under the loof, at other forwards or backwards in a line with the coronct, or directly inward upon the cartilage. The most effectual metlod of treating quittor is to force some strong caustic, sucl as corrosive sublimate, into the sinuses. The following mode of applying it will be found convenient. Spread some powdered sublimate on thin paper, then roll it up, and twist the paper so as to make it rather stiff, and bring it to a point, that it may be introduced into the sinus. When it cannot be got any further in this way, let the part which remains out of the sinus be cut off, and that which is within must be forced with a probe to the bottom of the sinus; other portions are then to be introduced in the same way, until the sinus or sinuses are filled. This severe treatment will, of course, cause considerable pain and inflammation, to moderate which, the foot should be wrapped in a ponltice. After a few days, a slongh or core, as farricrs term it, will come off; leaving a large opening, but with a red lealthy appearance, which generally lieals readily, by means of Friar's balsam, or a solution of blue vitriol. 


\section{Thrush.}

A DISEASE of the frog, consisting in a discharge of foetid matter from its cleft or division. It appears to originate in inflammation of the sensible frog, caused either by a contraction of the heels, or by the horse's standing in filth and moisture. Having removed the cause of the disease, and clcansed the frog perfectly, that is, the cleft or division of the frog, let some astringent preparation be applied, such as a solution of blue or white vitriol, egyptiacum, tar, with a small proportion of sulphuric acid $(1 \mathrm{oz}$, to $1 \mathrm{lb}$.) The disease sometimes occurs in a more severe degree, spreading over the whole of the sensible frog; and separating its horny covering. In this case, the detached horn should be cut away, and some astringent dressing applied daily, which, aided by moderate pressure, will generally cure the disease. *

* Mr. Bracy Clark, in his "Dissertation on the Foot," considers the disease as often arising from a rupture of that part of the horny frog which forms its cleft or division, and which he has nained the frogslay or bolt. "When this loorny cone," he observes, " is defectively formed by Nature, as by want of sufficient bulk, or by weakness of its contcxture-when reduccd and wasted away by the same evils which reduce and waste the general mass of the horn of the frog, or bccoming too brittle, hard, and dry, is of consequence liable to be brokcn by cxternal violence, or is decayed or weakened by much exposure to wet or filth; in either of these cascs, its rupture admits a passage and lodgement for external destructive agents, as wet, dirt, urine, \&c., and thus the thrush appcars to be formed." "After 


\section{Canker.}

\section{THrs also is a disease of the sensible frog, and}

this part has been once ruptured, or weakened, or thrushed even, it may be formed again by a fresh growth of the part, especially if the foot be kept cool and moist, as at grass; the disease then :will appear obliterated: but dhe new formed horn, not having the same altachment to the surrounding parts as the origrinal hurn, and being of a weuker wature, shall me'lely by the exposure of the foot to the heatei litier, with healing jood, and the other infam. atutory agents of the stubte, rupture a ain, grive out a discharge, and become a complete tlumsh." This Mr. Clark considers a discovery; and thungh there does not appeal any novelty in it, I am glad to observe he, for once, acknowledges the injurions effects of hot litter, and the otlier inflammatory ageuts of the stable on
the feet of horses.

Mr. Colemai has always taught that thrush is a disease of the sensible frog, brought on by various causes, and that the secreting surface of the latter is an extension or continuation of the ly in that part which forms the fissure or alceration, particolar these affections, it becomes more ur less detached froun either of covering, and discharges a dark coloured stinking matter. Professor Girarl considers it in the same light. In speaking of this disease, which he names ta furrchetle echareffe (heated or infamed frog), he otserves: " Tle frog may ba allected with thrushes become so thick and iuelastic (tlat is, by suffering the sole to, heat in the foot), hut chiefly by the horse a morbid degree of urine." It consists in a discharge of standing in durg and mour; which, accumulating inge of a puriform blaclsish huhorny eovering, and if not attended to, the fros, deiaches its degrce of the discase which he names la fourchede poute a higher advises its being washed, after boures la fourchelte pourie. He tached horn, with a solution paring away the partially dewater. 
often extends to the sole, elastic membranes, and other parts of the foot. It is almost always very obstinate, and often incurable. The first thing to be done is to expose completely all the diseased parts, by cutting away the horn which covers them: to accomplish this, it is often necessary to remove the whole of the bottom of the hoof, that is, the frog, sole, and bars. This being donc, the diseased fungous surface is to be removed with a knife, or scraped away with a drawing knife, and when the bleeding has ceased, the following caustic powder is to be freely sprinkled over the whole surface. The foot is then to be covered with tow, and wrapped up in canvas. Great care must be taken to kecp the foot dry and clean, as nothing is so injurious in this complaint as the moisture and filth of the litter. The following day the same dressing is to be repeated, first removing as mucl of the diseased surface as will cone away, by rubbing with tow, or by scraping with a blunt knife or drawing knifc. After a few dressing of this kind, the parts will have a more healthy appearance, and the offensive smell will be corrected; milder dressing will then be proper. It often happens in this disease that while one part appears to be healing, another will continue foul, in which case, the caustic powder should be applied to the latter only; and not unfrequently, while healing in one part, it will be spreading in another: therefore, a carcful examination is necessary at crery time of dressing, and whenever the discase is observed to be spread- 
ing under the horn, whether it be the soles, bars, or crust, that horn should be immediately cut away, and the diseased part completely cxposed, that it may be dresscd with caustic powder. A caukered foot should be dressed daily; and some effectual means should be adopted for keeping the diseased foot dry and clean, and for kceping up a constant pressure upon the diseased surface.

\section{Caustic Pouder.}

Corrosive sublimate, powdered ..... 1 oz. Sulphate of copper ........... 2 oz. Prepared chalk

............ oz.

Mix.

\section{Liquid Cauśtic.}

Corrosive sublimate ............. $1 \mathrm{dt}$. Muriatic acid.$\ldots \ldots \ldots \ldots \ldots \ldots$. $\frac{1}{4} \mathrm{o} \%$. Spirit of wine and water, of each ... $2 \mathrm{oz}$.

Various preparations may be used as liquid caustics, such as butter of antimony, muriatic acid, sulphuric acid, \&c.; but the above powder is, I think, preferable.

\section{Mild Dressing.}

No. 1.

Tar

White vitriol, fincly powdered, $\ldots . . .180 \%$ Mix. 
No. 2.

Tar .................. 802 .

Verdigris, powdered, $\ldots . \ldots \ldots \ldots .10 \mathrm{oz}$

Mix.

No. 3.

Chrystallized verdigris, powdered, .... 1 oz. Honey $\ldots \ldots \ldots \ldots \ldots \ldots \ldots \ldots, 3 \mathrm{oz}$. Alum ..................... Bole .................... Vinegar ... ................ 4. oz. Mix over the firc.

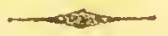

Culling.

A rronse is said to cut, when he wounds the insicle of the fetlock joint with his foot in travelling. This may arise from various causes, the most common of which scems to be an improper position of the foot; the toc, instcad of bcing in a line with the point of the shoulder, inclining cither inward or outward. In the latteir case, we generally find that the inner quarter of the hoof is lower than the other, and that the faulty position of the foot depends upon this incquality of the quarters: it must be obvious, therefore, that the remety, in this case, consists in lowering the outer guarter, and making the inuer brancl of the shoc 
thicker than the other. When the toe inclines inward, it renders a horse liable to cut on the inside of the knee, at the lower part of the joint: this is termed the speedy cut, from its happening upon the trot or gallop, and is considered as a dangerous failing in a horse, the violence of the pain which the blow occasions sometimes causing him to fall very suddenly. The remedy for this is to keep the toe as short as possible, that being the part which generally inflicts the wound, and to alter the improper position of the foot. Cutting frequently depends upon weakness or fatigue, and. is therefore very liable to happen to young horses, when rode hard over deep lieavy ground. The only remedy, in this case, is to avoid the cause, until the legs acquire more strength, or to protect the wounded part with leather, or a boot, as it is termed. Whenever a horse cuts, it is adviseable to ascertain what part it is that inflicts the wound, and this may often be done, by applying tar to the wounded part: this will of course adhere to the part of the hoof, or shoe, which comes into contact with the wound. Should it be the edge of the shoe, which, I believe, is seldom the case, the cause may be easily removed by the farrier. Whatever part of the hoof it may be, it should be rasped away, as much as can be done with safety, and particular attention paid to the position of the other foot, which, if improper, should be improved, as much as it can be, by shocing. 


\section{CHAP'TER VIII.}

\section{MISCEI,LANEOUS.}

\section{OF BLEEDING.}

THIs operation is frequently necessary in the diseases of horses, and is performed either with a lancet or fleam, in the neck vein.

The blood should always be preserved, that the quantily drawn may be accurately known, and that its quality may be ascertained. If, after it has coagulated, a white, or rather a light buff-coloured jelly be found on the surface, an inflammatory state of body is indicated; but, in order to render this criterion useful, the blood must not be taken from too small an orifice, nor should it be suffered to run down the sides of the vessel which receives it.

Blood, drawn from a healthy horse, very soon congulates, and appear's like a uniformly red jelly, with a small quantity of fluid, resembling water, floating on its surface. This red jelly may, by washing, be rendered of a light buff-colour, and exactly resembles the buff, or size, as it is termed, of inflamed blood. The most healthy blood, therefore, contains this size; and the cause of its not being conspicuous in such blood is, that congula- 
tion takes place before the red colouring matter. can have time to separate from it; but as blood, that is drawn from an animal labouriug under general inflammation, or fever, always preserves its fluidity much longer than healthy blood, and as the red colouring particles are specifically heavier than the fluid with which they are mixed, they will, of course, be gradually subsiding, as long as the mass continues fluid, leaving a coat of buff-coloured jelly on the surface.

It has been observed before, that healthy blood, when suffered to coagulate, appenrs to consist of two parts, the red jelly, termed crassamentum, and the water, or serum; and that the former may afterwards be scparated, by washing, into two parts, viz. the red coloured particles, or red globules, as they are termed by anatomists, and buff-coloured jelly, or coagulable lymph. The proportion, with these component parts of the blood bear to each other, secms to depend upon the state of the system at the time it is drawn. When the body is healthy and vigorous, we find but little scrum; when it is preternaturally excited, or in a state of inflammation, there is still less; and when the animal is weak and debilitated, there is generally an abundance of serum. Another circumstance to be attended to, in examining blood, is the firmness or tenacity of the coagulum. In health, the blood, when drawn, and suffered to coagulate, is of a moderately firm consistence, and easily broken; but when the system is highly excited, as in general 
inflammation; so grreat is the tenacity of the mass, that the finger can scarccly penetrate it. On the other hand, when the powcrs of life are weak, as in the latter stage of symptomatic fever, the blood almost loses its power of coagulating. I recollect a glandered horse, that was made the subject of experiments, and that died in consequence of large and repeated doses of mercury; the debility this produced was exccssive; and the blood appeared as thin, and nearly of the same colour, as claret. The necessity, therefore, of cxamining blood that is drawn from a diseased horse, must be obvious, as it assists in forming a judgment of the nature of the disease, and points out the proper remedics. When blood exhibits buff on its surface, particularly if, at the same time, the congulum be firm and solid, we may be certain that the complaint is inflammatory, and that bleeding may be repeated with advantage. If, on the other hand, the mass of blood be wanting in tenacity, and have more serum than usual, we may safely conclude that the system is in a state of debility, and consequently, that bleeding is highly improper.

In cases of symptomatic fever, it will gencrally be necessary to take away foul or five quarts of blood at the first bleeding; I have secn even six quarts taken, with manifest advantage. It is at this period of the diseasc (its commencenent) that copious bleeding is particularly useful; and it is fiom an absurd prejudice, which obtains against this practice, that so many horses are destroyed by 
such fevers: It is truly laughable to hear a groom or furrier pronouncing, with an affectation of micrring sagacity, upon the qualities of blood, frecquently observing, that it is too hot, and that consequently the horse must have a fercr; that it is too dark coloured, and therefore foul; or that it is too thick, and consequently unfit for circulation; and sometimes it is said to be fill of humours. With respect to the heat of the blond, it will be sufficient to observe, that it preserves nearly the same temperature, while circulating in the body, whether the animal be an inhabitant of the most sultry or of the coldest country, whether in liealih or in the highest fever.

As to the colour of the blood while flowing from the body, it may be cither red or of a dark colour, as the operator pleases; since, by pressing on the vein, for a short time before the orifice is made, it may always be made to appear of a rlark colour. If an artery be opened, the blood which flows from it will be of a bright scarlet colour. The opinion that blood sometimes bccomes thick, or viscid, in the body, was supported by many respectablc philosophers, but is now universally abandoned, because it has been proved to be crroncous.

I think it a bad practice to blced horses fiequently, when there is no urgent occasion, as they thereby accouire a plethoric habit; and unless the operation be regularly performed, and gradually increased in ficquency, troublesome discases might 
ensue. Horses of a full habit, that are consequently liable to inflammatory complaints, will receive most benefit from moderate and long continued exercise, and good grooming. When bleeding is performed for the cure of important inflammatory diseases, a large orifice should be made in the vein, and the blood drawn in a large stream, as we thereby diminish the action of the heart and arteries, much more readily than if it were drawn slowly from a small orifice. In cases of external and circumscribed inflammation, topical bleeding is eminently useful, which is done by opening some veins contiguous to the affected part, or by scarifying the inflamed surface.

\section{Of Physic.}

Is purging horses, great care and attention are necessary, their bowels being particularly irritable, and liable to inflammation. The physic commonly given is certainly too strong, and I am convinced, that many horses have been destroyed by the immoderate doses that have been recommended by writers on farriery. When this happens, the mischicf is generally attributed to the coarseness or impurity of the medicine, and the druggist is undeservedly censured. A modern author has ingeniously availed himself of this prejudice, to explain the violent effects which his cathartic prescriptions 
have sometimes produced. I must presume, howcver, to suggest, that these effects were more probably occasioned by the excessive quantity, than by the impurity of the purgative ingredients.

The only certain and safe purgative for horses is aloes; and of the different kinds of aloes, the Barbadoes is undoubtedly the best. The suc. cotrine, which is generally considerced the mildest, as well as the most certain in its effect, is too weak, and so very uneertain and variablc in its operation, that we cannot use it without frequent disappointment. Practitioners seem now to be convinecd of the superiority of the Barbadoes alos, as it has been sold of late nearly at double the price of the succotrine.

If the reader wisl to have farther information on this subject, he is requested to consult the autlior's second volume, or Vetcrinary Materia Medica, \&c.

It is adviseable to preparc a horse for physic by giving him bran maslies for a day or two. This will gently relax the bowels, and remove any indurated frees that may be lodgred in them: it will also tend to facilitate the operation of the medicinc.

About a peek of bran, divided into four feeds, will be suffieient for twenty-four hours; and, as it is desirable to give the horse but a small quantity of hay, I think it adviscable to add to each bran mash about a pint or more of bruised or broken oats, which will tend to preserve his strength and condition. He should be allowed to drink a mo derate quantity of water frequently, 
When a horse is purged for the first time, it is prudent to give a very moderate dose. Were the common quantity given to one of weak, irritable bowels, there would be danger not only of producing great debility, and thereby of counteracting the intention of the medicine, but likervise of destroying the animal, by bringing on an inflammation of the bowels: and this is by no means an unusual occurrence. Should the first ball not operate sufficiently, a stronger may be given, after an interval of a few days.*

* Mr. Jolin Lawrence recommends from onc ounce and a half to fourteen drams of snccotrinc aloes, as a moderate dose for a race horse, a dose which I am sure would in many loorscs prove very injurious; and as a remedy for that kind of colic or gripes, which often happens from ton strung a dose of physic, or from bad mitnagcment during its operation, lie recummends in slight cases a cordial hall, and in more serious eases canplior dissolved in a sinall quantity of gin, with oil of amber, and balsam of capivi and Peru, all of them powerful stimulants, and very likely in such cases to produce inflamination in the bowcls. Whencrer at horse appcars sick and griped after taking physic, or, as the above authur properly descrihes him, hanging down his head, rcfusing his fond, appearing as if $\mathrm{s}$ wollen in the carcase, hcaving in his flanks, and frequently throwing up his tail, without ability to evacuate, all medieines of a stimulating quality should be avoicled, the straight gut shonid be emptied by the hand, and afterward clysters of water-gruel, with olive or linsecd oil, sliould be injected. The horse should be allowed to drink frequently of worm watcr, or thin watcr-gruel; and if he refuse to drink, it is absolutely nccessary to drencil him sevcral timcs a dil. These mcalys, assisted by walking cxcreise, will soon bring on au cracuation, and the horsc will be relieved. It is often sujlposed, that these 11 pleasant sympenms arc catnsed by sonec bal quality in the aloes, But 1 an sunvinced, from long expericnes, 
The morning is the best time for giving a purgentive, the horse having previously fasted two or three hours. If he be disposed to drink aftcr tilk" ing the ball, give a modcrate quantity of warm water, or a small thin bran mash, which will promote its solution in the stomach, and consequently expeditc the operation. During this day the horse is to be kept in the stable, and fed with bran mashes and a moderate quantity of hay: he may be allowed also to drink plentifully of warm water; and if he refuse it in this state, let it be offered nearly cold. The following morning he is to be exercised; and at this time the medicine will generally begin to operate. Should the purging appear to be sufficient, he need not be taken out a second time; but when the desired effect does not readily take place, trotting exercises will tend to promote it. During this day also he is to be carefully supplied with bran mashes anci warm water. Warn

that it is not so; and I will venture to affirm, that the above symptoms are always oeeasioned either by too large a dose of aloes, or by treating the horse improperly after he has taken it. Another eireumstance may sometimes assist, and that is, the stomach containing ton large a quantity of food at the time physic is given, and particularly if the food be deficient in moisture. But this eain never happen if the directions we have given be duly observed. I have for several years empluyed the Barbadoes aloes very extensively, giving often from thitty to fifty doses in the course of a week; and have found, that from half an ounce to one ounee may be eonsidered as the proper dose. For a clelicate blood-liorse half an. ounec generally proves suffieient; to a common saddle-horse, fivo or six drams; to a waggon-horse, one
ounce. 
clothing, more particularly when out of the stable; must not be omitted. The next day the purging will generally have ceased, and then a small guantity of corn may be allowed. When physic does not operate at the usual time, the horse appearing sick and griped, relief may generally be obtained by giving a clyster of water-gruel, and making him drink freely of warm water, assisted by excrcise. When the purging continues longer than usual, and the horse appears to be considerably weakened by the evacuntion, let arrow-root or wheat-flour gruel be given.

It will be observed, perhaps, that some ingredients, commonly thought necessary in physic, lhave been omitted in the following formulæ. These medicines have been proved, however, to be pelfectly useless. Jalap, though given to the amount of four ounces, will produce very little purgative effect upon a horse; nor will salts, or cream of tartar. Rhubarb, however large the dose, will not operate as a purgative, though it may be useful in moderate doses as a stomachic.

\section{No. 1.}

Barbadoes alocs .......... $5 \mathrm{dr}$.

Prepared nation .......... $2 \mathrm{dr}$.

Aromatic powder ........ $1 \mathrm{dr}$.

Oil of Caraways .......... 10 drops.

Syrup enough to form a ball for one dose. 
No. 2.

Barbadoes aloes .........6 $6 \mathrm{dr}$. Castilc soap ............. $\frac{1}{q}$ oz. Powdered ginger .......... $1 \mathrm{dr}$. Oil of caraways ........... 10 drops. Syrup enough to form a ball for one dose.

$$
\text { No. } 3 .
$$

Barbadoes alocs ..... $7 \mathrm{dr}$. to $1 \mathrm{oz}$. Prepared natron .......... 2 dr. Aromatic powder ........... I dr. Oil of anise-seeds ......... 10 drops. Syrup enough to form a ball for one dose.

The ball No. 2 I have generally found sufficient for strong horses, and have scarcely ever had occasion to go farther than No. 3. Should any one, however, be desirous of a stronger medicine, it may readily be procured by adding one or two drams of aloes, or one dram of calomel to the ball No. 3 : but I must not omit to observe, that there appears to me to be a considerable dangcr in making the addition. 


\section{Diuretics.}

These are medicines; which, by stimulating the kidneys, increase the secriction of urinc. The following formulæ I have found both convenient and efficacious :-

No. 1.

Castile soap $\quad \ldots \ldots \ldots \ldots \ldots \ldots \ldots$ 4. oz.

Powdered resin and nitre of each $\ldots 22 \mathrm{oz}$.

Oil of juniper $\quad$.............. $\frac{1}{8} \mathrm{oz}$.

Linseed powder and syrup enough to give it a proper consistence, to be divided into six balls for stroug, or cight for wcak delicate hor'ses.

$$
\text { No. } 2 .
$$

Castile sonp ................ 4 oz.

Venice turpentine ............ $2 \mathrm{oz}$.

Powdered anisc-secds cnough to give it a proper consistence, to be divided into six balls.

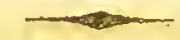

Alleralives.

'These are medicines which produce their effects almost insensibly; the following formulæe will be found efficacious. 
Alterative Powders.

No. 1.

Levigated antimony ........6 oz. Flowers of sulphur ....... 8 oz.

Mix for eight doses.

No. 2.

Powdered resin $\ldots \ldots \ldots \ldots \ldots$ 4 oz. Nitre ............... 3 oz. Tartarised antimony ........ 1 oz. Mix for eight doses.

$$
\text { No. } 3 .
$$

Unwashed calx of antimony ...2 $2 \mathrm{oz}$. Calomel ................ $2 \mathrm{dl}$. Powdered anisc-seeds ....... 4 oz. Mix for eight doses.

Should a balt be thought mole convenicut than a powder, the change may be easily made by the addition of syrup and linsced powder.

A dose of the alterative powder should be given evely evening with the corn, until the whole quantity (that is, eight doses) is used.

But the powder, No. 3, should not be continued so long, on account of the ealomel which it contains, unless the horsc be taken great eare of; and the effects of the medieine carcfully watched. Whenever it is observed to occasion sickness, grip- 
ing pains, loss of appetite, or purging, it should be immediately discontinued, until these symptoms go off,

\section{Laxatives.}

THIs term is applicd to opening medicines that operate very mildly, and produce so gentle a stimulus upon the intestines, as merely to hasten the expulsion of their present contents without incrcasing their secretions. Castor oil scems to be the best medicine of this kind, though the oil of olives or of linseed will produce nearly the same effect. The dose of the former is about a pint; but the latter may be given to a pint and a half. When"a laxative ball is required, the following will be found useful :-

Laxative aloes $\ldots \ldots \ldots \ldots \ldots \ldots$.

Castile soap .............. $3 \mathrm{dr}$.

Syrup enough to form a ball for one dose.

3. Blisters.

Prevrous to the application of a blistcr, the hair should be cut from the part as closely as possible, the blistering ointment is to be well rubbed on it, and afterwards a small quantity is to be 
spread over the part with a warm knife. When the blister begins to operate, horses are very apt to bite the part, which, if suffered, might produce a permanent blemish. It is necessary, therefore, to guard against this accident by putting what is termed a cradle about his neck, or by tying him up to the rack. When the legs are blistered, the litter is to be entirely swept away, as the straw might irritate the blistered parts.

\section{Blistering Ointment. \\ No. 1.}

Spanish flics, powdered, ......... $\frac{1}{3}$ oz. Oil of turpentine ............. I oz. Dintment of wax or hog's lard ...... 4 oz. Mix.

No. 2.

Oil of turpentine $\ldots \ldots \ldots \ldots \ldots \ldots, 1 \mathrm{oz}_{\text {. }}$ To which add gradually,

Vitriolic acid ............... $2 \mathrm{dr}$. Hog's lard $\ldots \ldots \ldots \ldots \ldots \ldots \ldots \ldots$. 4 oz. Spanish flies, powdered, ........... I oz. Mix.

No. 3.

Common tar ................ 4 oz. Vitriolic acid $\ldots \ldots \ldots \ldots \ldots \ldots \ldots 2 \mathrm{dr}$.

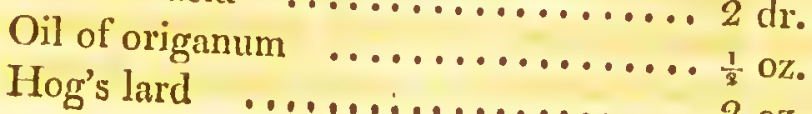
$2 \mathrm{oz}$. 
Spanish flies, powclered, $\ldots . . .1 \frac{1}{2}$ or 2 oz. Add the vitriolic acid gradually to the tar, and then the rest of the ingredients.

Remark.-The blister No. 3 is remarkably useful in removing enlargements of the baek sinews or windgalls. It is neeessary to be very careful in mixing the vitriolie aeid with the tar; for', unless they are intimately incorporated, the aeid will aet as a caustic upon the skin, and produce uleeration. I have seen horses suffer severely from this, particularly when in blistering the leg's it has been applied also to the back part of the pastern, or to the heel, a part that should always be protected from the action of the blister, by having some hog's lard smeared over it; being so irritable that a blister sometimes causes uleers, which in this part are difficult of cure. Sublimate is often reeommended as an ingredient in blisters, but it is very apt to ulcerate the skin, and leave a permanent mark or blemish. I have therefore omitted it in the above formulæ; but in cases of bone spavin, in whieh severe blistering is necessary, it may be employed with advantage. I have for some time cmployed the following blister for common purposes, and find it more convenient than the otlicrs.

No. 4.

Hog's laid $\quad: \cdots \cdots \cdots \cdots \cdots \cdots$ 6 oz.

Veniee turpentine .......... 4. oz.

Bees' wax .............. 2 oz. 
Yellow Resin

Oil of origanum $\ldots \ldots \ldots \ldots \ldots \frac{1}{2} \mathrm{oz}$.

Powdered cantharides ........ 3 oz.

Mclt the first four ingredients; and when removed from the fire, and not too lot, stir in the oil of origanum and cantharides: continue stirring until cold. Should this blister become too hard in winter, it may be softened by rubbing it with a little oil of origanum or turpentine, in a mortar or on a slab. (See vol. ii.)

\section{Fomentations.}

Fomentations are commonly made by boiling wormwood, southernwood, camomile flowers, and bay leaves, in water, so as to make a strong decoction, which, being strained off, is to be applied as hot as it can be, without giving pain to the animal, by means of large flannel cloths. The efficacy of fomentations depends in great measure on their use being continued for a considcrable time together, and being frequently repented.

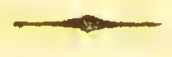

\section{Poultice.}

The following mixture will be found useful as a common poultice: Fine bran one quart; pour 
on it a sufficient quantity of boiling water, to make a thin paste; to this add of linseed powder enough to give it a proper consistence.

\section{Rowels.}

When these are used with a view of relieving internal inflammation or fever, it will be found useful to apply some stimulating liniment, such as equal parts of common oil and oil of turpentine, or the digestive commonly made use of, for this will produce a considerąble degree of inflammation in a short time.

\section{Clysters.}

A varIETy of compositions have becn recommended for clysters by those who have written on the subject, there bcing scarcely an article in the Materia Medica, that has not bcen occasionally employed in this way. I have found, however, from considerable cxperience, that, for a common clyster, water-gruel is as efficacious as the most elaborate composition. When this cannot be readily procured, I have been in the habit of using warm water, and without perceiving any difference in the effect. Wherc a purgative clyster is required, from four to cight ounces of common salt may 
be added; and if an anodyne be wanted, or an astringent, let from one to two drams of opium, or from 1 oz. to $1 \frac{1}{8} \mathrm{oz}$. of laudanum, be dissolved in a quart of water-gruel. The best method of administering clyster's is by means of a bladder and pewter pipe. If a clyster be employed for the pnrpose of emptying the large intestines, or of purging, the quantity of liquid should not be less than a gallon, or six quarts; but when it is used as an anodyne or astringent, from a quart to three pints of liquid will be sufficient.

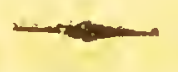

\section{Pulse,}

IN the mnuagement of sick horses great advantage may be derived from attending to the state of the pulse, as we are thereby enabled to judge of the degree of violence of the disease, and the probability there may be of recovery: we are in some measure assisted also by it, in ascertaining the nature of the complaint, and in the application of re-
medies.

In a healthy horse the pulations are about 36 or 40 in a minute, and may be felt very distinctly either on the left side, or in an artery which passes over the lower jaw-bone; in short, pulsation may be felt in every superficial artery.

When a horse appear's rather dull, and does not feed properly, it is adpisenble to examine the pulse, 
and if he be found to exceed the standard of health, immediate recourse should be had to bleeding. By this timely interference many dangerous complaints may be prevented. When the pulse rises to 80 or 90 in a minute, there is reason to bc apprehensive of danger; and when it exceeds 100, the disease frequently terminates in death.

\section{Of the Age of a horse.}

The age of a horse may be discovered by certain marks in the front teeth of the lower jaw and the tushes, until the eighth year, about which tine they are generally worn out. An experienced person can, however, after this period, judge of the age, with some degree of accuracy, by the countenance. and general apperance of the animal, as well as by the length of the teeth, and form of the tushes.

Between the second and third year, a colt begins to change his sucking leeth, as they are termed, for others of a larger size and of a different form and colour. The sucking teeth are small, and of a delicate white colour. The number of tecth in the front of the mouth are twclve, six in the lower and six in the upper jaw. (We take no notice of the molares, or grinders, as they are not concerned with this subject.) When a colt is three years old, we may observe that the four front sucking toelth 
are lost, and that, instead of them, four others have sprung up, of a'very different appenrance, being. larger, of a darker colour, and having a considerable cavity on the upper surface; these are termed horse's, or permantnt teeth. Between the third and fourth year, the four teeth next these are lost, and leplaced, in the way we have just described, by horse's teeth; so that when a colt has completed his fourth year, there are eight horse's teeth observable, and only four colt's teeth, one at each extremity, or corner, as it is termed. About the middle of the fifth year these also fall out, and are succeeded by horse's teeth. The corner teeth of the horse, particularly of the under jaw, are different from the rest being smaller, and of a shelllike appearance: their cavities are chiefly within the upper surface being a mere edge; but abont the end of the fifth year they are larger and more like the other teeth. It is generally between the fourth and fifth year that the tushes make their appearance, though sometimes earlier.-The tushes are four in uumber, and situate about an inch from the corner teeth; at first they are small, terminate in a sharp point, are rather convex on their cxternal surface, but within have two eoncavities or grooves, separated by a ridge. 'These, as well as the teeth, are gradually undergoing an alteration in their form, becoming longer; and losing the concavities on the internal surface. About the seventh year. the concavity is considerably diminished, and in old borses the surface becomes con- 
vex, the tush acquires a round form, and the extremity, instead of being sharp, is quitesblunt, as if the point had been broken off, and the new surface afterwards polished. We must now return to the teeth, the appearances of which we have described, as far as the completion of the fifth year of a horse's age. After this period we judge of the age by the size of those cavities which we have described on the upper surface of the tooth: for the friction to which that surface is almost constantly exposed gradually wears it down, and at length the cavity or mark is totally obliterated. The marks in the upper teeth most commonly remain until the twelfth year, 'sometimes longer, but those in the under teeth are worn out about the end of the eighth yenr; we shall therefore confine our description now to the under jaw.

As the two front teeth are the first that make their appealance, it is obvious that their marks will be lost sooner than those of the other teeth; and if we examine the mouth of a horse that has just completed his fifth year, we shall find, that they are nearly, and sometimes quite worn out: those in the adjoining teeth are about half their original size, while the inarks of the corner or end teeth are perfect. At the end of the sixth year, the only cavities observable are in the corner tecth, and these are about half their original size: the tooth has at this period lost the shell-like appearance we have before described, and is not different from the other tceth, except in haying a maxk or 
cavity on its upper surface. At the end of the seventh y'ar, the marks of the corner tecth are also obliterated, and then the horse is said to be aged. We often find, howcver, that the marks of the cormer teeth are not totally effaced at this peliod : a small dark coloured spot may be observed in most horses, until about tlie end of the ciglith year. From this period we have no criterion by which the age may be ascertained, but it is said that the marks of the upper teeth will cnable us to judge of the age until the thirteenth year; the marks of the fiont teeth being worn out when he becomes eight years old, those of the adjoining teetl at tell, and the corner teeth at twelve; but I cannot say how far these marks can be depended upon.

On the Management of a Horse during a Journey.

Previous to setting out on a journey, every precantion should be cmployed to bring a liorsc into as perfect a state of health as possible, as we thercby avoid much trouble and inconvenience. It is necessary also to examine the fect, and see that they are in good order, and property shoed: the saddle, or harness, should also be inspected. By attention to all these circumstances, a horse would generally perform the journey with ease to himself and comfort to his rider; and I have often, in the course of a long practice, had occasion to witness 
the oecurrence of the most vexatious and expensive delays during a journey from a want of such attention. Before a horse is taken out for a long journey, he should, for a fortnight previous, be rode out daily for cxcrcise; not mercly walked about for twenty minutes, or lialf an hour, but kept out for an hour or two, during which time, he should have some trotting, as well as walking, excrcisc. It is adviseable to have the horse shocd four or five days before he sets off on the journey; bccause if they do not exactly fit him, or if a nail should have been driven too close, the error ean be corrected without much inconvenience. Should he be at all subject to grease, or swelling of the legs, a dose of physic is to be recommended, taking care to preserve the heels cleall, and to keep up a brisk eirculation in the legs by frequent hand rubbing. Should the feet of the horse be tender, it is necessary to inquire into the cause of that tenderness: if it arise from corns, let the directions be followed that are given under that head; if it proceed from flat and thin soles, great care is required in adapting the shoes to the feet, and nailing them securely; as such feet are gencrally thin and brittle, and the loss of a shoe might occasion severe lameness. If the frogs are tender from thrushes, let them be made perfectly clean, and then dressed at first with a solution of white or blue vitriol, or of sugar of lead, afterwards with tar. If the fect are hot, dry, and inflamed, let them be softened and cooled by a poultice. Horses that travel during the winter 
are very liable to have their hecls inflamed and cracked, as it is tcrmed, unless great attention is paid to them in the stablc. In cases where the hcels are already thus affected, they should be waslied with moderately warm water as soon as the horsc gets in, and afterward carcfully wiped diry with a soft cloth; if much inflamed, a poultice, and afterwards the astringent lotion are to be applied; and if there he any ulcers or cracks, use the astringent ointment, and let the altcrative powder, No. 2, be given occasionally. When a horse's wind appear's to be imperfect, he should not be allowed to fill himself with hay or water, and nust be prevented from eating his litter, which hor'ses of this description are gencrally inclined to do, particularly when stinted in hay: in this case, costiveness sometimes occur's, which always increases the complaint. To remedy this, let a clyster and a few bran mashes be given. Too high fecding is . also very prejudicial in these complaints, as any thing which tends to create a plethora, and determine too much blood to the lungs, is sure to aggravate the disease. To a horse that purges or scours in travelling, and appears faint, sweating much with moderate excrcise give the cordial ball, the efficacy of which is sometimes increased by being mixed with a pint of alc or strong beer : if the complaint do not give way to this treatment, let the astringent ball be given. As soon as a horse comes into the stable, let
his fect be well cleaned, and all dirt or gravel care- 
fully removed. It is a very common practice with ostlers, even in winter, to tic the horse up in the yard, that he may undergo the ceremony of having his heels washed with cold water. This should never be permitted during the winter, as many bad consequences may arise from it. During hot weather, when the roads are dry and dusty, allow a liorse to drink a small quantity of water now and then, while on the road; this not only refreshes him considerably, but has the useful effect of cooling and moistening his hoofs, as he will generally be made to stand in the water while drinking, nor is there the least danger to be apprehended from it, unless he is rode very hard immediately before or after. In winter he should never be taken into the water, if it ean be avoided eonveniently.

Should the horsc appear dull, and lose his appetite, let him be bled moderately, and take a dose of nitre with a bran mash; this, witl a little rest, will soon reeover him. It is a eommon praetice, when this liappens, to give cordials, which are very improper, and often do mueh injury to the animal, by bringing on a fever. Somc horses are partieularly subject to the flatulent eolic, or gripes: this is often the ease with crib-biters: on such oecasions, it is adviscable to be always provided with a remedy' and, as a ball is the most convenient form, I have given a recipe for the purpose. (Sec Flatulent Colic, or Gripes.) A suppression of urinc, or great difficulty and pain in staling, is an accident that 
sometimes occurs in travelling; and in such cases a diuretic ball is commonly given, which, though sometimes successful, has often done mischicf. The most effectual way of relieving the hor'se is by throwing up a clyster, and bleeding moderately: should there be no appearance of inflammation in the kidneys, a close of nitre may also be given. The common practice of loading a lorse with clotles, and keeping him in a close warm stable, if he liappen to take cold during a jonrney, is certainly improper, since lie is liable to be frequently exposed to wet and cold in travelling. It is a well known fact, that animals are not hurt by being kept in any uniform temperature, whether it be lot or cold; and that their diseases more commonly arise from sudden changes, or frequent variation of temperature.

When a lorse becomes suddenly lame in travelling, let the fect be carefully cxamined. Should the lameness be occasioned by a wound from a nail or flint, apply tincture of myrrl or Friar's balsam, having previously removed all dirt or gravel from it; and if the wound have been inflicted by a nail, let it be carefully opened to the bottom with a small drawing knife, and proper means used to prevent dirt from getting to it. 


\section{Cordial Balls.}

No. 1.

Cummin seeds,

Anisc-secds, and

4. Oz.

Caraway seeds, of each ......

Ginger ............. 2 oz.

Treacle enough to make it of a proper consistence for balls. The dose about two ounces.

\section{No. 2.}

Anise-seeds,

Caraway seeds, ........... 4. oz.

Swcet fennel seeds, and ......

Liquorice powder, of each ...

Ginger and cassia, of each .... $1 \frac{1}{12}$ oz.

Honey enough to form them into a mass. The dose about two ounces.

\section{No. 3.}

$\left.\begin{array}{l}\text { Cummin sceds, } \ldots \ldots \ldots \ldots \\ \text { Coriander secds, and } \ldots \ldots\end{array}\right\}$ 4. oz.

Caraway seeds, of each .......

Grains of paradise ......... $1 \mathrm{oz}$.

Cassia ................. $\frac{1}{y} 0 z$.

Cardamom sceds and saffiron, $\} 2 \mathrm{dr}$. of each

Liquorice dissolved in white wine $2 \mathrm{dr}$. Syrup of saffiron chough to form a mass. The dose about two ounces. 
No. 4.

Powdered ginger .......... $4 \mathrm{oz}$.

Powdered caraway seeds ....... $8 \mathrm{oz}$.

Oil of caraways and $\ldots \ldots \ldots \ldots$ ?

Oil of anise-seeds, of each $\ldots .\} .2 \mathrm{dr}$. Liquoricc powder .......... 8 oz.

Treacle enough to form a mass.

When cordial balls camnot be readily procured, a little warm beer, with some grated ginger, may be substituted for them. 


\section{APPENDIX.}

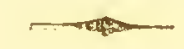

J.OCKED JАY.

I HAVE lately met with a case of locked jaw, that appeared to have been caused by a wound in the foot, which was completely cured by the following treatment. Upon examining the horse, I found the wound in the foot nearly healed; the jaws so closed, that he could not even take food into his mouth, though he was constantly endeavouring to do it, and appeared very liungry, having been incapable of eating any thing about twenty-four hours before I saw him; the muscles of the neck were in a natural state, though the jaws were so closed as to prevent his taking food into his mouth; the teeth were not absolutcly in contact; and we were able, but with great difficulty, to introduce gradually a large dose of opium and camphor. When we first attempted to give this draught, the animal appeared so agitated, and resisted so mucl, that it required the assistance of several men to gire it. $\Delta$ s soon as the medicine was given, a strong blister was applied to the spine or middle of the back, beginning at the withers, 
and continuing it the whole length of the spine, even to the basis of the tail ; the blistcr was carefully rubued in, and afterward a fresh quantity was spread upon it, in order to expedite its aetion. A caustic was then applied to the wound in the foot. In about six hour's we endeavoured to give some strong gruel, and found much less diffieulty in doing it, than in giving the medieine at first. The jaws, however, were still nearly close, and some dexterity was required to pour the gruel into the throat. Soon after this, another dose of opium and eamphor was given, and water-gruel several times. During this time, the jaws appeared to be rather more open, and there was less difficulty in giving the gruel. Abont twenty-four hours after the applieation of the blister, during which time he had taken two strong doses of opium and eamphor, and some gruel, the liorse was able to feed, and even to eat hay. Another close, but weaker, of opium and camplor was given: the complaint did nol return. The fatality of this disease in horses, and the eonsideration that a clearly stated case can be more elosely fullowed than a general deseription of the treatment, have induced me to give a detailed account of this suecessful case.

Since the former edition of this work, I linve had an opportunily of porusing "A Treatise on Locksd bau and Epidemic Catarh, or Distemper;" 
by William Wilkinson, Veterinary Surgeon, of Newcastle-npon-Tyne, and finding in it some useful obscrvations, and a description of twenty-four cases of the former disease, in which his mode of treatment proved successful, I should think a short account of it would not be decmed superfluous. With respect to the epidemic catarrh, or distemper, it is sufficient to observe, that $\mathrm{Mr}$. Wilkinson's mode of treatment does not differ essentially from that I have recommended, especially in my fourtl volume, from which he has made extracts: but in the treatment of locked jaw, there are circumstances worth noticing, especially as the result of his treatment was so unusually successful. The peculiarity of the practice consists in giving a strong purgative at the commencement of the disorder, and in covering the affected parts with sheep-skins, having previonsly embrocated them with some stimulating liniment. There is so little variation in the author's detail of the symptoms and treatment, that it will only be necessary to extract one case, in order to give the readcr a knowlcdge of the treatment and charactcr of the disorder.

Case.- "On being called to examine this case, I found the symptoms were a spasmodic affection of the muscles of the jaws, head, neck, back, hinder cxtremities, and abdomen, which occasioned them to bccome rigidly contracted, and the abdomen was muclı drawn in, the pulse was about fifty, with some irregularity, the breathing a little quickened, the jaws were considerably shut, but not so close 
but medicine might be administered as a drench with a small horn, the appetite not diminished, but she could not masticate hay, the head somewhat raised, and on elevating it a little more, the haws covered great part of the ball of the eye, the nose was thrown out from the chest, the nostrils expanded, the ears erect or perched up, a great stiffness of the neck and back, the tail a little elevated, and, upon a little fatigue, a shaking of it, a straddling of the hinder extremities; the animal was very costive, and the urine was somewhat diminished. The mare had been shoed about three weeks before, and the farrier had driven a nail into the sensible part of the foot while shoeing her. The lameness thus produced was soon removed, and the disease came on after performing a journey; that is about three weeks alter the injury in the foot had been inflicted. Two quarts of blood were taken off; a purgative drench and an emollient clyster swere given; considerable friction was used over the muscles of the jaws, head, neck, and back, particularly where they were found most rigid; a stimulating liniment of turpentine, hartshorn, mustard, and oil, was well rubbed over those parts, which were afterwards covered with sheep-skins, as recently taken off the sheep as they could be procured, which soon brought on sensible perspiration. The diet was principally thin bran mashes and oatmeal-gruel, of which she frequently took a little. The next day, pulse the same, breathing a little quicker, jaws not morc locked ; a constant perspi 
ration had been kept up by the sheep-skins; the purgative drench not operating, another clyster was administered, which promoted its action: the liniment was repeated. Next day (the ninth), symptoms nearly the same, perspiration copious, the purging having subsided, the anti-spasmodic medicine, composed of opium, camphor, and assafotida, was given with a small hom morning and evening, and a similar mixture, with the addition of three pints of a decoction of ruc, was administered, as a clystcr, morning and evening. The drench and clysters were repeated morning and evening till the 14.th; and during this, the quantity of opium, viz. I dram, was increased or diminished according to the violence of the spasms, which at times were very severe. It was always administered in such a manner as to have its effects constant in the system, without producing much restlessness; during this time, there was also a most copious perspiration going on under the sheep-skins. The howels becoming costive again, another purgative drench and an emollient clyster were administered. On the $15 \mathrm{th}$, the drench not operating, an emollient clyster was given, which produced the desired effect. Pulse and breathing a little hurried and irregular, jaws not more locked, still perspires under the sheep-skins, appetite good, but cannot masticate hay. 16th, Pulse morc regular, breathing more calm, perspires fiecly under the skins: the purging having subsided, the opium, \&c. were administered as before, and continued until the 21 st, 
when another purgative drench and emollient elyster were given. The jaws were now morc open, and the mare could masticate hay: the museles of the head, neek, back, and hinder cxtremities, bccame considerably relaxed, and on raising the head, the haws did not cover mueh of the eye. On the $23 \mathrm{~d}$, thc purging having subsicled, the antispasmodic medieinc was again employed until the 10th of April, when another purge was administered. On the 12 th, the purging subsided: the anti-spasmolic was again used a few days longer, when she was completely cured of the eomplaint. After this, tonies were given, whieh, with a nourishing dict and suitable cxereise, soon restored the tone of the muscles, and the animal beeame as unseful as ever."

Nine of the twenty-four cases deseribed came on after docking or eutting of the tail, from ten days to a month after the operation. In sueh eases, the tail was fomented with warm water, and the sore dressed with digestive ointment. It shoukd be remarked, that in all the successful eases the jaws were not so completely elosed but medicine could be giren with a small horn, or introduced as a bolus, by means of a cane. In some instances, there appears to have been considerable difficulty in giving medicine at first, but by persevering carefully, both medieine and food were introdueed in sufficient quantity. With respect to cold application, Mr. Wilkinson says, he has only tried it once, when the whole of a mare's body, affected with 
locked jaw, cxcept the nostrils, was immersed in snow for somc time, without producing any relaxation of the muscles; on the contrary, the symptoms afterwards gradually increased, and she dicd the third day.

In four cascs that terminated fatally, the jaws were so completcly closed, that neither food nor medicine could be given by the mouth. On cxainining these horses after death, there was some degree of inflammation in the lungss, stomach, and bowels; he "generally found on opening the spinal canal, that the mombrancs covering the spinal marrow cxhibited a very inflamed appearance, and the spinal marrow itsclf was tinged of a darker colour, and the membrancs of the brain cxhibited some unarks of infammation." Of the twenty-eight cases given by Mr. Wilkinson, all cxecut eight were occasioned by some external injury; and in these the cause does not scem to liave becn apparent, though attributed in two of them to catarrlh, or exposure to cold. One of them canc oun alter inflanmation of the lungs. In onc case only, the disordcr camic on three weeks after castration or gelding.

Mr. Wilkinson's observations on this formidable treatment appoars to have been cminently successftil. It will not perhaps be uninteresting if I conclude this subject witl Giloson's brief, but familiar, description of this disorder; from which it will appear, that most of the cases which occurred in 
the course of his practice appeared to originate in irritation or ulceration of the stomach and bowels by botts, wornus, or from some disease of the diaphragm, such as impostlumation or ulceration. Gibson also strongly recommends rubbing the parts well with stimulating liniments; and mentions a case where the jaws, were so much shut, that the horse could neither eat nor drink for three weeks; only, by continually rubbing the jaws and neck, he could sometinies make a shift to suck about a handful of scalded bran, or sometimes a little oatmeal moistened with a little warm water; and he thinks, that during the three weeks he did not eat enough to sustain him one day, and during all this time he was supported by nilk and oatmenl injected by the fundament. During all this time the contraction of the jaws continued obstinate; therefore, he caused lialf an ounce of opium to be given in one of his clysters, soon after which, the liorse lay down, could move his ears and neck very freely, and his mouth was so far at liberty that he took his drenches with little or no difficulty, and could eat hay or bran sufficient to sustain him. In one of Gibson's cases, the discase begnan in the hind parts, and proceeded gradually forward to the jaws; but Mr. Wilkinson states, that of sixty cases of locked jaw that he las met with in the course of twenty years practice, not one of them comnenced in that manner, but invariably began with an affection of the muscles of the jaw, and as 
the disease advanced, the muscles of tlie head, neck, back, and hind extremities became affected.

\section{Gilson's Description of Locked Jaw.}

As soon as a loorse is seized with this complaint, his head is raised, with his nose towards the rack, his cars pricked up, and his tail cocked, looking with eagerness, as a lungry lorse when hay is put down to him, or like a high spirited horse when put upon his mettle; insomuch, that those who are strangers to such things, when they see a horse stand in this manner, will scarce believe that any thing of consequence ails him; but they are soon convinced, when they see other symptoms come on apace : his neck grows stiff, cramped, and almost immoveable; and, if a hor'se in this condition lives a few days, several knots and ganglions will arise on the tendinous parts thereof, and all the muscles, both before or behind, will be so much pulled or cramped, and so stretclied, that he looks as if nailed to the pavement, with his legs stiff aside and straddling. His skin is drawn so tight on all parts of his body, that it is almost impossible to move it, and if trial be made to make him walk, he is ready to fall at every step, unless lie is carefully supported: his eyes are so fixed witl the inaction of the muscles, as gives him a deadness in lis looks; he 
snorts and sneezes often, pants constantly with shortness of breath, and this continues increasing till he drops down dead, which generally happens in a few days, unless some very sudden and effectual turn can be given to the distemper. It almost always scizes suddenly, and without any previous symptoms. Young horses, from four to six years old, are most subject to it, and the large coach breed, and all kinds of draught horses more than saddle-horses. The most usual cause of this universal cramp or convulsion is from botts in the stomach, which generally come to maturity in the months of April, May, and June. It is sometimes (he thinks) owing to other causcs, sucl as imposthumation, or ulcers of the midriff or diaphragm. In such cases, there are some previous symptoms: the lorss, first of all, falls off; his stomach grows gradually wcak, fecble, and dispirited in his work, turns short breathed with the least excrcise. These are signs which I have observed go before the distemper, though they are also common in many other inward disorders.-Gitson on the Diseases of Horses, vol. i. p. 250.

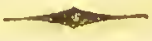

Ferer.

In the former editions of this work, ferei was considered either as a simple or original complaint, arising from suddenly suppressed or checked per- 
spiration, or as a symptomatic or complicated disease, depending upon an affection of one or more of the internal orgaus, or their membranes. In both cases, lleeding was recommended as an essential remedy. My practice, since that time, has not given me reason to change this opinion materially; but, as some modern writers on farriery have described another kind of fever, termed putrid, or typhus, in which bleeding is extremely injurious, I think it necessary to state the observations, which all extensive practice has suggested to me on this subject. The grand characteristic of fever I conceive to be, an unusually quick pulse, $i$. $e$. from seventy to a hundred in a minute; a peculiar kind of sensation which it gives to the finger, as if it were struck sharply by the vibration of a cord; and at the same time a feebleness, or smallness, quite different from that gradual swell of the healthy pulse. Whien a liorse labours under considerable debility, eitlıer from liard work, want of sufficient food, or other causes, except fever, the pulse is more or less languid, or weak; sometimes slower, at others a little quicker than usual; still, however, it swells gradually, and does not give that sensation we liave described, and which physicians term hardness.

In fever, there is either a total loss, or a diminution of appetite, and the animal appears to be in pain; the natural evacuations (dung and urine) are generally deficient; and, upon lifting the eyelid, we generally find it unusually red. The mouth 
feels hotter, and the tongue is commonly dryer than usual.

In simple debility, or weakness, whether it be occasioned by hard work, or any other cause, except fever, the mouth and tongue are in their natural state; the pulse, though weak, and sometimes not easily felt, if we press much upon the artery with the finger, does not give that sharp hard stroke which characterises fever; the horse readily sweats; and when the weakness is considerable, the ears and hind legs will feel rather cold, and his flanks generally move quicker than usual. If blood be drawn, it will be found very different from that of a horse labouring under fever or inflammation. (See Bleeding.) The appetite, though diminished, is not quite gone; the inner surface of the eyelid is not unusually red, often less so than in health; and the horse does not appear to be in pain. Though bleeding, in sucl cases, is extremely injurious, a mild laxative is useful, unless the dung be softer and in greater quantity than natural; and if there be a deficiency of urine, or any difficulty in voiding it, a diuretic, composed of camphor and nitre, should be givell. This symptom, however, seldom occurs in these cases. After the laxative, tonics, with a nutritious diet, and good grooming or nursing, generally restore the animal in a short time to health. This disease is sometimes mistaken for fever, and treated improperly; they are cases of this kind, however, 
that farrier's so frequently cure, under the name of ferer, by medicines of the cordial or tonic kind.

I never saw any kind of fever, in which bleeding, and, generally, laxatives, were not manifestly useful, if employed judiciously, at an early period; that is, if the quantity of blood drawn, and the strength of the laxative, were properly adapted to the strength of the animal, and the violence of the disease, and employed at its first appearance. Several cases have occurred, where debility quickly succeeded the infammatory commencement, and rendered bleeding, sometimes purging also, highly improper; and it is, perhaps, such cases, that some writers have mistaken for the typhus, or low putrid fever: others appear to me to have copied their description of it from that given by
writers on human disenses.

In cases of simple debility, I have found the following medicines of great use, giving the laxative in the first place, if the horse be costive, ol even if the bowels be in a natural state; during its operation, however, it is adviseable to give strong gruel, insteal of bran mashes.

\section{Laxalive.}

Barbadoes aloes ........... $3 \mathrm{dr}$.

Powdered canella ............. $1_{\frac{1}{2}} \mathrm{dl}$.

Prepared kali ............ I dr.

Mint water ............. 8 oz,

Mix for one draught. 
Tonic.

Yellow Peruvian bark ........ $6 \mathrm{dr}$.

Cascarilla ............... $1 \mathrm{dr}$.

Powdered opium $\ldots \ldots \ldots \ldots \ldots \frac{1}{2} \mathrm{dr}$.

Prepared kali ............. 1 sc.

Syrup enough to form a ball for one dose.-It is often neeessary to increase the proportion of bark, and sometimes of the other ingredients; but when the horse becomes costive, the opium must be omitted.

The most proper food, on these occasions, is good sweet oats, and the best hay, given frequently in small quantities. The horse should be allowed to drink, also, frequently; his exereise slould be very moderate; and, when the weakness is considerable, he should be allowed to exercise himself in a large stall or box, and not taken out until he gets stronger. If he beeome eostive; a elyster, or even a mild laxative, may be givel. I have met with a disease, in colls of about tiro or three years old, in whieh the debility was extremely obstinate. rhe disease began with swelling about the ehest and belly, great wealsness, diminished appetite, and a rather quick pulse, without the hardness characteristic of fever. In the most remarkable case of this kind, the colt (three years old) was attaeked in the month of May, while running in a finc piece of grass: the first appearance of illness 
was his separating himself from his companions, standing with a dejected appearance, and not grazing as usual. When examined, considerable swelling was observed about the chest, between the fore legs; and when I saw him, the pulse was about sixty in a minute, yet soft: he did not refuse his food entirely, but appeared indifferent about it; nor was there any symptom which indicated an affection of the internal organs. He voided his urine with difficulty, and in the usual quantity; but as the dung appeared harder, and in less quantity than is usual with horses at grass, a weak laxative was first administered. He was taken up and put loose into a cool stable, whicl opened into a large court, the door being left open : he was offered frequently young lucerne, clover, \&c., and allowed to drink when he chose it. The swelling and weakness increased considerably; a medicine, composed of bark, vitriolated iron (salt of steel), and a little canella, was therefore given, and a more nutritious diet allowed; vir. gruel, arrow root powder, boiled in the usual way with water, and a handful of onts now and then. The tonic medicine so improved his appetite, that he readily took a moderate quantity of this food; yet and the pulse remained in a slow feeble state, but rather slower. The swelling was scarified, and a large quantity of water evacuated, by which it was greatly diminished; the dose of tonic medicine was increased, and joined with diuretics occasion- 
ally. His appetite improving, he was allowed to take an unlimited quantity of the most nutritious food, which was varied so as to keep up his appetite; and, by persevering in this plan about a fortnight, he appeared to be quite recovered. About a fortnight after this, the disease returned with greater violence, the swelling extended all over the under part of the chest and belly, the pulse became very weak, but not much quicker than before, and the animal was extremely feeble. By persevering in the use of the tonic medicines, and assisting them by the most nutritious diet, such as strong gruel, new milk, oats, \&c., the colt perfectly recovered. I have seen several cases of this kind, one of which proved fatal from the negligence of the owner, who did not supply the colt with a sufficient quantity of nutriment, which seems to be as necessary as medicine; and when a colt in this complaint refuses his food, I have found it necessary to drench him frequently with strong gruel, boiled arrow root, sago, or milk. It is proper also to vary the food, so that the animal may be tempted to eat oftener than he would otherwise: for this purpose, car'rots, lucerne, \&cc. are useful. The onts should be perfectly sweet; and should the colt be found to prefer them in a moist state, they may be sprinkled with water. 


\section{Epidemic Fever, or Distemper.}

The epidemic diseases of horses generally apd pear in the form of a violent caturrh, or cold. The first symptoms are cough, heaviness of the head, the eyes often watcry, or a little inflamed: sometimes there is a quickness of breathing; and the inflammation of the membrane, which lines the throat, nose, and windpipe, is often so considerable, as to cause a difficulty in swallowing; the pulse is generally quicker than usual. If the proper remedies be not employed at this period, the horse becomes very weak, and considerable fever takes place; the appetite goes off; the cough and quickness of brcathing increase; and debility is so great, that the animal staggers in his walk. There is an offensive discharge from his nose: and, after lingering some time, the horse dies from a consumption. More commonly, however, a discharge of white matter takes place from the nose after the discase has continued a few days, by which the cough and other symptoms appcar to be lessened; but though the horse slowly recovers lis liealti and strength, a troublesome and sometimes incurable cough remains. When the disease is properly treated at its commencement, the hor'se perfectly recovers in a short time, unless the attack is very violent; and even then, by juclicious management, the cough, as well as the other symptoms,
may be cured. 
When an epidemic happens, horses should be carefully watched; and on the first appearance of any symptoms of the disease the horse should be bled freely, unless he is in low condition, or previously exhausted by hard work, old age, or unwholesome food. After bleeding, give the following laxative, and let the loorse's diet consist of bran mashes, sweet hay, and a very small quantity of oats. Whien the attack is moderate, these remedies are generally sufficient to effect a cure, taking care to prevent a relapse by nursing, and giving every day one of the following powders.

But when the inflammatory symptoms are at first violent, when there is a quickness of breathing, soreness of the throat, and distressing cough, a blister to the throat is necessary; and, unless weakness forbids, bleeding even to five quarts is proper. A laxative is always beneficial at first, if the bowels be not already open; after which, the following powder is to be given daily. Warm clothing, and frequent liand-rubbing to the legs, are useful; but a close stable is injurious. The horse should be turned loose into a large stall; and if a discharge from the nose appear, let it be encouraged by causing the vapour of warm water to pass through the nostrils, and clothing the head and ears. When the disease, from being neglected or improperly trented at first, becomes alarming, and the weakness considerable, nothing but tonic medicines and a nutritious dict can do any good. 


\section{Laxative.}

Barbadoes aloes ........2 to $3 \mathrm{dr}$. Tartarised antimony ........ $1 \mathrm{dr}$.

Mix first with about 4 oz. of warm water; and then add $4 \mathrm{oz}$. of castor oil

To be given at one dose.

Powder for Epidemic Fever.

No. 1 .

Powdered nitre ......... $\frac{1}{\mathrm{y}}$ oz. to $1 \mathrm{oz}$. Antimonial powder ............ 2 dr. Camphor .............. 1 dr. to $2 \mathrm{dr}$.

Mix.

No. 2.

Tartarized autimony $\ldots \ldots \ldots \ldots 1 \mathrm{dr}$. Powdered resin $\ldots \ldots \ldots \ldots \ldots 3 \mathrm{dr}$. Nitre ...............

Mix.

One of either of these powders is to be given daily, or twice a-day, until a considerable diuretic effect is produced: it is then to be discontinued for a short time. They may be formed into balls with flour and syrup. 


\section{Diseases of the Stomach.}

The principal diseases of this important organ have been before described. There is one, however, which I have but bricfly noticed, and which has been denominated slomach staggers, from its resemblance to apoplexy, or brain staggers.

A description of the symptoms has been given already. (Sce Staggers, p. 92-95.) It has been proved, that this disease arises from a distention of the stomach by food.* The stomach, with its contents, of one horse that died of this complaint, weighed nearly sixty pounds. Its conts were so stretched, that they were easily torn, and had, no loubt, lost all power of contracting some time before death. The fond which it contained was rather hard, consisting of imperfectly masticated hay and oats. The yellowness observable in the horse's eyes and mouth appeared to have been occasioned by the pressure of the stomach upon the gall duct, causing the bile to return into the circulation. A considerable number of horses, that died of this disease, were examined, and the same appearance observed in all of them: we therefore concluded, the immediate cause of this kind of staggers was

* The case noticed in the articles S/aggers, and In/lammation of the Bowels, seems to prove that, though the stomach is almost always found full and distended in horses that dic of staggers: yet the distention is more probably an effect of some distased state of the stomach, thith the cause of the disorder. 
an accumulation of indigestible food in the stomach : but as the disease also happened to horses at grass, and, in two or three cases, even to such as had been at grass some time withont being changed into other grass, it became necessary to cnquire into the cause of this accumulation. In many cases where it attacked horses kept in stables, it was ascertained without difficulty. The horses most liable to it were such as had been much cxhausted by hard work, unwholesome food, or old age; and not unfrequently all three of these causes had concurred in exhausting the animal's strength. Most commonly, the immediate cause was found to be that which we have before alluded to in page 256 : that is, allowing a horse that has been kept a considerable time without food, and just come into the stable from a long and fatiguing journey, to eat an unlimited quantity of food, without giving a sufficient quantity of water to enable the stomach to digcst it. This, however, could not have been the cause in the horses attacked at grass; yet, upon inquiry, it was found that such horses had been used ill or worked hard, previous to -their going to grass, and were generally old horses. It is probable, therefore, that the discase was brought on by the horse's cating voraciously of some unwholesome grass, which might act as poison on the stomach, depriving it of the digestive power, the effect being more readily produced in weak stomachs or debilitated constitutions. Whenever the stomach staggers happen, the proprietor is 
grently alarmed, from an opinion which generally prevails of their being contagious. There are some circumstances which seem to countenance this opinion; 1st, that they often attack more than one horse when several are kept in the same stable, not at the same time, but in succession: many farmers having lost several horses in a short time from this discasc. I am satisfied, however, that they are not infectious; and when a farmer happens to have several horses attacked with slaggers, either at the same time or in succession, it can only be attributed to his negligence or hard treatment of the animal : considerable experience and careful investigation have convinced me of the truth of this remark. * The only method of removing this disease is to exhibit strong purgatives, joined with aromatics and other stimulants, at an early period; for if the stomach be distended to a certain degree, no medicine can restore it. $\uparrow$

* The numerous cases of staggers which occurred at Swansea, and of which a detailed account is given in the third volume, certainly strengthen, if they do not confirm, the opinion of the disease being contagious.

+ When the stomach bas its vital power enniderably dimiuished, ito conteuts become subjeet, in some degree, to chemical laws, by which all dead maller is governet, or, in, otler words, fermentation will take plate, and a quantity of air be $e x-$ tricated in eousequence, so as to inerease the distention. This often oecurs to horned caltle, when bronght suddenly into a luxuriaut pasture, particularly clover. I onee met with a case where a loose, getting loose during the night, found the eornchest open: next morning he was lying dead in the stable; and, on opening the body, a large quantity of oats was found in the 
I do not think it adviseable, in this disease, to give a large quantity of purgative medicine at once, but some powerful stimulus must be cxhibited, in order to give the stomaeh suffieient energy to expel its eontents. The purgative, with weaker stinulants, may be repeated once in ten or twelve hours; and about a pint of salt water every sceond hour, with a tea-spoonful of compound spirit of ammonia. This will scrve to moisten the eontents of the stomach, and stimulate moderately at the same time. Clysters are also to be given now and then, so as to remove any hard exerement, that may get into the last gut. 'The extension of the stomacl eauses an aeeumulation of blood in the vessels of the brain; the horse hangs down his head, or forees it against the wall, appearing insensible. It is neeessary then to take a moderate quantity of blood from the neck or temporal artery; but in debilitated eonstitutions eopious bleeding is very injurious. It is adviseable, when this symptom is observed, to contrive some means for supporting the horse's head. If by these means we sueeeed in procuring an evacuation of hard dung, there is reason to expeet a reeovery, particularly whon, after cmptying the gut by a elyster, or by the hand, a fresh quantity is soon after found in it. When the exerement beeomes thinner, or the liorse purges, we may be satisfied that the dis-

stomach. In one part it was ruptured, and soune of the corn liad fallen lirough the opening into the cavity of the belly. I
have since heard of two similar cases. 
ease is removed, and then we have only to support the animal's strength with strong gruel given frequently, a small quantity of oats now and then, and tonic medicines. Should the horse be inclined to eat hay, a very small quantity only should be allowed at once. By adopting this plan, I have succeeded in curing this dangerous disease; but it is absolutely necessary to watch the horse constantly, and apply the proper remedies frequently. Without this attention, success must not bc expected. Besides, horses thus affected, will often injure themselves during their delirium, unless constantly watched and prevented. I do not think it difficult to distinguish between this and that kind of staggers which depends simply on an affection of the brain: in the latter, there is a more furious delirium; the eyes and mouth are not tinged yellow; there is not that convulsive twitching in the breast; the fore legs do not give way now and then, as if the horse were on the point of falling; it generally attacks horses in high condition, particularly such as have been well fed and not sufficiently exercised.

The stomach slaggers, on the contrary, generally attack horses of debilitated constitutions, that are worked hard and ill fed. When they attack horses apparently in good condition, we commonly find that they are rather old, and have been exposed to hard work: cases of this lind sometimes occur among waggon-horses, particularly when, from the sickness or inability of one or two of the team, 
the remainder are obliged to perform the whole of the labour: sometimes it liappens, as we have before observed, from fecding roraciously as soon as a horse returns from a loug journcy, and not taking in any water, or not enough, to moisten the food and render it digestible, or from swallowing the food hastily, withont proper mastication. In whatever way this complaint is brought on, the symptoms are always ncarly the same, varying only in degrec. The delirium is generally proportioned to the distension of the stomach. When this is considerable, the animal appears to suffer the most cxeruciating pain; and though generally delirious or stupid, it is very different from that fillrious madness, which infammation of the brain occasions. When the stomach staggers liave happened to horses at grass, they are generally found in the hedge; and, if taken out, are always attempting to go forward until they meet with some obstacle: and are so inscnsible, that, if a decp ditch or pit lie in their way, they do not endeavour to avoid it, but generally fall into it. I never saw a case in which there was not that convulsive twitching of the chest, and tottering of the forc legs, bcfore described: yellowness of the cyes and mouth is also a constant symptom. I thought it necessary to be thus particular on this sibject, as it is really a very serious and destructive disensc, and, unless attended to in scason, almost always proves fatal. I shall subjoin a few formulo for the medicines to be griven in this discase. 
Stomachic Purgative.

No. 1.

Barbadoes aloes ......6 $6 \mathrm{dr}$. to $1 \mathrm{oz}$.

Calomel ........... 1 dr. to $2 \mathrm{dr}$.

Cascarilla ......... 2 dr.

Oil of peppermint ....20 drops.

Tincture of cardamoins .. $2 \mathrm{oz}$.

Watcr (as warm as it

$\left.\begin{array}{l}\text { can be convenicntly } \\ \text { given) } \ldots \ldots \ldots \ldots\end{array}\right\} 12 \mathrm{oz}$.

Mix for one dose.

The quantity of alocs must be regulated by the horse's sizc, strength, \&rc. I have sometimes added a dram of prepared ammonia to this draught, which, though it renders the calomel less active, scems to be a uscful addition. If no evacuation be obtained in about twenty hours, give another dose, with laalf the quantity of alocs, and about 6 oz. of castor oil; and, during the interval, let some moderate stimulant be given; as, -

\section{No. 2.}

Common salt $\ldots \ldots \ldots \ldots \ldots \ldots 1$ oz.

Water .............. 8 oz.

Compound spirit of ammonia 1 to $2 \mathrm{dr}$.

Mix. 
APPENDIX. - PURGATIVES, OR PHYSIC, 419

No. 3.

Tincture of cardamoms ...... 2 oz.

Mint water ............ $12 \mathrm{oz}$.

Mix.

Clysters also are to be given often, composed of Common salt ....... \& oz. Water .......... on 5 quarts. Linseed oil .......... st oz.

Mix.

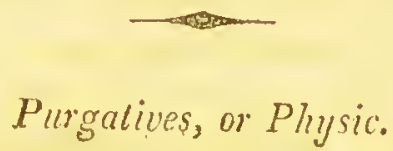

IT is a fortunate circumstance for horses, as well as for their owners, that immoderately strong physic is not so frequently given as it used to be. Among the numerous inconveniences arising from the strong purgatives recommended by writers on farriery, snch as twelve or fourteen drams of aloes, either alone or with calomel, * there is one we have not hitherto noticed, which we shall now describe.

* A feir weeks ago, I was requested to attend a sick borse: it appcared, that the groom laad given him $10 z$ of Cape aloes, which operated with great violence, and had coutinued to act two or three days after. On my arrival, it was too late to save the animal: he soon after died from inflammation of the bow cls. The Cape aloes are ecrtainly the weakest kind. I have secn several horscs destroy'ed by smaller doses than this, sueh as ten, twelve, or fourtecn drams; and as often, and perhaps more, from succotrine than barbadoes aloes. (Sce note to page 3il).) 
'Though they do not destroy a horse, they often wcaken him so much, that it requires sometimes several weeks to restore the strength; but scveral cases have occurred where the bowels had been rendered so irritable from the violent effect of physic, that they became subject to troublesome and even dangcrous diseases. Sometimes obstinate costiveness is occasioned by it; at othcrs, a constant tendency to diarrhoea and colic. When a horse, whose bowels have been thus injured, is attacked with colic or gripes, the strong remedies commonly employed, such as gin, pepper, \&c., often prove fatal by exciting inflammation. The following draught will be found most useful, giving frequently small quantitics of gruel, linseed tea, or any other mucilaginous fluid, and injecting a clystcr of the same kind. The only method of curing the irritability or tenderness of the bowels radiealJy, is to avoid every thing of an irritating quality, and very cold water, until they have recovered their original strength.

\section{The Drenght.}

Oil of peppermint ....... 20 drops.

Tincture of opium $\ldots \ldots \ldots \frac{1}{2}$ oz.

Gum Arabic (dissolved in a pint of warm water) $\ldots\} 2 \mathrm{oz}$.

Mix for one dose.

The costiveness produced by the above practice occasions symptoms, which often deceire the in- 
experieneed practitioner. The horse appears to be in pain; often makes fruitless efforts to dung; sometimes there is a suppression of urine, particularly when the proper remedies have not been seasonably applied; some degree of fever takes plaee; and at length colie pains. All these symptoms may be speedily removed, by drawing out the exerement with the hand; afterward throwing up a clyster, and giving the oily laxative. But I have seen hot drenehes given in this complaint; and when these were found to inerease the pain, instead of affording relief, the animal was profusely bled. When the suppression of urine was observed, diuretics were given. In some eases, the disease is eured by an effort of nature: sometimes it continues so long as to cause inflammation of the bowels.

Previous to physieking a horse, it is of importance to bring the bowels into a proper state, by giving the horse bran mashes for two or three days. This will soften the dung in a moderate degree, and render the operation of the physic more safe and certain. It is of importance also to give the physie at a time when the stomaeh has but little food in it, or only a very small thin mash, but not when it is quite empty. As to the kind of aloes, I am still of opinion, that the Barbacloes is the best. When physie operates too powerfully; it should be eheeked, by giving gruel made of arrow-root or fine wheat flour. A late writer, who seems to consider Barbadoes aloes as a "conrse 
and injudicious material," for physic, has, very injudiciously, in my opinion, prescribed a pint of port wine, in which an ounce of cinnamon has been boiled, and a table-spoonful of tincture of opium, in such cases. This would, I think, be likely to cause inflammation of the bowels. I have scarcely cver known arrow-root fail; but when it does not prove sufficient, about $\frac{1}{2} \mathrm{oz}$. of tincture of opium should be given with it. It is rather singular that $\mathrm{Mr}$. Peall should have advised this treatment after saying, "Let it not be supposed that I mean to insinuate, much less to admit, that horses which die under the operation of physic sink in consequence of the mere exhaustion resulting from the action of the medicine, inasmuch as the cause of death, in all such cases, is uniformly owing to inflammation taking place in some part of the alimentary canal."

Oily Laxative.

Barbadoes aloes ....... 2 to $3 \mathrm{dr}$. Preparcd kali ............. $1 \mathrm{dr}$. Mint water ............ 3 oz. Castor oil ............... 8 oz.

Mix for one dose.

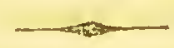

Mollen Grease.

THus is a disease of the intestines, and generally 
dependant on some constitutional affection. Horses that have been well fed, and had but little exercise, are more liable to this complaint. Though such horses appear sleek and fat, they are not fit for violent or long-continued exercise, mnless brought to it gradually; therefore, when suddenly put to work in this state, and particularly if employed in hunting or other violent exercises, a fever is often the consequence, which commonly depends upon general inflammation or increased action of the whole arterial system. In this disease, naturè sometimes makes an effort to remove it; that is, a violent purging takes place; the mucus, which is constantly formed upon the inner surface of the bowels in order to lubricate and protect them from the action of any acrimonious matter that may happen to be passing through, is now formed in greater quantity, and is often so abundant, as to appear something like fat mixed with the dung. When blood is drawn from a horse in this state, a large quantity of the inflammatory crust (the coagulalle lymph, or buff-coloured jelly, before described) appears on its surfacc. * (See Blecding.)

* According to Mr, John Lawrence, molten grease consists in a colliquation, or general melting of the fat of the body, great part of which is absorbed, and thrown upon the blood and "pon the intestines, when it is voided with the excrement. Mr. Blaine, in his "Treatise on Veterinary Medicinc," las ealled this explanation of the disease an absurdity 1 and though I fecl all due rospect for the efforts of Gibson, Brackeri, and Bartlet, as well as for their commentator and pancgyrist, Mr. Jo/n Lawrence, I ain compclled by experience, and tlic knowledge I lave obtaincel 
Mollen grease, therefore, is not to be considered as a distinct discase; but only as a symptom, which sometimes appears in general inflammation, or fever: it happens more frcquently however in the latter. When a horse labours under fever, or gencral inflammation, we most commonly find some of the internal organs more affected than others. When there is a difficulty of brcathing, the flanks moving with unusual quickness, and the nostrils expanded, it indicates an affection of the lungs; when molten grease appenrs, it shows, that the mucous membrane of the bowels is more particularly affectcd: sometimcs both these parts are affected at the same timc. The principal remedy in this diseasc is copious bleeding, according to agc, strength, and other circumstances of the casc. (Sec Bleeding and Fever.) It is often nccessary to repcat the operation; oily laxatives are to be given, and rowcls insertcd in the clest and bclly, if the lungs be the principal seat of the disease; and the sides may be blistered, or the mustard embrocation rubbed on the sidcs and belly. In molten grease, or whicn the bowels are affected, if therc be a copious purging, let no attempt bc made to suppress it by astringents or opium; but give frequently decoction of linseed, gum Arabic dissolved in water, or gruel, made of arrow-root or wheat flour.

of the animal economy, to acknowlcdge, that Mr. Lawrence's description is rally an absurdity, and aftords a convincing proof of his incompctency cither to teach or practise the Veterinary Art. 
When the dung is voided only in small quantity, but frequently, particularly if there be any knobs mixed with it, give a pint of castor oil, which may be repeated, if nccessary, about two day's after. In this case, also, it will be proper to rub the mustard embrocation on the belly. Should the disease continue after this, and particularly if there be considerable irritation about the anus, the horse frequently ejecting a small quantity of excrement, and appearing to suffer much pain, the opiatc clyster may be given. If this appear rather to increasc than remove the pain and irritation, the dose of castor oil must be repeated, and a clyster thrown up, composed only of water gruel and a little oil.

Mr. Blaine, in his "Treatise on Veterinary Medicine," describes this disease somewhat differently, and considers it to be the same as the human dysentery. I must confess, however, that, during an extensive practice of twenty years, I have never met with a single case, that resembled the dysentery described by medical authors. I have often observed, during the progress of symptomatic fever, internal inflammation, mucus mixed witl the dung, which had sometimes the appearance of part of onc of those long white worms so often found in the horse's bowels; at others it rescmbled a fatty membrane. I have obscrved the same thing in horses apparently liealt lyy, or after the operation of very strong physic. I have also seen many cases where there was tenesmus, or considerable irritation in the rectum, the horse frequently void- 
ing a small quantity of dung, and appearing in pain. IBut this was always eitler a symptom of some more important complaint, and easily removed, or the effect of physic, and very unlike dysentery. (See Inflammation of the Lungs and Bouels, and Symptomatic Fever.)

\section{Opiate Clyster.}

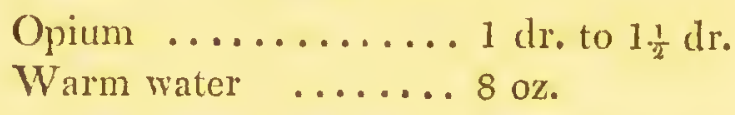

Mix.

To this add about a quart of starch water; that is, starcl boiled in water in the usual way, and of a proper consistence for a clyster.

\section{Grease.}

This disease has been described before in page 226.

In inveterate cases of grease, the hecls often become ulcerated, sometimes in a considerable degree. These ulcers are generally very painful, particularly when situate on the back part of the pastern; they are also more difficult to cure in this situation, from the frequent motion of the part. In the treatment of these ulcers, or cracks, as they are often termed, cleanliness is of great importance; and, when they appear inflamed and painful, apply a soft poultice, in which a little 
Goulard has been mixcd, for two or three days. The following ointmont (No. 1) may then be applied, spread on tow, and sccured with a light thin bandage. It often happens, that cracks, or ulccrs, appear in the lieels, without that gencral swelling of the lcg, and discharge of matter, which constitutc the disease named grease. It may then be soon cured, by applying the astringent ointment, and giving a few doses of the diuretic alterative (see Vol. II, or Materia Medica): but when it is accompanied by the greasc, laxatives or purgatircs are proper, according to the condition of the animal. If the ulcers in the heel bc deep, cxercise appears to prevent their hoaling; and I have found it the best plan, when sucl ulccrs are not accompanied with much swelling, to kecp the horse in the stable, until they are ncarly healed, drcssing the sore with the ointment (No. 1), and applying a bandagc, so as to kcep the part as stcady as possible. When this plan is adoptcd, it is necessary to kecp the horse on a cooling opening diet, and to rub the lcgs frequently and briskly with the hands: a few of the diuretic alterative powders should also be given. When proud flesh, as it is commonly termed, appears in the ulcers--that is, when the new flesh rises above the level of the skin-it must bc destroyed by caustics; such as blue vitriol powdercd, or dissolved in war'm watcr, or lunar caustic. When this is neglectcd, they sometimcs increasc to a large sizc, and bccome almost of a horny consistence, in whicl state thcy 
arc commonly named grapes. Should the ulcer continue foul, after applying the poultice, without that red appearance, which indicates healing, the hot solution of bluc vitriol is to be poured upon it, and the poultice repeated: this will cause a separation of the foul parts, or a sloughing, as it is termed; after which, the sore will look red and healthy, discharging white matter, and gradually filling up with ncw flesh, which, if it rise above the surface, is to be repressed with caustic.

In recent cases of grease, in which the hecls are inflamed and swollen, and discharging a whitish coloured matter, I have seen much good done by fomenting them for a considerable time with warm watcr, in which a small quantity of Goulard has been mixed, and applying immediately aftcr the Goulard poultice. In obstinatc cases of grease, wherc the matter discharged is vcry foetid, the fermenting poultice is useful; that is, a poultice of linseed meal, warm water, and yeast; this soon removes the offensive smell, and causes a more healthy or less acrid matter to be formed. Powdcred charcoal has been recommended for the same purpose.

In these inveterate cases, rowels in the thigh are necessary, and should always be employed before any astringent applications are used. This unpleasant remedy, however, is only necessary when the disense, has continued some time. In recent cases, the Goulard poultice and mild purgatives will soon reduce the inflammation considerably; 
and then the cure is easily accomplished by astringent lotions. To prevent a return of the complaint, cxercise and good grooming are indispensably nccessary: frequent hand-rubbing of the lcgs, and a diuretic powder now and then, are also useful. Horses with white hind legs, or such as are much disposed to swelling of the legs, should be bandaged for some time, particularly after hard work, keeping the bandage constantly moist with a solntion of alum in water. In those hard habitual swellings, which arc sometimes a conscquence of grcase, I have several times seen blistering and firing tricd, bnt ncver saw them do any good: the best palliative in such cases is the bandage applicd ans before directed.

In somc cases of grease, the inflammation seems to extend to the cellular membrane under the skin, causing more scvere pain and lameness, than when it is supcrficial. This inflammation gencrally terminates in an abscess of the heel, which bursts, and leaves a decp ill-looking ulccr. 'After this, the general swelling of the leg subsides, and the animal appears to be considerably relieved: the ulcer, however, is cxtremely irritable, and difficult to heal, particularly if the horse be excreised. By applying poultices and warm digestive ointment, and by keeping the horse at rest, the ulcer gradually heals. 


\section{Oinlment.}

No. 1.

Fresh hog's lard .......... 4 oz. White lead, finely powdered .... $1 \mathrm{oz}$. Mix.

\section{Aslringent Ointment.}

No. 2.

Hog's lard $\quad \ldots \ldots \ldots \ldots \ldots \ldots$. oz. Palm oil ............... 2 oz. Fine olive oil $\ldots \ldots \ldots \ldots \ldots .1 \mathrm{oz}$.

To be melted, by placing the pot which contains it in boiling water: when melted, stir in $1 \frac{1}{2}$ oz. of the water of acetated litharge, and continue stirring till nearly cold.

When ulcers of the heels do not appear disposed to heal, the above ointment should be changed for one more stimulating, or the sore should be washed with a solution of blue vitriol previous to its application.

Stimulating Ointment.

Ointment of yellow resin ......... 4 oz. Olive oil ................. $\frac{1}{8}$ oz. Red nitrated quicksilver, in fine powder $\frac{1}{2}$ oz. Mix. 


\section{Diseases of the Eye.}

Among the various diseases to which domestication and improper management have subjected the horse, those of the eye are more frequent, and generally more difficult of cure, than almost any other; and what makes the subject pecnliarly.interesting and important is, that inless the horse's eyes are perfect, he is liable to start, and stumble, and somctimes more dangerons to ride, than one that is totally blind. The most common disease of the eye, and that which leads to almost every other, is inflammation, which generally begins in the exterior membrane of the eye, or tunica conjunctiva. * Sometimes, however, the interior parts also are at first affected, and then the disease is particularly obstinate. On the first attack, the eye-lids are partially closed, and the eye watery, the tear's generally flowing over the cheek: but it often is so slight as to escape notice, or to be considered by the groom only as a trifling accident, arising from dust or hay-seeds having fallen into the eye; therefore, it often happens that no attention is paid to this serious disease at the only time perlaps when a radical cure can be effected. The inflammation then increases, and spreads to the interior parts; the eye becomes extremely irrita-

* In my Veterinary Dictionary, the reader may find a short anatounical description of the horse's eye. 
blc, and incapable of bearing even the light, so that it is kept constantly closcd. If the hor'se is lcft to the management of the groom, or an ignorant farricr, some stimulating mixture is commonly applicd, and the eye constantly cxposcd to the more stimulating vapours of foul litter, which are often so powerful as to give pain even to thc healthy eye: how injurious, then, must it be to one that is already in an inflamed and highly irritable state. It is by this mismanagcment, probably, that the diseasc is so pcculiarly obstinatc, and so often incurable. I am not speaking of that kind of inflammation which is produced by blows, bites, or other accidents, but of that which depends upon some constitutional affection, and is, in medical languagc, termed opthalmia membranarum.

There have been various opinions respecting the remole cause of this disease. As it most commonly happens about that period when horses have attained thcir full growth, that is, betwcen the fifth and sixtl year, in gencral, but carlier in some horses: it depends probably, upon plethora, or fulncss of habit, which is particularly apt to cxist at this period: and it may be obscrved, that this is the time when not only opthalmia but all other inflaminatory complaints most frequently occur. The occasional or cxciting causes of the discaseare the irritating vapours of the litter, checked per-spiration, higl fecling without proportionatc exercise, violcnt exertion particularly in drawing, with tight collars. It has been thought, that the 
present fashion of reining up carriage-horses with a gag rein is liable to impode, in some degree, the return of blood from the head, by producing a pressure of the jaw-bone against the lower branch of the jugular vein. Dark stables certainly tend to make the eyes irritable, and therefore contribute to the production of the discnse. Hol'ses kept at grass are rarely attacked with diseases of the eye, cxcept from the irritation of flies: these sometines cause a good deal of infammation; but it is ensily cured, by taking the horse in, and washing the cyes with the lotion (No. 1).

Mules and asses are searcely ever known to be affected with ophthalmia: it has therefore becn asked, why the complaint should be confined to the horse, and not take place at the adnlt period in these animals also? The cause appears very obvious: both mules and asses, in this country at lcast, are bred up and treatcel very differently from horses, and are no more liable to coughs, inflanmation of the lungs, and other infammatory complaints, so common among horses, than they are to opthalmia. Upon the whole, it appears that the cause of this clisease, as well as its peculiar frequeney among horses, may be filirly attributed to bad management; and it is no less probable, curing it radically, depends in some measure on its not being scascuably and properly attended to. It is of importance, therefore, as soon as a horse's
eye is affected with inflummation, to remove him 
fiom a stable where lic is occasionally, if not constantly, exposed to the vapours of the litter, and place him in one that is cool and properly ventilated, and not occupied by other horses. Herc let him be kept clcan, and as free as possible fiom those irritating vapours. As the complaint is much infuenced by the state of thic skin, let him be regularly cxerciscl, in a situation where the eyc will not be exposed to a cold wind, dust, or bright sun-shine; and as soon as he gets into the stable, let him be well brushed and wisped, his legs well hand-rubbed, but never washed, and let him have moderately wrm clothing. Blecl according to his condition and the violence of the disorder. If the inflammation is considcrable, and the horse in good condition, four or five quarts may be taken off; but if he is thin, has a staring coat, and is hide bound, about two or threc quarts will be sufficient. Give a mild dose of physic. If the inflammation is violent, and the eyc rery irritable, lct it be often fomcnted with warm water, or a decoction of white poppy-heads. A seton passed immediately under the cyc is useful; blistering the cheek would be equally, if not more, beneficial, did it ofien tempt a horse to rub the part against the stall or manger, by which some of the blister may get into the eye, and increase the inflammation. I lave seen much advantoge derived from searifying the inner surface of the eyclids with a lancet, when there is a great deal of inflammation; but unless this operation is performed 
neatly, it is apt to do more harm than good. The vein which goes from the inner corner of the eye towards the nose may always be opened, and when it bleeds freely, much good may be derived fiom it. When, by these means, the inflammation begins to abate, the cye appearing more open and less irritable, let it be frequently washed with one of the following lotions : but it will be adviseable, at first, to use it milk-warm, and diluted with an cqual quantity of water. When the irritability is inconsiderable, the lotion may be used alone, and cold. It may be neeessary to repent the gencral, is well as the local, bleeding, two or three times. The dict shonld consist of brun mashes, grecn food, and, after the operation of the physic, one of the following alteratives may be given daily. Too much attention cannot be paid to the state of the skin: the horse should be well brished three or four times a-day, and crefully gruarded against cold wind or rain, or a partial eurrent of air in the stable. When the eye appears perfectly frec fiom inflammation, the alterative medicine and lotion may be discontinued; but the same attention to diet, grooming, exereise, \&re. must be persisted in for some time, or until the cye is restored to its original strengtls: for, though the cye may appear perfectly liealthy, it will have become more susceptible of inflammation than it was originally; therefore, it is a matter of great importanee io avoid carcfully the exciting causes of the discase, and use crery means to licep the hares in a state 
of health, until this norbid susceptibility is completely worn out. When ophthalmia is neglected, at its firs: occurrence, or treated improperly, the cornca or glass of the eye becomes of a yellowish and sonetimes of a daik blood colonr: in some cases, a yellowish matter is seen within the eye, at the lower part, or attached to the margin of the iris, and partially or wholly obstructing the pupil. Sometimes the surface of the cornea appears as if covered with a whitish film, but this is most commonly an effect of external injury, such as the stroke of a whip, or a bite; and goes off gradually by bathing the eye frequently, at first with warm water, or the decoction of poppy-heads, and afterwards with the cooling lotion.

Though the cornea, or surface of the eye, may have recovered its transparency, and the eye appear, to an inexperienced person, free from disease, yet, upon examining carefully the interior parts, some important disease may often be cliscovered: and, to a person about to purchase a horse, when he cannot have the advice of a veterinary surgeon, a particular examination of the eye is certainly adviseable. Having brought the horse's head towards the stable-door, and placed him so that the light shall fall equally upon both eyes: let him observe whether the pupils, or, as they are commonly termed, the apples of the cye, are of the same size and form. If they are different, it is a certain indication of disease. A further trial may be made by placing the hauds on the 
hor'se's eyes, as he stands at the stable-door, so as to exclude the light, and keep them there about a minute; if, upon removing his hands, the pupils are observed to contract unequally, it serves to confirm the former observation. If cither pupil appears very small and immoveable, that is, if it continues of the same size in different lights, or if its edges are irregular, it is a sign of adhesions having taken place betwecn the iris and the capsule of the crystalline lens. It may be asked, which cyc, when the pupils are different, is to be considered as the disensed one? I think that with the smallest pupil; because it denotes a morbid irritability of the nervous structure of the cye.

There is another disease, but not common, that is quite of an opposite nature, consisting in a diminution or total deprivation of that irritability with which the nervous structure of the eyc is naturally endued. This cliscase, commonly termed glass-eyes, technically, ammurosis, or gulla serena, is distinguished by the largeness of the pupil, and by its continuing of the same size, whether in the shade or cxposed to the direct rays of the sun. The pupil of the eyc, however, is sometimes unusually large, and approaches more to the circular, than the healthy oblong form, when therc is not so material a defect in the ncrvous structure, and this depends upon a cloudiness or want of perfect transparency in the crystalline lens or its capsule. (See Veterinary Dictionary, article Eye.) Such horses are generally starters; their sight mny often 
be improved by applying diluted tincture of opium or brandy and water; but the good effect is only temporary, nor can any permanent benefit be by any menns obtained: I believe, however, the defect is always increased by violent exertion, or any thing which tends to reduce the animal's health. It is difficult to convey a correct idea of those diseases: I, thercfore, attempted to illustrate the description in the fouth volume by a plate, which I have now placed in this volume. There is another disease, caluract, which, in the horse, is certainly irremediable. This consists in a total or complete opacity of the crystalline lens, or humour.

Cataract in the human eye is removed either wholly or partially by an operation, and a useful degree of vision is often restored; but the same operation in the horse would be useless, because catarnet is often complicated with general derangement of structure in the interior parts of the eye: and were this not the case, the want of a crystalline lens would render vision so confused and imperiect, that it would be of no use to the animal, for the deficiency could not be stipplied with glasses, as it is in the human eye. When the first attack of ophthalmia is neglected, or improperly treated, and the intcrior parts of the eye have becone diseased, the inflammation will frequently, after a time, appear to subside, and the horse will sec tolerably well, and continue so perhaps several wecks; but the disorder generally returns, often sudklenly, and the eye will have become, in the 
course of a night, probably, as bad as ever. In this fluctuating state, the cyc sometimes continues many montlis; and, though the disease docs not reeur at regular periods, it is commonly, and absurdly enough, supposed to be influcneed by the changes of the moon, and has therefore been called moonblinduess. In eoneluding this subject, I wish to observe, that notwithstanding the little ehance there is of a perfect recovery from ophthalmia, cspecially when it is not seasonably and diligently attended to, a partial, but permanent, restoration of sight sometines takes place. When a hor'se affected with ophtralmic inflamnation las a complete cataraet formed in one eyc, the other is generally, almost always, restored to its natural healthy state, and no longer disposed to oph thalmic inflammation. Sometimes a partial eataraet takes plaee in one or both eyes; that is, one or more white specks are perceptible in the pupil when the horse's head is plaeed under a shed, or near the stable-door. If the opaque spots are not in the ecntre of the pupil, the rays of light will still pass through, and vision will not be materially impeded; and as in this ease, like the foregoing, the oph thalmic inflammation, as well as the disposition to it, usually ecases, and the speeks searcely ever become larger, it may be eonsidered as a favourable termination of the disorder : but a permanent eessation of the disease is not to be depended on in this ease so mueh as in that where a complete entaract forms in one eyc. Another termination of ophthalmia is in a small tixed 
pupil, that is, the pupil is always of the same size and form in whatever light the eye may be placel. This commonly depends upon an adhesion of the iris to the capsule of the crystalline lens, and being generally accompanicd with a morbid state of the nervous structure of the eye, is a defect of considerable importance. Whenever the pupil is in this state, a small quantity of the extract of belladonna may be intreduced between the eye-licis. If the pupil does not appear larerer an hour or two after its application, it is a proof that adhesions have taken place. This extract has the peculiar property of enlarging the pupil; and I think it has sometimes been applied advantageously in incipicnt affections of the iris: it deserves, I think, a further trial. It may be thought superfiuons, pcrlaps, to say any thing of the vulgar and absurd prejudice of the discase being caused by the wolf's tooth, as a very small supcrnumerary tooth, or denticulus, close to the first grinder, is commonly named. But I still meet with persons foolish cnough to belicve in such norsense, upon the high authority gonerally of a groom or blacksmith. I can assulc such persons that this little tooth may often be secn in horses whose eyes have always been perfectly sound; and that I have many times seen it removed in hor'ses with discascil eyes without doing any good. I am at a loss to conceive in what this opinion originated, unless the name was at first applied to one of the upper molar tecth that had grown so as to lacerate the inside of the 
cheek, a circumstance that sometimes happens in old horses. This might more reasonably be supposed to affect the eye, but 1 have ncver known it to do so.

$$
\text { Eye-Waier. }
$$

No. 1.

Goulard's extract ........... $1 \mathrm{dr}$. Watcr ................. 12 oz.

'Tincture of opium ......... 1 oz.

Mix, and filter through blotting-paper.

No. 2.

Superacetate of lead (sugar of lead) $3 \mathrm{dr}$. Snlphatc of zinc (white vitriol) . s $3 \mathrm{dr}$. Watcr ............... $1 \frac{1}{2}$ pint.

Mix, and filter through blotting-paper.

No. 3.

Superacetate of lead ......... $2 \mathrm{dr}$. Distilled vinegar .......... $1 \mathrm{oz}$. Watcr ............... $1 \frac{1}{2}$ pint.

Mix, and filter.

$$
\text { No \&. }
$$

Sulphate of copper ......... $2 \mathrm{~d}$. Water .................. $1 \frac{1}{\frac{1}{4}}$ pint.

Mix. 
The irritability of an inflamed eye varies considerably; when highly inflamed, even cold water will sometimes prove too stimulating, and warm water only can be applied with advantage. The above recipes are about the medium strength; but if they appear to irritate the eye, they should be diluted, and sometimes it may be proper to use them rather warm. 'The best method of applying eye-water is by a soft clean spunge, and this should be used several times a-day. Eye-waters should be transparent, especially when the eye is in an irritable state. In films, or opacity of the cornea, in conseruence of blows, the above cooling eye-waters should be applied until the inflammation is perfectly subclued, and then something stronger is necessary. A little tincture of opium, or brandy, diluted with an equal quantity of water, may be squeczed into the corner of the eye with a small bit of spunge; and, if that fail, a small pinch of salt, fincly powdered, may be placed between the cye-lids, or a little finely powdered glass mixed with honey. 
New operation for Chronic, and otherwise incurable lameness, or Founder, commonly termed Nerving.

THIS operation consists in the excision of about an inch or more of the nerves which supply the foot; whereby the sensibility of those parts which are the seat of founder, or chronic lameness, seems to be completely destroyed, whilst its vitality remains unimpaired. 'The merit of this discovery is due to Mr. Sewell, sub-professor of the Veterinary College, and was, some time since, published in the Philosophical Transactions. The good effect of the operation is immediately perceived; for as soon as the hobbles are taken off, and the horse gets upon his legs again, he will be found perfectly free from lameness, however lame or crippled he may have been previous to the operation. The nerves which supply the foot pass down the leg, near the flexor tendon, or back sinew, one on the inside, and another on the outside. About three or four inches below the knee, the nerve on the inside of the leg gives off a branch, which passes over the back sinews, in an oblique direction downwards, and joins the outside nerve abotit three or four inches above the fetlock joint. On the sides of the fetlock joint, rather towards the back part, and about two inches above the most prominent part of the joirt, both the inside and outside nerve are very superficial, and are readily seen on making incisions througl the skin, and dissecting off' a little cellular membrane, accom- 
panied by the principal vein and artery: the latter, at this part, is rather deeper than the vein, and need not be exposed in the operation; the rein also may be easily aroided. Immediately below this part the nerve divides, but the branches do not divcrge much; they separate just cnough to allow the artery, which here becomes more superficial, to pass between them: in this way, they proceed down the pastern, to be clistributed to the foot.

From this view of the nerves, it will appear that the best parts for opening the skin, in order to gret at the nerve, is on each side of the fetlock joint, about two inches above it, raher towards the back part. The nerve may be readily found also on each side of the pastern, the part which Mr. Sewell prefers for the operation: but here there will be two branches to operate on, on each side; and from the artery lying between these branches, and almost close to them, there is more danger of its being wounded than in the former situation, where the artery is not so superficial as the nerve. There is no difficulty in gretting at the nerve above the part I liave pointed out; but, from the view I have given of the distribution or course of the nerves, it must be obvious, that if the inside nerve be divided below that part where the branch is given off, and the outside nerve, above the part where the branch joins it, there will still be a rervous cormmunication with the foot by means of this branch. The following figure will serye to exemplify this: 
$a, a$, the inside nerve; $b, b$, the outside nerve; $d$, the knee joint; $c$, the fetlock joint; $e, e, e$, the branch given off by the inside nerve; $f$, the part where it joins the outside nerve. If a portion of the nerve, therefore, be cut out at $g$ and $h$, the foot will still be supplied by means of the branch $e, e, e$. From the knec to the line $i$, the nerve is covered by

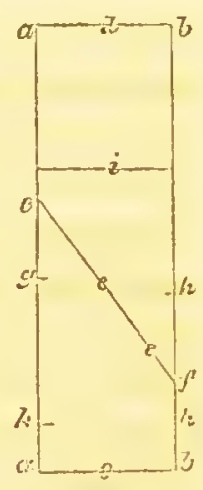
a sheath of tendon, which ought not to be wounded, leaving scarcely room for the opcration on the inside nerve, above the part where the branch is given off; $k, k$, thereforc, appears the most eligible part for the operation. Though this seems very plain upon viewing a disscetion of the lcg, in which the course of the nerves is cxhibited, yet, having been informed that a veterinarian oft sonse eminence advised the operation to be performed three or four inches above the fetlock joint, I determined to put it to the test of experimont. A foundered horse, very lame in botl fect, was operated on at the parts $g, h$, in one leg, and $k, k$, in the other. $\Lambda$ s soon as lie got up, after the operation, he appeared quite free from lamencss. About an inch of the nerve was chit out from the nerves of both legs. When the wounds were healed, the horse was rode, and found to be still lame in that foot, the nerves of which had been divided at $g, h$. The horse was again operated 
on at the part $k$, on the outside only, and, immediately after, was perfectly free from lameness. In this case, the sensibility of the foot was so far diminished by the first operation, the small branch $e, e$, being the only medium of communication between the foot and the brain, that the lameness was for a time removed; but this small branch gradually increased in power, and at length became capable of restoring the sensibility of the foot.

Should it be found, at some future time, that the effect of the operation is not permanent, it will probably depend upon some minute and undiscorered branches of nerve having become capable of transmitting sensation from the foot to the brain. It is to be regretted, that those practitioners who are capable of giving satisfactory information on the subject should withhold it from the public: for what reason they do so is best known to themselves. No one can be competent to perform the operation, unless he has some knowledge of anatomy, and has learned from actual disseetion the structure of the leg. This must be sufficiently obvious to the proprietor's of horses, to prevent them from allowing persons to attempt the operation who are ignorant of so essential a point. The silence of practitioners, with respect to this operation, has given rise to many disadvantageous reports of its effects. I think it was stated in a provincial paper, and copied into many others, that a horse which had undergone the operation lost 
his hoofs in consequence. That a horse may lose his hoofs after the operation is possible, and perhaps as probable as that he may lose his life; but that the hoofs were lost in consequence of the operation I feel no hesitation in denying, that is, if the operation was skilfully performed. * In onc

* If a nerved horse happen to bc pricked in shoeing, or otherwise injured in the foot, it will not, of conrse, be discovered by lameness, as in other horses; such cases, therefore, may possibly be neglected by the proprictor, until matler forms and breaks out at the coronet. Horses with corns or thin soles may also, by careless shoeing, have inflammation produced in the affected heel or sole, which, not causing lameness, as in othar horses, may pruceed to suppuration, and the matter may break ont at the coronct before the inischief is discovered. In this way, it is possible that the matter may be allowed to penetrate between the horn and sensitive foot, so as nearly to detach the former: but such extreme negligence as this can scarcely ever happen, and the possibility of its nccurrence is pointed out, to slivw the necessity of paying the same attention to the fect of nerved horges as of others. This circumstance, howcrer, does not render horses, witl corns or thin soles, unfit subjects for the operation; on the contrary, by destroying the sensibility of the diseased parts, they liccomc less liable to injury. Mr. Sewell of Bath had a horse lame, from corns, which, aftcr the operation, gradually disappeared, and the heels becanic considerably wider. Horses that have been lame a considerable time from founder, acquire a contracted step, and the muscles of the limb and shoulder ippear to sufter a diminution of power, and of their natural extent of action: such horses, therefore, when nerved, should be allowed a run at grass, and bronglit into work gradinally; for if urged to cousiderable excrtion as soon as the wound is healed, they may be thrown down, or some mitcrial injury may result from it. I have secu onc case in which the tendon below the fetlock joint had heen much injured in this way. Such horses should wear shoes rather thick, or a little turned up 
of the horses I operated on, this consequence was apprehended by the proprictor; but in a letter I have lately received from him, he says, "I am glad to find that the horse's hoof's grow as freely as before: I have found it neccssary to remove the shoes, and pare away a good deal of horn." Another, and a more plausible, objection is, that a horse must go very awkwardly and unsafely after the opcration, from having no feeling in his fect. 'To this objection I camot reply with so much confidence as to the former, not having had, as yet, sufficient experience; but, from the little I have secn, it appears cqually unfounded. About a month since, I operated on a horse that was lame in one foot only. I have seen him twice since, and had him trotted up and down hill, and on level ground, and could not perceive anything unusual in the motion of the limb: now, as only one leg was operated on in this case, had there been any. thing unusual in the horse's going, it could not, I think, have escaped notice. Upon the whole, the operation may be recommended, I think, with great safety and confidence, for those old and obstinate lamenesses of the feet which hare resisted the usual remedies. I might, perhaps, add, without deviating from truth, that it is equally bencficial in old and obstinate cases of (as they are commonly considered) chest-founder, or shoulder lame-

at the lieels, fihen first jut to pork, unless brought to th rery gradually. 
ness, which arc almost always seated in the foot. (Sce the article Founder?) 'The opcration is capable, I think, of affording almost incalculable relief to those unfortunate animals, who, though foundered, and crippled, and nearly incapable of workin.r, are nevertheless often urged, by the cruel application of whip and spur, into the most violent excrtion. Our stage.coaches and post-chaises afford too many melancholy examples of this kind.*

* Mr. Bracy Clark, in his "Disseration on the Ilor'se's Font," has, very feelingly, described the sufferings of these invaluable, but persecuted, animals. It will he seen under the head Diseases of the Feet, and Shocing, that thesc lamenesses are considered by Mr. Clark as unavoidable consequences of shoeing; and, though I have found it necessary to withold my assent to this position, I cannot but appland the indefatigable diligence, as well as the skill and ingenuity, with which lie has insestignted the subject. "The first effect," lie observes, "of tenderness, or of pain, that is not very acute, will be, that the animal will not permit the limb to take the full extent of its motion, and restrining the action of the shoulder, will occasion a contracted stop. This being the first external indication of the pain, it is often, by superficial observers, referred to the shoulder itself. Tho fout, for the same reason, will not be raised so hight ahove the ground, in order that the impulse on is desccut maly bccome tess, thus inducing tripping. Our roads cvery where exhibit what may be naturally looked for as the eorisequences of the inplesfections of the inade of going of our lorsecs. beople on borscback are secn quarrelling with their loorses, and violently abusing them fur their negligence and want of rare, as they apurreliend it to be, in their gnilng; gaguing their mouths with the bit, or using the whip or the spur an kecp them altive, and prevent their falling; sunetimes cutting the on one sloulder, and sometimes on the ather: for it is a matter that has not yet becu decided, whether, in these cases, it is bet. 
There is one advantage peculiar to this opera: tion, which is, that in lameness of two or three years standing, or even longer, it is just as effectual as in more recent cases, wherens the severe operation termed fring is frequently performed at a period when it is too litte to do any good, and too often in cases that are incurable. Though the nerve operation * is at present, I believe, recommended in lameness of long standing after blistering, firing, \&c. have proved ineffectual, and the animal has become absolutely useless, yet, if further experience should prove, that the relief it affords is permanent, and that it does not render a horse unsafe, or dangerous to ride or drive, I do not see why it should not be performed at a much earlier period of the lameness : or, should its bene-

ter to punish the offending limb or that which is opposite. As horses, when brought into a crippled condition, are no longer of much value, sn they ustally fall, soon after, intn the hands of unprincipled men, whn makc them scrviccable by sevcrity of treatment: and wish such insolence are their measures carried on, that reasonable men senrely dare to interfere, as the laws do nnt protect them : thus are they unate in endure the most intolerable hardships and abuse, as if their inability were of their own makiog, and they merited to be ill-treated. In this wretclicd state are they nften secn, severely punished, and alused, when they have done their utmost labour, because they cannit do more; and the laws which protect the mnst trifling rights of men in respect to personal safety, have prnvided no protection to these innncent, and nften beneficial, slaycs, from ill usage, howevel gross alld unmerited."

* The term nerving is aften applied to this operation, but certainly is not apprnpriatc. 
fieial effect be limited to one or two years, still it may be eonsidered an useful diseovery. Every experienced practitioner will admit, I think, that, after all that has been attempted for the eure of lameness, depending on eontraction of the hoof or founder, nothing essential has been aceomplished, though it has been a prominent objeet of attention ever sinee the establishment of the Veterinary College. It is true, that much relief is often afforded by soaking the hoof, paring it properly, good shoeing, blistering, a run at grass, \&e. But when the lameness has been established a short time, how rarely does it admit of a radical cure. One of the horses that I performed the nerve operation on, had been lame three years, and during that time, had been blistered several times, and fired both in the legs and shoulders, without deriving the least benefit from the treatnent; but, by the nerve operation, he was instantly relieved. I have just been informed, by a veterinary surgeon, who has operated on more than twenty horses, that it has almost uniformly afforded immediate relief; that several have been in constant work more than a year, other's, six, eight, and nine, months, and that the opinion of the horses' aetion being injured by it, and their being rendered unsafe to ride, is totally void of foundation. Great care, however, is necessary in shoeing such horses; for should the smith happen to prick or otherwise injure the foot, so as to excite inflammation, as the aceident would not cause lameness, it may remain undisco- 
vered until matter burst out at the coronet. This, however, cannot be considered a serious objection to the operation. It is probable, that the relief afforded by the operation will, in some instances, be partinl or incomplete; for, thougl the feet may be the parts originally affected, the nuscles of the shoulder may, in time, partake of the affection, that is, if a horse is for a consideralle time prevented from stepping out boldly, by pain in his feet, the muscles of the shoulder will be incapable of a more extensive action, when the pain in the feet is put a stop to by the nerve operation: whether they will afterwards gradually acquire their original power by running at grass remains perhaps to be tried. Post and coach horses, though generally first ruined in the feet, are commonly forced to a continuance of painful labour, until other parts are more or less injured ; in such cases, the benefit resulting from the operation will of comrse be incomplete, yet, perhaps, it may be so far beneficial, even in such cases, to render the horse useful in some degree, and cinable lim to work witlıut pain.**

* Since this article was written, several months latve elapsed, and I lawe, therefore, an opportunity of stating, that my experience during that time, as well as the information I have obtained from other practitioners, tead to colifirm the favourable oplinion I have given of the operation. It is to be regretted, however, that it is sometimes porformed at t: 0 late a period, or, when other parts besides the feet have sustitined material injury; the benefit, therefore, resulting from it bas not been so complete as it would have been had proper subjects been 


\section{Glanders.}

I oBsERved in the preface, that a work had latcly appenred in France on glanders, by M. Dupuy, one of the professors of the Vetcrinary School at

opcrated upon. The public appear to be still prejudiced against the operation; whether this prejudlicc he well founded or not, cannot perhaps at present be satisfactorily detcrnined; it is my duty, however, to state, that I ensider it a valuable discovery, but would alvise its heing performed earier than it commonly is at present, and before the other parts of the limb or the grncral constitution of the animal have sustained any matcrial in. jury. I think it neecsary also that the horse should be allowed a fun at grass afterwards. I bave been infurmed that Mr. Sewell, assistant profesor of the Veterinary College, has the same falvourable opinion of the operation he lad originally. Mr. Sewell of Bath also plices great confidence in it. Mr. Barrett of Taunton says, the inore experience be his with regard to the operation, he more is he convinced of its eflicacy; and he is satisfied that the failure of the operation must depend on improper subjects baving heen ehosen for it. On the other hand, I lave been infurmed that some practitioners in Ijelaud have abandomed the operation in eonsequence of the failnres they have cxperienced. I an inclined to believe that the benefit of the operation extends fatlier than it is commonly supposed to do, and that it often removes that morbid heat of tle foot, upon which contraction of the horny matter depends; that it improves the growth and quality of the horn or looof of such fect, rendering it less brittle, and of comrse less liable to loss of shoes, prieks, and sand cracks. On the same principle, it may improve fat thin soles, and relieve horses that ate latne from ossified cartilages or ring bones. It may perlaps be worth while to try its efrect in canker and in lockel jaw, when caused by woutids of the foot.

It is dilicult to determinc with precision in what ingrec or kind of laneness this opcration is advisable. It has liatherto been cunployed, I believe, only in very bad cases of what are 
Alfort, near Paris, in which the disease is considered as a tubcrcular (tubercleuse) affection, and not of a contagrious naturc. He does not profess to have discovered a remedy for glandcrs, but thinks, that by breeding fiom stallions and mares that are hicalthy, and of strong constitutions, and rearing colts in pastures that are ratlicr elcvated, where they can have sufficicnt nourishment, and be occasionally shcltered from the weather, the discase may be in great measure prevented. "Cattle," he says, "as wcll as horses, are very liable to tubercular nfections, from hereditary infuence, or from bcing bred in low, marshy, cold situations, or from want of sulficient nourishment." Thic strangles, the bastard strangles, \&c. of horses, and most of the diseases of the other domestic animals, are, according to M. Dupuy, of the samc kind.

termed for $n$ ter, or chronic lameness, from contraction of the hoof, and after the usual remedics had been tried, to no purpose; or after the hurse had been. worked in a lame statc for a considerabletine, and lad become incapable of working any longer. 1 am of opinion that it should be peiformed at in carlier period ; and, as it is much less painful than the opcration of firing and blistering so generally and fruitlessly employed in those lamenesses, I think it may, with great propriety, he substituted for it. Mr. Sewell's reason, 1 apprehend, for oplerating in the pastern is, that the fetock joint may not be aflected or rendered instusible. Mr. Scwell of Bath infurms me that he latcly examincd a liorse that had been nerved above fiftecn montis, and was perfectly sonnd, for the purpose of detcrmining this point. In one les there was no sensibility below the npper head of the liarge pastern bone, but in the other, sensibility was very evident below the artienlation of the two pasterns. 
He seems rather to consider liereditary influcnce as the predisposing or remote cause; and thinks that "the tubercles are developed by cold, moisture, watery, unwholcsome food, damp, ill-ventiIated stables, without light, and exposed to the fumes of dung-heaps, or common sewers, musty oats and hay, \&c. \&c." By hereditary influence, it appears to me that M. Dupuy means nothing more than that colts produced by mares, or got by stallions, of weak constitutions, and especially when both mare and stallion are of that kind, are very liable to the tubercular affection when exposed to the cxciting causes. He considers the glanders as one peculiar (speciale) form of the tubercular affection, or rather peculiar, as to the part it attacks, viz. the cavitics of the nose, \&ic. The tubercles that most conmonly occur are those of the miliary lind, so named from their resemblance to millet sced. At first, thicy are very small hardish substances, of a greyish colour, and of a cellular tcxture, in which are deposited phosphate and caibonate of line. 'The tubercle is generally enveloped in a cyst, and there remains stationary a considerable time willout producing any symptom by which its cxistence can be detected; and it is only by examining horses that have dicd from accidents, \&c. that they can be seen in this their first stage, which our author has named la morve cachée, or latent glanders. Sooncr or later, however, these tubercles degrencrate into ulcers, and as the mucous membrane which lines the cavities of the 
nose is most commonly their situation, the first symptom is a discharge from the nostril. When a considerable number of tubercles are near cach other, and degenerate about the same time, they produce an nilcerated surface within the nostrils, often of considerable extent. M. Dupuy concludes the first division of his book with the following recapitulation:-_" 1 . The shlanders is really a tuberioulous affection. 2. That it is analngous to the pulmonary consumption of the human subject. 3. That the miliary variety is most conmon. 4. That the mucous membrane of the left nostril is most commonly affected. 5. That tubercles, or ulcers, are rarely seen on the membrane lining the cavities temerl simuses. 6. That a glandered horse may contract a gangrenous discase. 7. That this gangrenous affection, being contagions, should be carefully distinguished from the true glanders. I hope," he says, "to put this last proposition beyond doubt, by the observation hereafter to be made on the acule glanders, which, in reality; is a gangrenous affection. Oul work would be incomplete were it confined to granders. We have observed tubercles in other tissues than that of the mucous membrane of the nasal cavitics; principa!ly in the substance of the lungs, in the lympratic glands, in the cellnlar membrane, in the skin, in the body of the testicles, and nuncous nem. brane of the intestines. The tubercles which are developed in the lymphatic glands, are composed of the same elements: and pursue the sane course 
as those situated in the nasal cavities. The glands most commonly attacked are the sublingual and those about the pharynx. The bronchial, the mesenteric, and the inguinal, are also liable to this affection, especially when glanders is complicated with farcy, grease, \&c." "If the glanders is complicated with a tuberculous affection of the lungs, the animal coughs frequently, is fatigued by moderate exercise, and readily sweats about the neck and flanks; he loses his strength and spirits, becomes relaxed and languid, and liable to catarrl, fluxions from the cyes, cutaneous eruptions, grease, farcy, \&c." "We cannot but consider farcy bucls as scrophulous tubercles: they are developed under the same influences, have a similar organization, experience the same changes of state and degeneration as the tubercles which form in the lungs. They often degenerate, it is true, into cancerous sores; but may not this be attributed to the canstics which are so generally employed as remedies?" "We shall concisede these considerations by observing that glauders, or phthisis of the mucous mem. brane of the nostrils and cavities connected with them, is sometimes transformed into a cancerous affection; that in others, it is complicated with a disease analogous to the typhus of horncd cattle, and the contagious disteniper of sheep (claveau confluenl,) which becomes very destructive when complicated with typhus." "We have observed three varieties of tubercles in the lung's, the miliary, the pisiform, and unciform. These morbid 
bodies are contained in a cyst, and cousist of a whitish substance, which is easily broken by the fingers, aud is similar to the earthy matter of bone. When the tubercles are large, they are small in number: but when of the miliary kind, they are generally very numerous.

"At first, the tubercles are firm, organized, and always situated in the course of the vessels, the calibres of which are much enlarged: at length, they degenerate and destroy the substanee of the lungs. We have observed tubercles in other tissues of the animal economy; those of the liver are small, white, hard, and of the miliary kind, and are often found in the substance of this organ. The substance of the kidneys is sometimes the seat of tubercles of the pisiform lind; the cyst is thick, hard, and nearly cartilaginous; the matter contained in it is similar to that of the pulmonary tubercle.

"The testicles are oftener the seat of tubercles than the liver or kidneys, and are more frequently thus affected than practitioners are aware of. The epididymis participates in the affection. Farcy, as has been before observed, in a scrophulous (i.e. tuberculous) affection, perhaps that disease so singrularly named eaux aux jambes (grease), is an effect of the same canse; and we may add, that serophula attacks also the bones, the periosteum, and the cartilages. The disease so ridiculously named te crapand (canker), which changes the fibrous structure of the horny frog of the foot, is probably 
an effect of the same eause. Canker affects horses that are bred in low marshy eountries, and are of a peculiar constitution. This cireumstance has led us to point out the rescmblance. Some idea may now be formed of the ravages of seroplunla (tuberculous affection) among horses : no part of the system is exempt from its influence; it appears, at first, as a trivial disorder, but always destroys, sooner or later, the most vigorous constitutions. Animals affeeted by this disease perish in great number about the age of six or seven: at this period they are rendered nearly unservieeable, and oeeasion only expense and trouble. Are not these eonsiderations sufficient to induee us to investigate every thing that relates to the serophulous affeetion, and to deeide, by positive experiments, if it is hereditary? For then the true preservative would be known, as we eould easily remove from the breeding establishments stallions and mares that were tainted with it. If we consider that the eause whieh determines this disorder oceasions a secretion and aeeumulation of osseons matter in the lings and other parts (tissus), may we not probably discover means of opposing this morbid secretion, or prevent it from being deposited on organs whose funetions are so important." "It appeared of great importance to prove, in reporting partienlar and authentie observations, that the glanders is latent at the time of its invading the interior of the affected parts; from which itresults, that the elements which compose the new body, which we 
call scrophulous tubercle, are brought together and united, under the influence of causes which appear to be hereditary, and under that of cold and moisture. These causes may not be distinctly known, but the existence of the effects, which we shall describe, are sufficiently evident.

"The tubercle, then, is formed without giving any signs by which its formation can be detected: the animal enjoys good health until the tubercle is disorganised, and degenerates into ulceration; then the constitution is more or less affected, and finally sinks under the disorder."

"It is a fact," says Gilber', " that has been thousands of times demonstrated, but, unfortunately, too little known, that animals, of whatever kind they may be, cannot he taken from one country into another without experiencing some change or derangement in their constitutions. This change, more or less sensible, in proportion to the difference of climate and other circumstances, generally continues until the animals become naturalized with the soil, the food, the climate, \&rc. But, however active the influence of such changes may be, there is no doubt that it might be considerably modified by proper management." "The otler" domestic animals, as well as the horse, experience modifications or clianges in their constitutions, when exposed to the same influences; and may not these clianges which happen in the economy of domestic animals be principally attributed to two causes, vizu the influence of exterior causes and 
crossing the brecd?" "The strangles," accord- * ing to Gilbert, "is in some mcasure similar to the suall-pox: it prevails most in temperate climates: horses are not liable to it a sccond time, unless they have it incomplctely. It generally takes place between the sccond and fifth ycar of thcir agc: when it hapnens after that period, it exhibits different symptoms, and is tcrmed the bastard strangles (fausse gourme). The symptoms do not differ from those of gglanders; and if there be no essential difference in this respect, why should they be considered as differcnt maladics. The existence of bastard strangles appcars to prove this. That discase appears, at first, with nearly all the symptoms of genuine strangles, but witl less intensity. How frequently do the inflammatory symptoms suddenly disappcar, and the glands under the jaw, thoughl appearing as if about to suppurate, become suddenly cold and indolent, sometimes subsiding almost entircly, while the running continues from the nosc, whatever means may be cmployed to suppress it? In a word, the horse is then affected with well marked glandcrs. This is generally the termination of the bastard strangles, and sometimes that of the genuine kind. If to these facts, which are well-known to all practitioners, we add, that theglanders is sometimes acutcor inflammatory, and has really all the characters of strangles, and that, in mules and asses, it is ncarly always of the acute kind: it appears to the author (Gilbert), that the perfect identity of the two discases cannot be 
disputed, though they have hitherto been regarded as cssentially different." "Wc sec, then," says M. Dupuy, "that the memoir of Gilbert gives a new vicw of the subject, and that no preceding author has given so luminous, a description of it. I agree with Gilbert on one point-I beliere that the strangles, the bastard-strangles, the farcy, the grease, the periodical defuxion from the eyes, commonly named moon-blindness (la fluxion periodique?) are very often cfiects of the same specific cause; that they ought all to be attributed to the tuberculons affection. I $\mathrm{nm}$ not satisfied merely with advancing a similar proposition, but have reported observations that have put it beyond doubt. It has been observed beforc, that the tubcrcular affection is more common than it is gencrally believed to be; that its origin is imperceptible, because it is developed without deranging the functions of the affected part: if it does occasion derangement, it is so slight as to escape notice, or be mistaken for an inflammatory disease; that the peculiar symptoms do not appear till the tubercles become numerous, and especially when they become disorganized. I think, then, that all thesc diseases which have been placed separatcly in the artificial and very imperfect classifications that have been formed of the disorders of domestic animals, should be brought together into a regular nosology, since they depend on a similar organic lesion. Whatever the cause may be which determines them, they depend on the production of a new substance, which I have 
named miliary lubercle, the nature of which is always the same. These tubercles are nourished in a peculiar manner; they attract the materials which they assimilate; they multiply, change their state, become disorganized, and degenerate into ulcers more or less deep and extensive. These tubercles, then, always occasion scrious disorder's, which generally tend to the destruction of the affected parts, and have always an unfavourable termination. When developed to a certain degrree, these parnsitical bodies cannot be resolved: the diseases arising from them are never followed by a favourable crisis, and an unfuvourable prognostic may safely be given of the animal that is attackect by them. After these considerations, we ought to feel much interest in determining with precision the conditions which occasion the developement of the tuberculous affection; whetler it is hereditary or acquircel; or if there are any signs by which we can distinguish the constitution, or particular conformation that is most liable to this destructive malady. It may be fairly presumed, that a disease which attacks so many parts of the body will exhibit a variety of symptoms, depending on the difference in the structure or texture (tissu) of the parts which it attacks; and that when several parts are affected at the same time, it will moic quickly prove fatal. The progress of glanders is very slow when it affects the mucous membranc lining the frontal, maxillary, and sphenoidal sinuses, the membrane in these parts being less vascular than 
that which covers the spongy bones (les cornets), and the cartilaginous partition of the nostrils: in the latter situation, therefore, the disease spreads more quickly: when the lungs are the seat of the tuberculous affection, its progress is gencrally slow; in this case, it takes the form of catarrh, peripneumony, or even pleurisy, chronic catarrh, \&c. All these diseascs are, in certain cases, effects of the tuberculous affection." "It is worthy of remark, that in the number of horses (whose cases are described by M. Dupuy) that had a running from one nostril only, there was but one that had the right nostril affected, whereas eight had a running from the left nostril."

The foregoing extracts from M. Dupuy's work will be sufficient to show what the author's opinions are, relative to glanders; a subject on which I have so fully treated in the third volume, that it would have been unnecessary to dwell on it here, had not M. Dupuy's book appeared. Since the last edition of the third volume was published, I have had opportunities of making further observations on glanders, and find what I have there advanced on the subject fully confirmed. The opinious for which I contend are these: 1. That glanders is a specific disease peculiar to the horse, the ass, and the mule, and that it is propagated by contagion. 2. That if glanders is generated in the system, independently of contagion, we liave no positive knowledge of the manner in which, or of the causes by which, it is, in such cases, produced. 3. As to 
the nuanner in which the diseuse is communicated, there appears to be sufficient cvidence to prove that it is not by the application of glanderous matter to the nostrils, nor by exhalations from the lungs, the skin or the excrement of the discased animal, but by the glanderous mattcr bcing taken into the mouth, and swallowed, or by its coming into contact with a part where the cuticle is removed or the skin wounded. 4. That glanders may be produced with certainty by inoculating a healthy horse or ass with glanderous mattcr; and that the matter of strangles, bastard strangles, catarrh, whether chronic, acute, or epidemic, greasc, \&c. will not produce a similar effect. The matter of virulent grease, howcrer, will, by inoculation, produce a peculiar local effect, which, after a sher't time, gets well, withont the aid of topical applicxtions or medicine. 5. That if a very young ass be inoculated with glanderous matter, though the horse from which the matter is taken have the disorder in the slightest or mildest degree, the acute glanders will generally be produced, and the young ass will be destroyed by it in a short time. If a full-grown strong liealthy ass be inoculated with matter from the same liorse, the effect will be less violent, and still less, if a horse be inoculated: in this last ease, the effect is variable; in some instances, an extcnsive ulceration has taken place about the part inoculatel, and a running from the nostril (generally one only) has come on in a slort time; in others, the local effect is not con- 
siderable, and it is sometimes before the constitutional symptoms appear, which are a discharge from one or both nostrils, and a swelling under the jaw. In one horse it was about two months before the constitutional symptoms were prodnced. 6. That the only certain diagnostic or characteristic symptom of glanders is the contagious quality of the matter which flows from the rostrils; that diseases often occur which resemble it so perfectly in every other respect that the most experienced practitioners are unable to distinguish them.

$\Delta$ knowledge of these facts led me to propose the inoculation of a sound animal with the suspected matter, as a criterion by which the glande:s may be distinguished with certainty from other diseases. Since the publication of the third roJume, in which this test was described, other experiments have been made, which tend to establish its ntility. In one case only, the inoculation did not succeed until the animal had been inoculated four times, which, at first, led to a conjecture that the matter was not, at first, of a glanderous nature, but gradually degenerated, and at the time of the fourth inoculation, had become eapable of communieating the disense; but, on reviewing all the circumstances of this experiment, it appears more probable, that the failure of the three first inoeulations arose from negligence. The fourth time it was done with grent care, and the animal died of glanders about three weeks afterwards. This case is notieed to show the necessity of conducting 
the inoculation with care and attention. A young ass, even a sucking foal, is the best subject for the purpose, as lic is more easily affected, and becomes so manifestly glandered in a short time, as to leave no donbt as to the nature of the disease. It is not necessary to wait until a running at the nostrils takes place, though that symptom generally appears in about a fortnight, as well as a swelling nuder the jaw : but if the suspected matter be realJy of a glanderous nature, the inoculated part will, in four or five days, become a painful ulcer, and shortly after, the surrounding skin will be swollen and tender, and the absorbent vessels about the part will also be swollen, appearing as corded veins. These appearances are sufficient evidence of the disease being glanderous; and at this period the little animal should be desiroyed, for if kept longer', the sore spreads rapidly, and the constitution is often violently affected, so as to cause much pain. The matter should be taken from the nose of the suspected horse in the moning, before he lias been watered or fod, when it has accumulated about the lower part of the nostril. It should not be in a solid or dry state, nor so fluid as to run of: quickly from the bit of glass or tile on which it may be collected. It should be rather viscid and semi-transparent, but not whitisl, thick, and opaque, like the matter of an abscess. The neck is a convenient part for the inoculation; the hair should be cut off for about the space of a crownpiece, and a superficial incision mado in the cuti- 
cle with a lancet, that is, the flat part of the lancet should be introduced under the cuticle, so as to make an opening about a quarter of an inch in width and half an inch in depth, in a descending direction, so that the matter, when introduced, may readily run off, or be washed off, should a little blood happen to flow. In making this opening between the cuticle and the skin, it is proper to go so near the skin as to cause a few drops of blood to appear; but this should be carefully wiped off before the suspected matter is introduced. A horse lancet is the best instrument for the purpose, but the matter may be applied by means of a thin slip of wood, with which it may be gently rnbbed a few times about the part. This part of the operation must be carefully attended to, and rather ovcrdone than otherwise; for though a trivial sore may be produced by poking about the part, and performing the opcration rather roughly, even with the matter of a common abscess, or without introducing any matter at all, yet it disappears in a day or two; but it must not be done so rudely as to causc bleeding, by which the glanderous matter may thereby be washed off, or rendered iuert by dilution. In some horses, where there is but a small quantity of matter discharged, there may, at times, be a good deal of a watery fluid formed within the nostrils, which may too much dilute the glanderons matter: it should therefore be collected carefully, at the time, and in the state before described. It may be proper, however, to 
remark, that when the inoculation is carefully performed by an experienced person it may be done so slightly, that there will be no sore produced till two or three days afterwards; but it is better, I think, to make rather a larger opening, and introduce more matter than is absolutely necessary. After the inoculation, the ass should be confincd, and not turned into a field, where he would probably lie down, and rub off the matter in the grass; nor should a part be chosen for the operation which the animal is able to lick. During a period of many years, I have had frequent occasion to employ this operation as a test or criterion for determining with certainty the nature of those discharges from the nostrils of liorses which so often occur, and am now so satisfied with its utility, that I can recommend it with confidence to the public.

The diseases which M. Dupuy considers as tuberculous affections, are no doubt very destructive, especially among cattle, and appenr to be produced by exposure to cold and moisture. Constitutional weakness, whether hereditary or dependant on other causes, will of course render animals more liable to such affections. In this country, the diseases so produced are commonly of the catarrhal kind, and when neglected, often degenerate into consumption. Those epizootic or contagious diseases, by which an incalculable number of cattle have been swept off at different periods, are, in this country, almost unknown in the present age; and it is probable, that the fatal diseases which are 
now so often occurring, may, by proper management, be in grent measure prevented. Much praise is due to M. Dupuy for the zeal he has shown in the investigation of the subject, and the means he has suggested for the preservation and improvement of our domestic animals are certainly deserving of attention; as to his opinions relative to glander's, they are not likely, I think, to lead to any improvement either in the prevention or treatment of that disense: on the contrary, should nny converts be made to lis opinion of the noncontagious nature of the disorder, much mischief may result from it. The little progress that has hitherto been made in this interesting inquiry may probably have arisen from the diffieulty of distinguishing genuine glanders from other diseases which nearly resemble it, except in one point, that is, in its contagious quality; and though many horses may have escaped the disorder that have been kept with such as are nominally glandered, such circumstances ought not to have any wcight when opposed to so many positive proofs as have been adduced of its contagious nature. If it be said that glanders is not so contagious as many suppose it to be, I will readily accede to the opinion, and think it probable, that opinions are sometimes given upon the subject too hastily, and that lorses are sometimes destroyed under a supposition of their being glandered, when they have had some other disorder. If this be admitted, we can account for the cures that have at times heen bossted of as well as for the contradictory 
opinions that have prevailed on the subject. I presume, therefore, to hope that the test I have proposed will be thought worthy of publie attention. Admitting the contagions nature of glanclers as a fact clearly proved, it does not follow, that a sound horse will, with certainty, contract the disease by standing, or being kept by one that is glandered, there is probably a eonsiderable chance of his eseaping. In the first place, the glandered hoise may not diseharge a sufficiont quantity of matter; he may not deposit it in a situation where the other can readily get it. Glanclered horses will often lick up the matter which they throw oint about the manger themselves. The sound horse may not be disposed to lick up the matter'; and if lie unavoidably swallows the morbid matter, by drinking out of the same pail, or by partaking of the same feed, it may be too mueh cliluted, or mixed witl other matter, to produee any effect; or the sound hor'se may be of so hardy a nature as to resist the infuence of the poisonous matter. It las been satisfaetorily proved, that glander's is not conlmunicated by the application of glandierous matter to the nostrils; from which, and the above considerations, we may casily coneeive that sound horses may frequently have cseaped the contagion, though kept with glandered horses: and yet those who have denied the contagious nature of the discase have addueed some instanees of this kind as conclusive evidence in favour of their opinion. They say, they have seen a sound and a glandered horse kept together, and that the former has not 
contracted the disorder. Now besides the chances of escape before noticed, there is another to be considered : the horse that is said to be glandered may not be so in reality; what proof do they ever give of it? None. It will surely be admitted, that if only one clear case can be adduced of a perfectly sound horse contracting the glanders by standing with a horse that is labouring under that disorder, it is more satisfactory evidence of its contagious nature than ten instances of a horse escaping it, under such circumstances, would be to the contrary. If matter be taken from the nose of a glandered horse, mixed up with flour and honey, and given to a sound horse, and if the latter, though taken great care of, and properly fed, groomed, and exercised, became glandered, does it not prove that the glanders is contagious? St. Bel gave glanderous matter in this way to three horses; one of them contracted the disorcler in a month, the others some time after. If a small quantity of matter taken from the nose of a glandercel horse be inserted under the cuticle, or scarf skin, in any part of the body of a sound horse or ass, it produces at first a disease similar to farcy: that is, the inoculated part becomes an ulccr or chancrous sore of a peculiar appearance, the ehancre spreads, often rapidly, farcy buds appear in the course of the absorbent vessels, which are swollen or corded; after a short time, there is a ruming, gencrally from one nostril only, and a swelling under the jaw, but on the same side as the affected nostril; the running increases, and ulceration takes place 
within the nostrils; in short, the loorse is completely glandered, as may be proved by the matter which flows from his nostril being capable of communicating the same disease to another horse. Is not this a sufficient proof of the contagious nature of glanders? If further proof is required, then, I would say, that if fifty horses or asses were inoculated with matter from the same glandered horse, a similar effect would be produced in all of them; that is to say, similar in kind, but varying in degree. In a young ass, six months old for example, an acute kind of glanders would be produced, which probably would destroy the animal in a few weeks; but in an old hardy horse it may be two months before the running at the nose appears, and the inoculated part may soon get well. M. Dupuy would, perhaps, give a distinct name to each variety: he would call the disease, as it appears in young asses, gangrencuse or charbonneuse, \&c. but this would not alter the fact, or the inference I have drawn from it. A healthy young ass was turned into a field with a glandered horse, the ass, in a short time, contracted the disorder and died of it. A glandered horse was turned into a large pasture, where sevcral healthy horses and colts were running: it was in the month of September, the weather had been temperate, and there was plenty of grass and places for shelter. After a short time, several of them became glandered: I was desired to examine them, and found eight of them, colts and horses, completely glandered. A glandered horse rubbed his nose on it 
sore part, produced by the crupper, near the tail of a healthy horse, in consequence of which, he soon became glandered; in the first place, however, the sore near the tail was converted into a spreading clancre, similar to the sores produced by inoculation. It is needless, I trust, to adduce any further proof of the contagions nature of glanders. The tubereulous affection is, I beliere, very common, cspecially among cattle, and is generally produced by the influence of cold and moisture, which may be considered as exciting causes; while food of a bad quality, and insufficient in quantity, execssive labour, hereditary weakness of constitution, confinement in close stables, and in short, whatever diminishes the health and vigour of the system in a considerable degree, are causes that predispose to the disease.

This is a subject of much greater importance than it is commonly supposed to be. If scei in its true light by those enlightened agriculturists who have already done so mucl for the improvement of the breed of clomestic animals, it will no doubt lead them to the adoption of a system by which the destruetive discases that now prevail may. be prevented, and a stop put to the absurd and expensive attempts that are so often made to cure incurable diseases. Although epizootic disenses seldom happen in this country, it is highly probable that the fatal disorders which are so often occuring are wholly referrable to the causes beforc alluded to, that is to say, constitutional weakness or liability to disense, whether produed 
by inattention to breeding, improper food, or other causcs, and exposure to cold and moisture. As to the curc of glanders, M. Dupuy does not pretend to have discovered a certain method of accomplishing it. "The trentment," he says, "ought to be divided into what concerns the regimen, or dietetic part, and the medical treatment. The diet should be strengthening the food of the best quality; the stable should be well ventilated, and in a situa. tion where the air is pure and dry: when bad weather prevents lis being moderatcly exercised out of door's, he should be well wisped and brushed in the stable." May not grain, such as wheat, which contains a large proportion of azote (nitrogen) be given with advantage; or gluten? Why not add to it panada wine and meat broth? Vicqd'Azyr says, he has seen animals cured by it (of an epizootic or epidemic disease) in every stage of the malady. Among the numerous medicines that have been recommended for the tuberculous affection, tonics are the best; but cren these are seldom productive of any permanent good. The vegetable tonics arc gentian, elecampane root, tansy, aromatic powders, cinchona bark, hemlock, fox-glove, water-.liemlock. Among the minerals that have been cmployed are sal ammoniac, carbonate of ammonia, kermes mineral, emetic tartar, corrosive sublimate, calomel, cinnabar, sulphur, \&c.; also, aloes, gum ammoniacum, assafoctida, resin, and nitre. Revulsine means have also been employed to diminish the inflammation of the lungs with which the disease is often complicated: 
such are setons, blisters, and the actual cautery, applied to the sides. M. Dupuy cannot be aecused of being too sparing in lis enumeration of reputed remedies; but had he added every other artiele in the materia mediea, he would not perhaps have exceeded the truth, as there is searcely one that has not been tried, and few that have not been reeommended as remedies for glanders.

The matter of a real farcy sore, or rather of a farey bud, whielı has suppurated, appears to possess the same contagious quality as the glanderous matter, produeing, by inoculation, precisely the same phenomena; but this disease, like glanders, is resembled by other diseases; and I think it but a fair calculation that, out of twenty eases of what smiths, and persons ignorant of the subject, term farcy, not above three or four are really of that description: henee it is that we hear of different kinds of farcy; sueh as the water-farey, the button-farey, Sxe. M. Dupuy says, that farey buds often degenerate into eaneerous sores, which he attributes to the caustics that are eommonly applied to them. I have found, however, invariably, that causties are the best loeal remedies for farey sores, and that one or two sueh applieations are often suffieient to destroy their peeuliar charaeter, and cause them gradually to heal without any thing more being applied. It is worthy of remark, that after farey buds have been eured, espeeially when it has been effeeted by topieal applicntions only, it is most commonly followed by glanters: but the interval between the disappearance of farey and 
the appearance of glander's varies eonsiderably; the longest interval I have known is about five or six months. I shall eonelude with one more extraet from M. Dupuy to show how extensive he seems to consider the influenee of the tubereular affection. After enumerating the various diseases which it oeeasions in horses, oxen, sheep, pigs, hares, rabbits, and even poultry, he adds, "Do we not observe analogous alterations in vegetables? I shall be told perhaps that this is pushing my analogies too far: but botanists and gardeners have long since observed eoneretions in eertain fruits, as in the wild pear of St. Germain, \&c. The hard parts are termed stones, and the name of quarry is given to the mass whieh results from their union. These regetable stones, says Ventenat, appear to be organized, and seem to grow like organized bodies. Duhamel thinks they are formed from clusters of ressels, \&c." Vaquelin has found that these coneretions do not eontain either phosplate or carbonate of lime, as had been suspected, but eonsisted of ligneous matter, similar to the tree whieh produees the firuit. It has been proved by the aceurate analyses of MM. Thenard and Dulong, that tubercles are composed of phospliate and carbonate of lime, in the same proportions as they are found in bone. The bones of animals that have died of the tubcreulous affection are evidently more transparent and lighter than the bones of healthy animals. It appeared, then, of some importance to determine whether 
the milk of a cow affected with tubercles (la pommeliere, or incipient phthisis), contained a larger proportion of phosphate of lime than that of a sound cow. M. Labillardiere, chemical operator at our school, has proved that it contains seven times more phosphate of lime than the milk of a healthy cow. This, if confirmed by other experiments, is a valuable discovery, and furnishes a most useful indication. It may explain why the milk of such cows is found injurious by persons affected with consumption, and show the necessity of ascertaining that the milk used by consumptive patients is produced by a healthy cow. It points out also the advantages likely to result from confining animals to a suitable regimen when affected with the tuberculous disease, and by rejecting such food as contains phosphate of lime!" M. Dupuy has certainly carried his speculations to a great length, and had he not endeavoured to propagate an opinion which appears to me highly dangerous, viz. that glanders is not contagious, I should not have noticed his work, or dwelt so long on the subject, as it has been so fully treated of in the third volume. 


\section{N D EX.}

A вромen, or belly, 56 .

Abscess described, 85 .

treatment of, 85 .

Age of a horse, 382.

Alteratives, 169,374 .

for the mange, 185.

mercurial, 231.

balls and powder, 19, 144, 152, 181, 185, $227,228,375$.

Amaurosis, 437.

Anatomy of the internal organs, 56 .

\section{foot, 302 .}

Anodyne drenches, 115, 124, 420 .

Anticor, 198.

Aorta, 63.

Apoplexy, or staggers, 185, $26 \overrightarrow{5}$.

$\Lambda$ ppendix, 393.

Arsenic, 54.

Astringent lotions, 229.

\section{ointments, $230,231$.}

powders, 50, 231, 232 .

urenches, 115, 192.

ball, 192.

A uricles of the heart, 63 .

Balls, cautions on giving, 43 .

— cordial, 5.5, 98, 390, 391 .

- diuretic, 101, 139, 155, 374.

- purging, or cathartic, 152, 170, 372.

- tonic, 54, 129, 130, 131, 406.

expectolant, $147,164$. 
Balls, alterative, 49, 144, 152, 181, 185, 22 \% .

— for retention of urine, $123,126$.

- for fiatulent colic, or gripes, 116.

— camphor, 123, 126, 137.

— for bloody urine, 131.

- for incontinence of urine, 133.

— laxative, 139, 140, 146, 227, 376.

— cough, 153.

— stomachic laxative, 47 .

- mercurial purgative, 51 .

- fever, 90 .

- astringent, 192.

- farcy, 215, 216.

Belly, dropsy of, 196.

Bile, 76 .

Bladder, description of, 80 .

Bleeding, 364 .

Blisters, 271, 376 .

Blood, 63, 364.

Body, divisions of the, 56 .

Botts, see Worms.

- sometimes injurious to the stomach, 119.

Bowels, diseases of the, 50, 102.

Brain, dropsy of, 195.

Broken wind, 159.

__ knees, 270.

Bruises, 268.

Canker, 359.

Catalepsy, 218.

Cataract, 438 .

Catarrh, 60, 99, 145, 409.

Caustic powder, 361 .

$$
\text { liquid, } 361 .
$$

Cellular membrane, 58. Note.

Chest, diopsy of, 196.

founder, 342,148 .

Chronic cough, 149.

Circulation of the blood, 63 .

Clysters, 106, 126, 380, 419. 
Cold, see Catarrh.

Colic, flatulent, or gripes, $32,110,111$.

- how distinguished from inflammation of the bowels, 110.

Condition, 12.

Corded veins, 206, 213.

Cordial balls, $55,98,390,391$.

Corns, 354.

Cough, see Catarrh. chronic, 14.9.

Crib-biters, 388.

Curb, 298.

Cutting, 362.

Diabetes, or excessive staling, 128.

Diaphragin, or midriff, 56 .

Diarrhoea, or purging, 191.

Digestion, 73.

Distemper, 409.

Diuretics, 101, 127, 139, 154, 155, 374 .

Drenches, colic, 115.

- anodyne, 115, 124, 420 .

- oily laxative, 115,422 .

astringent, 115.

diuretic, 127.

cough, 153.

purgative, 188 .

laxative, 89, 405, 411.

stimulant, $418,4.19$.

Dressings, mild, 361, 362 .

Dropsy, 195.

Dysentery, 194 .

Limbrocations for bruises, 268, 269.

$$
\text { strains, } 289 .
$$

windgalls, 294.

Epiglottis, 57, 69 .

Epilepsy, 217.

Exercise, see Feeding, 14.

Eyes, disenses of the, $221,431-442$,

Eye-waters, 4ti. 
Farcy, 206, 210.

Feeding and Exercise, 14, 21, 32, 45, 74.

Fever, 86, 88, 402 .

symptomatic, 91 .

catarrhal, 99.

Fistula, 273.

epidemic, 409.

Fits, 217.

Fomentations, 379.

Foot, management of the, 20, 29.

- its defects generally owing to bad shoeing, 300 .

- anatomy of, 302 .

- diseases of, 326 .

Foundering, 336, 443.

Irret, see Colic.

lirog, see Foot.

(iangrene, 86.

(Gastric juice, see Digestion.

Ylanders, 199, 455.

(Ylass-eyes, 437.

(ilyster, see Clysters.

(irease, 226, 126.

Gripes, see Colic.

Grogginess, 339.

Grooming, 13.

(iullet, 68.

Gutta Serena, 437.

Haw, 225.

Heárt, 62.

Hidebound, 179.

Hoof, see Foot.

Incontinence of urine, 133.

Inflammation, 81 .

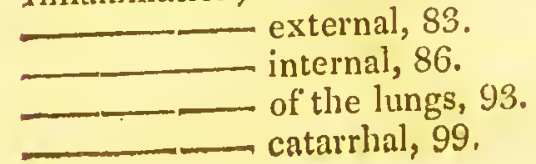


Inflammation of the intestines, 102, 110.

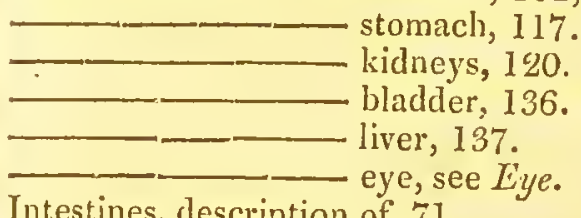

Intestines, description of, 71 . stomach, 117 . length of, 71 .

Jaundice, 139.

Joints, structure of, 257.

- wounds of, 258 .

Journey, management during a, 385.

Kidneys, description of, 79 . inflammation of, 120 .

Knees, broken, 270.

Lacteals, $72,77,79$.

Lameness, see Foundering.

Lampas, 44 .

Larynx, 57.

Laxatives, 47, 89 note, 115, 139, 14.0, 146, 227, 376, $4.05,4.11,4.22$.

Liniments, volatile, 107.

Liver, 75.

mustard, 107.

- diseased, 49, 137 .

Locked jaw, 219, 393, 395, 401 .

Looseness, 50.

Lotions for the mouth, 40.

- mange, 184. astringent, 229.

for saddle-galls, 279.

Lungs, 56 .

saturnine, 288.

inflammation of, 93.

Lymph, coagulable, see Bleeding.

Malanders, 232. 
Management during a journéy, 385.

Mange, 182.

Mediastinum, 57 .

Megrims, 217.

Mesentery, 72 .

Molten grease, 192, 194, 422.

Moon-blindness, 4.39 .

Mortification, see Gangrene.

Mouth, tenderness of, 39 .

lotion for, 4.0 .

Mustard liniment, 107.

Nerving, 443.

Nutrition, process of, 72 .

CEsophagus, 68 .

Ointments, stimulating, $142,275,430$.

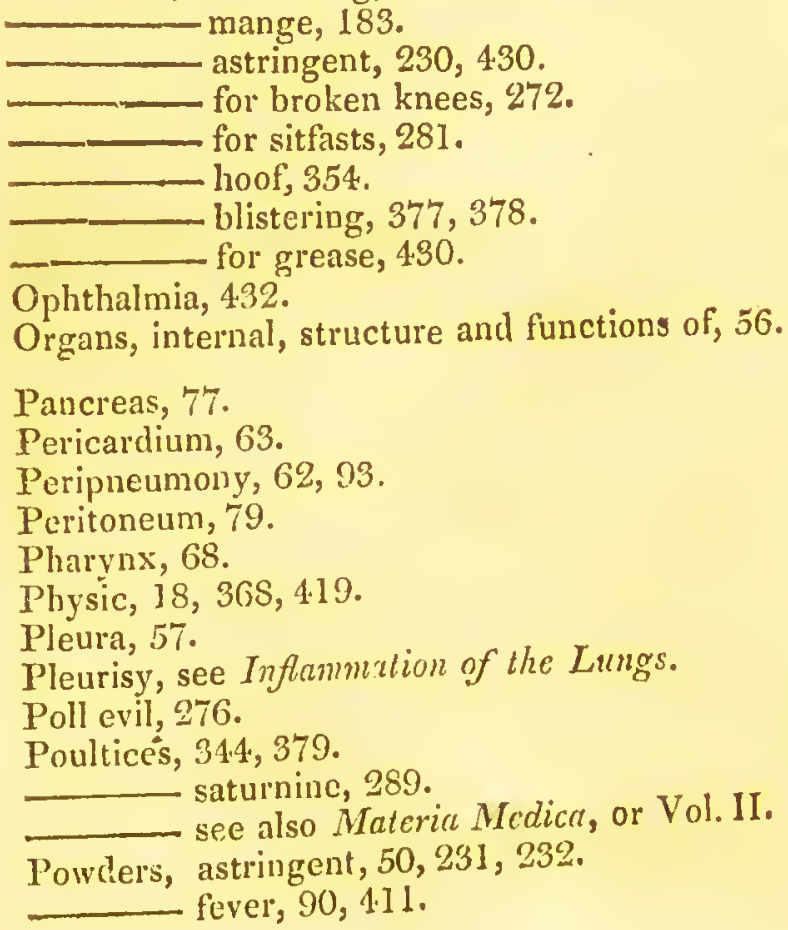


Powders, diuretic, 15\%, 228.

caustic, 361 . alterative, 228, 375 .

Pulse, 381, 403.

Purgatives, see Physic.

Purging, see Diarrhcea.

Pylorus, 71.

Quidders, 42.

Quittor, 356.

Respiration, 59.

Retention of urine, 121, 123.

Ring-bones, 292.

Roaring, 155.

Rowels, 380.

\section{cautions respecting, 127 .}

Saddle-galls, 279.

Salanders, 232.

Sand-cracks, 351 .

Scouring, 191.

Shoeing, 300, 318.

Shoulder-shook, 342.

Sinews, back, 286 note.

Sitfasts, 280.

Sole, drawing the, 247.

Spavin, 296.

Splents, 294.

Stable, construction of, 1 .

Stagger's, $185,265$.

Staling, excessive, 128.

Stimulants, $4.18,419$.

Stomach, 68, 73.

inflammation of, 117 .

purgative, 4.18.

staggers, $186,112$.

Stone in the kidncys, ureters, and bladder', 134.

Strains, 281.

Strangles, 14.1. 
Strangury, 121.

Sulphat of copper, 54 .

Suppression of urine, $121,126$.

Surfeit, 181.

Teetli, see Age.

Tents, mischiet of, 235.

Thoracic duct, 79 .

Thorax, 56.

Thorough-pin, 292.

Thrush, 358 .

Tonics, 54, 129, 130, 131, 4.06.

'l'achea, see Lamgrs.

Uieters, 80.

Urinary discases, 121, 128, 131, 134 .

Valve of the throat, 70 .

Ventricles of the heart, 63.

Vertigo, $21 \%$.

Viscera of the abdomen, 68.

Viscera of the chest, 56.

Vomiting, 69, 70, 71 .

Warbles, see Saddle-galls.

Water, 24-29, 46.

Wind, broken, 159.

Wind-galls, 263, 293.

Windpipe, 56.

Withers, fistula in the, 273.

Worms, 48, 73, 118, 119, 167 .

Wounds, 233.

-

___ lacerated and contused, 236.

— the chest, 253.

belly, 254.

- sheaths of tendons, 262.

it vein, $26 \%$

Yellows, see Jaundice 


\section{7}

\section{DESCRIPTION OF THE PLATES.}

Plate I.-Fig. 1. Represents the botton of a colt's foot: $a, a$, the frog; $l, b$, the bars; $c, c, c$, the sole; $d$, $d$, the seat of corms.

Fig. 2. The bottom of a contraeted foot.

Plate II.-The clust or wall of the hoof separated from the other parts.

Fig. 2. Represents it recently separated: $a, a, a$, the elactie proeesses of the hoof; $b, b$, the extremities or horny heels; $c$, the groove within the eoronet.

Fig. 1. Lepresents the same subject after it had been licpt a few days ; $a, a, a$, the elastie processes ; $l, l$, the heels shrumk and bent inward; $c$, the groove within the eoronet.

Plate III. Fig. 1. A shoe for a good foot.

Fig. 2. The hinged shoe reconmended by Mr. Clark: $a$, the steel rivet whieh forms the hinge; ?, a separate view of the rivet.

Plate IV.-Fig. 1. A French shoe for the fore foot.

Fig. 2 . Represents the adjusture of the shoe: $a, a$, a plain surfiec on which the shoe rests; $l, b$, the outer branch of the shoe. This, however, is better shown by the side view of the shoed foot.

Fig. 3. $a$, the front of the font ; $b$, the quarter; 3 , the heel; $c$, $c$, shows that the toe and lieel of the shoe have no bearing on the gromud, which is represented by the horizontal line $e, e$.

Fig. 4. The hind sloe.

Fig. 5. The adjusture; $a$, 4 , the ground; $b, b$, the side of the shoe.

Plate IV.-No. 2. Represents the different degrees of obliquity of the loof.

PLAtr V.-Represents the sensible foot recently drawn out of the hoof: $a, a$, , the sunsitive elastie proeesses; $b, l, l$, the coronary ring or ligament, the bourrelct of Bourgelet, which tills the gronve on the inside of the coronet, shown in Plate II, and named by the French le lerecau. 
Plate VI.-Represents the bottom of the sensible foot, recently separated from the homy sole, frog, and bars.

Plate VII.-A perpendicular section of the foot and pastern : $a$, the coffin bone or foot bone; $b$, the navicula, shuttle, or nut bone; $c$, the small pastern or coronary bone; $d$, the large pastern bone; $e$, the back sinew; $f$; that part of the sinew which passes over, and slides upon the nut bone; $g$, the termination or insertion of the back sinew in the bottom of the coffin bone; $h, h$, the elastic matter of the sensible frog; $i, i$, the horny frog; $l$, the horny sole; $l$, the crust or wall; $m$, the clastic processes.

PLATE VIII.-A transverse section of the foot: $a$, the cofin bone; $b$, the nut bone.

Plate IX.-Posterior vicw of the sinews and cartilages.

Plate X.-A postcrior view of the ligament, cartilages, and bone.

Plate XI.-Front view of the bones.

Plate XII.-Back vicw of the bones.

Plate XIII.-The front shoc.

Plate XIV.-The clip shoe.

PLATE XV.-The horny box or hoof separated from the sensible parts.

\section{DIRECTIONS FOR PLACING THE PLATES.}

Plate V. to face the Title page.

$$
\begin{gathered}
\text { VI. — page } 300 . \\
\text { XIV. _ page } 318 .
\end{gathered}
$$

The remainder, in numerical order, to follow this page. 



\section{Plate 1}

Fia. 1.

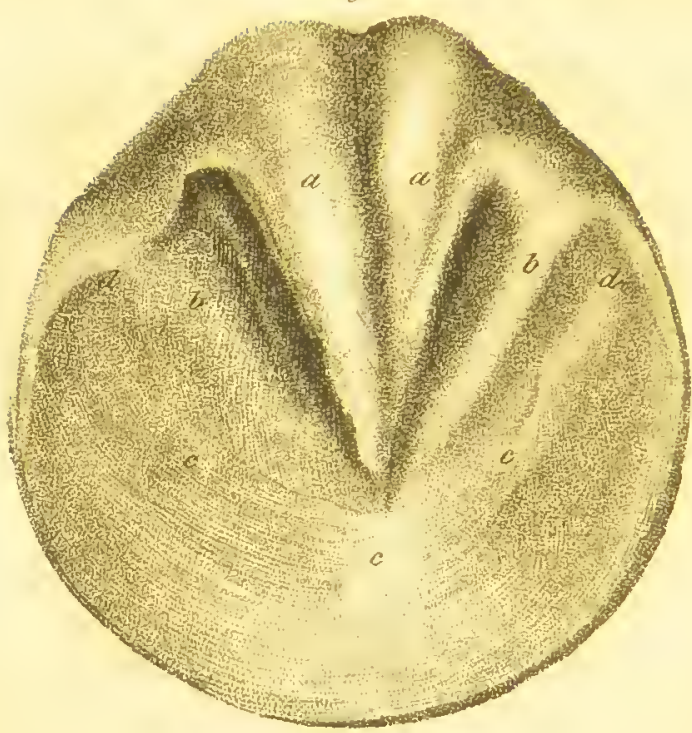

Fig. 2.

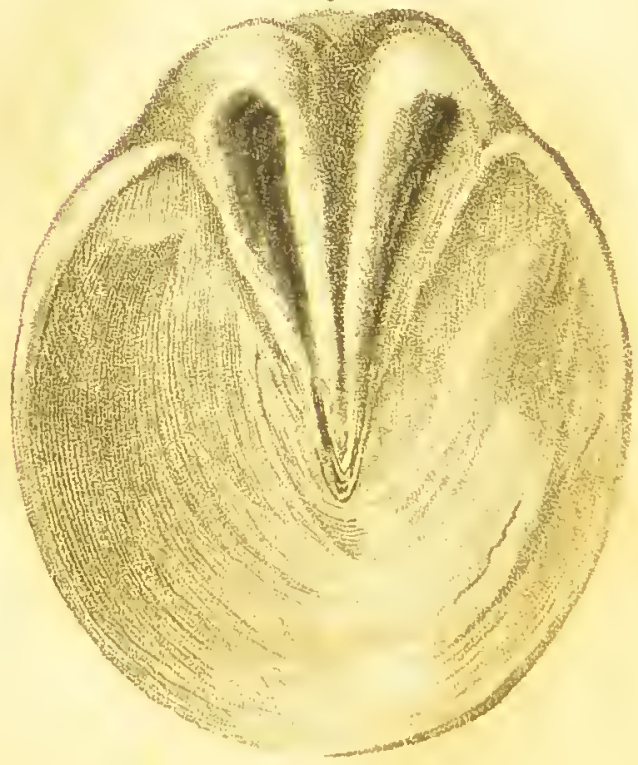

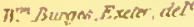


Plate 2.
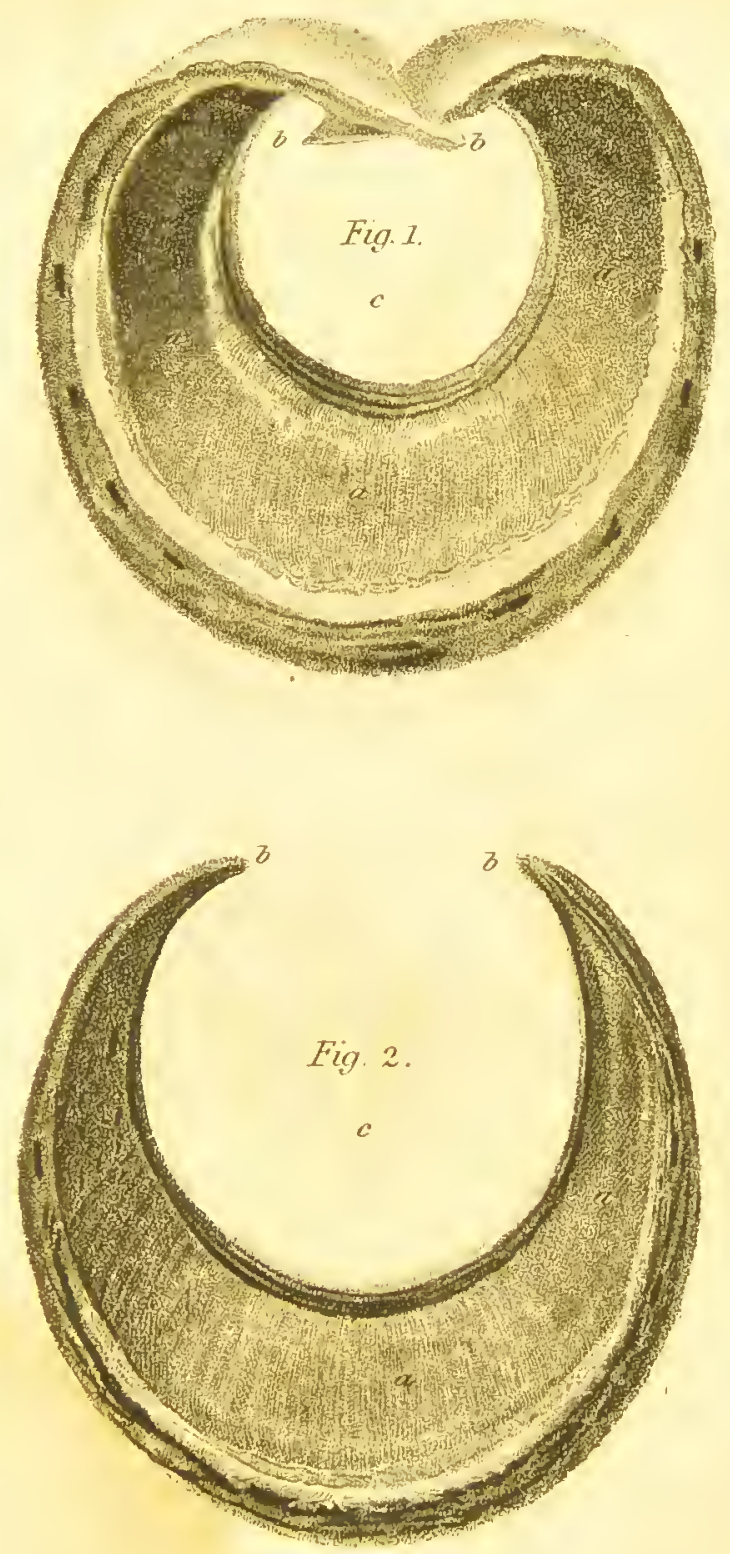

7. Salliner, saito. 

Plate. 3 .

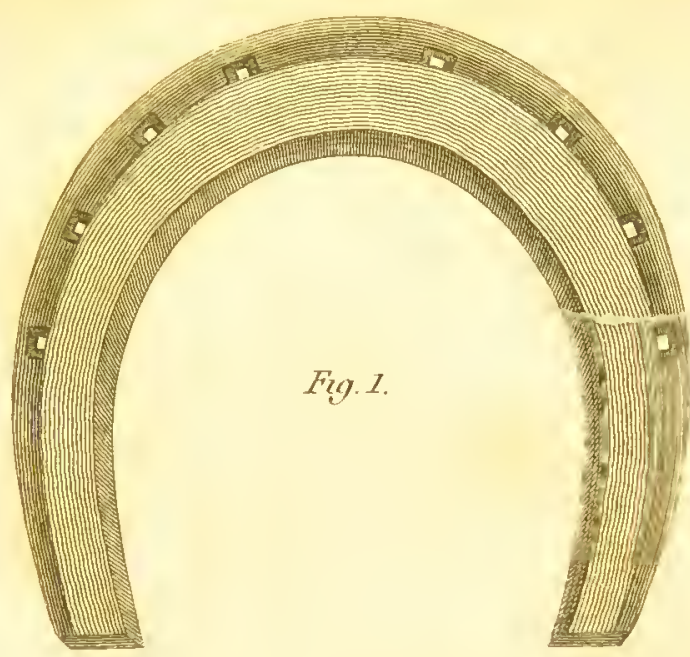

Fiq. 2.

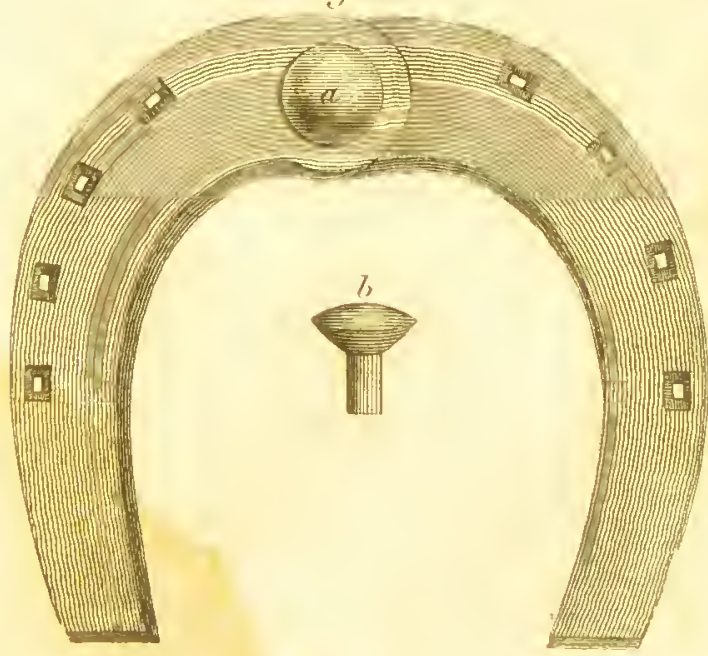

Ispencer det 
Plate $4 \cdot \mathcal{N}^{\circ} 2$
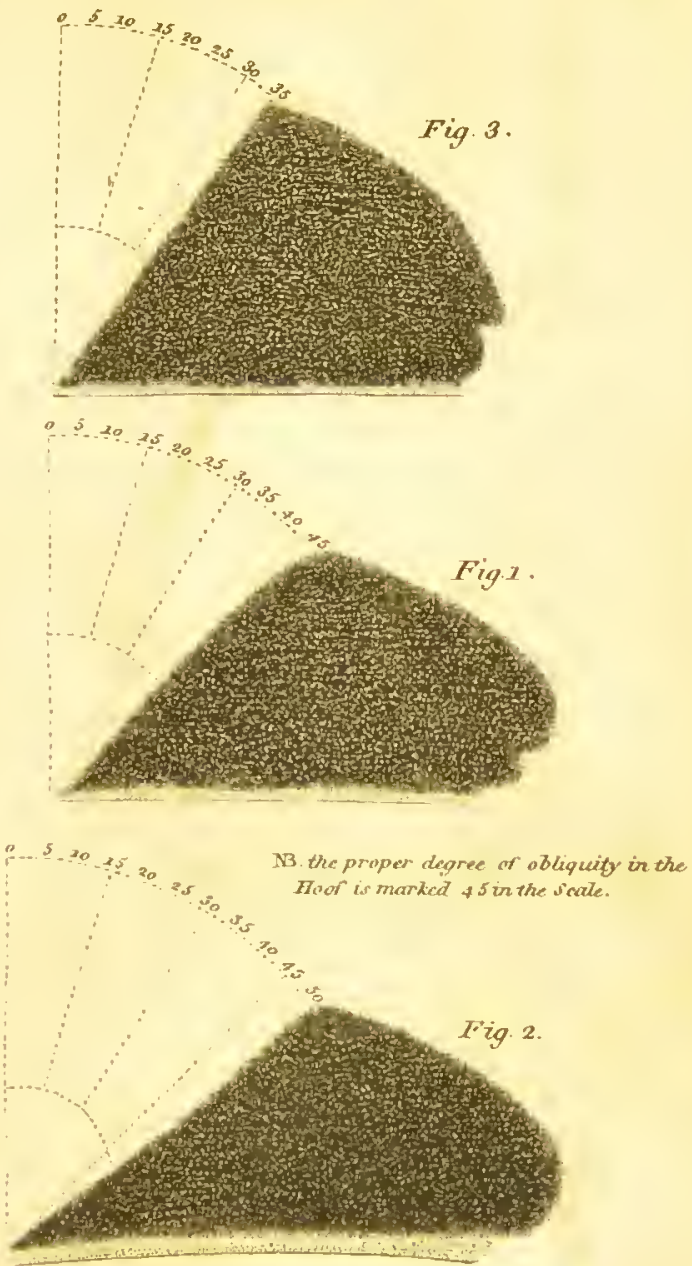

Fig. 1. A side view of the sound Hoof with a scale shewing the proper de gree of obliquity to be 45 degrees of elevation. a the Puriter. b.the Feel. $A$. the Toe

Fyg. 2. Side view of the Comve or Pumice Foot, in which the Hoof has lost its natural form and approaches 5 degrees toward the Horimontal line.

Fig. 3. AHoof approaching too nearly the perpendicular. 




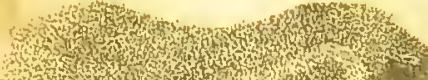
1. 5. s.

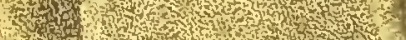

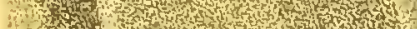
tos 3 .

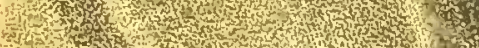
3. 0 . W.

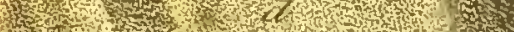

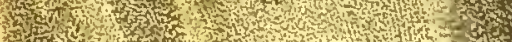

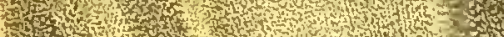

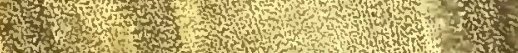
3 1. W 4 4 c

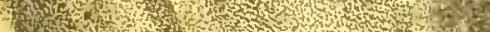
S. $15 x$.

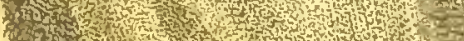

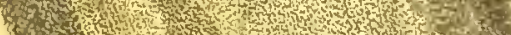

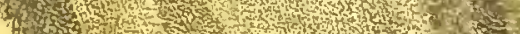

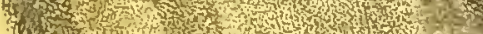

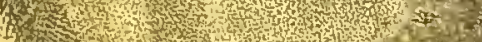

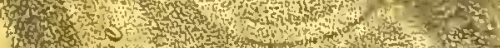

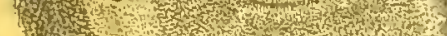

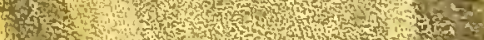

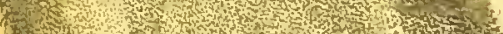

Th 1 .

a 1 .

M 17.

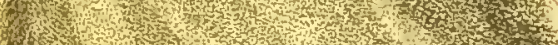

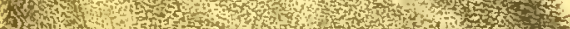

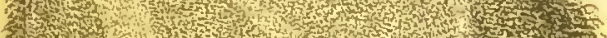

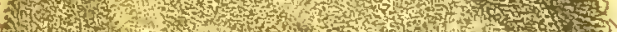

H.

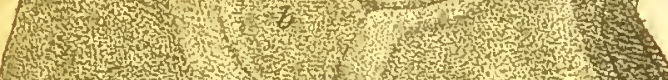

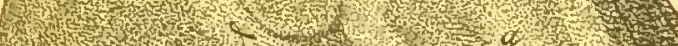

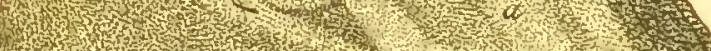

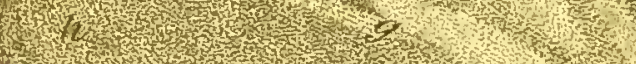

W

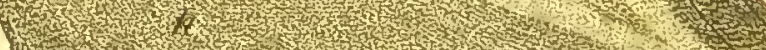

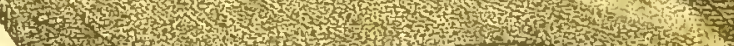

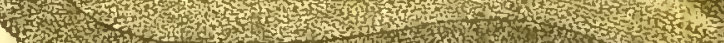
Q 2 the

Perpendicular Section of the Pastern \& Foot. 

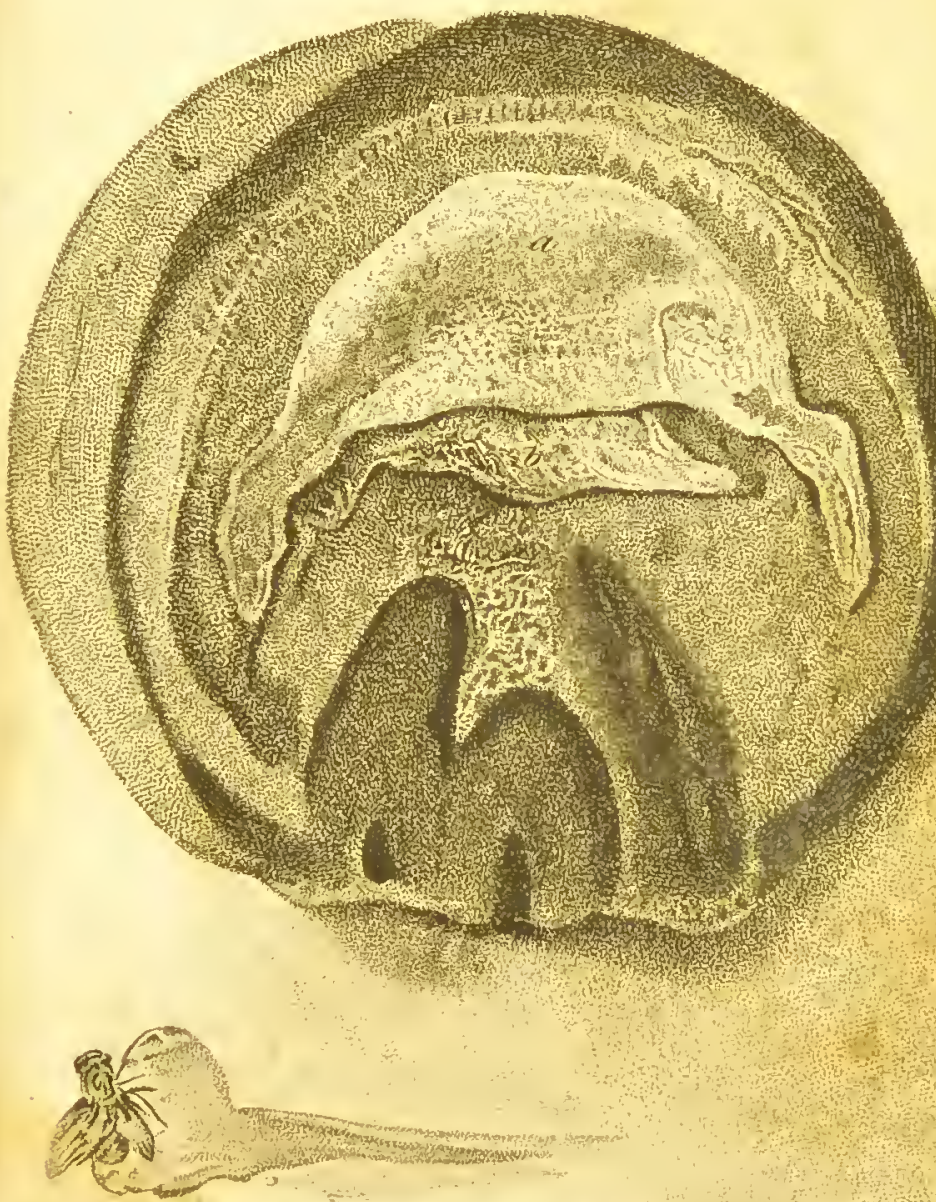

- The foot divided tonnoversely a little below the coronet. showing the horny matter, the elnstic mesnbmues, between the coffurbone and Noof, the Coffin bone, and the Navicula or nutbone. 




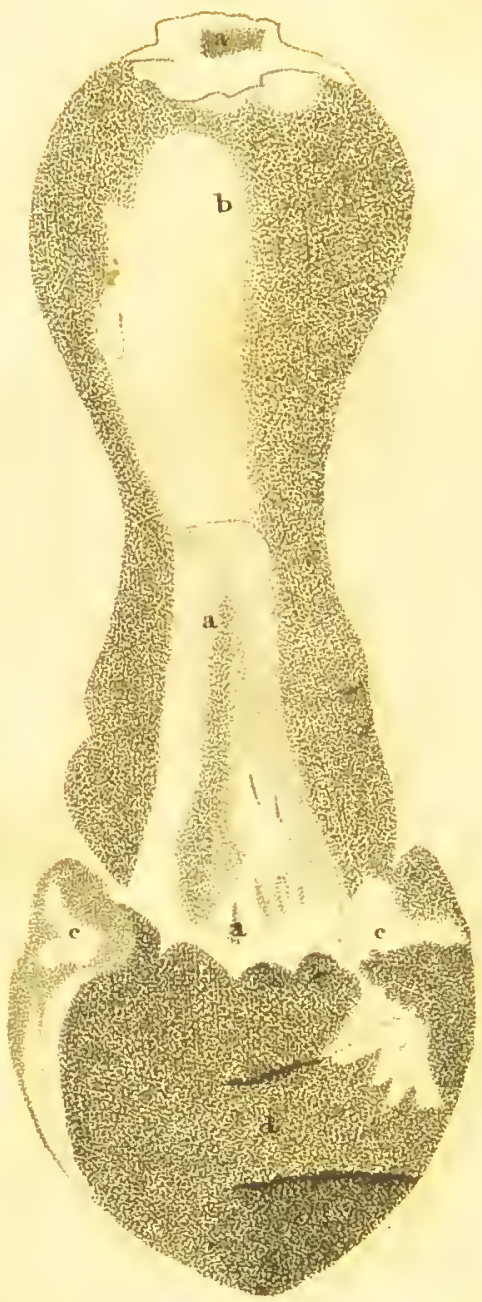

- A back view of the Bones, Iigaments, and Tendons, - a a the back Sinew. b its shemtle. ec the lateral Carrilages. d the botfom of the Comin bone "I 


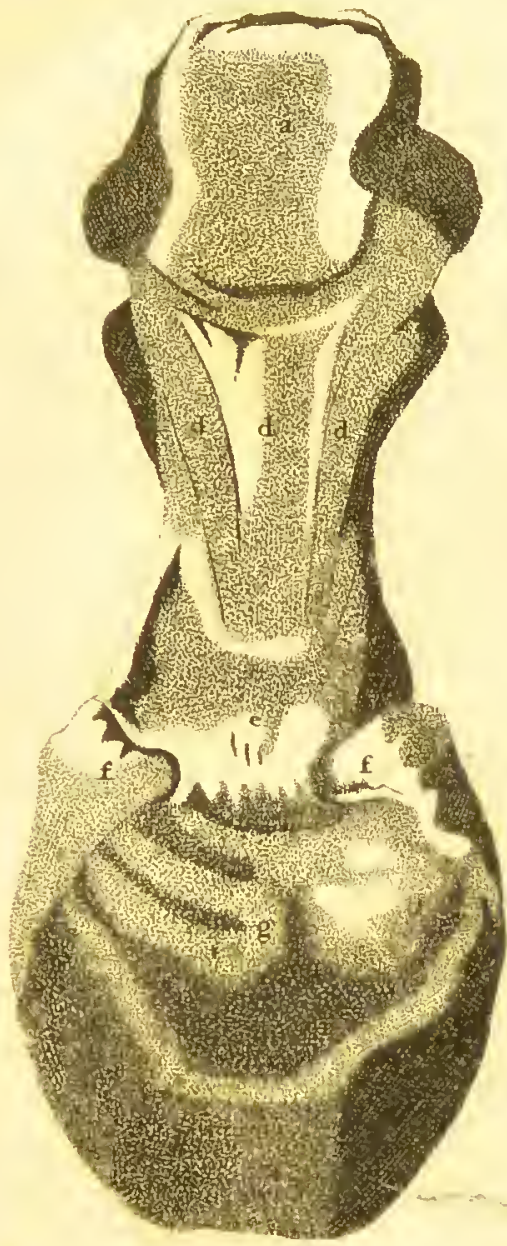

A back view of the Bone e. Lignments and Tekdons. the Tendans having been removed ou order to shew. the Lignments that lie immediately under them. a the the brot Sinew. forming a horkt sinew passes. b the liogment which encloses this prepantion somte part of the lion it, and keeping it in is situation ; in smowdi surfacs a: didd a liugme hament was removed. in order to shew the Pastern: it the seems to be that of going from the sesamoid Bones to the small the obligue postion of the Pattrn itong strength in the Pastern Joint. which. From

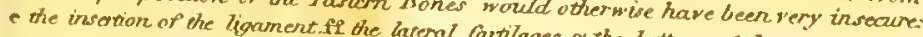





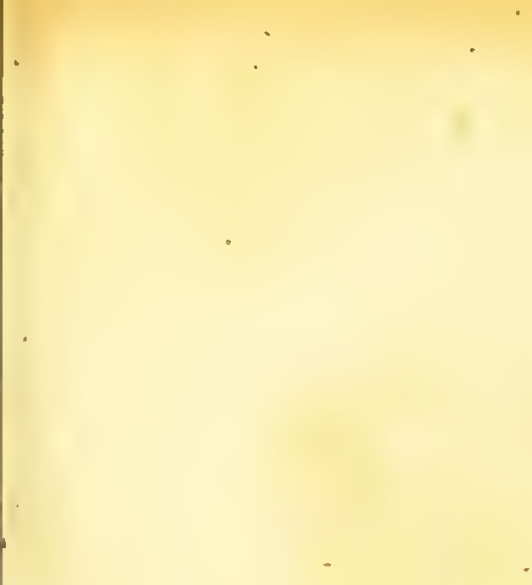

. 
sto
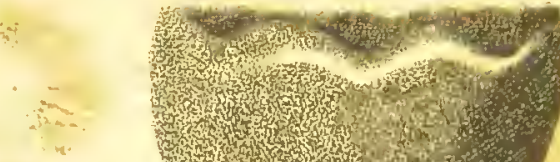

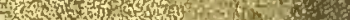

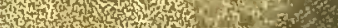

$20,435)$.

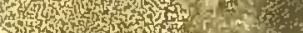

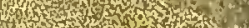

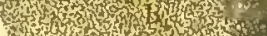

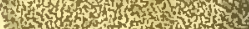

int of th

H.

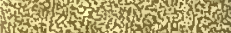

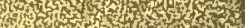

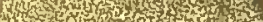

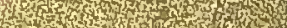

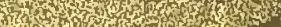

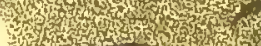

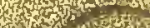

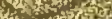

S.

20. $x^{2}$ th

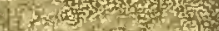

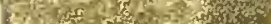

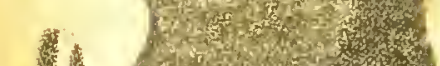

3.

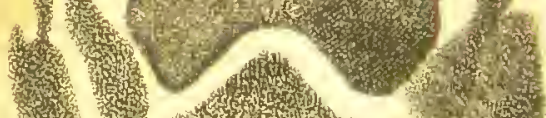

b
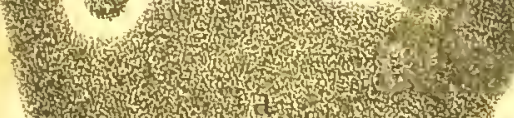

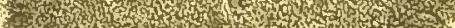

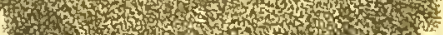

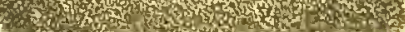

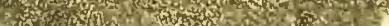

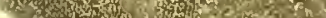

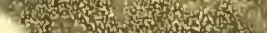

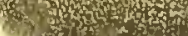
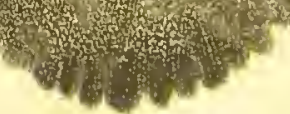

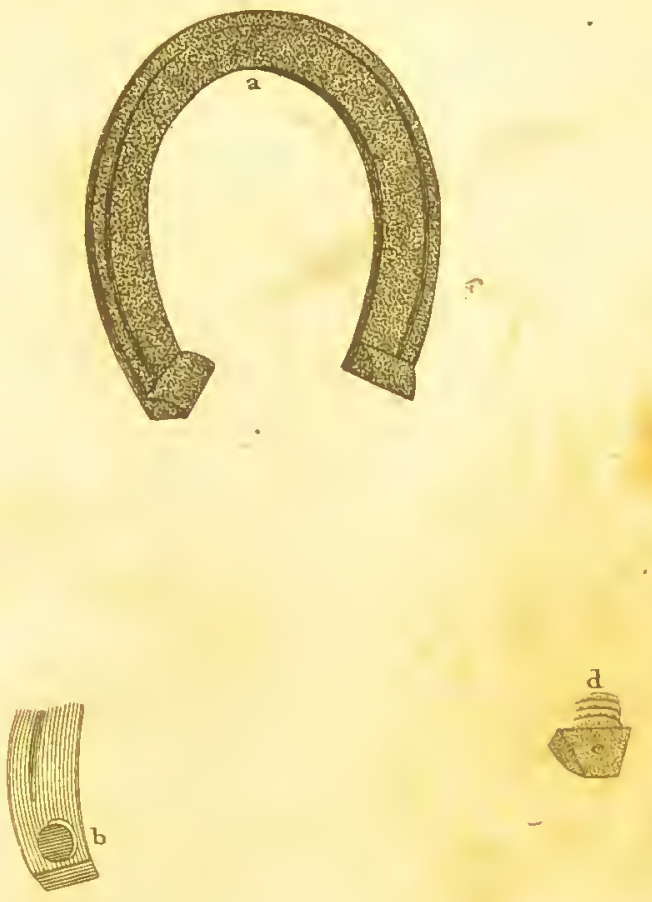

(1)

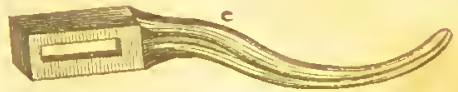

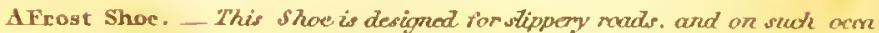

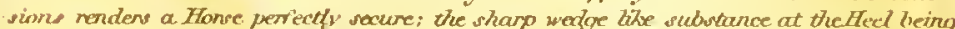
merily sonesved into the shoe may be remover and applied again at pleasure. - at the Shere complete, b the female screw in the Heel, c the wodge that sorew's into it, a. ths scow, e the kęp for fïing and removing the wedge.

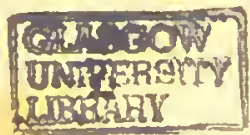

Engraved for Whitris Forvery. 


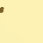







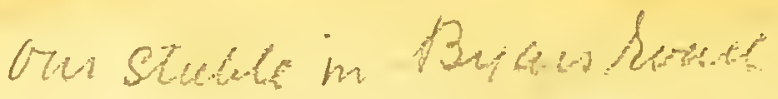

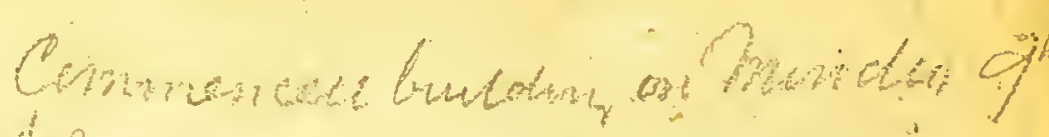

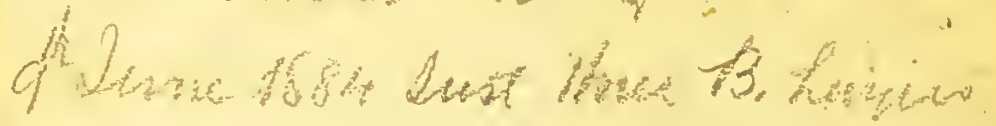

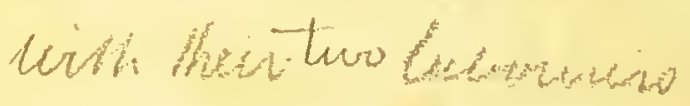

Wighond 
